W B I IEABNING RES OURGES SERIES

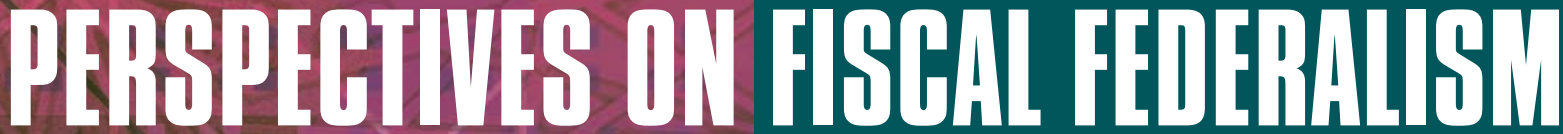

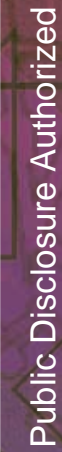

Edited by

Richard M. Bird

François Vaillancourt

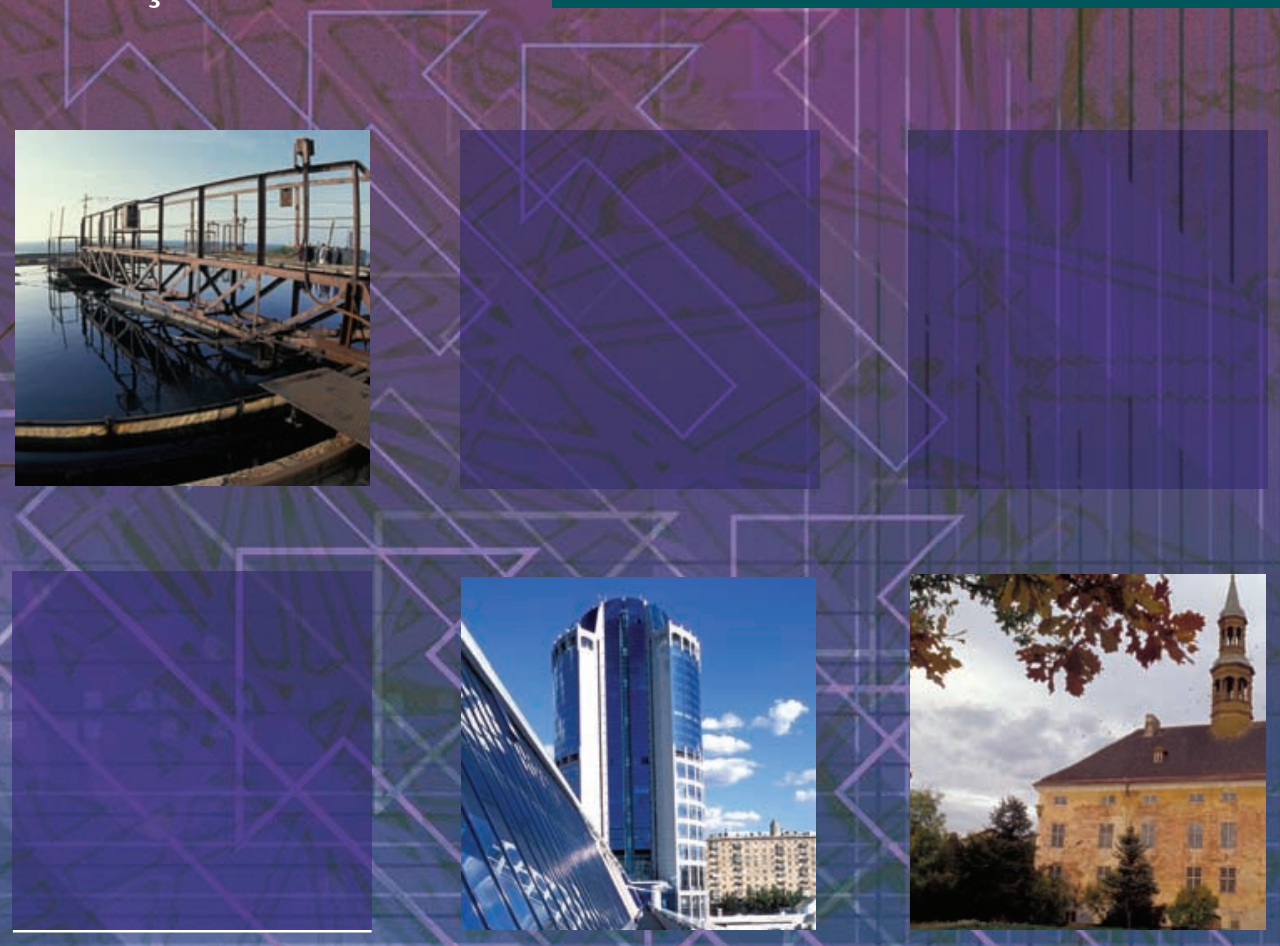

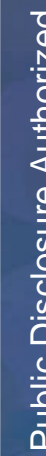

WORLD BANK INSTITUTE 


\section{Other Titles from the World Bank Institute}

India and the Knowledge Economy: Leveraging Strengths and Opportunities 2005. ISBN: 0-8213-6207-0. SKU: 16207

Intergovernmental Finance in Hungary: A Decade of Experience 1990-2000

2005. ISBN: 0-8213-6051-5. SKU: 16051

Intergovernmental Fiscal Relations in Central and Eastern Europe: A Sourcebook and Reference Guide 2005. ISBN: 0-8213-5705-0. SKU: 15705

Reducing Poverty on a Global Scale: Learning and Innovating for Development-Findings from the Shanghai Global Learning Initiative

2005. ISBN: 0-8213-6362-X. SKU: 16362

Beyond Economic Growth: Meeting the Challenges of Global Development (2nd edition)

2004. ISBN: 0-8213-5933-9. SKU: 15933

Building State Capacity in Africa 2004. ISBN: 0-8213-6000-0. SKU: 16000

Granting and Renegotiating Infrastructure Concessions: Doing It Right 2004. ISBN: 0-8213-5792-1. SKU: 15792

Leadership and Innovation in Subnational Government: Case Studies from Latin America 2004. ISBN: 0-8213-5707-7. SKU: 15707

Subnational Data Requirements for Fiscal Decentralization: Case Studies from Central and Eastern Europe 2004. ISBN: 0-8213-5699-2. SKU: 15699

The Right to Tell: The Role of Mass Media in Economic Development

2002. ISBN: 0-8213-5203-2. SKU: 15203

China and the Knowledge Economy: Seizing the 21st Century

2001. ISBN: 0-8213-5005-6. SKU: 15005

Economic Analysis of Investment Operations: Analytical Tools and Practical Applications 2001. ISBN: 0-8213-4850-7. SKU: 14850 


\title{
Perspectives on Fiscal Federalism
}

\author{
Edited by \\ Richard M. Bird and François Vaillancourt
}


(C2006 The International Bank for Reconstruction and Development / The World Bank

1818 H Street NW

Washington DC 20433

Telephone: 202-473-1000

Internet: www.worldbank.org

E-mail: feedback@worldbank.org

All rights reserved

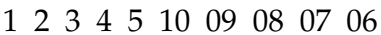

This volume is a product of the staff of the International Bank for Reconstruction and Development / The World Bank. The findings, interpretations, and conclusions expressed in this volume do not necessarily reflect the views of the Executive Directors of The World Bank or the governments they represent.

The World Bank does not guarantee the accuracy of the data included in this work. The boundaries, colors, denominations, and other information shown on any map in this work do not imply any judgement on the part of The World Bank concerning the legal status of any territory or the endorsement or acceptance of such boundaries.

\section{Rights and Permissions}

The material in this publication is copyrighted. Copying and/or transmitting portions or all of this work without permission may be a violation of applicable law. The International Bank for Reconstruction and Development / The World Bank encourages dissemination of its work and will normally grant permission to reproduce portions of the work promptly.

For permission to photocopy or reprint any part of this work, please send a request with complete information to the Copyright Clearance Center Inc., 222 Rosewood Drive, Danvers, MA 01923, USA; telephone: 978-750-8400; fax: 978-750-4470; Internet: www.copyright.com.

All other queries on rights and licenses, including subsidiary rights, should be addressed to the Office of the Publisher, The World Bank, 1818 H Street NW, Washington, DC 20433, USA; fax: 202-522-2422; e-mail: pubrights@worldbank.org.

ISBN-10: 0-8213-6555-X

ISBN-13: 978-0-8213-6555-7

eISBN: 978-0-8213-6556-4

DOI: 10.1596/978-0-8213-6555-7

\section{Library of Congress Cataloging-in-Publication Data}

Perspectives on fiscal federalism / edited by Richard M. Bird, François Vaillancourt.

p. cm. - (WBI learning resources series)

Includes bibliographical references.

ISBN-13: 978-0-8213-6556-4

ISBN-10: 0-8213-6556-8

ISBN-13: 978-0-8213-6555-7

ISBN-10: 0-8213-6555-X

1. Intergovernmental fiscal relations. 2. Local finance. 3. Revenue. I. Bird, Richard Miller, 1938- II. Vaillancourt, François. III. World Bank. IV. Series.

HJ197.P38 2006

336--dc22 


\section{Contents}

\begin{tabular}{ll} 
Foreword & \multicolumn{2}{|c}{} \\
Preface vi & \\
Contributors & $\mathrm{x}$
\end{tabular}

1. Introduction and Summary 1

Part I. The Structure of Intergovernmental Finance 13

2. Revenues and Expenditures in an Intergovernmental Framework 15 Jorge Martinez-Vazquez, Charles McLure, and François Vaillancourt

3. Budgeting, Financial Management, and Financial Markets in an Intergovernmental Context 35

François Vaillancourt

4. The Structures and Conduct of Intergovernmental Relations 57 Ronald H. Neumann and T. Russell Robinson

5. Fiscal Flows, Fiscal Balance, and Fiscal Sustainability 81 Richard M. Bird

Part II. The Provision of Services 99

6. Fiscal Aspects of Alternative Methods of Governing Large Metropolitan Areas 101 Enid Slack

7. Providing Public Services in Remote Areas 123 Harry Kitchen and Enid Slack

8. Local Government Enterprises 141 Harry Kitchen

\section{Part III. Revenues 175}

9. Local and Regional Revenues: Realities and Prospects 177 Richard M. Bird

10. Alternative Approaches to Taxing Land and Property 197 Enid Slack

11. Local Business Taxes 225 Richard M. Bird

12. Fiscal Federalism and the Taxation of Nonrenewable Resources 247 Kenneth J. McKenzie 



\section{Foreword}

When Russia declared its independence from the Soviet Union in 1991, an era of reforms was launched throughout Central and Eastern Europe and Central Asia to make the transition from command to market systems (economic decentralization). Key among these reforms has been the process of decentralizing the governance of the socialist state- the devolution of fiscal powers and responsibilities from central to local governments and the creation of a functioning federal state. Indeed, the World Bank's World Development Report on Entering the 21st Century (1990-2000) concluded that such localization is, along with globalization, one of the two forces that now shape the world in which development policy is defined and implemented. Since the early 1990s, the World Bank Institute has supported this change process through the sustained delivery of courses and seminars.

As noted in the preface to this volume, there are few countries where the success of fiscal reform is as important as it is in Russia; and few countries have as much to offer as does Canada in terms of lessons to be learned about sustainable federalism. To facilitate this exchange of knowledge, in 2001 the World Bank Institute (WBI) joined with the Russian Ministry of Finance and the Canadian International Development Agency (CIDA) to develop a Russian language course on Intergovernmental Fiscal Relations and Local Financial Management to help prepare future trainers in all seven Okrugs (Administrative Regions) build the capacity to design a successful decentralization strategy. The course was organized by WBI's Migara De Silva in cooperation with Dr. Alexei Lavrov of the Russian Ministry of Finance and Guillaume Legros of CIDA. The course materials on Canada were developed by Professors Richard Bird (University of Toronto) and Francois Vaillancourt (University of Montreal), who worked with the team of experts who have contributed chapters to this book.

Perspectives on Fiscal Federalism adds to the existing series of WBI publications on intergovernmental fiscal relations, complements the core course which is now fully managed and delivered by our Russian counterparts, and further strengthens the knowledge partnership among Canada, Russia, and the World Bank.

Frannie A. Léautier

Vice President

World Bank Institute 


\section{Preface}

Extensive political and fiscal decentralization is underway worldwide, from China to Cambodia, India to Indonesia, and Sudan to Sierra Leone. But nowhere has it been more dramatically evidenced than by the collapse of the Soviet Union. Moreover, because the world needs an economically robust and decentralized postcommunist system, there are few countries where the success of federalism is more important than it is in Russia. And, few countries have as much to offer in terms of knowledge about federalism than does Canada.

Russia is a country that has a huge potential for global and regional economic power, yet that has a remarkably poor record of performance. Today's Russia has a population four and a half times that of Canada, but a GDP half its size. The United Nations Human Development Index assigns Canada a ranking of .95 (1.00 is the maximum), making it 4th in the world out of 171 countries, while Russia comes in at .80, making it 57 th. Similar comparisons can be made between Russia and several other states that, for the 45 years following the end of World War II were also under the rule of the former Soviet Union. Thus, comparisons between Russia and Croatia, the Czech Republic, Estonia, Hungary, Latvia, Lithuania, Poland, and the Slovak Republic tell a similar, albeit less dramatic, story of Russia's falling behind. While there are several reasons for this disappointing record, recent empirical work suggests that the failure to decentralize fiscally is one of them.

At the time of its independence in 1991, it was generally accepted that some form of federalism was the only political system that would fit the size and diversity of Russia; however, the recent consolidation of power under the government of President Vladmir Putin has cast doubt on the extent (or maybe just the pace) of this commitment. Whatever the present degree of commitment or the pace, it is clear that for Russia to realize its economic, social, and political potential there must be a functional and appropriate system of intergovernmental fiscal relations.

Drawing on Canada, this book is about what is functional and appropriate. Recognizing there is no one "correct" model for, or path to, a well-designed intergovernmental fiscal system and that many dissimilarities exist between the two countries, it is also true that Russia and Canada have many similarities and that there are lessons to be shared.

The dissimilarities include those of culture, history, and the markedly different systems of governance that the two countries have operated under over the past century. Although both Russia and Canada are ethnically and linguistically mixed, naturally rich in resources, and highly diverse in their geographic character as well as in their urban vs. rural profiles, Russia is much more fractionalized in each of these categories. And then there is the matter of sheer size: Canada spans 6 time zones while Russia spans 11. Another big difference is time: Canada's federal experience spans nearly 14 decades, whereas the new Russian experiment is a scant 14 years old.

In 139 years, citizens have time to change a system. The Canadian Constitution Act of 1867 contained 147 articles, many of which have been repealed, overridden, or otherwise modified in some manner. As the editors of this volume point out, although Canada is far from having the conceptually ideal structure of federalism, it has nevertheless done many things "right" with respect to the central vs. subnational fiscal relationship. Of course, just what Canada's federalism looks like in its 15 th decade will be different from that of its 14 th; however, the basic system will remain in place. Indeed, the flexibility to adjust to new circumstances, economic, 
demographic, technological, and political, is one of the great merits of a robust federal system such as Canada's.

Russia, however, does not have 14 decades to work it all out. The future is arriving much more rapidly in the first decade of the 21st century than it did in the mid-19th (the law of compound economic growth attests to that), and in an era of market globalization and the growing global desire of people for self-determination and devolution of governmental power, the pressure is on for Russia to exploit more fully its full potential. However, as part of its post- Soviet legacy, Russia is grappling with how to decentralize fiscal power at the same time that its public sector is striving to retain many attributes of a heavily centralized state. The result is a gap between the goal of initiating a well-designed federal system as expressed in its 1993 Constitution, and the reality whereby the division of powers remains obscure, with fiscal relations sometimes confrontational and chaotic.

So, the differences matter. But so do the similarities. And here is where there is a great deal of common ground. The similarities are of two types: there are institutional similarities and similarities pertaining to knowledge. Institutionally, there are two common elements. The first is that, in the case of both Russia and Canada, part of the impetus behind the "new" federalist discussion (one in the 1860s, the other in the 1990s) was to devise a system that recognized the legitimate interests of different regions in a geographically expansive country and at the same time needed to establish the intergovernmental competence of the central ("federal") government. Thus, Canadian politics focused on addressing the divergent interests of both upper (anglophone) and lower (francophone) Canada. Russia has a similar starting point of divergent regions, such as those of north and west vs. south and east of the Ural Mountains. And, just as did Canada in its beginnings, Russia has a need to become intergovernmental in a manner that affirms the primacy of central law.

The second common institutional feature is that, for both countries, the question of "whither federalism" has been at the historic core of the process whereby the nation defines the scope and character of its collective actions. This is true even though the content of that discussion has been vastly different. For Canada, one could characterize the content as a fiscal "magnificent obsession." For Russia, it has oftentimes (at least before 1991) been a "perverse obsession." But in both cases it has been a fiscal obsession.

For the Canadian "founding fathers" who participated in three constitutional conventions between 1864 and 1867, federalism was about a combination of national survival and identity, and the hard, cold political give and take between upper and lower Canada. Underpinning both was an urgency to avoid the violence of the then ongoing Civil War in the United States, which served as a signal to many that the U.S. "bottom-up" model was a failure. And so it has gone since 1867, with the Canadian notions-and practice-of federalism serving as a flexible vehicle for subsequently accommodating matters such as the interests of western province demands for powers over land and natural resources (granted in 1930), the equal status of the French and English languages in New Brunswick (1993), permitting Québec to organize school boards along linguistic lines (1997), and creation of the new Territory of Nunavut (1999). Indeed, there is a Canadian saying (at least among the federalism crowd) that whatever social issue may arise in Canada, the correct response is "Is it good or bad for the federal system?"

The same robustness of the federalism debate characterizes the history of the Russian Soviet Federative Socialist Republic (1924-1991) and the Russian Federation (1991-present). With 11 time zones, fractionalization, and rich vs. very poor regions, federalism matters. However, Russia's history provides few good lessons in federalism. The fiscal structure envisioned by Vladmir Lenin was a transitory federal system that would serve as the "surest step" to a centralized socialist state. Joseph V. Stalin similarly argued that federalism in Russia was merely a transition to a centralized union, and that to think of Canada (which he 
specifically cited in a 1918 interview with Pravda) as having a stable system was "an infatuation." The result: citizen desire for autonomy was supplanted by autocracy, and pluralism by plutocracy. However, in December 1991, the Soviet concept of federalism as a "free federation of people in equal rights" (USSR Constitution of 1924) gave way to the concept of "a democratic federal rule of law ... whereby the people of the Russian Federation shall exercise their power directly and also through organs of state power and local self-government" (Constitution of the Russian Federation, 1993).

Editors Richard Bird and François Vaillancourt have identified three areas in which the Canadian experience informs the policy and implementation challenges that Russia faces in making its new federalism work: the structure of intergovernmental finance, provision of services, and revenue mobilization. In their introduction, the editors provide a detailed overview of the contents of each of the 11 supporting chapters; that discussion is not repeated here. What is useful here is to note how these chapters fit Canadian-Russian knowledge sharing. To summarize:

STRUCTURE OF INTERGOVERnMENTAL FinANCE. Both countries have understood from the start that in order for there to be a strong subnational system of finance, the central authority must have the capacity to be intergovernmental. Thus, as the first chapters explain, Canada has expenditure and revenue assignment largely "right" in its federal-provincial relationship. Recognizing that a well-designed intergovernmental structure it not just about assignment, but also about how to manage and implement that assignment, the book proceeds to addresses the practical areas of budgeting and public financial management, the necessary institutional framework for the conduct of intergovernmental relations, and how to bring all this information together into a sustainable set of central-subnational relationships through a system of fiscal planning, measurement, and monitoring.

Provision OF SERVICES. Having established the structural underpinnings for an intergovernmental system, the next two sections turn to the economist's raison d'etre for fiscal decentralization: the promise of efficiency gains that can be exploited once there are local variations in preferences and costs of local public services. The first section turns to the expenditure side of the intergovernmental budget, addressing three topics where the Canadian experience is particularly relevant to the emerging federalism dialogue. The first two topics focus on questions of jurisdictional size and degree of population concentration-that is, on the choices of implementing service delivery in a metropolitan agglomeration (city regions such as Toronto, Vancouver, and Halifax) vs. rural areas (including regions such as the Yukon, Northwest Territories, and Nunavut). Together the two chapters, metropolitan and rural, weave a single story of when to use tools such as one- vs. two-tier governmental structures and alternative forms of intragovernmental cooperation, and of how the urban vs. rural framework frames the choice of tax handles. The discussion on service delivery is then rounded out by a focus on the role of local governmental enterprises. A special merit of the government enterprise chapter is that it moves from first addressing the important questions of the role and rationale for local government enterprises to providing a framework for evaluating their governance.

REVENUES. The provision of services is only one side of the intergovernmental budget equation and the efficiency argument for decentralization. The other is that, at the margin, the tax decision to provide decentralized public services must be local. This is true even though there remains a clear role for transfers from "senior" governments. But for the efficiency goal to be realized there must be clarity in the subnational authority's power to levy "own" revenues. And, with respect to revenue policy and practice, Canada has much to offer. Accordingly, this 
section addresses issues ranging from the principles and practice of the conventional-for example, user charges and the variants of real estate taxation_to two less conventional local taxes, personal income tax surcharges (piggybacking) and provincial destination-based valueadded taxes. Again, as is true throughout this book, the discussion is not what Russia "should" do but, rather, how to think about its options from an operational perspective.

Robert D. Ebel

Senior Fellow

Tax Policy Center, Urban Institute

District of Columbia

United States 


\section{Contributors}

Richard M. Bird is professor emeritus of economics, adjunct professor of business economics, and codirector of the International Tax Program at the Joseph L. Rotman School of Management of the University of Toronto. He has been a visiting scholar at a number of overseas universities, and has frequently been a consultant to the World Bank, the International Monetary Fund, the Canadian federal government, and other national and international organizations. In addition to numerous publications on tax and federal finance issues in Canada, Bird has written extensively on the fiscal problems of developing and transition countries and on comparative public finance in general.

Harry Kitchen is a full professor in the Department of Economics, Trent University, Peterborough, Ontario. He has published extensively in the field of local public finance, especially in relation to Canada. He has carried out numerous consultancies in this area and, in particular, has been involved in issues of local government mergers and restructuring.

Kenneth J. McKenzie is a full professor in the Department of Economics, University of Calgary, Alberta. Specializing in public economics with an emphasis on taxation and political economy, McKenzie has acted as an adviser to governments and institutions at the international, federal, and provincial levels. He was appointed to the Taxation and Finance Committee of the Alberta Economic Development Authority and was a member of the Alberta Business Tax Review Committee in 2000.

Ronald H. Neumann is the director of intergovernmental finance in the Finance Department of Manitoba. Since 1998 he has also served as a consultant to the Financial and Fiscal Commission of South Africa. He has participated in projects related to transfer payment formulas and the conduct of intergovernmental fiscal relations in Russia and in China.

T. Russell Robinson was assistant deputy minister for federal-provincial relations in the Canadian federal Department of Finance (1986-93) and deputy secretary to the Cabinet in the Intergovernmental Affairs section (1993-95). As a public policy consultant since 1995, he has participated in projects in China, Mongolia, Russia, and Vietnam dealing with policy reform areas that include intergovernmental arrangements and structures.

Enid Slack is president of Enid Slack Consulting, Inc. Slack is an economic consultant specializing in municipal, education, and intergovernmental finance. She was a special adviser to the Greater Toronto Area Task Force, a member of the Who Does What Panel in Ontario, and a member of the City of Toronto's Business Reference Group on tax policy. Her clients in Canada and abroad include municipal, provincial, territorial, and federal governments; government commissions; school boards; and private companies. Slack has published numerous books and articles on local government finance.

François Vaillancourt is a full professor in the Economics Department and a fellow of the Economics Research Center, Université de Montréal. He has published extensively in the area of public policy, especially on federalism, human resources, and taxation issues. He has acted as a consultant for various bodies, such as the Canadian International Development Agency, the Economic Council of Canada, Finance Canada and Finance Québec, Statistics Canada, the United Nations Development Programme, and the World Bank. 


\title{
Introduction and Summary
}

\author{
Richard M. Bird and François Vaillancourt
}

This book deals with a wide range of questions relating to intergovernmental finance around the world. While we do not purport to provide a comprehensive treatment of all the issues that arise in this context-even for Canada, the country of most of the authors, or for Russia, the country for which earlier versions of these materials were prepared-some chapters cover important new ground, and the book as a whole should prove useful to scholars and policymakers everywhere who are concerned with intergovernmental and local finance issues.

The coverage and contents of any book largely reflect its origins. The original impetus for this book arose from several years of experience with the Intergovernmental Finance Course the World Bank Institute (WBI) offered to developing and transition countries. ${ }^{1}$ In part because of the short duration of the course, it could not adequately cover a number of issues critical in many countries. Thus one factor that led us to prepare this book was the desire to provide more complete coverage of some important subjects in the field. Coincidentally, the Canadian International Development Agency expressed interest in working with Canadian scholars and WBI to develop and present a course on intergovernmental finance developed specifically for the complex and evolving situation in the Russian Federation and drawing, to the extent possible, on experience with these issues in Canada. As we were the principal Canadian scholars involved with the WBI course, we were charged with the task of pulling together pertinent papers, and we also took the opportunity to attempt to fill some of the gaps in the existing course.

The 11 substantive chapters in this book arose from this project. They were prepared almost entirely by Canadian scholars and policymakers drawing in large part on their experience with these issues in Canada, although all also had some relevant experience in the developing and transition countries. Some chapters were initially intended to assist Russian policy analysts and policymakers in areas of special concern in Russia, such as property taxation, natural resources taxation, and the provision of services to remote areas. However, as many other countries must also grapple with similar problems, this material should be of interest to a much wider audience. In addition, to help fill some gaps in the materials available for analysts and policymakers everywhere with respect to certain aspects of intergovernmental finance, chapters were prepared on a number of other subjects: local business taxation, local business enterprises, finances of metropolitan areas, fiscal flows, and federal-regional relations. Finally, in the course of adapting the WBI course materials for Russia, we realized that some revision and extension of several of the core materials was also desirable. The result was the chapters on tax and expenditure assignment, budgetary policy, and local and regional revenues.

The three parts of this book are not, however, organized in terms of its varied origins, but in terms of three basic issues that arise with respect to intergovernmental finance in general: the structure and functioning of the intergovernmental finance system, the provision of services, and revenues. The balance of this introduction provides a brief overview of the key

1. The current version of this course may be found at http://www.worldbank.org/wbi/ publicfinance/decentralization/coursemodule.htm. 
issues in fiscal federalism in general and then summarizes the key points of each of the subsequent chapters.

\section{Key Issues in Fiscal Federalism}

Six questions arise with respect to intergovernmental finance in any country (this framework and some of the discussion in this section are taken from Bird forthcoming). The first five focus on content as follows:

- The question of expenditure assignment: Who should do what?

- The question of revenue assignment: Who should levy what taxes?

- The question of vertical imbalance: How should any imbalance between the revenues and expenditures of subnational governments be resolved?

- The question of horizontal imbalance or equalization: To what extent should fiscal institutions attempt to adjust for differences in needs and capacities between different government units at the same level of government?

- The question of access to capital markets: What, if any, rules should exist with respect to subnational borrowing?

The sixth question concerns the process by which these questions are answered, that is, the institutional framework within which the technical and political problems of fiscal federalism are resolved.

Each of the six questions must be analyzed taking the specific circumstances of each country into account. For example, the relevant policy objectives for a particular country may include not only the classic goals of efficiency (allocation), equity (distribution), and stabilization, but also achieving economic growth, preserving a regional balance, and maintaining national integrity and political stability. Moreover, in the case of transition countries such as Russia, additional important objectives may include developing market-facilitating institutional and real infrastructure (property rights, rule of law, transportation networks, and so on). Not only may some of these objectives conflict in theory and practice, but important differences often exist between local and central perceptions of the weights that should be attached to them. Moreover, intergovernmental fiscal policies have to take both political constraints and economic constraints into account. Finally, the fiscal institutions in place in any country reflect the results of an accretionary process of policies over time, and the inertia inherent in such institutions must not be underestimated when policy changes are contemplated or initiated. To understand, let alone to resolve, the intergovernmental fiscal puzzle therefore requires substantial institutional as well as analytical knowledge.

That said, the basic requirement for efficient and effective subnational government may be summarized as the "matching principle." Ideally, to the extent possible, for any type of public services, benefit areas (such as school catchment areas or areas serviced by public transit) should be matched with financing areas (fees or taxes used to finance the relevant service), as in the benefit model of local finance. In addition, expenditure responsibilities should be matched with revenue resources. Most important, revenue capacities should be matched with political accountability.

The basic rule of efficient expenditure assignment is to assign each function to the lowest level of government consistent with its efficient performance, an approach that the European Union refers to as subsidiarity. The economic literature expresses much the same idea in the so-called decentralization theorem. So long as local variations in tastes and costs exist, carrying out public sector activities in as decentralized a fashion as possible clearly has potential efficiency gains. Local decisionmakers should decide what services are to be provided, to whom, and in what quantity and quality, and-an important point-local taxpayers should pay for the services provided. Scarce public funds should, of course, be managed as efficiently and used as effectively as 
possible. Both financial honesty and political accountability require budgeting and financial procedures to be properly established and implemented. Budgeting, financial reporting, and auditing should be comprehensive, comprehensible, comparable, verifiable, and public.

In relation to revenues, a completely subnational tax may be defined as one that subnational governments assess, determine the rates for, and collect, and one whose proceeds accrue to subnational governments. In the real world, however, many taxes may possess only one or two of these characteristics, and who "owns" them may be unclear. We suggest two basic principles for assigning revenues to subnational governments. First, own source revenues should ideally be sufficient to enable at least the richest subnational governments to finance all locally provided services that primarily benefit local residents from their own resources. Second, to the extent possible, subnational revenues should be collected only from local residents and should preferably be related to the benefits they receive from local services. Establishing a clear connection between those who make decisions about local taxes, those who pay such taxes, and those who benefit from them is critical for sound intergovernmental policy.

Regardless of the revenue sources made available to subnational governments, if they do not have the capacity to finance services at adequate levels, if externalities are associated with the services in question, or if a country wishes to take inter-regional differences in needs into account, transfers are needed. A well-designed system of intergovernmental transfers inevitably constitutes an essential component of any decentralization strategy. Three key factors in the design of intergovernmental fiscal transfers are the size of the pool available for distribution, the basis for distributing transfers, and the conditionality attached to transfers. Three possible ways to determine how much money is to be distributed through intergovernmental fiscal transfers are

- As a fixed proportion of central government revenues or some other "macro" basis, for example, as a percentage of gross domestic product

- On an ad hoc basis, that is, in the same way as any other budgetary expenditure

- On a formula-driven basis, for instance, as a proportion of specific local expenditures or in relation to some general characteristics of the recipient jurisdictions.

With respect to subnational borrowing, inappropriate subnational borrowing generally reflects basic, underlying inadequacies with respect to the intergovernmental fiscal system. Once that system has been corrected by means of such measures as reassigning revenues, and perhaps expenditures; revising the transfer system; introducing transparent, timely, and reliable reporting systems; and establishing a stable, accepted, periodic review process, the problem of unsustainable subnational borrowing should largely be solved. Until then, however, certain specific rules and limits may have to be put in place to reduce the likelihood of undesirable outcomes. Essentially, only two basic ex ante limits on subnational borrowing seem to be necessary. First, borrowing should be permitted only for investment purposes, a restriction that may not always be easy to enforce in the absence of strictly segregated and meaningful capital budgets. Second, explicit national approval should be required for borrowing abroad.

In the long run, unless subnational governments are able to save themselves from fiscal crises by drawing on their taxing powers, their only options are bankruptcy or bailouts. The fiscal root of this problem is the limited taxing power available to subnational governments that are expected and required to carry out a much wider range of functions than they can finance on their own without extensive reliance on central support, either directly through transfers or, less desirably, indirectly through bailouts The political root of the problem, however, lies in the continuing expectation by all players-citizens, subnational and national politicians, and lenders - that, in the end, the central government will come to the rescue. So long as central actions, ex post, reinforce this expectation, ex ante administrative controls on borrowing, such as requiring prior central government approval or limiting debt service to a certain proportion of current revenues, may have to remain in place. 
Good fiscal federalism outcomes are likely to occur only when a good institutional framework is available within which to discuss and resolve the inevitable problems. In general, we argue as follows:

- Transparency is needed for good fiscal management.

- Good fiscal management is needed if a decentralized political structure is to work relatively effectively and efficiently.

- Some sort of specialized agency (or agencies) is needed to perform such functions as providing good, relevant, and timely analysis of intergovernmental fiscal relations; training good analysts; facilitating and encouraging productive technical exchanges between and within governments; and providing neutral, competent input into public discussions of intergovernmental fiscal and financial policy.

Such intangible, but critical, institutional factors will, in the end, play a vitally important role in making decentralization work in any country.

Because all countries are different, and because no federal country is exactly like any other federal country, international comparisons of federal financial arrangements are both difficult to make and hard to interpret once made. In Canada, for example, the two worlds of federalprovincial and provincial-local fiscal relations are almost totally different in most relevant respects, and the federal government has little direct interaction with local governments (Bird and Chen 1998). In contrast, in Russia not only does the federal government's role extend much more deeply into the local government sector, but governments at all levels remain deeply involved in what would be considered private sector activities in most other countries. Nonetheless, despite the difficulties of comparing one country with another, considering the experience of one country in light of the experiences of other countries can be useful, including both their successes and their failures. Such comparisons, explicit and implicit, underlie the papers in this volume.

\section{The Structure of Intergovernmental Finance}

Part I of this book contains four chapters covering important issues related to the general setting of intergovernmental finance in any country, that is, assignment, budgeting, institutional, and measurement issues.

\section{Assignment}

Chapter 2, by Jorge Martinez-Vazquez, Charles McLure, and Francois Vaillançourt, sets the stage for the rest of the volume by considering the key issues related to the nature of government intervention and decentralization, the assignment of responsibilities, the assignment of revenues, and the sequencing of such assignment. Several important points emerge from this discussion.

Governments have three main ways to intervene in the economy: spending (including tax expenditures), taxing, and regulation. All three should be clearly assigned to appropriate levels of government. While expenditure and taxes have been discussed extensively in this context, regulation must not be forgotten, because regulation can mandate private agents to carry out tasks that would otherwise be carried out by governments and would therefore require budgetary or tax expenditures. Indeed, in modern federations, regulatory powers are sometimes found at the very center of intergovernmental relations. In Canada, for example, one of the key intergovernmental issues arises from a continuing push by the private sector, which wants to have the power to regulate securities moved from the provinces and territories to the federal level (Vaillancourt and Bird 2002). 
More generally, exactly what one means by decentralization must be clear. The term can be seen as encompassing the following three distinct types of behavior:

- Deconcentration: giving regional or local offices of the central government decisionmaking power previously held in the central offices in the capital

- Delegation: making a subnational government responsible for carrying out a function for which the central government retains responsibility

- Devolution: transferring responsibilities from the central government to subnational governments.

When economists talk about decentralization, they usually mean devolution, but when governments decentralize they are often really deconcentrating or delegating rather than devolving responsibility. Because what a government is trying to do affects how it should be done, being clear about the real objectives of decentralization is critical.

In all cases, the first fundamental step in designing a system of intergovernmental fiscal relations should be a clear assignment of functional responsibilities among different levels of government. Instability and controversy have often resulted in practice when the law is silent or unclear about the competencies (responsibilities) of different levels of government. The assignment of responsibilities should be guided by a concern for efficiency, with particular attention to matching the service area with the level of government.

Another important point concerns tax assignment. For fiscal decentralization to be a reality, subnational governments must control their own sources of revenue, because if they lack independent sources of revenue, they are likely to be under the financial thumb of the central government. Of course, increasing tax autonomy may result in increased tax competition, but, as chapter 2 notes, this is not necessarily a bad thing.

Thus stable and meaningful decentralization requires both an unambiguous and welldefined assignment of responsibilities among the different levels of government and sufficient budgetary, regulatory, and tax autonomy to carry out the assigned responsibilities at each level of government. Moreover, getting the sequence right is important. In particular, assigning revenues in the absence of a clear assignment of responsibilities is to put the cart before the horse. Unfortunately, undue focus on the revenue side of decentralization and neglect of the need for a clear assignment of expenditure responsibilities has characterized decentralization in many transition countries and has invariably resulted in relatively poor outcomes.

\section{Money Management}

Even if every government obtains the right amount of money from the right sources, for it to succeed it must manage its funds properly. Thus chapter 3, by Vaillancourt, addresses a set of mundane, but nonetheless critical, issues that discussions of intergovernmental finance have all too often neglected, that is, accounting concepts, the role and preparation of budgets, the structure of capital markets, bond issuance, and credit rating processes.

Accountability is the key to good government, and good accounting, budgetary, and financial documents are necessary for three types of accountability: administrative accountability, both internal and external; economic accountability to attain the greatest level of efficiency possible and provide taxpayers with value for money; and political accountability, which allows citizens to assess the performance of their elected politicians. In this regard, an understanding that, for example, bookkeeping conventions matter, is critical. For instance, single-entry bookkeeping on a cash basis, which is common in many developing countries, particularly at the subnational level, means that expenses and revenues are entered in one column with a positive value for revenues and a negative value for expenses. With this system proper budgeting is obviously difficult, because expenses and revenues are intermingled and cancel each other out 
and arrears do not show up in the accounting system. In contrast, double-entry bookkeeping on an accrual basis has two columns, one for revenues and one for expenses. This form of recording transactions allows the production of an expenses and revenues statement, which is one of the two basic documents of modern accounting (the other is the balance sheet).

Of course, everyone recognizes that budgets are key legal, managerial, and political documents. Budgetary choices affect the well-being not only of today's citizens, but also of tomorrow's. Thus, as chapter 3 discusses, carefully thinking through not only the form and content of the final budgetary document but also the process used to establish the budget is important.

Despite the potential problems with subnational borrowing alluded to earlier, access to financial markets through borrowing is important for subnational governments (and their enterprises), because it allows them to allocate the costs of capital expenditures appropriately over the lifetime of a project so that those who benefit from it pay for it, rather than requiring unduly high saving by current generations to finance infrastructure that their descendants will enjoy. Thus chapter 3 also discusses some critical aspects of subnational access to capital markets.

\section{Institutional Framework}

Chapter 4, by Ronald Neumann and Russell Robinson, focuses on the institutional framework needed to make a federation work. Of course, each federation will organize its intergovernmental relations differently depending on its constitutional and legal framework, on its history, on the role of political parties (regional or national in scope), and so on. Nonetheless, presumably the aim is always to make the federation work. To do so, it needs to accomplish a number of tasks and develop institutions to ensure that that the tasks are carried out in an appropriate and timely way.

A first task is to identify the issues to be discussed. Such issues may be broad and general, for example, whether there is a fiscal disequilibrium, or narrow and technical, for instance, how to measure a given tax base for equalization purposes. A second, and particularly crucial, task is to develop relevant and accepted common statistical information. One possibility may be a specialized intergovernmental agency; another may be an independent statistical agency. Until governments and other interested parties, such as beneficiaries of public spending, are familiar with and generally agree on the facts (which does not, of course, imply agreement on their interpretation), developing policy options is difficult, let alone reaching either consensus, or at least informed dissent. A third task is the critical one of policy adoption, implementation, administration, and coordination. The appropriate institutional way in which to achieve these various objectives may, as chapter 4 discusses, vary from one policy to another.

A final important task discussed in chapter 4 is how to achieve accountability. While chapter 3 discussed how to obtain the meaningful financial numbers needed for accountability, chapter 4 raises some broader questions about how to use these and other numbers to ensure that the system is working correctly and that people get what they want and what they are paying for. A current Canadian example illustrates this problem. The federal government, which transfers substantial funds to provinces intended, at least loosely, to finance health costs, has established a health council to which the various provincial governments, which actually do all the direct spending on health (including much from their own resources) would report information in a uniform fashion that lends itself to comparison and assessment. Most large provincial governments have resisted, arguing that they are accountable to their citizens through the political process and that this proposal represents unwarranted federal interference. Issues such as this come up all the time, in all decentralized systems, and need to be resolved by means of some appropriate institutional framework. 


\section{Fiscal Measurement}

The final chapter in part I, chapter 5 by Richard Bird, turns to a different question that appears to arise in different ways in most decentralized systems, and certainly in most federal states. How can one measure how well the federal fiscal system is working? The literature offers three approaches to this question: fiscal flows, fiscal balance, and fiscal sustainability. Chapter 5 suggests that each of these concepts is fraught with conceptual and practical problems and must be handled with great care.

Inter-regional fiscal flows refer to the amount of federal taxes collected in a region and the amount of spending done in a region. Such numbers are difficult to obtain and hard to interpret. Taxes are not necessarily paid by the residents of the region in which they are collected, for example, consider customs duties collected in a port city but paid by all the consumers of the relevant goods. Similarly, the residents of a region through which a highway passes do not necessarily receive benefits equal to the value of their share of that highway. Even if fiscal flows are properly measured-taking the real incidence of taxes and spending into accountwhat a surplus or deficit means is far from clear. If a country has a progressive tax system, for example, and more rich people live in one region than in the others, then there will appear to be a fiscal flow out of that region. Is the implication that taxes should be paid back to that region?

Fiscal imbalance may be vertical, that is, between levels of government, with typically the central government having excess revenues and the other levels having deficiencies, or horizontal, that is between governments at a given level. While widely used, these measures too are dubious. Vertical fiscal imbalance, for example, is often calculated based on assumptions about required expenditures and feasible taxes, and all such calculations are obviously subject to challenge and more useful in political debate than for analytical purposes.

Despite the problems with many of the common measures outlined in chapter 5 , attempting to produce relevant indicators is obviously important to permit the evaluation and appraisal of fiscal federalism structures and policies. Fortunately, though again difficult both to measure and to interpret, the fiscal sustainability approach appears to be the least flawed way to assess how well structured, and hence how sustainable, a federal system may be. Thus the chapter suggests that future work should concentrate on improving this aspect of fiscal measurement in decentralized government systems.

\section{The Provision of Services}

Part II of the book contains three chapters related to the provision of public services. These chapters shift the focus from federal-regional relations to the local level of government, where many services are actually delivered. The emphasis is not on the characteristics of particular services, important though that consideration may be in practice, but on the institutional structure that delivers services at the local level. Chapters 6 and 7 discuss the issue from two distinct, but important, perspectives: first that of a large metropolitan area and then that of a small remote area. The first question is how best to resolve the fundamental assignment issues raised in chapter 2 in these two completely different sets of circumstances. The second, related, but distinct, issue is how best to structure local government institutions to deliver local services in these two extreme cases. While some overlap between these two chapters is inevitable because the questions raised and the factors to be taken into consideration are essentially the same, the answers are quite different, demonstrating the inevitable context specificity of policy in this area. The final chapter in this part, chapter 8 , focuses on a different question, namely, the appropriate role and structure of local government enterprises in providing public services. 


\section{Providing Public Services in Large Metropolitan Areas}

Chapter 6, by Enid Slack, examines large metropolitan areas. The levels and types of local government expenditures in large metropolitan areas differ from expenditures in other areas because of the size of the population; the large number of people living in close proximity, which creates agglomeration economies; and the presence of a heterogeneous population in terms of social and economic circumstances, and often in terms of ethnicity, birthplace, or mother tongue.

Unfortunately, economies of scale are often not important in this context, so the result is higher spending per capita even on services provided in smaller areas, but fortunately, metropolitan areas not only spend more, they can tax more. They generally have a larger, more diversified tax base than smaller areas. Not only can they more easily levy their own taxes, they often have greater fiscal autonomy than other areas. Because they can finance many of the services residents and business demand out of own sources of revenue, large cities generally need to rely less on grants from senior levels of government than other areas, though, of course, metropolitan area politicians, like those everywhere, prefer to secure less politically painful grants (or so-called shared taxes) than to raise more tax revenue.

The extent to which taxes reflect the benefits received in the way of local services is determined largely by the governing structure of the metropolitan area, which also affects the ability of large metropolitan areas to share the costs of local government in a fair and efficient way. The optimal design for the government structure depends on the importance of such factors as economies of scale, externalities, and equity, which favor large government units, versus local responsiveness, access, and accountability, which point toward smaller government units.

To attain good allocative outcomes, some form of structure encompassing the entire area of the city is needed to address problems of a regionwide nature, such as fiscal disparities and externalities. The form such a regional structure takes will vary with local circumstances, which may sometimes suggest a unified (one-tier) metropolitan government and sometimes a federated (two-tier) structure.

A one-tier structure is simpler and more transparent than a two-tier structure, and thus would appear to enhance political and fiscal accountability. Two-tier structures are more complex and may result in duplication, overlap, and confusion among citizens as to who does what and who pays for it. However, a two-tier structure may achieve greater efficiency than a more centralized one-tier structure is likely to attain. Desirable economies of scale and scope can be realized at the upper tier level, while at the same time the lower tier permits more responsiveness to local variations in preferences. Voluntary intermunicipal agreements about the provision of services may work in a few cases, but cannot replace the need for an effective institution to facilitate, encourage, and require the necessary degree of regional cooperation.

\section{Providing Services in Remote Areas}

By contrast, as chapter 7 by Harry Kitchen and Slack notes, local governments in remote areas often lack the financial, human, and technological means to provide more than basic services to a sparse and dispersed population, particularly outside the regional hub. Financing these services is more difficult in remote areas because of a combination of low tax bases (low property values, little economic activity) and high unit costs of services (because economies of scale are low and transportation costs high). As a result, transfers inevitably represent a higher share of revenues for local governments in such areas.

Chapter 7 argues that in these circumstances, the most appropriate local government structure is a single-tier structure. Two-tier structures, special districts, and intermunicipal agreements such as those discussed in chapter 6 are unlikely to work well because of a lack of contiguous government. Even though central governments should not intervene by directly 
providing services as this reduces accountability, they can and should use grants to achieve the desired level of services. No matter how the lily is gilded, however, in the end the dispersion of residents and the relatively low levels of public resources and services available in remote areas mean that local governments are unlikely to play a large role in remote areas. (As chapter 12 notes, however, matters may be completely different if such areas are blessed with highly valued natural resources.)

\section{Local Government Enterprises}

In the final chapter of part II, chapter 8, Kitchen raises four key issues. The first, and most basic, is why do local government enterprises exist at all? Noting that many reasons that make no economic sense often account for their existence, including adhering to legal requirements and traditions, creating jobs, avoiding controls or revenue sharing with central governments, and hiding revenues, chapter 8 argues that only sensible reason is when providing services through this organizational structure is more efficient than the alternatives.

Even if, in principle, an enterprise can be more efficient, however, this gain is not achieved costlessly. The removal of enterprise decisions from general politics may mean that they become subject, in a nontransparent way, to special politics. Coordination between enterprises and local governments and the sharing of common resources may prove troublesome. Moreover, accountability is clearly weakened in most cases. Chapter 8 argues that enterprise performance should be closely monitored using appropriate indicators, noting that alternative means of service delivery include contracting out, franchises, or public-private partnership of various kinds.

An issue that turns out to be surprisingly complex in practice is how to set enterprises' prices. Various possibilities exist, such as average cost pricing, multipart pricing, and so on. The appropriate method will vary from service to service, and is often not simply technically complex, but politically important. For both reasons, an important question is whether and how to regulate enterprises' prices.

Finally, should local government enterprises earn profits and should their revenues be earmarked? In principle, chapter 8 suggests that the answer is that enterprises should be expected to earn a normal rate of return on capital and that the extent to which earmarking is appropriate depends on the type of enterprise. Taxes should be paid if the enterprise competes with private firms.

\section{Revenues}

In the end, discussions about fiscal federal issues often come down to where the money comes from. Part III contains four chapters about revenue matters. The first provides an overview and the last three deal with specific tax questions that are generally important in a regional or local context.

\section{Local and Regional Revenues}

Chapter 9, by Bird, reviews the entire field of possible regional and local revenues. The theory of fiscal federalism prescribes that subnational governments taxes should be easy to administer locally, should be imposed solely (or mainly) on local residents, and should not create problems of harmonization or competition between governments. Essentially only property taxes, taxes on vehicles, and user charges and fees meet these conditions. Local governments may indeed be able to finance purely local services through property taxes and user fees on residents, but regional governments responsible for social services cannot rely solely on such a narrow fiscal base. Chapter 9 argues that a good subnational tax system should provide sufficient revenue 
for the richest subnational units to be essentially autonomous and should impose fiscal responsibility at the margin on all subnational governments.

The chapter then reviews various revenue sources from this perspective, noting that the first rule of subnational finance should be wherever possible, charge. If properly designed, user charges (service fees, public prices, and specific benefit taxes) help ensure that citizens value what the public sector supplies, at least at marginal cost, and promote economic efficiency by providing demand information to public sector suppliers. In addition, a low-rate, uniform property tax has an important role to play in financing local governments along with other land-based taxes, for example, betterment levies and special assessments. Excise taxes may also play a role in financing subnational governments, particularly automotive and fuel taxes, although more in large urban areas than in poor rural areas.

Turning to less conventional local taxes, supplementary (piggybacked) local income taxes are another good possibility, especially at the regional and metropolitan government level. Such taxes would be visible, and hence in principle would satisfy the criteria of political responsibility and accountability. Unfortunately, a good local income tax is only possible when there is a good national income tax, and few developing or transition countries have such taxes. Payroll taxes are another possibility. They have the merit of being both easily administrable, at least when imposed on large enterprises, and relatively productive at relatively low rates. However, such taxes are a barrier to employment in the modern sector and compete with social security systems. To the extent that payroll taxes can be made effective on a regional basis, so can flatrate personal income taxes, which, in practice, are probably levied on much the same base without the bias against employment inherent in payroll taxes.

General sales taxes are often the answer to the search for a regional revenue source that is economically respectable, administratively viable, and reasonably elastic. Retail sales taxes are a nonreproducing breed confined to parts of North America. General turnover taxes are inappropriate, because they tax a significant number of intermediate business activities and often create a variety of totally unenforceable distinctions between activities. The sales tax of choice is now the value added tax (VAT), so the issue is how best to design and implement a subnational VAT. While Canada has demonstrated that this can be done, whether such a system can work satisfactorily in developing and transition countries remains unclear (Bird and Gendron 2001). This chapter also briefly discuss a variant form of VAT, the so-called business value tax, which is taken up in more detail in chapter 11.

\section{Property Taxes}

In many countries, property taxes are the mainstay of local finance. In many others, local governments are frequently urged to make more use of such taxes. Chapter 10, by Slack, sets out alterative approaches to taxing land and property in some detail (for an extended treatment, see Bird and Slack forthcoming). The chapter argues that a property tax can be best viewed as a highly visible benefit tax. It therefore makes for good accountability and is a good source of autonomous revenues for local governments, provided they can set the rate themselves.

The chapter discusses many aspects of property taxes in some detail. It notes, for example, that the key problem to developing a successful property tax in many countries is the difficulty of establishing ownership of the land and the structures on that land, but contends that this can generally be overcome to a considerable extent. Exemptions for certain types of properties, such as churches and schools, and favorable treatment for other types of properties, particularly owner occupied single family dwellings, complicate administration and are hard to justify, because the use of local services does not vary in proportion to the more or less favorable treatment of such properties. Regular updates of property tax bases, for instance, assessed values, are important to ensure fairness, revenue elasticity, and sensible allocative outcomes. Finally, harking back to an issue touched on in chapter 3 , chapter 10 notes that special assessments, land 
value increment taxes, and exactions (lot levies, development charges) can play useful, if limited, roles in financing local infrastructure investment in some circumstances.

\section{Business Taxes}

Economists tend to argue that regional and local governments should not tax business as such, but governments always want to do so. Recognizing that regional and local governments are no different than central governments in this respect, chapter 11, by Bird, notes that local and regional taxes on business and capital are indeed likely to be economically costly, and that the mobility of the tax base (and income shifting across boundaries) make it difficult for small governments to enforce such taxes. Moreover, to the extent they can be "exported," local business taxes reduce accountability and weaken the hard budget constraint needed to ensure that decentralized public sector decisions are efficient, because they weaken the link between payment and benefits.

Nonetheless, as chapter 11 notes, taxing businesses can be both efficient and equitable to the extent that businesses derive benefits from general local spending, although political factors often mean that the level of business taxes is higher than the level of benefits received. In practice, the local and regional business taxes found around the world take many forms: corporate income taxes, taxes on internal trade, gross receipts taxes, fixed or proportional taxes that vary by type of business and location, local sales taxes, nonresidential real property taxes, and a variety of licenses and fees unrelated to public services. Most of these taxes are not equitable, almost none are neutral, all accentuate disparities between localities, most lend themselves to tax exporting, and most are costly to administer. However, such taxes are clearly politically acceptable, they provide an important, and relatively elastic source of revenue, and they are often one of the few ways in which local governments have any degree of fiscal autonomy.

Given these conflicting realities, chapter 11 concludes that what is needed to improve the situation is essentially a move toward a more strictly benefit system of business licenses and fees for smaller local governments and toward a more neutral and uniform variety of VAT, imposed on an income-origin basis, for large local governments and regional governments (see Bird and McKenzie 2001 for a detailed proposal for such a tax at the regional level).

\section{Natural Resource Taxes}

In many countries, natural resource taxation has become a critical issue in fiscal federalism. In addition to Canada and Russia, other significant examples include countries as disparate as Colombia, Indonesia, and Sudan. Chapter 12, by Kenneth McKenzie, does not purport to provide a thorough review of this exceptionally complex and controversial area, but sets out a possible general framework within which to approach the question of who should get how much from taxing nonrenewable natural resources like oil.

The key characteristics of such resources are that their total supply is inherently limited and that they tend to be unevenly distributed across geographic regions. The first characteristic generates a scarcity rent, while the second means that this rent is concentrated in specific areas. In principle, if resources are located in one region of a multiregion federation and if the government of that region can tax them, one result will be to induce inefficient migration from other regions, because residents from those regions will want to benefit from the lower taxes, higher expenditures, or both provided by the lucky regional government. For this reason, an efficiency argument favors having such resource rents collected centrally.

However, the rents to be collected centrally should be net of the costs of providing public services and the infrastructure to extract the resources and net of the externalities (pollution, damage to infrastructure, and so on) associated with resource extraction, if any. Moreover, especially if secession is a credible option, resource-rich states may need to be permitted to maintain 
a significant share of the rents generated by natural resources within their boundaries so that they agree to remain part of the federation. Doing so need not make other states worse off, as presumably all can share in the surplus resulting from the continuation of the federation; this surplus results from gains from trade and economies of scale.

Turning to how to tax natural resources, chapter 12 notes that the breakdown of extraction time is a key parameter, because it determines the intergenerational allocation of the income obtained from the resource stock. Firms will choose to extract resources according to a time path that maximizes their profits in present value terms. Because severance taxes-perhaps the most common form of local tax-encourage the postponement of production, while royalties (gross or net) have an uncertain impact on this choice, the best choice for a local or regional tax would appear to be a property tax. Such a tax, provided it is levied on the present value of the remaining resources net of extraction costs, is similar to a so-called resource rent tax, and hence is neutral with respect to extraction decisions.

\section{References}

Bird, Richard M. Forthcoming. "Fiscal Federalism in Russia: A Canadian Perspective." Public Finance and Management.

Bird, Richard M., and Duanjie Chen. 1998. "Federal Finance and Fiscal Federalism: The Two Worlds of Canadian Public Finance." Canadian Public Administration 43(1): 51-74.

Bird, Richard M., and Pierre-Pascal Gendron. 2001. "VATs in Federal Countries: International Experience and Emerging Possibilities." Bulletin for International Fiscal Documentation 55(7): 293-309.

Bird, Richard M., and Kenneth J. McKenzie. 2001. Taxing Business: A Provincial Affair? Commentary no. 154. Toronto: C. D. Howe Institute.

Bird, Richard M., and Enid Slack. 2004. International Handbook on Land and Property Taxation. Cheltenham, U.K.: Edward Elgar.

Vaillancourt, François, and Richard M. Bird. 2002. "Changing With the Times: Success, Failure, and Inertia in Canadian Federal Arrangements, 1945-2002." Paper no. 151. Stanford: CA: Stanford Center for International Development. http:/ / credpr.stanford.edu/ publications/abstracts.html\#151. 


\section{Part I \\ The Structure of Intergovernmental Finance}





\title{
2
}

\section{Revenues and Expenditures in an Intergovernmental Framework}

\author{
Jorge Martinez-Vazquez, Charles McLure, and François Vaillancourt
}

Countries throughout the world are increasingly recognizing the benefits of fiscal decentralization. If done properly, decentralization allows people to have a greater influence on government decisions that affect their lives (see, for example, Bird and Vaillancourt 1998 for developing countries; Bird, Ebel, and Wallich 1995 on countries in transition from socialism; Litvack, Ahmad, and Bird 1998 for a review of World Bank experience with decentralization in a variety of countries). Even if decentralization is primarily adopted for such political reasons as assuaging separatist tendencies in certain regions, it may also improve the welfare of the population.

This chapter examines general principles of federalism, how expenditure responsibilities should be allocated across levels of government; how taxes should be assigned to various levels of government; and how transfers, if necessary (and they almost always are), can be designed. ${ }^{1}$ Before doing this, however, distinguishing among the different varieties of decentralization is important to ensure that the concept is well understood. There are three commonly used meanings of decentralization as follows:

- Deconcentration: gives regional or local offices of the central government decisionmaking power that was previously held by the central government's offices in the capital within parameters specified by the central government.

- Delegation: makes a subnational government responsible for delivering services for which the central government retains responsibility.

- Devolution: transfers responsibilities for service delivery from the central government to subnational governments.

When economists talk about decentralization, they usually mean devolution; however, when governments decentralize they are often really deconcentrating or delegating rather than devolving responsibility.

\section{Principles for Dividing Revenue Responsibilities and Revenue Sources}

Two classic contributions to the literature focus on the division of revenue responsibilities and revenue sources: the seminal work by Musgrave (1959) and the refinements by Oates (1972). Musgrave (1959) suggests that, for conceptual purposes, the activities of government should be separated into three functions or branches: macroeconomic stabilization, income redistribution, and resource allocation. The stabilization branch is to ensure the achievement of high employment and price stability, the distribution branch is to achieve an equitable distribution of income, and the allocation branch is to make sure that resources are used efficiently. Which

Section two of this document draws on "Tax Assignment and Subnational Fiscal Autonomy" Bulletin for International Fiscal Documentation 54(12):626-635, 2000 by Charles McLure. We thank the International Bureau of Fiscal Documentation for granting us permission to use this material.

1. Borrowing is not addressed here, as it is discussed at length in chapter 3 in this volume. 
level of government, central or subnational, should perform each function is the question of interest here. $^{2}$

The stabilization function-the maintenance of high employment and price stability-is ordinarily assigned to the central government for two reasons. ${ }^{3}$ First, subnational governments commonly cannot have much of an effect on macroeconomic conditions within their boundaries, because most of the effects of macroeconomic policy attempted by subnational governments will leak out of their jurisdiction. Second, subnational governments have no power to print money and often have limited power to borrow money, thus they often have difficulty in engaging in the deficit financing that is frequently required to implement expansionary policy.

This perspective neglects two points, however. First, subnational governments may be responsible for activities that lend themselves more easily to countercyclical spending than the national government. For example, varying road expenditures-a subnational activity in Canada and the United States, for example-according to macroeconomic needs is easier than varying spending on military airplanes, a national responsibility. Second, second-tier governments in some countries (Canada, the United States) set some labor standards, such as rules on the length of the warning period for mass layoffs and the amount of severance pay when layoffs occur. The requirements thus set may reduce the amplitude of employment cycles, but at the expense of employment levels. ${ }^{4}$

Subnational governments are also usually limited on the revenue side. The taxes commonly thought to have the most powerful stabilizing effects are the corporate income tax and the progressive individual income tax. ${ }^{5}$ The former is considered stabilizing because profits fluctuate more than general economic conditions, ${ }^{6}$ and the latter because of the stabilizing effects of graduated rates (including tax-free amounts). This suggests that these two taxes should be assigned to the central government.

The distribution function is primarily assigned to the central level of government, because subnational attempts at redistribution may not succeed and are likely to distort the geographic allocation of economic resources. Progressive taxation intended to "soak the rich" may drive out capital and high-income individuals. If this occurs, taxation that appears to be progressive may actually be regressive. ${ }^{7}$

2. The term subnational is used to describe all levels of government below the national level. Second tier is used for the highest level of subnational government, for example, the states of Australia, Brazil, and the United States; the provinces of Argentina and Canada; the lander of Germany; and the oblasts of the former Soviet Union. Local is used for all governments below the second tier.

3. Sewell (1996) suggests that there may be more latitude for subnational stabilization policy than in Musgrave's view.

4. Differences in policies across subnational governments on the use of factors of productions will also affect the impact of national stabilization policies

5. Progressive taxation takes a percentage of income that rises as income rises; regressive taxation takes a percentage that falls; proportionate taxation takes the same fraction of income at all income levels.

6. Specific provisions of the corporate income tax, such as depreciation rates, can also be varied to encourage private investment in a given time period. Such incentives were common in Canada in the 1960s and 1970s.

7. The contrary problem occurs on the expenditure side. Transfer payments by subnational governments are likely to attract the poor, which may discourage the use of such policies. Sewell (1996) reviews evidence that subnational governments do, indeed, engage in income redistribution. In Musgrave's threebranch system, only transfers and taxes would be used to modify the distribution of income; other types of expenditure policies would not be used. While tax policy can "level down," it cannot reduce poverty or "level up"; that must be done on the expenditure side (refundable tax credits are transfers and thus expenditures). If implementation problems prevent the use of transfers, as is common in developing countries, using expenditure policy related, for example, to health and education, may be appropriate for reducing poverty. Considerations discussed by Sewell (1996) suggest that, while these policies may best be implemented locally, they should be financed nationally. 
The explanation just presented relies heavily on the mobility of factors of production, and of people in particular. The internal mobility of labor varies between countries according to the strength of family ties, culture, and tradition. If the borders of subnational jurisdictions coincide with those of ethnic, linguistic, or religious groupings, then redistributive policies carried out at that level are less likely to induce migration. This is observed in Canada, with Quebec being a high-tax, second-tier jurisdiction, but with the lowest out-migration rate of all the provinces because the majority ( 80 percent) of its population is French speaking, while the Canadian labor markets outside Quebec are English speaking. Also in some countries, the limited availability of housing and poorly developed housing markets limit mobility. Under these circumstances, subnational policies may have more latitude to redistribute income than in the Musgrave model.

So far the discussion has been about policies to modify the current distribution of income, given the characteristics of the members of a society. In a longer-term perspective, what matters are the policies that determine these characteristics. In this respect, education policies, and in particular, equal opportunities for all, may be what matter the most for the intertemporal evolution of inequalities. Such policies are often, at least in part, within the domain of subnational governments, but national standards may be required to achieve the desired results. ${ }^{8}$

The third function of governments is efficient allocation of resources, which is where subnational governments can play their most important role. Musgrave (1959) argues that the policies of subnational branches of governments should be permitted to differ to reflect the preferences of their residents. The decentralization of taxing and spending power allows subnational governments to tailor schemes that match the demands of their constituency. This ultimately increases efficiency, because local governments have better information about their residents' needs than the central government. Because of their size and proximity to citizens, subnational governments may also be less subject to capture by various established groups, such as bureaucrats or unions.

Oates (1972) puts forward four criteria to assign specific roles to specific levels of government as follows:

- Economies of scale will vary across goods and services. Economies of scale are significant in broadcasting, for example, where the unit cost per viewer drops by half when the number of viewers of a given program doubles, but negligible in the provision of individualized health services such as surgical treatment. The existence of significant economies of scale constitutes an argument for a higher level of government to provide a particular good or service.

- Heterogeneity of preferences and of circumstances also matters. Groups living in different parts of a country may display strong heterogeneity of preferences or may be faced with different environments in terms of climate or topography. They may therefore prefer or may need different amounts (more or less) of services, a different quality of service (for a given amount), or a different language for delivering public services. Decentralization is appropriate if these groups are separated by borders that match those of areas with differentiated preferences or circumstances.

- The presence of externalities, negative or positive, has an impact. If some of the activities of one government at a given level have important external effects on the individuals or businesses located in other jurisdictions or on other governments at the same or a different level, then these activities should be more centralized, or at a minimum the actions of lower-level authorities should be well coordinated.

8. National standards can result from either a central government decision if the constitutional and legal framework permits or from an agreement among subnational governments. 
- Emulation, also referred to as competition, which helps increase or introduce best practices in government, requires at least two, and probably more, units involved in a given activity. This is an argument for decentralizing government activities.

\section{Assignment of Responsibilities}

The first fundamental step in the design of a system of intergovernmental fiscal relations should be a clear assignment of functional responsibilities among different levels of government. Instability and controversy in the practice of decentralized systems have resulted in many cases where the law is silent or unclear about the competencies, or responsibilities, of different levels of government. Governments have two main ways to carry out their responsibilities: spending, including tax expenditures, and regulation, and these powers should be clearly assigned to appropriate levels of government. Regulation should not be forgotten, because these two approaches are both complements and substitutes. For example, regulation can mandate private agents to carry out tasks that the government would otherwise carry out and would therefore require public spending. For instance, requiring households or firms to recycle makes them spend time and money on this activity while reducing the landfill costs incurred by the government. The use of regulation to impose costs on individuals or firms cannot be justified solely on the basis that it reduces government spending, or worse, that it hides the costs to society of government decisions. It can be appropriate if the private sector's production costs, including the regulatory burden costs, are lower than the public provision cost, given that those that create the social costs will bear them. ${ }^{9}$

In some countries, subnational governments are given autonomy to formulate budgets and to spend their funds any way they want, but the central government determines revenues and the overall budget levels of subnational governments. In most cases, the main revenue sources are taxes whose base and rates are set centrally and that are often collected centrally. As a result, subnational governments have little or no access to tax expenditures or tax incentives to achieve their policy objectives. Similarly, their access to regulatory power is also often restricted. Regional and local governments may have autonomously elected legislatures, but in many cases the central government continues to appoint the heads of executive agencies. Such institutional confusion has resulted in some countries having an unwieldy mix of deconcentration and devolution of government activities.

The efficient provision of government services requires that the government satisfy taxpayers' needs and preferences as well as possible. This is best achieved by the subsidiarity principle. ${ }^{10}$ One aspect of this principle is that responsibility for the provision of services should be at the lowest level of government compatible with the size of the benefit area associated with those services. For example, the benefit area for sanitation service (garbage removal) is the local community, but for air traffic control, the benefit area is the entire national territory, or even a supranational one, such as the European Community.

9. Governments need to be extremely careful in relation to their use of regulation, because it could turn into something akin to unfunded mandates, where the central government requires the provision of a good or service by another level of government, but does not provide the funds to cover the cost of doing so.

10. This is put forward as a key principle in the proposed European constitution (Article I-9). The European Parliament set forth the following definition on November 5, 2003 (http://www.europarl .eu.int/factsheets/1_2_2_en.htm):

The general aim of the principle of subsidiarity is to guarantee a degree of independence for a lower authority in relation to a higher body or for a local authority in respect of a central authority. It therefore involves the sharing of powers between several levels of authority, a principle which forms the institutional basis for federal States. When applied in a Community context, the principle means that the Member States remain responsible for areas which they are capable of managing more effectively themselves, while the Community is given those powers which the Member States cannot discharge satisfactorily. 
Leaving the supply of public services with wider benefit areas to smaller units of government is likely to result in the inefficient underprovision of services, with taxpayers unwilling to pay for services provided to others. An example is a tertiary public hospital providing regional services that is financed solely by a single municipality.

Efficiency may also be enhanced if governments can use regulatory instruments to mandate private provision, as in the following examples:

- A local government responsible for parking issues may find that mandating that new buildings be built with an adequate number of parking spaces is less costly than having to build and operate public parking facilities, while at the same time ensuring that those responsible for the demand for additional parking bear the costs of providing it.

- A second-tier government responsible for watershed management may prefer regulating discharges from various privately operated treatment facilities to building a larger water treatment plant or sewer system. The regulatory approach also ensures that polluters provide the required treatment services. ${ }^{11}$

The application of the principles put forward by Oates and of the subsidiarity principle guides the assignment of responsibilities to different levels of government, but does not always yield an unequivocal answer. Some public services, for example, primary education and primary health services, may be of a local nature by the size of their benefit area; however, because of their relevance for welfare and income redistribution, they may also be considered a responsibility of the central government. Thus talking about the best assignment of expenditure responsibilities in any absolute sense is not meaningful. What is considered the best assignment is likely to change over time with changes in costs and technological constraints that affect the production of publicly provided goods and services, changes in the preferences and human capital endowments of individuals, and changes in the relative endowments of the regions of a country. For example:

- The increased capability of computers to handle large datasets, coupled with the reduced cost of transmitting information across the Internet and greater labor mobility, may mean that welfare supervision, which is often a local responsibility because local authorities know their clients best, could now be regional or national.

- The increased mobility of labor between regions of a country or the need to accommodate a larger flow of international immigrants that need to become familiar with their new country may mean that the school curriculum in some topics now needs to be set nationally.

Nonetheless, at any given moment, having a clear, concrete assignment of expenditure responsibilities among the various assignments-preferably one that could be considered optimal-is necessary. Failure to have such a transparent, concrete assignment may lead to instability in intergovernmental relations and to inefficient provision of public services.

In centralized systems, the lack of a clear assignment of expenditure responsibilities may be less important in practical terms. For example, in the former Soviet Union, because all government budgets were integrated with the federal budget, subnational governments could count on additional resources when they faced an unexpected shortfall. As unitary systems become more decentralized, however, and especially for federal systems, the failure to establish a clear assignment of expenditure responsibilities for each government level can become a source of conflict between the central and subnational governments and can lead to an inefficient (and often insufficient) provision of key public services. If treasury functions (tax collection and

11. Even though a pollution rights market would generally be preferable, this would be difficult to implement in lower-income countries given the extent of their institutional capacity. 
disbursement) are centralized, as is the case in France and in French-inspired African systems, then the issue is often that the central government keeps the limited funds collected, even as payments of local taxes, to finance central expenditures.

Table 2.1 presents one possible assignment of specific responsibilities between levels of governments put forward by Shah (1994). It is of interest, because it shows how the principles discussed in this chapter can be applied. Table 2.2 presents data on expenditures on education,

Table 2.1 Possible Detailed Expenditure Assignment

\begin{tabular}{|c|c|c|c|}
\hline Expenditure category & $\begin{array}{l}\text { Policy, standards, } \\
\text { and oversight }\end{array}$ & $\begin{array}{l}\text { Provision and } \\
\text { administration }\end{array}$ & Comments \\
\hline Defense & $\mathrm{F}$ & $\mathrm{F}$ & Benefits and costs national in scope \\
\hline Foreign affairs & $\mathrm{F}$ & $\mathrm{F}$ & Benefits and costs national in scope \\
\hline International trade & $\mathrm{F}$ & $\mathrm{F}$ & Benefits and costs national in scope \\
\hline $\begin{array}{l}\text { Monetary policy, currency, } \\
\text { banking }\end{array}$ & $\mathrm{F}$ & $\mathrm{F}$ & Benefits and costs national in scope \\
\hline Interstate commerce & $\mathrm{F}$ & $\mathrm{F}$ & Benefits and costs national in scope \\
\hline $\begin{array}{l}\text { Transfer payments to } \\
\text { individuals }\end{array}$ & $\mathrm{F}$ & $\mathrm{F}$ & Redistribution \\
\hline $\begin{array}{l}\text { Subsidies to business and } \\
\text { industry }\end{array}$ & $\mathrm{F}$ & $\mathrm{F}$ & $\begin{array}{l}\text { Regional development, industrial } \\
\text { policy }\end{array}$ \\
\hline Immigration & $\mathrm{F}$ & $\mathrm{F}$ & Benefits and costs national in scope \\
\hline Unemployment insurance & $\mathrm{F}$ & $\mathrm{F}$ & Benefits and costs national in scope \\
\hline Airlines and railways & $\mathrm{F}$ & $\mathrm{F}$ & Benefits and costs national in scope \\
\hline Fiscal policy & F, S & F, S, L & Coordination possible \\
\hline Regulation & $\mathrm{F}$ & F, S, L & Internal common market \\
\hline Natural resources & $\mathrm{F}$ & F, S, L & Promotes a common market \\
\hline Environment & $\mathrm{F}, \mathrm{S}, \mathrm{L}$ & $\mathrm{S}, \mathrm{L}$ & $\begin{array}{l}\text { Benefits and costs national, } \\
\text { regional, or local in scope }\end{array}$ \\
\hline Industry and agriculture & $\mathrm{F}, \mathrm{S}, \mathrm{L}$ & $\mathrm{S}, \mathrm{L}$ & $\begin{array}{l}\text { Significant interjurisdictional } \\
\text { spillovers }\end{array}$ \\
\hline Education & $\mathrm{F}, \mathrm{S}, \mathrm{L}$ & $\mathrm{S}, \mathrm{L}$ & Transfers in kind \\
\hline Health & $\mathrm{F}, \mathrm{S}, \mathrm{L}$ & $\mathrm{S}, \mathrm{L}$ & Transfers in kind \\
\hline Social welfare & $\mathrm{F}, \mathrm{S}, \mathrm{L}$ & $\mathrm{S}, \mathrm{L}$ & Transfers in kind \\
\hline Police & $\mathrm{S}, \mathrm{L}$ & $\mathrm{S}, \mathrm{L}$ & Primarily local benefits \\
\hline $\begin{array}{l}\text { Water, sewage, refuse } \\
\text { collection }\end{array}$ & $\mathrm{L}$ & $\mathrm{L}$ & Primarily local benefits \\
\hline Fire protection services & $\mathrm{L}$ & $\mathrm{L}$ & Primarily local benefits \\
\hline Parks and recreation & $\mathrm{F}, \mathrm{S}, \mathrm{L}$ & $\mathrm{F}, \mathrm{S}, \mathrm{L}$ & $\begin{array}{l}\text { Primarily local responsibility, but } \\
\text { national and provincial } \\
\text { governments may establish own } \\
\text { parks }\end{array}$ \\
\hline \multicolumn{4}{|l|}{ Highways } \\
\hline Interstate & $\mathrm{F}$ & $\mathrm{S}, \mathrm{L}$ & Internal common market \\
\hline Provincial & $\mathrm{S}$ & $\mathrm{S}, \mathrm{L}$ & Provincial benefits and costs \\
\hline Inter-regional & $\mathrm{S}$ & $\mathrm{S}, \mathrm{L}$ & Inter-regional benefits and costs \\
\hline Local & $\mathrm{L}$ & $\mathrm{L}$ & Local benefits and costs \\
\hline Spending power & $\mathrm{F}, \mathrm{S}$ & $\mathrm{F}, \mathrm{S}$ & $\begin{array}{l}\text { Fiscal transfers to advance own } \\
\text { objectives }\end{array}$ \\
\hline
\end{tabular}

F Federal responsibility.

S State or provincial responsibility.

L Local responsibility.

Source: Shah (1994). 
health, and social welfare by different levels of government for selected countries and years. It shows the great diversity in the assignment of responsibilities for public spending across countries.

\section{Tax Assignment}

If fiscal decentralization is to be a reality, subnational governments must control their own sources of revenue. Subnational governments that lack independent sources of revenue can never truly enjoy fiscal autonomy, because they may be-and probably are-under the financial thumb of the central government. Therefore important questions are which revenue sources can and should be assigned to subnational levels of government and how these assignments will be carried out. This is commonly referred to as the tax assignment problem. ${ }^{12}$ It is closely related to the expenditure problem, both because of the importance, at least in principle, of benefit taxation in the finances of subnational government, and because of the need to ensure that subnational governments have revenues that are adequate to finance the expenditures assigned to them.

To the extent possible, services the government provides should be financed by user charges and fees. This is both fair and efficient in the sense of encouraging responsible use of the nation's economic resources. User charges, fees, and taxes related to the benefits of public spending are likely to be regressive or, at most, proportionate to income. They are unlikely to reduce inequality in the pretax distribution of income..$^{13}$

Where strict compliance with benefit finance is infeasible because of the difficulty or undesirability of exclusion from the benefits of public spending, the principle is, nonetheless, instructive. For both equity and efficiency, tax payments should reflect the costs and benefits of public services to the extent possible. Among the examples of benefit-related taxes are those levied on motor vehicles and motor fuels and used to construct and maintain roads. Such taxes can also be used to reduce congestion, pollution, or both when set to take both the direct value of the service provided to the user and these social costs into account.

Each level of government should be assigned taxes that are related to the benefits derived from spending them. Thus the proper assignment of taxes that are related to benefits depends on the assignment of responsibilities and expenditures. A rational assignment of taxing powers helps each level of government control its fiscal destiny. In particular, it permits choice in the level of public spending by governments at each level. Subnational governments must have enough own revenues to finance the services they provide. If a subnational government legislates and collects its own taxes, protected by meaningful constitutional safeguards of its right to do so, it clearly has a source of own revenues. Even if such a government must rely on grants from a higher-level government, it may reasonably be considered to have adequate own revenues, provided the grants are determined in an objective way and are guaranteed by the constitution or by long-standing legislation. By comparison, own revenues may not exist in any real sense if grants are made at the sole discretion of the higher government, perhaps on an ad hoc, arbitrary, and unpredictable basis, and even well into the fiscal year and subject to renegotiation. Between these extremes lies a variety of arrangements that provide more or less

12. Musgrave (1983) asks, "Who Should Tax, Where, and What?" The tax assignment problem is part of a larger set of questions that can be referred to as the revenue assignment problem. The latter includes the design of intergovernmental grants and the framework for borrowing by subnational governments.

13. This statement is incomplete if the benefits of public spending, as well as tax burdens, are considered. Taxes related closely to marginal benefits may finance expenditures that involve substantial inframarginal benefits. These inframarginal benefits may be of special value to low-income families. Obvious examples include the provision of safe drinking water. Many consumers would probably consider themselves better off if they had access to safe water, even if they had to pay for it. The problem is often access, not cost. 
Table 2.2 Total, Education, Health, and Social Security and Welfare Expenditures by Level of Government, Selected Countries and Years (percentage of total)

\begin{tabular}{|c|c|c|c|c|c|c|c|c|c|c|c|c|}
\hline \multirow[b]{2}{*}{ Country and year } & \multicolumn{3}{|c|}{ Total expenditure } & \multicolumn{3}{|c|}{ Education } & \multicolumn{3}{|c|}{ Health } & \multicolumn{3}{|c|}{ Social security and welfare } \\
\hline & Central & State & Local & Central & State & Local & Central & State & Local & Central & State & Local \\
\hline Albania, 1998 & 84.11 & 0.00 & 15.89 & 19.80 & 0.00 & 80.20 & 70.45 & 0.00 & 29.55 & 80.92 & 0.00 & 19.08 \\
\hline Argentina, 2001 & 56.40 & 43.60 & 0.00 & 19.84 & 80.16 & 0.00 & 16.79 & 83.21 & 0.00 & 91.27 & 8.73 & 0.00 \\
\hline Australia, 1998 & 56.68 & 38.15 & 5.17 & 27.82 & 72.05 & 0.12 & 51.88 & 47.45 & 0.67 & 90.28 & 8.25 & 1.46 \\
\hline Austria, 1994 & 83.25 & 16.75 & 0.00 & 68.38 & 31.62 & 0.00 & 76.89 & 23.11 & 0.00 & 91.00 & 9.00 & 0.00 \\
\hline Azerbaijan, 1998 & 0.35 & 0.00 & 99.65 & 17.05 & 0.00 & 82.95 & 15.53 & 0.00 & 84.47 & 98.93 & 0.00 & 1.07 \\
\hline Belarus, 2001 & 60.96 & 0.00 & 39.04 & 18.17 & 0.00 & 81.83 & 21.96 & 0.00 & 78.04 & 97.32 & 0.00 & 2.68 \\
\hline Bolivia, 2001 & 69.73 & 18.52 & 11.75 & 60.58 & 33.62 & 5.80 & 66.15 & 26.21 & 7.65 & 91.27 & 6.73 & 2.00 \\
\hline Botswana, 1994 & 96.58 & 0.00 & 3.42 & 98.90 & 0.00 & 1.10 & 91.00 & 0.00 & 9.00 & 61.98 & 0.00 & 38.02 \\
\hline Bulgaria, 2001 & 83.37 & 0.00 & 16.63 & 41.06 & 0.00 & 58.94 & 84.27 & 0.00 & 15.73 & 90.24 & 0.00 & 9.76 \\
\hline Canada, 1999 & 41.33 & 43.36 & 15.31 & 5.32 & 58.16 & 36.52 & 2.63 & 96.12 & 1.25 & 69.10 & 27.13 & 3.77 \\
\hline China, mainland, 1999 & 43.55 & 56.45 & 0.00 & 8.55 & 91.45 & 0.00 & 4.10 & 95.90 & 0.00 & 11.56 & 88.44 & 0.00 \\
\hline China, Macao, 2001 & 93.39 & 0.00 & 6.61 & 100.00 & 0.00 & 0.00 & 99.97 & 0.00 & 0.03 & 95.65 & 0.00 & 4.35 \\
\hline Croatia, 2001 & 87.93 & 0.00 & 12.07 & 84.43 & 0.00 & 15.57 & 99.12 & 0.00 & 0.88 & 99.02 & 0.00 & 0.98 \\
\hline Czech Republic, 2001 & 80.28 & 0.00 & 19.72 & 61.07 & 0.00 & 38.93 & 98.49 & 0.00 & 1.51 & 94.59 & 0.00 & 5.41 \\
\hline Denmark, 1996 & 55.57 & 0.00 & 44.43 & 53.37 & 0.00 & 46.63 & 4.57 & 0.00 & 95.43 & 47.79 & 0.00 & 52.21 \\
\hline Estonia, 2001 & 75.17 & 0.00 & 24.83 & 32.78 & 0.00 & 67.22 & 97.26 & 0.00 & 2.74 & 91.23 & 0.00 & 8.77 \\
\hline France, 1993 & 82.49 & 0.00 & 17.51 & 62.82 & 0.00 & 37.18 & 97.81 & 0.00 & 2.19 & 91.19 & 0.00 & 8.81 \\
\hline Georgia, 2000 & 69.44 & 0.00 & 30.56 & 20.41 & 0.00 & 79.59 & 53.95 & 0.00 & 46.05 & 92.71 & 0.00 & 7.29 \\
\hline Germany, 1996 & 59.63 & 24.15 & 16.22 & 4.20 & 68.44 & 27.36 & 72.44 & 12.47 & 15.09 & 78.62 & 10.86 & 10.51 \\
\hline Hungary, 1999 & 76.97 & 0.00 & 23.03 & 53.00 & 0.00 & 47.00 & 55.17 & 0.00 & 44.83 & 88.01 & 0.00 & 11.99 \\
\hline Iceland, 1998 & 71.19 & 0.00 & 28.81 & 46.90 & 0.00 & 53.10 & 98.60 & 0.00 & 1.40 & 77.65 & 0.00 & 22.35 \\
\hline India, 1999 & 52.96 & 47.04 & 0.00 & 10.56 & 89.44 & 0.00 & 26.64 & 73.36 & 0.00 & 0.00 & 100.00 & 0.00 \\
\hline Ireland, 1997 & 74.86 & 0.00 & 25.14 & 78.23 & 0.00 & 21.77 & 51.57 & 0.00 & 48.43 & 93.68 & 0.00 & 6.32 \\
\hline Israel, 1999 & 86.57 & 0.00 & 13.43 & 74.02 & 0.00 & 25.98 & 99.09 & 0.00 & 0.91 & 94.18 & 0.00 & 5.82 \\
\hline Kazakhstan, 2000 & 55.34 & 0.00 & 44.66 & 16.03 & 0.00 & 83.97 & 13.99 & 0.00 & 86.01 & 88.29 & 0.00 & 11.71 \\
\hline Kenya, 1994 & 96.53 & 0.00 & 3.47 & 97.91 & 0.00 & 2.09 & 92.73 & 0.00 & 7.27 & 52.94 & 0.00 & 47.06 \\
\hline Kyrgyz Republic, 2000 & 77.30 & 0.00 & 22.70 & 59.62 & 0.00 & 40.38 & 59.85 & 0.00 & 40.15 & 90.89 & 0.00 & 9.11 \\
\hline Latvia, 2001 & 73.86 & 0.00 & 26.14 & 28.02 & 0.00 & 71.98 & 95.21 & 0.00 & 4.79 & 93.39 & 0.00 & 6.61 \\
\hline Lithuania, 2001 & 78.86 & 0.00 & 21.14 & 31.72 & 0.00 & 68.28 & 99.37 & 0.00 & 0.63 & 89.78 & 0.00 & 10.22 \\
\hline Luxembourg, 1995 & 84.48 & 0.00 & 15.52 & 78.60 & 0.00 & 21.40 & 98.21 & 0.00 & 1.79 & 97.77 & 0.00 & 2.23 \\
\hline
\end{tabular}


Table 2.2 (continued)

\begin{tabular}{|c|c|c|c|c|c|c|c|c|c|c|c|c|}
\hline \multirow[b]{2}{*}{ Country and year } & \multicolumn{3}{|c|}{ Total expenditure } & \multicolumn{3}{|c|}{ Education } & \multicolumn{3}{|c|}{ Health } & \multicolumn{3}{|c|}{ Social security and welfare } \\
\hline & Central & State & Local & Central & State & Local & Central & State & Local & Central & State & Local \\
\hline Moldova, 2001 & 71.04 & 0.00 & 28.96 & 24.21 & 0.00 & 75.79 & 30.99 & 0.00 & 69.01 & 98.35 & 0.00 & 1.65 \\
\hline Mongolia, 2001 & 68.94 & 0.00 & 31.06 & 29.01 & 0.00 & 70.99 & 47.19 & 0.00 & 52.81 & 98.97 & 0.00 & 1.03 \\
\hline Netherlands, 1997 & 78.29 & 0.00 & 21.71 & 66.71 & 0.00 & 33.29 & 95.41 & 0.00 & 4.59 & 85.64 & 0.00 & 14.36 \\
\hline Norway, 1999 & 65.88 & 0.00 & 34.12 & 36.22 & 0.00 & 63.78 & 22.20 & 0.00 & 77.80 & 81.41 & 0.00 & 18.59 \\
\hline Poland, 2001 & 69.31 & 0.00 & 30.69 & 28.16 & 0.00 & 71.84 & 6.91 & 0.00 & 93.09 & 93.57 & 0.00 & 6.43 \\
\hline Romania, 2001 & 82.61 & 0.00 & 17.39 & 43.55 & 0.00 & 56.45 & 99.85 & 0.00 & 0.15 & 94.12 & 0.00 & 5.88 \\
\hline Russia, 2001 & 61.20 & 0.00 & 38.80 & 17.82 & 0.00 & 82.18 & 11.85 & 0.00 & 88.15 & 87.16 & 0.00 & 12.84 \\
\hline Slovak Republic, 2001 & 99.29 & 0.00 & 0.71 & 99.77 & 0.00 & 0.23 & 99.74 & 0.00 & 0.26 & 99.61 & 0.00 & 0.39 \\
\hline Slovenia, 2001 & 88.37 & 0.00 & 11.63 & 77.00 & 0.00 & 23.00 & 98.78 & 0.00 & 1.22 & 98.50 & 0.00 & 1.50 \\
\hline South Africa, 1998 & 69.73 & 30.27 & 0.00 & 22.02 & 77.98 & 0.00 & 17.65 & 82.35 & 0.00 & 32.60 & 67.40 & 0.00 \\
\hline Spain, 1997 & 67.60 & 20.22 & 12.18 & 28.73 & 65.13 & 6.15 & 37.28 & 59.69 & 3.04 & 94.15 & 3.75 & 2.10 \\
\hline Switzerland, 2000 & 52.04 & 28.53 & 19.44 & 9.74 & 55.24 & 35.02 & 54.98 & 25.70 & 19.32 & 76.10 & 15.26 & 8.64 \\
\hline Tajikistan, 2001 & 69.07 & 30.93 & 0.00 & 17.64 & 82.36 & 0.00 & 18.70 & 81.30 & 0.00 & 96.33 & 3.67 & 0.00 \\
\hline Thailand, 1996 & 90.69 & 0.00 & 9.31 & 95.35 & 0.00 & 4.65 & 91.92 & 0.00 & 8.08 & 95.83 & 0.00 & 4.17 \\
\hline Uganda, 2000 & 81.05 & 0.00 & 18.95 & 67.21 & 0.00 & 32.79 & 82.06 & 0.00 & 17.94 & 0.00 & 0.00 & 100.00 \\
\hline Ukraine, 2001 & 70.30 & 0.00 & 29.70 & 39.51 & 0.00 & 60.49 & 18.18 & 0.00 & 81.82 & 83.16 & 0.00 & 16.84 \\
\hline United Kingdom, 1998 & 77.90 & 0.00 & 22.10 & 34.08 & 0.00 & 65.92 & 100.00 & 0.00 & 0.00 & 79.70 & 0.00 & 20.30 \\
\hline United States, 2000 & 49.74 & 27.45 & 22.81 & 4.55 & 43.76 & 51.69 & 56.11 & 33.02 & 10.87 & 67.82 & 23.94 & 8.24 \\
\hline
\end{tabular}

Note: Countries were selected if information was available for second-tier or local governments in the data source; years reported on are the latest found in the data source. We use the items total expenditure B1, education B4, health B5, and social security and welfare B6 from the relevant tables in the International Monetary Fund publication in our calculations. State expenditures are from $\mathrm{S}$ tables and local expenditures from $\mathrm{L}$ tables in the same publication.

Source: International Monetary Fund (2002). 
complete subnational ownership of revenues. Tax surcharges collected by higher-level governments might be seen as own revenues if there is no substantial risk that the higher-level government collecting the revenues will not remit them to the subnational government.

Even if subnational governments have own revenues, they may be unable to influence the amount of revenue they receive. This is true, for example, if the central government shares revenues from certain taxes with subnational governments. ${ }^{14}$ By comparison, if subnational governments legislate and implement their own taxes, or even if they are allowed to impose surcharges on the taxes levied by the central government at rates they choose, they can influence the amount of revenues they receive, and thus, at the margin, control their revenues. This distinction is crucial, because subnational governments must be assigned marginal sources of own revenues, that is, revenues with a level they can control, if they are to be truly autonomous. Only by choosing to pay higher or lower taxes can residents of subnational jurisdictions choose the level of public services they want.

An important prerequisite for the exercise of subnational fiscal autonomy is therefore the ability to choose statutory tax rates. ${ }^{15}$ A given tax should be assigned to the lowest level of government that can implement it (or for which it can be implemented) and for which it is not inappropriate. This is the application of subsidiarity to taxation. The notion of subsidiarity in taxation was introduced to the European Union with the Maastricht Treaty amendments to the Treaty of Rome (Article 3B). Subsidiarity requires member states to determine their own fiscal policies unless those policies have negative spillover effects on the entire Union. The Commission of the European Communities (1991, p. 7) explained that subsidiarity requires that "Member States should remain free to determine their tax arrangements, except where these would lead to major distortions." Compliance with this principle is important to minimize the tendency toward vertical imbalance that exists because subnational governments have difficulty implementing many taxes, but higher levels of government can implement almost any tax that a lower level of government can implement.

Tax competition can protect citizens from the rapaciousness of politicians and bureaucrats. It helps ensure that taxpayers are getting what they pay for and that the composition of government spending, as well as the level, is appropriate. ${ }^{16}$

Many services that governments provide, including those subnational governments provide, can be described as producing generalized benefits, or benefits that cannot be closely related to taxes on the beneficiaries. Although generalized benefits may not be conducive to the use of charges and fees, or even taxes closely related to benefits, such as taxes on motor transport, they can be related in a general way to taxes paid. Thus, for example, the general benefits of government spending may be loosely related to income or to private consumption. Unless there is some reason to believe that benefits rise more or less rapidly than income or consumption, relying on flat-rate taxes on income or consumption to finance such services may be reasonable. At the subnational level, if people do not work where they live (or if they do not invest

14. In such a case, these are own revenues but not marginal revenues of subnational governments

15. An issue here is why statutory and not effective tax rates. Effective tax rates would vary if subnational governments could alter deductions, exemptions, and so on, but this would mean changing the base and not the rates. This would increase the complexity of the system and the compliance costs of firms operating in multiple jurisdictions.

16. Brennan and Buchanan (1983) provide a strong argument for tax competition (see also McLure 1986). This is only part of the story, although an important part. Because those who enjoy public goods cannot be excluded from enjoying the benefits, they have little incentive to reveal their preferences for such goods. There is thus a tendency to underprovide public goods that tax competition might aggravate (see Gordon 1983 for a theoretical analysis of the inefficiencies that can result from decentralization, including tax competition). Benefit taxation helps to combat this source of market failure (Wildasin 1986). Tax competition makes it difficult for subnational governments to tax mobile factors - capital and highly educated or skilled labor-and therefore to engage in progressive taxation. 
their savings where they live), one must ascertain whether production or consumption (income earned or income spent) is the better measure of generalized benefits.

If the benefits of public spending are more closely related to production or the earning of income than to consumption or the spending of income, origin-based taxes on value added and payroll taxes levied where employment occurs would be superior to destination-based value added taxes (VATs), retail sales taxes, and residence-based income taxes as measures of benefits received.

A priori reasoning suggests that consumption (the spending of income) is probably more closely related to the benefits of public spending than is production (the earning of income). For example, education is usually provided where people live, not where they work, and the same tends to be true for health care. The implications of this reasoning concerning generalized benefits of public services for the problem of tax assignment are clear. In principle, residence-based income taxes are probably superior to employment-based payroll taxes, and destination (consumption)-based sales taxes are better than origin (production)-based ones.

A variety of approaches to assigning revenues to subnational governments can be distinguished. These approaches differ in the degree of fiscal autonomy they provide subnational governments, the ease of compliance and administration, the fairness and neutrality they are likely to produce, and the degree of interjurisdictional redistribution they can accommodate. Four aspects of revenue assignment can be distinguished: (a) which level of government chooses the taxes from which subnational governments receive revenues, (b) which level defines the tax bases, (c) which level sets the tax rates, and (d) which level administers the taxes.

From the viewpoint of subnational fiscal sovereignty, the capacity to set rates is clearly the most important of these, and also the most efficient. The choice of rates is what allows subnational governments to choose the level of public services while minimizing the compliance costs associated with collecting the required revenues. Subnational governments clearly cannot be allowed total discretion in the choice of the taxes they will levy, for example, they should not be allowed to levy import duties on international trade or trade between subnational jurisdictions or to impose taxes likely to be exported in large part. Excessive subnational latitude in the choice of tax bases and in tax administration can create unacceptable complexity and administrative burdens, as well as inequities and distortions in the allocation of resources.

A first approach, independent subnational legislation and administration, provides subnational governments with the most fiscal autonomy. Under this approach, subnational governments choose the taxes they levy, define the tax bases, set the tax rates, and administer the taxes. ${ }^{17}$ This is the approach followed in Canada, Switzerland, and the United States. Because they are subject only to general constitutional limitations (for example, due process and noninterference with inter-regional and international commerce) and almost no statutory limitations, the provinces, cantons, or states can do virtually anything they want in these four areas. Carried to the extreme, this approach is vulnerable to inconsistency, duplication of effort, and excessive complexity of compliance and administration. These problems can occur if different jurisdictions choose radically different taxes (for example, if some levy retail sales taxes, but others levy VATs as is the case in Canada), define their tax bases in different ways (as in the case of state corporate income taxes and retail sales taxes in the United States), or administer the same taxes in different ways. Inequities and economic distortions can also occur if the tax systems of various subnational governments do not mesh, resulting in gaps or overlaps in taxation. Within limits, these problems-which differ in importance from tax to tax-can and should be tolerated in the interest of gaining the benefits of decentralized government. Serious complexities, inequities, and distortions should be avoided, however. This objective can be

17. Subnational constitutions or laws may limit any of these, but self-imposed restrictions in the constitutions of subnational governments differ from restrictions imposed from above by law or as part of a national constitution. 
achieved without greatly compromising the fiscal autonomy of subnational governments through intergovernmental compacts among subnational governments or the imposition of uniform ground rules by a higher level of government, for example, rules governing the definition and division of the corporate income tax base.

A second approach is subnational surcharges, which provide most of the important fiscal autonomy of independent subnational legislation and administration. Under this approach, a higher level of government defines the tax base and collects both its own tax and surcharges set by subnational governments. This approach ideally avoids the problems that occur when different subnational jurisdictions define the tax base in conflicting ways, use different apportionment formulas, and administer the tax in different ways. Because of their power to set surcharge rates, subnational governments retain the most important attribute of fiscal sovereignty in the tax field. The ability to define the tax base and administer taxes is much less important.

There is no reason, in principle, why the tax rate of the central government cannot be zero for a particular tax. In such a case the central government would simply administer the tax of subnational governments, thereby ensuring uniformity and avoiding duplication of effort. A problem does exist, though, with providing incentives for the central government to collect a tax that it does not keep and, indeed, of trusting it not to keep the revenues it ostensibly collects for subnational governments. These problems exist in any system of surcharges. Surcharges should, of course, be limited to that portion of the tax base reasonably deemed to arise in, or be attributed to, the taxing jurisdiction. Subnational surcharges appear to be the most appropriate means of providing subnational governments with their own marginal revenues in countries where administrative resources are scarce. For example, even though three Canadian provinces (among the four largest and wealthiest) collect their own corporate income taxes, others rely on the federal government. In both cases, tax bases and apportionment formulas are the same.

A third approach, tax sharing, is generally much less attractive than subnational surcharges. Under this approach subnational governments receive fixed fractions of revenues from particular national taxes originating within their boundaries. The sharing rates are usually uniform across jurisdictions, though not across taxes. As with surcharges, formulas may be needed to determine the deemed origin of tax revenues. In many countries the data needed to share revenues may not exist or may be unreliable. This approach severely restricts subnational governments' fiscal autonomy. Individual subnational governments have autonomy over how to spend a given amount of revenue, but not the power to alter the amount of revenue they receive from shared taxes. They therefore cannot control the level of public spending. Although all subnational governments, acting as a group, can attempt to influence their share of revenues from these taxes, no subnational government, acting unilaterally, can hope to do so.

Table 2.3 presents one possible detailed tax assignment put forward by Shah (1994), and table 2.4 shows the distribution of tax revenues for three taxes (income, property, and goods and services) by level of government for countries selected using the same criterion as for table 2.2. As was the case for table 2.2, it reveals a large amount of diversity across countries.

\section{Transfers}

A system of tax assignment designed in accord with the principles outlined previously may produce vertical imbalance in the revenues available to various levels of government or horizontal fiscal disparities among governments at a given level. Vertical fiscal imbalance is likely because many of the taxes that, from a conceptual point of view, are appropriately assigned to subnational governments cannot easily be administered in a way that implements this assignment. Finding taxes that can be implemented in a way that provides subnational governments with marginal sources of own revenues is especially difficult. The likelihood of vertical fiscal imbalance explains the earlier emphasis on subsidiarity in taxation. 
Even if tax assignment follows the principles outlined here, horizontal fiscal disparities are likely unless taxable capacity is evenly distributed across subnational jurisdictions. Unequal fiscal capacity generally occurs where income levels are quite different. Inequalities in income levels make it difficult for poor jurisdictions to collect as much tax revenue from income and sales taxes as their more affluent counterparts. Disparities between regions have a number of causes (Dafflon and Vaillancourt 2003), such as differences in opportunities for economic growth, impossibility of attaining a sufficient threshold of production capacity because of population size or density, and higher costs of producing and delivering local public services because of geographical conditions. Particular combinations of industrial structures and tax assignments can create or aggravate horizontal disparities. The assignment of taxes on important and geographically concentrated natural resources to subnational governments is perhaps the most obvious example of this. The assignment of the corporate income tax to subnational governments can also aggravate these disparities, especially if the tax base is apportioned primarily on the basis of origin-related factors, such as payrolls and property. Where tax assignment does not follow the principles outlined earlier, horizontal disparities may be even worse. The assignment of all or a share of excise taxes, customs duties, or VAT on imports to the jurisdiction where production or importation occurs instead of the jurisdiction of consumption is perhaps the most obvious example of a worsened situation.

Thus in many countries, taxes reasonably assigned to subnational governments will probably be inadequate to finance the provision of services assigned to those governments or will result in horizontal fiscal disparities. If so, using grants from higher-level governments to compensate for vertical fiscal imbalance or to offset horizontal fiscal disparities may be desirable. Grants intended to offset vertical imbalance or horizontal disparities should provide inframarginal funding for subnational governments so as not to affect the marginal decisions of those governments regarding the choice between public and private spending. Grants may be appropriate because of interjurisdictional spillovers of benefits of services provided by subnational governments. By their nature, these types of grant should be designed to change the terms on which private income can be exchanged for public services characterized by spillovers and, indeed, the terms of the trade-off between these and other public expenditures.

Subnational governments should not be penalized for raising additional revenues with a reduction in grants. Some favor including provisions in grants that reward a greater subnational tax effort. This policy is unattractive unless there are reasons to believe that the choices of subnational governments are being artificially constrained to suboptimal levels. Even then, removing the obstacles seems more appropriate than rewarding the tax effort.

From the grantor's perspective, usually the national government, grants are an expense that should be limited and controlled. From the recipient's perspective, for example, subnational governments, they are revenues that should be maximized. Open-ended grants, where the grantor will pay whatever is appropriate, (for instance, 50 percent of expenses, which are decided by the recipients, are thus dangerous from the grantor's perspective. Grantors will prefer close-ended grants, with a total maximum amount to be paid in any given time period. Such a set amount is a block grant if it is not linked directly to spending.

Grantors prefer tied (or conditional) grants, because they link the amount received to a change in behavior, such as spending more on the relevant item. From recipients' perspective, the greater the freedom to spend as they wish, the better a grant, and thus they prefer untied (unconditional) grants. Governments should seek to avoid formulas that will create unfavorable outcomes, such as encouraging capital spending in place of maintaining existing equipment.

The design of a grant requires that the following two fundamental issues be settled:

- The total amount of the transfers that are to be made, that is, how much money in total the national government will transfer to subnational governments. This is referred to as the vertical distribution, because it goes from one level of government to the one below, or as the primary distribution, because it is done first. Related to this issue is how this transfer 
Table 2.3 Possible Detailed Tax Assignment

\begin{tabular}{|c|c|c|c|c|}
\hline \multirow[b]{2}{*}{ Type of tax } & \multicolumn{2}{|c|}{ Determination of } & \multirow{2}{*}{$\begin{array}{l}\text { Collection and } \\
\text { administration }\end{array}$} & \multirow[b]{2}{*}{ Comments } \\
\hline & Base & Rate & & \\
\hline Customs & $\mathrm{F}$ & $\mathrm{F}$ & $\mathrm{F}$ & International trade taxes \\
\hline Corporate income & $\mathrm{F}$ & $\mathrm{F}$ & $\mathrm{F}$ & Mobile factor, stabilization tool \\
\hline \multicolumn{5}{|l|}{ Resource taxes } \\
\hline Resource rent (profits, income) tax & $\mathrm{F}$ & $\mathrm{F}$ & $\mathrm{F}$ & Highly unequally distributed tax bases \\
\hline \multicolumn{5}{|l|}{ Royalties, fees, charges, severance taxes } \\
\hline production, output, and property taxes & $\mathrm{S}, \mathrm{L}$ & $S, L$ & $\mathrm{~S}, \mathrm{~L}$ & Benefit taxes/charges for state and/or local services \\
\hline Conservation charges & $\mathrm{S}, \mathrm{L}$ & $\mathrm{S}, \mathrm{L}$ & $\mathrm{S}, \mathrm{L}$ & To preserve the local environment \\
\hline Personal income & $\mathrm{F}$ & $\mathrm{F}, \mathrm{S}, \mathrm{L}$ & $\mathrm{F}$ & Redistributive, mobile factor; stabilization tool \\
\hline $\begin{array}{l}\text { Wealth taxes (taxes on capital wealth, wealth transfers, } \\
\text { inheritances, and bequests) }\end{array}$ & $\mathrm{F}$ & $\mathrm{F}, \mathrm{S}$ & $\mathrm{F}$ & Redistributive \\
\hline Payroll taxes & $\mathrm{F}, \mathrm{S}$ & $\mathrm{F}, \mathrm{S}$ & $\mathrm{F}, \mathrm{S}$ & Benefit charge, for example, social security coverage \\
\hline Multistage sales taxes (value added tax) & $\mathrm{F}$ & F & $\mathrm{F}$ & $\begin{array}{l}\text { Border tax adjustments possible under federal assignments; } \\
\text { potential stabilization tools }\end{array}$ \\
\hline \multicolumn{5}{|l|}{ Single-stage sales taxes (manufacturer, wholesale, retail) } \\
\hline Less centralized choice & S & S, L & S, L & Higher compliance cost \\
\hline More centralized choice & $\mathrm{F}$ & S & $\mathrm{F}$ & Harmonized, lower compliance cost \\
\hline \multicolumn{5}{|l|}{ "Sin" taxes } \\
\hline Excises on alcohol and tobacco & $\mathrm{F}$ & $\mathrm{F}$ & $\mathrm{F}$ & Health care shared responsibility \\
\hline Betting, gambling & $\mathrm{S}, \mathrm{L}$ & $\mathrm{S}, \mathrm{L}$ & S, L & State and local responsibility \\
\hline Lotteries & $\mathrm{S}, \mathrm{L}$ & $\mathrm{S}, \mathrm{L}$ & $S, L$ & State and local responsibility \\
\hline Race tracks & $\mathrm{S}, \mathrm{L}$ & $\mathrm{S}, \mathrm{L}$ & $\mathrm{S}, \mathrm{L}$ & State and local responsibility \\
\hline \multicolumn{5}{|l|}{ Taxation of "bads" (negative externalities) } \\
\hline Carbon & $\mathrm{F}$ & $\mathrm{F}$ & $\mathrm{F}$ & To combat global and national pollution \\
\hline British Thermal Unit taxes & $\mathrm{F}, \mathrm{S}, \mathrm{L}$ & $\mathrm{F}, \mathrm{S}, \mathrm{L}$ & $\mathrm{F}, \mathrm{S}, \mathrm{L}$ & Pollution impact may be national, regional, or local \\
\hline Motor fuels & F, S, L & $\mathrm{F}, \mathrm{S}, \mathrm{L}$ & F, S, L & Tolls on federal, provincial, and local roads \\
\hline Effluent charges & $\mathrm{F}, \mathrm{S}, \mathrm{L}$ & $\mathrm{F}, \mathrm{S}, \mathrm{L}$ & $\mathrm{F}, \mathrm{S}, \mathrm{L}$ & To deal with interstate, intermunicipal, or local pollution issues \\
\hline Congestion tolls & $\mathrm{F}, \mathrm{S}, \mathrm{L}$ & $\mathrm{F}, \mathrm{S}, \mathrm{L}$ & $\mathrm{F}, \mathrm{S}, \mathrm{L}$ & Tolls on federal, provincial, and local roads \\
\hline Parking fees & $\mathrm{L}$ & $\mathrm{L}$ & $\mathrm{L}$ & To control local congestion \\
\hline
\end{tabular}


Table 2.3 (continued)

\begin{tabular}{|c|c|c|c|c|}
\hline \multirow[b]{2}{*}{ Type of tax } & \multicolumn{2}{|c|}{ Determination of } & \multirow{2}{*}{$\begin{array}{l}\text { Collection and } \\
\text { administration }\end{array}$} & \multirow[b]{2}{*}{ Comments } \\
\hline & Base & Rate & & \\
\hline \multicolumn{5}{|l|}{ Motor vehicles } \\
\hline Registration, transfer taxes, and annual fees & $\mathrm{S}$ & $\mathrm{S}$ & $\mathrm{S}$ & State responsibility \\
\hline Drivers' licenses and fees & $S$ & S & $\mathrm{S}$ & State responsibility \\
\hline \multicolumn{5}{|l|}{ Other } \\
\hline Business taxes & S & S & S & Benefit tax \\
\hline Excises & $\mathrm{S}, \mathrm{L}$ & $\mathrm{S}, \mathrm{L}$ & $\mathrm{S}, \mathrm{L}$ & Residence-based taxes \\
\hline Property & S & $\mathrm{L}$ & $\mathrm{L}$ & Completely immobile factor, benefit tax \\
\hline Land & S & $\mathrm{L}$ & $\mathrm{L}$ & Completely immobile factor, benefit tax \\
\hline Frontage, betterment & S, L & L & L & Cost recovery \\
\hline Poll tax & $\mathrm{F}, \mathrm{S}, \mathrm{L}$ & $\mathrm{F}, \mathrm{S}, \mathrm{L}$ & F, S, L & Payment for services \\
\hline User charges & $\mathrm{F}, \mathrm{S}, \mathrm{L}$ & $\mathrm{F}, \mathrm{S}, \mathrm{L}$ & $\mathrm{F}, \mathrm{S}, \mathrm{L}$ & Payment for services \\
\hline
\end{tabular}

F Federal responsibility.

S State or provincial responsibility.

L Local responsibility.

Source: Shah (1994). 
Table 2.4 Share of Central, Second-Tier (State), and Local Governments in Total, Income, Property, and Goods and Services Taxes, Selected Countries and Years (percent)

\begin{tabular}{|c|c|c|c|c|c|c|c|c|c|c|c|c|}
\hline \multirow[b]{2}{*}{ Country and year } & \multicolumn{3}{|c|}{ Total tax revenues } & \multicolumn{3}{|c|}{ Taxes on income } & \multicolumn{3}{|c|}{ Taxes on property } & \multicolumn{3}{|c|}{$\begin{array}{l}\text { Domestics taxes on } \\
\text { goods and services }\end{array}$} \\
\hline & Central & State & Local & Central & State & Local & Central & State & Local & Central & State & Local \\
\hline Albania, 1998 & 99.4 & 0.0 & 0.6 & 100.0 & 0.0 & 0.0 & 99.6 & 0.0 & 0.4 & 98.9 & 0.0 & 1.1 \\
\hline Argentina, 2001 & 59.7 & 40.3 & 0.0 & 50.5 & 49.5 & 0.0 & 54.4 & 45.6 & 0.0 & 94.6 & 5.4 & 0.0 \\
\hline Australia, 1999 & 77.4 & 19.3 & 3.3 & 100.0 & 0.0 & 0.0 & 0.0 & 63.6 & 36.3 & 66.2 & 33.8 & 0.0 \\
\hline Austria, 1999 & 78.3 & 8.9 & 12.8 & 65.4 & 16.6 & 18.1 & 26.8 & 4.5 & 68.7 & 71.0 & 13.4 & 15.7 \\
\hline Belarus, 2001 & 64.4 & 0.0 & 35.6 & 35.6 & 0.0 & 64.4 & 0.0 & 0.0 & 100.0 & 57.0 & 0.0 & 43.0 \\
\hline Bolivia, 2001 & 79.1 & 3.4 & 17.5 & 79.7 & 0.0 & 20.3 & 79.7 & 0.0 & 20.3 & 82.0 & 5.9 & 12.2 \\
\hline Botswana, 1996 & 99.4 & 0.0 & 0.6 & 100.0 & 0.0 & 0.0 & 24.3 & 0.0 & 75.7 & 99.4 & 0.0 & 0.6 \\
\hline Bulgaria, 2001 & 88.0 & 0.0 & 12.0 & 58.2 & 0.0 & 41.8 & 0.1 & 0.0 & 99.9 & 100.0 & 0.0 & 0.0 \\
\hline Canada, 1999 & 52.5 & 38.5 & 9.0 & 63.5 & 36.5 & 0.0 & 0.0 & 21.1 & 78.9 & 41.0 & 59.0 & 0.1 \\
\hline China, Mainland, 1999 & 45.0 & 55.0 & 0.0 & 24.4 & 75.6 & 0.0 & 0.0 & 100.0 & 0.0 & 55.7 & 44.3 & 0.0 \\
\hline China, Macao, 2001 & 98.6 & 0.0 & 1.4 & 100.0 & 0.0 & 0.0 & 100.0 & 0.0 & 0.0 & 98.3 & 0.0 & 1.7 \\
\hline Croatia, 2001 & 92.5 & 0.0 & 7.5 & 55.7 & 0.0 & 44.3 & 32.0 & 0.0 & 68.0 & 99.4 & 0.0 & 0.6 \\
\hline Czech Republic, 2001 & 88.7 & 0.0 & 11.3 & 75.0 & 0.0 & 25.0 & 58.3 & 0.0 & 41.7 & 85.7 & 0.0 & 14.3 \\
\hline Denmark, 1996 & 68.7 & 0.0 & 31.3 & 51.4 & 0.0 & 48.6 & 41.0 & 0.0 & 59.0 & 99.9 & 0.0 & 0.1 \\
\hline Estonia, 2001 & 85.8 & 0.0 & 14.2 & 49.8 & 0.0 & 50.2 & 0.0 & 0.0 & 100.0 & 99.7 & 0.0 & 0.3 \\
\hline France, 1997 & 89.6 & 0.0 & 10.4 & 92.3 & 0.0 & 7.7 & 34.3 & 0.0 & 65.7 & 95.4 & 0.0 & 4.6 \\
\hline Georgia, 2000 & 69.6 & 0.0 & 30.4 & 27.9 & 0.0 & 72.1 & 0.0 & 0.0 & 100.0 & 92.8 & 0.0 & 7.2 \\
\hline Germany, 1998 & 70.7 & 22.0 & 7.3 & 43.4 & 36.6 & 20.0 & 0.8 & 48.6 & 50.6 & 62.8 & 37.0 & 0.2 \\
\hline Hungary, 1999 & 90.0 & 0.0 & 10.0 & 81.4 & 0.0 & 18.6 & 47.8 & 0.0 & 52.2 & 88.7 & 0.0 & 11.3 \\
\hline Iceland, 1998 & 76.2 & 0.0 & 23.8 & 51.9 & 0.0 & 48.1 & 54.6 & 0.0 & 45.4 & 100.0 & 0.0 & 0.0 \\
\hline India, 1999 & 62.6 & 37.4 & 0.0 & 100.0 & 0.0 & 0.0 & 14.9 & 85.1 & 0.0 & 41.5 & 58.5 & 0.0 \\
\hline Indonesia, 1999 & 97.1 & 2.9 & 0.0 & 100.0 & 0.0 & 0.0 & 74.9 & 25.1 & 0.0 & 95.9 & 4.1 & 0.0 \\
\hline Ireland, 1997 & 99.2 & 0.0 & 0.8 & 100.0 & 0.0 & 0.0 & 78.9 & 0.0 & 21.1 & 100.0 & 0.0 & 0.0 \\
\hline Israel, 2001 & 93.3 & 0.0 & 6.7 & 100.0 & 0.0 & 0.0 & 12.1 & 0.0 & 87.9 & 100.0 & 0.0 & 0.0 \\
\hline Kazakhstan, 2001 & 50.7 & 0.0 & 49.3 & 38.7 & 0.0 & 61.3 & 2.6 & 0.0 & 97.4 & 87.1 & 0.0 & 12.9 \\
\hline Kenya, 1998 & 98.1 & 0.0 & 1.9 & 100.0 & 0.0 & 0.0 & 0.0 & 0.0 & 100.0 & 98.7 & 0.0 & 1.3 \\
\hline Kyrgyz Republic, 2000 & 85.6 & 0.0 & 14.4 & 73.9 & 0.0 & 26.1 & 50.0 & 0.0 & 50.0 & 79.1 & 0.0 & 20.9 \\
\hline Latvia, 2001 & 82.0 & 0.0 & 18.0 & 46.7 & 0.0 & 53.3 & -1.1 & 0.0 & 101.1 & 99.4 & 0.0 & 0.6 \\
\hline
\end{tabular}


Table 2.4 (continued)

\begin{tabular}{|c|c|c|c|c|c|c|c|c|c|c|c|c|}
\hline \multirow[b]{2}{*}{ Country and year } & \multicolumn{3}{|c|}{ Total tax revenues } & \multicolumn{3}{|c|}{ Taxes on income } & \multicolumn{3}{|c|}{ Taxes on property } & \multicolumn{3}{|c|}{$\begin{array}{l}\text { Domestics taxes on } \\
\text { goods and services }\end{array}$} \\
\hline & Central & State & Local & Central & State & Local & Central & State & Local & Central & State & Local \\
\hline Lithuania, 2001 & 79.2 & 0.0 & 20.8 & 33.6 & 0.0 & 66.4 & 0.0 & 0.0 & 100.0 & 99.9 & 0.0 & 0.1 \\
\hline Luxembourg, 1997 & 93.9 & 0.0 & 6.1 & 84.5 & 0.0 & 15.5 & 100.0 & 0.0 & 0.0 & 99.8 & 0.0 & 0.2 \\
\hline Moldova, 2001 & 76.4 & 0.0 & 23.6 & 17.2 & 0.0 & 82.8 & 0.0 & 0.0 & 100.0 & 84.9 & 0.0 & 15.1 \\
\hline Mongolia, 2001 & 79.2 & 0.0 & 20.8 & 42.8 & 0.0 & 57.2 & 22.5 & 0.0 & 77.5 & 69.1 & 0.0 & 30.9 \\
\hline Netherlands, 1998 & 95.9 & 0.0 & 4.1 & 100.0 & 0.0 & 0.0 & 68.4 & 0.0 & 31.6 & 98.3 & 0.0 & 1.7 \\
\hline Norway, 1999 & 81.6 & 0.0 & 18.4 & 54.5 & 0.0 & 45.5 & 43.0 & 0.0 & 57.0 & 99.0 & 0.0 & 1.0 \\
\hline Paraguay, 2001 & 98.0 & 0.0 & 2.0 & 98.0 & 0.0 & 2.0 & 84.2 & 0.0 & 15.8 & 99.0 & 0.0 & 1.0 \\
\hline Poland, 2001 & 81.0 & 0.0 & 19.0 & 78.3 & 0.0 & 21.7 & 0.1 & 0.0 & 99.9 & 99.2 & 0.0 & 0.8 \\
\hline Romania, 2001 & 81.8 & 0.0 & 18.2 & 51.7 & 0.0 & 48.3 & 0.0 & 0.0 & 100.0 & 80.5 & 0.0 & 19.5 \\
\hline Russia, 2001 & 69.7 & 0.0 & 30.3 & 27.6 & 0.0 & 72.4 & 5.2 & 0.0 & 94.8 & 82.7 & 0.0 & 17.3 \\
\hline Slovak Republic, 2001 & 95.4 & 0.0 & 4.6 & 87.2 & 0.0 & 12.8 & 30.8 & 0.0 & 69.2 & 98.2 & 0.0 & 1.8 \\
\hline Slovenia, 2001 & 92.0 & 0.0 & 8.0 & 71.7 & 0.0 & 28.3 & 9.4 & 0.0 & 90.6 & 97.9 & 0.0 & 2.1 \\
\hline South Africa, 1998 & 92.8 & 0.5 & 6.7 & 100.0 & 0.0 & 0.0 & 21.7 & 0.0 & 78.3 & 98.6 & 1.4 & 0.0 \\
\hline Spain, 1997 & 83.0 & 7.5 & 9.4 & 85.7 & 8.7 & 5.7 & 2.8 & 52.4 & 44.7 & 78.5 & 5.4 & 16.0 \\
\hline Switzerland, 2000 & 66.0 & 20.0 & 14.0 & 30.3 & 39.1 & 30.7 & 30.9 & 42.8 & 26.3 & 92.2 & 7.6 & 0.2 \\
\hline Tajikistan, 2001 & 72.2 & 27.8 & 0.0 & 16.5 & 83.5 & 0.0 & 21.2 & 78.8 & 0.0 & 78.0 & 22.0 & 0.0 \\
\hline Thailand, 2000 & 94.5 & 0.0 & 5.5 & 100.0 & 0.0 & 0.0 & 66.8 & 0.0 & 33.2 & 90.1 & 0.0 & 9.9 \\
\hline Uganda, 2000 & 96.5 & 0.0 & 3.5 & 87.6 & 0.0 & 12.4 & 59.4 & 0.0 & 40.6 & 99.0 & 0.0 & 1.0 \\
\hline Ukraine, 2001 & 74.3 & 0.0 & 25.7 & 35.6 & 0.0 & 64.4 & 0.0 & 0.0 & 0.0 & 80.5 & 0.0 & 19.5 \\
\hline United Kingdom, 1999 & 96.1 & 0.0 & 3.9 & 100.0 & 0.0 & 0.0 & 64.2 & 0.0 & 35.8 & 100.0 & 0.0 & 0.0 \\
\hline United States, 2001 & 69.3 & 19.1 & 11.6 & 83.0 & 15.5 & 1.5 & 10.0 & 8.0 & 82.0 & 15.7 & 67.6 & 16.8 \\
\hline Zimbabwe, 1997 & 96.3 & 0.0 & 3.7 & 100.0 & 0.0 & 0.0 & 9.6 & 0.0 & 90.4 & 97.8 & 0.0 & 2.2 \\
\hline
\end{tabular}

Note: We use the items total tax revenue AIV taxes on income AIV 11, taxes on property AIV 4 and domestic taxes on good and services AIV 5 from the relevant tables in the International Monetary Fund publication in our calculations. State revenues are from $\mathrm{S}$ tables and local revenues from $\mathrm{L}$ tables in the same publication.

Source: International Monetary Fund (2002). 
will be funded and according to which decision procedure. Several answers are possible, each with its advantages and disadvantages, namely:

- The amount is financed out of the general resources of the paying unit and established in its annual budget. This is a flexible solution, changeable from one year to the next, but it has two defects: first, recipient governments are not sure that they will receive a real (nominal is meaningless if inflation is present) comparable amount from one year to another, which renders planning difficult; and second, annual budgetary debates are subject to ad hoc political arrangements.

- The exact calculation of the amount is explicitly stated in the constitution or in a law. It may be formulated as a percentage of total expenditures; of total revenues; or of one, but preferably several, specific tax sources used at the central level. Using only one tax source and allocating a high percentage of revenues from it to transfers may result in the central government not collecting it as vigorously as if it kept 100 percent of revenues as discussed earlier. This solution has two advantages. First, with a specific legal foundation, the political debate on the size of transfers takes place when the constitution is amended or the law is passed, and not on an annual basis. Second, it avoids important variations in the amounts available if the amount is dependent on a sufficiently large basis. A variant of this is that the amount can be set initially and then indexed, and the indexing formula can take one or more of the following factors into account: inflation (overall or of specific items such as medication or road materials), population growth (overall or of specific age groups such as school-age children), gross domestic product growth, growth of specific taxes (such as gasoline-related taxes or VAT), and so on.

- If a specific tax or set of taxes is used, this can create fluctuations in the revenues available for sharing. This problem can be partially solved by setting up a fund fueled with these taxes. This can smooth transfer payments by leaving part of the amounts in the fund in good years to be used in bad ones. This intertemporal stabilization is what distinguishes this option from the preceding one.

- The amount to be provided to each recipient. This is referred to as the horizontal distribution, because it is between recipients at the same level of government. It is also called the secondary distribution, because it follows after the primary one. Transfer schemes require that the amount each jurisdiction will receive be determined by an appropriate formula. This will vary according to the purpose of the grant. If grants are made to stimulate the production by particular subnational entities of specific public services that generate positive externalities, then the central government may want to use indicators linked to the benefits outside populations receive, such as their size. If grants are made to alleviate vertical fiscal disequilibrium (absent horizontal equilibrium), then need as measured by such indicators as population, specific populations, topography, or urban density may be appropriate. Finally, in the case of grants aimed at alleviating horizontal disequilibrium, equalization, revenue capacity, and needs may all be taken into account. Jurisdictions with higher than average capacity should receive less (pay more); jurisdictions with lower than average capacity should receive more (pay less). It is generally accepted that explicit revenue equalization, if any, takes into account some fiscal or financial capacity indicator. Extra funding for governments facing additional charges caused by socio-demographic challenges, their geographic location, or both would necessitate some form of cost equalization

\section{Conclusion}

The success of decentralization often depends both on the sequencing of policy changes and the nature of the policies adopted. With respect to the first point, this is true both when a given 
state is moving from a more to a less centralized system and when an already decentralized state is modifying its institutional arrangements. In general, one aspect of the intergovernmental arrangements cannot be changed without addressing the other arrangements. For example, in the 1990s, some countries in Latin America made the mistake of assigning revenues to subnational governments and putting transfers in place before the central government decided what functional competencies would be transferred from the central government to subnational governments. The result was a weak decentralized system and a fiscally overburdened central government. Switzerland, which since 2000 has begun a re-examination of intergovernmental financial arrangements, is simultaneously clarifying the assignment of responsibilities and the financial transfer system (Dafflon and Perritaz 2002).

Stable and meaningful decentralization requires an unambiguous and well-defined assignment of responsibilities among the different levels of government. The assignment of responsibilities must take into account the principle of subsidiary, and thus differences in economies of scale, preferences, and objective conditions and the importance of externalities. Autonomy must be real and not simply formal. This requires fiscal autonomy on the part of subnational governments, and thus the ability to vary statutory tax rates. Because varying tax rates without inducing taxpayers to take steps that would minimize their tax burdens might be difficult, governments should rely as heavily as possible on fees, charges, and taxes that can be linked closely to the benefits of public services. Finally, transfer systems should be designed carefully to avoid undesirable behavior by recipient governments, such as a reduction in tax effort or skewed spending, while ensuring that they have the necessary resources to provide the desired level of public services.

\section{References}

Bird, Richard M., and François Vaillancourt, eds. 1998. Fiscal Decentralization in Developing Countries. Cambridge, U.K.: Cambridge University Press

Bird, Richard M., Robert D. Ebel, and Christine I. Wallich, eds. 1995. Decentralization of the Socialist State: Intergovernmental Finance in Transition Economies. Washington, D.C.: World Bank.

Brennan, Geoffrey, and James Buchanan. 1983. "Normative Tax Theory for a Federal Polity: Some Public Choice Preliminaries." In Charles E. McLure, Jr., ed., Tax Assignment in Federal Countries. Canberra: Centre for Research on Federal Financial Relations.

Commission of the European Communities. 1991. "Removal of Tax Obstacles to the CrossFrontier Activities of Companies." Bulletin of the European Communities (Supplement 4/91).

Dafflon, Bernard, and Steve Perritaz. 2002. "Federal-Cantonal Equalisation in Switzerland: An Overview of the Present System and Reform in Progress." Working Paper no. 356. University of Fribourg, BENEFRI Centre for Studies in Public Sector Economics, Fribourg, Switzerland.

Dafflon, Bernard, and François Vaillancourt. 2003. "Problems of Equalization in Federal Countries." In R. Blidenbacher and A. Koller, eds., Federalism in a Changing World: Learning from Each Other. Montreal: McGill Queens University Press.

Gordon, Roger H. 1983. “An Optimal Taxation Approach to Fiscal Federalism.” In Charles E. McLure, Jr., ed., Tax Assignment in Federal Countries. Canberra: Centre for Research on Federal Financial Relations.

International Monetary Fund. 2002. Government Finance Statistics Yearbook 2002. Washington, D.C.

Litvack, Jennie, Junaid Ahmad, and Richard Bird. 1998. Rethinking Decentralization in Developing Countries. Washington, D.C.: World Bank. 
McLure, Charles. 1986. “Tax Competition: Is What's Good for the Private Goose also Good for the Public Gander?" National Tax Journal 39(3): 341-48.

. 2000. "Tax Assignment and Subnational Fiscal Autonomy." Bulletin for International Fiscal Documentation 54(12): 626-35.

Musgrave, Richard A. 1959. The Theory of Public Finance. New York: McGraw Hill.

1983. “Who Should Tax, Where, and What?” In Charles E. McLure, Jr., ed., Tax Assignment in Federal Countries. Canberra: Centre for Research on Federal Financial Relations.

Oates, Wallace E. 1972. Fiscal Federalism. New York: Harcourt Brace Jovanovich.

Sewell, David O. 1996. “'The Dangers of Decentralization' According to Prud'homme: Some Further Aspects." World Bank Research Observer 11(1): 143-50.

Shah, Anwar. 1994. The Reform of Intergovernmental Fiscal Relations in Developing and Emerging Countries. Policy and Research Series no. 23. Washington, D.C.: World Bank.

Wildasin, David E. 1986. “Interstate Tax Competition: A Comment." National Tax Journal 39(3): 353-56. 


\title{
Budgeting, Financial Management, and Financial Markets in an Intergovernmental Context
}

\author{
François Vaillancourt
}

This chapter discusses the concepts of budgeting, financial management, and the financial market at the subnational level. It is designed to increase readers' knowledge and understanding of the major financing issues facing subnational governments (SNGs), such as oblasts in Russia or cities. After a brief description of the links between financial management and markets, the chapter is divided into five sections that cover accounting, the budget process, the capital market, bond issues, and credit rating.

\section{Financial Management and Markets}

This section begins by presenting how financial management and budgeting contributes to accountability. It then turns to the relationship with markets.

\section{Financial Management and Budgeting}

Financial management and budgeting refers to the whole set of activities by which the intentions of managers and politicians, expressed through a variety of means such as strategic plans, become operational. For plans to materialize, top decisionmakers must understand the relevant financial and budgetary information. This information is key to the concept of accountability, that is, the notion that managers and elected decisionmakers are responsible for their actions and that citizens require them to account for their actions. Accountability has three key dimensions: administrative, economic, and political.

ADMINISTRATIVE ACCOUNTABILITY. This type of accountability requires making available the necessary information to allow

- Adequate internal management controls to be established

- Supervisory bodies, such as ministries of the interior or of municipal affairs, to carry out their tasks

- Outside auditors, public as well as private, to not only certify that the financial reports of an SNG represent its true spending, but to ascertain the presence or absence of any corruption as well.

ECONOMIC ACCOUNTABILITY. This type of accountability requires making the necessary information available to allow decisions to be made in a manner that ensures resources are allocated with the greatest level of efficiency possible and that taxpayers are provided with the best services possible. This pursuit of value for money is made easier if the accounting tools (such as analytical accounting) used help establish the true cost of a service and provide information useful for making decisions, such as whether or not a service should be privatized. 
POlitical AccountabiLiTy. This type of accountability requires making sufficient information available to citizens to allow them to assess the performance of their elected politicians and to decide whether or not to re-elect them.

\section{Financial Markets}

Financial markets are the set of institutions, such as stock markets, and agents, such as banks, financial cooperatives, and foreign exchange brokers, found in varying degrees and combinations in every country worldwide. These institutions carry out various financial transactions. SNGs commonly make use of such institutions to borrow funds for capital expenditures. ${ }^{1}$ Although the specific organization and structure of such institutions will vary from country to country, the technical vocabulary of finance-maturity, yield, coupon, and so on-is used uniformly. Because public sector managers and politicians who must deal with financial markets often do not have a good understanding of this vocabulary, a discussion of these terms follows later in this chapter.

\section{The Link between Financial Management and Capital Markets}

Proper financial management is a prerequisite to accessing financial markets. Lenders demand high-quality financial information and well-managed finances before they will lend. In addition, some information required to access financial markets is the same as that needed for proper financial management. There is thus a natural link between these two topics.

\section{Accounting Concepts}

This section introduces several important basic accounting concepts: single- and double-entry bookkeeping, accrual and cash accounting, and balance sheets.

\section{Bookkeeping}

Bookkeeping refers to the operation of entering financial information (revenues and expenses) into a ledger book. Although this activity may seem innocuous-and even unimportant-it is the basis for all accounting because accountants use the information thus recorded to prepare financial statements. There are two types of bookkeeping: single-entry bookkeeping and double-entry bookkeeping.

SINGLE-ENTRY BOOKKEEPING. This type of bookkeeping requires that expenses and revenues are entered in one column, using a positive value for revenues and a negative value for expenses. The disadvantage of single-entry bookkeeping is that at the end of the year there is no way to ascertain revenues or expenses, only the difference between the two. Table 3.1 shows a situation where an SNG is in the same financial situation at the end of the period as at the beginning, yet expenses were incurred and revenues received.

Table 3.1 also shows a limitation of single-entry bookkeeping: the difficulty of doing proper budgeting because expenses and revenues are intermingled and cancel each other out. Although financial administrators using single-entry bookkeeping may maintain other documents that allow them to prepare the relevant financial statements, this obviously requires additional work. Moreover, in countries where accounting conventions (sometimes established by law) require the use of single-entry bookkeeping, supervisory authorities do not verify these

1. Capital expenditure is spending on investments that have a long life span, such as roads or sewers. It is seldom sensible - and often impossible — to finance such expenditures out of current revenues. 
Table 3.1 Single-Entry Bookkeeping Example

\begin{tabular}{lr}
\hline Transaction and date & Amount \\
\hline Initial amount on the books: January 1 & $1,000,000$ \\
Purchase vehicle: April 1 & $-50,000$ \\
Receive taxes: June 1 & $+50,000$ \\
Final amount on the books: December 31 & $1,000,000$ \\
\hline
\end{tabular}

additional documents. They therefore have no official status and can more easily be the object of fraud.

DOUBLE-ENTRY BOOKKEEPING. By contrast, double-entry bookkeeping has two columns: one for revenues and one for expenses. Recording transactions in this manner provides the information needed to produce an expenses and revenues statement, which is one of the two basic documents of modern accounting (the other is the balance sheet). The expenses and revenues statement records money spent and money received over a period of time, usually a budget year. Table 3.2 shows how incoming and outgoing money is recorded separately. The information can be used directly to construct and maintain balance sheets.

Note that there are no universal standards regarding the choice of beginning and end dates of the budget year. In the United States, for example, the central government's financial year ends on September 30, while in Canada it ends on March 31. With respect to financial year-end, for a country to have different year-ends for governments at different levels may make sense, because when grant-receiving levels of governments have a later year-end than the grantdispensing level, the budget may be facilitated at both levels. Of course, such coordination can also be achieved if the budget dates are appropriately staggered.

\section{Accrual and Cash Accounting}

When should a revenue or an expense be recorded for accounting purposes?

- Should it be when the decision to spend was taken, even if the cash was disbursed in a later year?

- Should it be when the money is actually spent?

- Should it be when the taxes or grants should have been paid legally?

- Should it be when the taxes or grants are actually paid?

ACCRUAL ACCOUNTING. This method of accounting records revenues and expenses when they were legally due or incurred. For example, if taxes are legally due on June 30 of a given year, this is when they appear in the SNG's revenue statement. If, after a given legal waiting period, they have not been paid, they will appear as revenue arrears (sometimes referred to as receivables). Revenue arrears are revenues still to come, but they differ from revenues because there is always some uncertainty as to whether they will actually be received. Presumably some will eventually become bad debts and then be deducted (struck) from revenues.

Table 3.2 Double-Entry Bookkeeping Example

\begin{tabular}{lcc}
\hline Transaction and date & Expenses & Revenues \\
\hline $\begin{array}{l}\text { Purchase vehicle: April 1, 2000 } \\
\text { Receive taxes: June 1, 2000 }\end{array}$ & 50,000 & \\
Annual total & 50,000 & 50,000 \\
\hline
\end{tabular}


Similarly, if a supplier is due a payment on a certain date, this is recorded as a payment on that date. If the supplier is not paid on time, then the due payment becomes expense arrears (sometimes known as payables). Some payment arrears are due to contractual disputes about the amount to be paid or the quality of the work, and others may reflect cash management issues.

CASH AcCOUNTING. This method of accounting waits for the money to be received or spent before recording it in the SNG's books.

Differences between CASH And ACcrual Accounting. The most important difference between cash and accrual accounting is in the treatment of arrears. In the following example, the SNG owes 100,000 to the national electricity utility for May, which is payable in June, but it does not pay. At the same time the central government owes the SNG a monthly transfer of 50,000 on the first of each month, but the SNG does not receive it. Tables 3.3 and 3.4 show how this is recorded using the two different accounting methods.

Note the difference between the two tables with regard to the bottom line. Cash accounting provides no information about amounts in arrears. Accrual accounting identifies this information under the items payables and receivables. This information can be extremely important if significant amounts of money are involved.

\section{Balance Sheets}

Balance sheets are the second key accounting document (the revenues and expenses statement was the first). The balance sheet describes, at a given point in time (usually the end of the financial year) both assets (financial as well as nonfinancial) and liabilities (what is owed to others).

Balance sheets measure the wealth of the SNG or regional government at a given point in time. Such wealth includes

- Financial assets, such as bank deposits, cash in hand, and amounts to be collected

- Nonfinancial assets, such as buildings, land, and equipment.

Table 3.3 Monthly Statement of Revenues and Expenses Using the Cash Accounting Method

\begin{tabular}{lrc}
\hline Transaction and date & Expenses & Revenues \\
\hline Taxes: June 1 to 30,2000 & & 500,000 \\
Salaries: June 15, 2000 & 250,000 & \\
Electricity: June 10, 2000 & 0 & 0 \\
Transfer from central government: June 1, 2000 & 250,000 & 500,000 \\
Cash recorded &
\end{tabular}

Table 3.4 Monthly Statement of Revenues and Expenses Using the Accrual Accounting Method

\begin{tabular}{lcc}
\hline Transaction and date & Expenses & Revenues \\
\hline Taxes : June 1 to 30, 2000 & & 500,000 \\
Salaries: June 15, 2000 & 250,000 & \\
$\begin{array}{l}\text { Electricity: June 10, 2000 (payables) } \\
\text { Transfer from central government: June 1, 2000 }\end{array}$ & 100,000 & \\
$\quad$ (receivables) & & 50,000 \\
Total accruals recorded & 350,000 & 550,000 \\
\hline
\end{tabular}


For equipment, one must assign a value to old assets purchased in the past. Assigning a value can be done either by using what the asset would sell for in a given year-which is called the current value - or by using accounting rules that depreciate (assign a value) to an asset over time. For example, it is common to assume that a building will last 50 years. As a result, a building that cost 1,000 15 years ago will be assigned a depreciated value of 700 this year and 6005 years from now. Specific rules depend on a country's accounting practices. If inflation is important (and, as is usual, there is no indexing for inflation), then the nominal value of assets may increase with the passage of time. The value of an asset may also depend on the regulatory environment. For instance, a public school located on a beachfront lot is worth less if the land can only be used for a school than if it might instead be used for a hotel.

\section{The Budget Process}

The budget is a document that outlines how resources will be used.

\section{Why Budget?}

Every SNG administration needs an effective budgeting process for legal, administrative, and political reasons.

LEGAL. In most countries the legal environment of SNGs requires that a budget be prepared annually. In many countries a supervisory body such as the ministry of municipal affairs or the ministry of the interior, must approve the budget.

MANAGERIAL. Effective financial administration requires that each specific activity, such as road maintenance, computer purchases, dogcatchers' salaries, and other items, must be assigned a specific budget amount for a given year. Assigning budget amounts for each activity provides a control mechanism to ensure that any specific spending request by an employee conforms with the choices of the SNG as a whole. Thus if a roads manager wants to order a ton of gravel costing 100,000 and no such amount appears in the budget, the purchasing department can refuse to authorize this spending by referring to an official expression of the SNG strategy as concretized in the budget. The budget is therefore a crucial tool for ensuring that each department head-all of whom would naturally like to have more resources for their departments-is constrained to spend within the assigned means.

POLITICAL. Budgets allow voters to ascertain whether politicians are carrying out their promises to cut back on one kind of spending or to increase another. Budgets therefore play a key role in ensuring a transparent administration. The budget represents how politicians spend the resources entrusted to them by citizens. Budgetary choices affect the well-being not only of today's citizens, but also of tomorrow's. Budgets often involve borrowing or building infrastructure. Both these activities have a long-term impact because they affect the resources available to provide services in future years (when any loans taken to build infrastructure will have to be paid). For this reason, it is important to scrutinize not only the final budgetary document, but also the process used to establish the budget.

\section{Establishing Spending Priorities}

The most demanding aspect of preparing a budget is establishing spending priorities. The importance of this aspect of preparing a budget depends in large part on the degree of freedom that an SNG has to determine expenditure. The following paragraphs discuss the factors that influence an SNG's degree of freedom. Although some or all of these factors may restrict the freedom of an SNG's budgetary choices, most SNGs will nonetheless have at least some 
flexibility. Most notably, they can vary current spending to some extent and, at least in some instances, they can borrow for capital spending.

PAst ChOices. Previous budgetary decisions, such as a decision to borrow, have a significant impact on the current budget. For example, a loan taken out to build a bridge in 2000 may take 20 years to repay. Repayments, of course, come out of current revenues, but in addition, new employees may have to be hired to maintain the bridge. Both these expenses must be kept up over time, the first to ensure that the SNG retains access to capital markets, because lenders do not appreciate nonrepayment of loans, and the second to ensure that the bridge remains functional and that the service for which funds were borrowed is indeed offered. A new administration elected in 2002 may not have built the bridge, but it is nonetheless faced with the fact that paying for and operating the bridge takes away resources that it would have preferred to use elsewhere.

EMPLOYMENT CHOICES. The SNG government may have too many employees. This may be the result of the changing nature of work, the introduction of new technologies that reduce the need for employees, or a change in the services being provided. Reducing the number of employees may be difficult because of the strength of their unions, for political reasons, or because the civil service law states that hiring is for life. Such surplus employees may not be strictly needed, but they are all too often a spending item that cannot be reduced. The SNG has fewer spending choices to make because it has fewer uncommitted resources.

LEGAL FRAMEWORK. Country legislation may mandate the SNG to carry out specific expenditures according to national standards or requirements. For example, SNGs may be required to offer civil registry services (such as births, deaths, identification cards) regardless of their population size, or they may have to build roads according to standards set nationally. If such requirements are not accompanied by resources-a situation often referred to as unfunded mandates - then the SNG again has less revenue available to spend as it might wish.

RESOURCES. Some SNGs are so poor that they simply have no choices to make regarding spending. In such cases more fundamental issues might be raised, such as the possibility of merging with a richer neighbor.

\section{Preparing a Budget}

Budget preparation ideally involves four stages: ascertaining the priorities of the population, preparing the budget document, approving the budget, and spending the budget.

Ascertaining the Priorities of the Population. Governments exist for people, not the other way around. In principle, therefore, the first and most important thing is to establish what people really want. Although various mechanisms may be used to determine what the people want, in the end they all require asking people for their opinions and genuinely listening to their views. One option might be to request written submissions from various bodies (such as nongovernmental organizations, business associations, unions, neighborhood councils, and so on), through advertisements in newspapers, or through the Internet. These submissions should then be examined carefully.

Another option is to hold public meetings in various parts of the SNG, inviting residents to voice their opinions about how the budget should be spent. ${ }^{2}$ The SNG council or the council's

2. Such meetings may be easier to arrange in cities than in rural areas, because the latter have scattered populations. However, attendance and interest may sometimes be higher and more representative in areas with smaller populations. 
budget committee can organize such meetings. Officials can then summarize the proposals generated from these meetings and carefully consider their feasibility.

As discussed previously, some spending choices may bind budget decisions in future years. For this reason, it may be appropriate to organize one type of public input system for current spending choices and another for capital spending, that is, for long-term investments such as bridges. This might allow more time and resources to be devoted to making proper choices for long-term decisions. As capital spending should be planned on a multiyear basis (three to five years) to ensure coherence and complementarity, planning public consultations around these timelines may be useful.

Some may be surprised by our emphasis on the need to consult voters on budgets, because presumably the public has elected politicians to make such decisions. If politicians are elected for a long term, however, then even if they faithfully carry out their promises, these may no longer represent the need of their electorate by the midterm of their mandate. For example, they may have promised when elected in 1998 to a six-year mandate to equip all libraries with a new encyclopedia by 2004, but by 2002 the best way to help children is to give them access to the Internet rather than to an encyclopedia. Should politicians be held to a now wasteful promise, or should they be able to modify their means of action after consulting with the public?

More important, no representative system is perfect. In an election with more than two candidates, politicians may be elected with far fewer than 50 percent of the vote and may not have good informal contacts with the supporters of their opponents. First-past-the-pole electoral systems with no proportional representation will not ensure that the losing side is represented on the SNG council. Regular public consultations give them access to the opinions of the whole community and more legitimacy. Of course, as noted previously, such consultations must be more than an opportunity to explain choices already made. Politicians must allow various opinions to be heard.

PREPARING THE Budget Document. In theory, each budget is unique and could be prepared without consideration of all previous budgets. In practice, this is not done for several reasons as follows:

- Past budgets contain information about voter preferences and about the trade-offs achieved at the political level in preparing that budget. Ignoring this information would be inefficient.

- Past budgets, as already mentioned, have often created commitments that cannot be easily changed from one year to the next. To neglect them means that the budget will not be workable. For example, if an SNG subsidizes sports clubs to carry out activities for the benefit of all children, to suddenly change this policy, even if legally the subsidy is renewed annually, will create ill-will and mistrust.

- Generally only a few experts, such as the SNG administrator and the chair of the finance committee, are really knowledgeable about budget preparation. An examination of past budgets can help other SNG councilors to better contribute to the debate.

However, there is also some danger in using existing budgets as a template for preparing new budgets. Expenditures that were once useful but have now lost their relevance may, for example, be again included in the budget. To avoid this situation, each area of expenditure should, in principle, be subject to a more in-depth analysis on a rotating basis (perhaps every five years). Another way to achieve the same goal is to use so-called sunset clauses, which state that a program will end unless it is explicitly renewed after a given time interval.

The people who actually prepare the first draft of the budget will vary according to practice and to capacities. Whether done by council committee or by officials, the exercise typically requires the following steps: 
- Forecast revenues. The expected amount of revenue (income) must be determined. The most basic forecast is to use revenues from the current year, often increased by a growth factor. This approach is not unreasonable if tax rates, tax bases, and compliance behavior have not changed, but it can hide key facts. For example, deterioration in tax compliance can be hidden by an increase in the tax base. It is thus preferable to forecast potential revenues using information on forecasted bases and planned rates to calculate explicitly what is legally collectable, and then to use information on tax compliance to forecast what the revenues are likely to be. The practice encountered in some countries of making forecasts based on perfect compliance, unchanged over time, even in the face of evidence that this is not observed should be avoided.

-For example, revenues in the past year from daily parking permits were 100,000 resulting from 10,000 permits at 10 each. A survey by outside experts shows that 15,000 permits should have been sold, but 5,000 users of parking spaces simply did not pay. If the SNG doubles the rate to 20 per day, can it forecast revenues at 200,000, or should it assume that evasion will increase, say from a third to a half, so that only 7,500 users are paying 20, yielding revenue of 150,000 ?

-Revenues from intergovernmental transfers may be more difficult to forecast, because the formula used to calculate them will often use information not available to the SNG. Ideally, the provincial or national government will provide a forecast. If this information is not forthcoming, in view of the importance of transfer revenue in many countries, SNGs (at least the larger ones) may want to acquire the necessary expertise to forecast these revenues.

- Forecast expenditures. Using past expenditures to forecast next year's expenditures is dangerous for a number of reasons:

-Salaries usually increase from year to year according to a set of rules (collective agreement, indexing, matching other civil servants, central government decisions).

-Debt repayments are made according to another set of parameters (nature of borrowing, amount outstanding).

-Other expenses respond to still other forces (natural disasters, energy price changes, age of equipment, and amount of deferred maintenance).

It is therefore better to forecast each type of expenditure explicitly with the aim of having the most accurate estimate possible. For example:

-For salaries, use data on the number of employees by salary level and multiply it by the proper salary.

-For debt, calculate the amount outstanding to be repaid and the interest payment owed with the help of financial advisers (if this information is not provided by the lender directly).

-For other expenses use estimates of quantities required (for example, liters of motor fuel) and prices to calculate the more important ones.

- Prepare a capital spending plan and, in many cases, a borrowing plan. As mentioned earlier, as a rule borrowing (the action of obtaining funds now in exchange for a pledge to pay that amount and interest on it in the future ) is required to finance investment. To borrow in financial markets, an SNG must prepare financial forecasts for the borrowing period, often in collaboration with a lending agency.

Forecasts of revenues, expenditures, and borrowing can be prepared taking into account the results of the consultation process described previously. Indeed, in more sophisticated consultations, preliminary forecasts might be used as the basis of the consultation process and final forecasts prepared after discussion and debate. 
Approving THE Budget. Once the budget has been prepared, it must be legally approved. Approval is usually done by a formal vote of the SNG council that typically must be held by a given date. In many countries SNG budgets are not official until the ministry responsible for SNGs has given its approval, which may be done either at the regional level (governorate or subgovernorate) or in the central ministry's offices.

SPENDING THE BUDGET. Once the budget has been approved, the SNG in theory has the means to spend as it sees fit. In practice, however, it may need to obtain approval from a central government office, such as the treasurer's office, to either contract for the provision of goods and services or to pay for such provision.

This second aspect raises the issue of who controls access to funds. In a number of countries SNGs, even the largest ones, do not have free access to their own funds. Such funds may be deposited in central government offices, and the authorization of a central government official is required before funds can be disbursed. In this situation, the temptation for the central government to use these funds as a source of liquidity may sometimes be strong, to the detriment of rational SNG financial planning and spending.

\section{Capital Markets}

The nature of capital markets varies from country to country depending on the legal framework and the degree of economic progress of each country. The capital market consists of the set of institutions by which the savings of savers are made available to borrowers and investors who, in exchange, agree to remunerate these savings with some payment such as an interest payment or a dividend payment. This section considers the subset of the financial markets that makes savings available to SNGs, and is therefore restricted to one financial transaction: a loan. In addition, the section focuses on one financial instrument: bonds, and does not address such aspects of capital markets as options, indexes, and stocks, because they are not relevant to SNG finances.

\section{The Institutions of the SNG Capital Market}

A country's SNG capital market (SCM) can vary from nonexistent to extremely diverse.

NONEXISTENT SCMs. A country may not have an SCM. In this case SNGs are formally forbidden from borrowing. Thus the only funds available to an SNG to finance a large investment in this situation are any savings it may have, perhaps complemented by national grants (which can be national savings made available to the SNG). In this case a relevant financial issue relates to what the SNG can earn on its savings. If SNG savings are kept in the national central bank or in the ministry of finance's national treasury with no interest paid, then saving for long periods usually makes no sense because inflation will reduce the value of these savings.

SNG BANK SCMs. When a country has a SNG bank, SCM SNGs can borrow, but must do so from a monopoly public agency that specializes in lending to SNGs. The state-owned, specialized SNG bank borrows from the national or international capital markets and relends to the SNGs. Its loans are usually guaranteed by the central government, either explicitly or through the use of the supervisory power of the central government. The public SNG lender will ensure that the borrower's annual budget includes the appropriate amount for loan repayment.

Advocates of such specialized SNG banks have argued that these banks can provide a wide range of services to SNGs. Not only can they provide financing, but they can also develop close relationships with their SNG clients, helping them with budget management, capital planning, and the like. Others have argued that while these may be useful services, they end up being 
paid for, as the bank charges above market rates of interest because these services must be financed. Nevertheless, such banks can often borrow from the market at lower rates than small SNGs. Such banks may sometimes be an appropriate step in helping SNGs access SCMs, but they should not be the final or only solution.

NATIONAL SCMs. If a country has national SCMs, SNGs are free to borrow from any national financial institution, such as private banks, pension funds, insurance firms, and so on, but they are prohibited by law from borrowing in foreign currency, and perhaps from abroad in local currency (an unlikely case). Some private sector firms are likely to develop some expertise in this area. SNG lending differs from private sector lending in that SNG assets are more difficult to seize and sell in cases of nonpayment.

NATIONAL AND INTERNATIONAL SCMs. Finally, in countries that have national SCMs and also allow access to international SCMs, SNGs can access any financial institution, even those abroad. In general SNGs have access to international lenders only if they are large in financial terms, because international lenders are interested in transactions of a minimum size to cover the extra costs and risks associated with dealing with a foreign SNG.

\section{Use of the SCM}

Assuming an SNG has access to some SCM, why should it want to borrow funds from the SCM? One reason is simply because SNGs face numerous critical needs, ranging from providing emergency shelter for the homeless and poverty relief to the poor to improving education, social services, roads, and potable water supplies. The specific demands on budgets are a function of both the extent of needs in the area and of the allocation of responsibilities among the different levels of government. Thus while in one country an SNG may face tremendous financial demands related to water systems, in other countries that responsibility may rest with the regional, or even the national, government.

SNGs must distinguish among needs and financing requirements. Many critical services require recurring operating expenditures year after year. For example:

- Subsidies for the routine provision of health care for elderly citizens can be expected to represent a relatively constant expenditure, with some variation as demographics change.

- Funds required to hire SNG police or to maintain the SNG hall remain similar from year to year, increasing gradually as the jurisdiction grows and as its resources permit.

Operating expenditures are not the only kind of expenditures required to satisfy the needs of citizens, however. Capital expenditures (investment in infrastructure) are also needed. These expenditures tend to be large in financial terms, that is account for a large part of an annual budget, and are usually nondivisible, that is, they must be paid as a whole. The financial demands of such investments tend to exceed the resources of SNG governments in any particular year. For example:

- Construction of a major roadway will require a huge amount of resources, but that need will stop once the roadway is built. Indeed, if the project is structured as a toll road, it might even begin to generate self-supporting revenues.

- Construction of a water treatment plant could, if paid for in a single-year budget, represent 100 percent or more of the entire budget. Clearly SNGs do not want to cut 100 percent of their other expenditures or raise tax revenues dramatically to cover such a onetime expense.

Even though capital investments involve significant expenditure in a short period of time, they also create assets that are both long-lived and often have the potential to generate 
revenues. Thus, if maintained in good condition, the water treatment plant might continue operating and generating revenues from user fees for say at least 30 years. Knowing that such projects can produce the funds to pay them back, investors may be more willing to lend money.

Capital expenditures, with their long lives and large size, raise different financial equity issues for governments than operating expenses, namely:

- If a water treatment plant is going to serve the community for 30 years, does imposing the entire burden of paying for its construction on today's taxpayers make sense?

- If the plant is going to generate revenues during that period, should today's taxpayers bear all the burden of construction while tomorrow's taxpayers get the benefits of the new revenues?

The reverse reasoning applies to the financing of current expenditures using borrowed resources. Borrowing to finance expenditures that will only benefit taxpayers in a given year, such as road cleaning, fireworks displays, or other short-lived expenditures, is not appropriate (equitable), because borrowing means that other taxpayers end up paying for the service.

Capital expenses and operating expenses affect an SNG's budget very differently. For this reason, developing separate capital budgets generally makes sense to. However, to work well, capital budgets need to be derived from a coordinated capital improvement or investment plan. The capital plan should drive the capital budget rather than the other way around.

\section{Capital Improvement Plans}

A capital improvement plan is a strategic program for funding needed capital improvements that

- Looks comprehensively at capital needs

- Prioritizes those needs to identify specific worthy projects

- Considers different funding sources for each project and evaluates their advantages and disadvantages

- Develops approved capital budget expenditures for each year that take into account the SNG's borrowing capacity as established for a reasonable time period, such as 5 or 10 years.

Developing a capital improvement plan offers numerous practical benefits. It requires the government to define its needs and priorities, to establish criteria for judging among needs, and to make sure its proposed projects are coordinated with available resources and broader government policies. This process can help rationalize and increase the transparency of government decisionmaking and build public support for the agreed on projects. Such a plan should produce investments that are well integrated and provide better services than unplanned capital spending of the same amount.

One of the most difficult steps in the process is determining how to set priorities among different capital needs. Another challenge is to identify projects that meet those priorities. Because no government has unlimited resources, the prioritization process is extremely important to highlight those projects with a real prospect of going forward. To make such decisions the SNG has to consider the following difficult questions:

- What is its strategic vision?

- What are its long-term development needs and goals?

- When can various projects be completed?

- What are the interrelationships among different projects?

Separating the initial decision to support a project from the decision about how to fund it is important, because a variety of funding approaches may exist for any given project. A project considered solely as a package, for example, a proposal to issue bonds to support the 
construction of a sports stadium, may end up pairing a good project with a bad financing mechanism, or vice versa.

\section{Borrowing in the SCM: Terminology and Activities}

Even if borrowing appears to make the most sense, the type of borrowing that is most appropriate needs to be considered carefully. For example, the simplest way to proceed might be to borrow from a local or national bank (public or private, monopoly or not) through a loan agreement. An SNG, for example, would simply take out a loan through a bank. An alternative method would be to issue bonds in either the domestic or international capital markets. Annuities are yet another option.

BONDS. A bond is a document indicating the issuer's obligation to repay a specified principal amount on a specific certain date (the maturity date), together with interest at a stated rate or according to a formula for determining that rate. A bond represents a promise by the issuer, for our purposes, an SNG, to pay back the bondholder-the people or institutions that purchase the bond-the principal plus a specified interest rate at given intervals, whether quarterly or annually. Although a loan agreement essentially has the same features as a bond, a bond has additional features that are different from those of a bank loan. A loan is with a specific financial institution (or group of institutions, in which case the group is referred to as a syndicate and the loan as a syndicated loan), while bonds are issued at large in the SCM and can be held by various institutions and by individuals. In technical terms, the principal being borrowed is often referred to as the par value of the bond, and the interest rate is referred to as the coupon rate. (The coupon rate derived its name because a bond traditionally had-and in some cases still does have- a detachable coupon that specifies the amount of interest payable at a specific date and place and is presented to the issuer's paying agent for payment.) Coupon payments are typically made twice a year in the United States and annually in the European market. The maturity date is the date on which all the principal and interest has been paid. In some cases all the principal is to be paid on that date, while in others some of the principal will have been paid before.

ANNUITIES. One technique used to pay a debt is to pay an annuity. This is an amount paid annually and calculated in such a way that with the last payment the debt is extinguished. The amount is made up of both interest payment and capital (principal) payment, with the proportion of interest decreasing over time and that of capital increasing (this is the same method generally used to pay off a mortgage on a private home except that the payments on mortgages are at least monthly, if not more frequent).

AdVANTAGES OF Using BONDS. The main argument that can be made for issuing bonds rather than borrowing from banks is that they allow a longer maturity (that is, a longer period before the capital is due to be paid off) than bank loans. Longer maturity debt helps to minimize the budget risk and contributes to the financial stability of SNGs because they create a more certain stream of expenses.

In addition, a bond is usually issued at a fixed coupon rate, whereas the interest rate on bank loans can vary over time. Bond markets may also provide cheaper sources of financing than domestic bank loans. However, if they intend to use bond markets, SNGs need to be aware of certain risk factors to ensure proper financial management, namely:

- Fixed and variable interest rates. Bond issues can be structured to pay interest at a rate fixed over the life of the bond. In other words, the coupon will be a constant specified percentage of the par value, paid on a regular basis. Under a floating or variable rate interest structure, the interest is not fixed until maturity, but is determined periodically, 
based on some specified formula, such as X percent above the prime or the central bank discount rate. The benefit of this structure for an issuer (that is, the borrower) is that floating rates are typically lower than a fixed rate at the time of issuance. However, the issuer runs the risk that the market rate will change unfavorably( increase) during the life of the issue, thereby increasing required interest payments to the bondholders. This makes it more difficult for issuers to budget with certainty for debt service payments over time.

- Foreign and domestic bonds. Although interest rates may be lower for bonds denominated in foreign currency than for local debt, the former require the borrower to bear the foreign currency risk. This means that if the currency of the borrowing country loses value (depreciates) with respect to the currency in which the bond is labeled, the borrower will have to pay more. This is illustrated in box 3.1.

REPAYMENT GUARANTEES. There are three kinds of repayment guarantees associated with three kinds of bonds: general obligation bonds, project bonds, and dedicated revenue bonds.

- General obligation bonds. For this type of bond, repayment is guaranteed by the "full faith and credit" of the issuing government. This means that the full taxing authority of the issuer is pledged to pay back the bonds. This can be a secure pledge if the issuer has both the capacity and the willingness to raise taxes as needed. In some circumstances bonds are secured by a physical asset, such as land, that acts as collateral for repayment. In the event that the SNG does not make a debt service payment, title to the land is transferred to the bondholders and the land is sold to repay the outstanding obligation. The strength of the general obligation pledge is also affected by the SNG's perceived willingness to raise taxes, cut spending, or take other steps necessary to ensure that bondholders will be paid back on time and in full.

- Project revenue bonds. Unlike general obligation bonds, project revenue bonds are not backed by the full faith and credit of the issuer, but are secured only by the expected stream of revenue from the project being financed. For example, bonds to build an

\section{Box 3.1 How Foreign Currency Risks Come Into Play}

The following is a four-step example of the risk of borrowing in foreign exchange:

- An SNG borrows US\$50 million by means of a bond issuance. The exchange rate at that time is Rub 10 for US $\$ 1$. The SNG therefore obtains Rub 500 million to build infrastructure.

- Ten years later, when the principal is due, the ruble has lost value and the exchange rate is now Rub 20 to US $\$ 1$. The SNG must therefore spend Rub 1 billion to acquire the US\$50 million to be repaid.

- If the coupon rate for borrowing in U.S. dollars on the international SCM was 10 percent instead of the 15 percent that the SNG would have had to pay on the domestic SCM, it would have realized savings of Rub 25 million per year $(500 \times 0.10-500 \times 0.15=-25)$ from borrowing on the international SCM, or Rub 250 million for the full 10 years that the bond is outstanding, assuming that the exchange rate remained unchanged until the capital had to be paid back. Because of the change in the exchange rate, however, the SNG faces a net loss of Rub 250 million, the difference between the Rub 500 million extra required to purchase the US\$50 million and the savings in interest payments over the period of Rub 250 million. If the domestic rate had been 25 percent instead of 15 percent, then there would have been a gain of Rub 250 million. (Of course the numbers mentioned in this example ignore a number of potentially relevant factors, such as the inflation rate over the period, the effects of inflation on revenues and expenditures, and the earnings from the interest saved.)

- Exchange loss risk is minimized when a project earns foreign exchange in the borrowing currency. For example, a utility could borrow U.S. dollars to build a hydroelectric dam in Canada to sell power to the United States paid for in U. S. dollars. 
electric utility might be backed by the anticipated revenues that the utility will collect from user charges as electricity is distributed. The issuer may be an SNG or some sort of public authority, such as a water authority, that is independent of the government.

- Dedicated revenue bonds. Under this structure, bond repayments are guaranteed by a particular revenue stream, which is unrelated to the project being financed and is held in a trust type of arrangement to ensure repayment. For example, a bond may be backed by the pledge of funds from intergovernmental transfers that the SNG is due to receive, or by specific tax revenues, such as a liquor, sales, or gas tax.

When bonds are backed by a dedicated revenue stream two main concerns arise. First, how certain is it that the specified revenue stream will be sufficient to meet debt payment obligations and that it will continue at that level for the life of the bond? For example, if intergovernmental transfers from the national government are being pledged, investors will have questions about the intergovernmental transfer system. Second, how stringent is the trust fund mechanism under which these revenues are segregated? For example, will the revenues first go into SNG coffers and then be transferred to a bank for deposit into a special trust? Or will the revenues go directly to the bank without ever passing through the government's hands?

Issuing at A Discount or A Premium. Bonds may be issued at, above, or below par value. Bonds issued below par value are said to be sold at a discount. The issuer collects proceeds from the sale below the total of the par value of all bonds issued, but pledges to pay back the total value at par. This approach allows an issuer to offer the bonds at a lower coupon rate.

Bonds issued at a premium are sold above par value. In this instance the coupon rate is higher than it would be if bonds were issued at par. The main reason why a borrower would not issue a bond at par value is because investors (those who purchase the bonds) ask them to do so, usually for tax reasons, for example, there may be a withholding tax on coupon payments or differential treatment of capital gains income and interest income, with more favorable treatment of capital gains (the difference between an asset's purchase price and resale price).

\section{The Bond Issuance Process}

The issuance of debt in the domestic or international capital markets, whether in the form of general obligation, project revenue, or dedicated revenue bonds, is accomplished through a complex process involving a wide variety of players. While the story of every bond issue is somewhat different, most issues demonstrate several general trends.

\section{Key Players Involved in Bond Issuance}

A thorough understanding of the process of bond issuance requires familiarity with the key players involved, and understanding that responsibilities may vary somewhat based on the type of bond issue and that the method of sale is important. Because underwriters and financial advisers have common expertise in some areas, for example, their responsibilities may overlap. Furthermore, the precise outline of different players' roles will be determined both by the expertise of the issuing SNG and by the complexity of the bond itself. Even though the definitions are fluid, it is still possible to describe the core responsibilities of each player in the process.

FINANCIAL ADVISERS. Issuers, particularly those new to the bond market, often choose to rely on financial advisers to guide them through a bond issue. Financial advisers become involved 
with the issuer's administration early in the process and may help them develop a capital plan and accounting practices. Their roles may include assisting the issuer to

- Assess borrowing capacity and project revenue flow estimates from specific projects

- Develop a long-term borrowing program, not simply the single bond transaction

- Devise policies for debt management, cash management, and improved credit condition

- Develop a credit rating strategy.

The issuer should make sure that the financial adviser does not have any conflict of interest in the sale of the bonds and is interested in the SNG's long-term financial health. A conflict of interest arises when the adviser to the bond issuer is the same entity that sells the bonds to investors. The underwriter or investment bank often plays both roles in order to better understand the needs of both the SNG and the investor community.

CONSUlTANTS. A number of consultants or consulting engineers may also be hired early in the process for project revenue or dedicated revenue bonds. While the consultants' responsibilities can be shaped however the issuer desires, consultants are generally used to provide technical advice regarding the feasibility of specific projects to be funded by bond issues.

UNDERWRITERS. The underwriter's basic function in a bond offering is to purchase bonds from the issuer and resell them to investors. In the vast majority of cases the underwriter commits to purchasing the bonds, whether or not it can sell them on the market. This risk spurs underwriters to price bonds carefully and to create syndicates with other firms.

Most underwriters are investment banks, securities firms, or commercial banks. Whatever the nature of the offering, the underwriter will have a great deal of influence over its ultimate success. The role of the underwriter, like that of the financial adviser, varies with the type of offering. In a competitive sale, an issuer publishes notice of the offering and underwriters present the issuer with firm bids for the right to underwrite the issue.

In a negotiated sale an underwriter is typically involved earlier in the process, assisting the issuer with structuring the offering. In this type of arrangement, underwriters negotiate directly with the issuer regarding the size of the spread, which is the underwriter's compensation (that is, the smallest difference between what the underwriter will raise in the market and what the underwriter will remit to the SNG).

INSTITUTIONAL AND RETAIL INVESTORS. Institutional and retail investors are a major constituency in bond markets at various stages of development. Both groups of investors share several broad concerns when investing in SNG bonds. The primary risks investors face are market risk and credit risk. Market risk refers to the risk that interest rates will go up, leaving an investor with bonds paying an interest rate that is below the market rate. Credit risk refers to the risk that the credit rating of an issuer will fall over time. If the risk that an issuer will be unable to meet its payment obligations on the bond increases, the price of the bond will drop.

RATING AGENCIES. Rating agencies evaluate an issuer's ability to repay its debt obligations and rate this ability by reviewing various criteria for different types of bonds. Bonds are rated in recognized categories (AAA, AA, and so on), and these ratings are made available to investors. Rating agencies have tremendous influence over the success of SNG bond issues, because investors use these agencies, especially when considering new issuers.

\section{Key Stages in the Bond Issuance Process}

In addition to knowing about the players, potential issuers should also be aware of the key stages in the process of issuing bonds. Here again there are differences based on the specific 
bond issue and the market in which money is being borrowed. Other differences are based on the customs of each market. Given the differences among the systems, there is no single series of stages. What follows, therefore, is a general description that must be tailored to different approaches and markets.

MAKING PRELIMINARy Decisions. Issuers need to undertake a substantial capital planning process before deciding whether to issue debt in the form of bonds. The issuer will need to consider its outstanding debt and how any new issues will affect its existing debt policies. If it decides to issue a bond, then the issuer, perhaps with the assistance of a financial adviser or consultant, must choose which type of bond to issue.

Structuring the BidDing Process. Once an SNG decides to issue bonds, it will normally engage the services of a financial adviser (or team of advisers and consultants). Among their first tasks will be to select an underwriter. There are two principal methods of soliciting bids from underwriters: competitive sales and negotiated sales.

- In a competitive sale the issuer structures the issue, with assistance from a financial adviser; advertises it; solicits bids from underwriting firms that submit bids based on their evaluation of the chance of successfully placing the bond with investors; and selects the bid with the lowest spread. The principal advantage of a competitive sale is that it increases the possibility that the issuer will receive the lowest available price for an underwriter's services. The process is transparent in nature, and the selection of a particular underwriter is easily justifiable because the lowest price wins. However, competitive bids may not be as universally advantageous as they may seem at first glance.

- In a negotiated sale an issuer negotiates pricing directly with an underwriting firm. This typically takes place relatively early in the process. A negotiated sale optimizes the issuer's ability to take advantage of rapidly changing market conditions. Using a negotiated sale, the underwriter is involved much earlier in the process and assists the borrower in structuring the issue. A negotiated sale may be particularly beneficial to a new issuer, because it allows the underwriter to make presale marketing efforts to wary investors on the issuer's behalf. Finally, an underwriter's early involvement in a negotiated sale may save some of the costs of a financial adviser. Issuers in developing countries may find that engaging underwriting firms in a competitive bidding process is difficult, particularly for international issues. Underwriters, especially when not involved in the structuring process, are hesitant to commit themselves to the purchase of an entire issue of bonds from SNGs without established credit. For such issuers the debate between a competitive and negotiated bidding process may therefore be entirely academic. By establishing a credit history through a negotiated sale process, issuers may gain the option of entertaining competitive bids for subsequent issues.

STRUCTURING THE ISSUE. Decisions made during the bidding process will affect the structure of the issue. With a competitive bidding process, the key structural matters will need to be resolved with the financial adviser before underwriters can bid. Under a negotiated sale arrangement, the underwriter will be able to play a major role in the structuring decisions with the issuer.

Sometime during this process, a marketing "road show" may be undertaken to key financial centers to tell the borrower's story and ascertain investor concerns and demand. Investor responses can then be factored into the structure decisions. Financial advisers can also prepare a preliminary structure for the competitive or negotiated process and allow the underwriters to suggest changes or refinements to their proposals. Rating agencies may play a role in structuring if the issuer is trying to achieve a certain rating grade. 
While the number of decisions in structuring the issue is almost infinite, the following are especially important:

- Type of issue. A key decision is whether the bond issue will represent a general obligation or whether it will be backed by project or other dedicated revenues. This determination drives many other decisions, including the market's eagerness to purchase the debt, the types of information rating agencies require, and the types of legal documents needed.

- Sizing the issue. The size of an issue will depend primarily on an issuer's particular needs. If it is issuing bonds to finance a particular project, the costs of the project must be budgeted in order to size the bond issue. If the issuer's goal is to refinance existing debt, the size of the existing debt will help determine the size of the issue. Regardless of the reason for a bond issue, an issuer may have to cover a number of costs with proceeds from bond sales, for example, pay the expenses of the issue, such as fees for bond counsel and financial advisers; fund a debt service reserve fund; pay interest on bond security; and fund other forms of credit enhancement.

- Determining final maturity. A bond's maturity date is based primarily on the issuer's financial condition, market conditions, and type of project being financed. If an issue is used to finance an infrastructure project, the final maturity of the debt should be tailored to the expected life of the completed project. If, for example, bonds are issued to finance a highway expected to last for 40 years, the final maturity may be at any time within 40 years. If, however, a fleet of police cars is being purchased that is expected to last seven years, the maturity should not be longer than seven years.

The market generally does not want issuers to be paying for projects when they are no longer in use. Issuers should also avoid using long-term bonds to finance a continuing operating deficit. For most SNGs in developing countries, issuing a bond for the expected life of the asset is not generally possible. International and domestic capital markets for issuers are too volatile and underdeveloped to allow for bond tenders to match the life of the assets being financed. Nevertheless, as these markets develop, issuers may increasingly be able to offer longer-term bonds for their infrastructure projects.

ObTAINING a CREDIT RATING. The financial adviser and/or underwriter generally play a substantial role in helping the issuer through the credit rating process. The credit rating agency will need information about the structure of the issue in order to rate the particular issue.

PREPARING THE Documents. Decisions regarding bidding and structure also shape the preparation of bond documents, in which the financial adviser, underwriter, and bond counsel all play a role.

UNDERTAKING MARKETING AND DistRIBUTION. While sovereign governments often go to their domestic capital market based on set auction dates, such as treasury bill auctions, SNGs in general often have more flexibility in timing their offering based on market conditions. During this phase the underwriters actually sell the bonds to investors.

Setting the Closing Date and Undertaking Ongoing Activities. The closing date is the time at which the issue is officially considered closed, meaning that underwriters are responsible for purchasing any bonds that have not been sold to investors by that date. After the closing, accounts among the syndicated members are balanced.

Even after the issue is closed, however, activities continue. The trustee remains responsible for protecting the interests of the bondholders, while the required interest payments must be made regularly, often through the paying agent. In addition, the credit rating agencies will 
continue to assess the issue throughout its life. If an active secondary market exists, then the closing of the issue is merely the prelude to perhaps years of continued trading of the bonds.

\section{Credit Ratings}

This section discusses credit ratings, why they are important, and how the credit rating process works.

A credit rating assesses an issuer's future ability to pay back, on time and in full, the monies owed to the investors who buy the bonds. Receiving a favorable credit rating is important to issuers for the following two key reasons:

- Many investors will refuse to buy bonds if they are not rated, and in some cases the central government may not even permit an SNG to sell unrated bonds.

- The rating serves as a critical determinant of the interest rate an SNG will have to pay to issue debt in the capital markets. The riskier the credit rating agencies think the issuer's ability to make debt service payments, the higher the interest rate.

\section{Who Determines the Credit Rating?}

A credit rating is an independent opinion on a borrower's future ability, legal obligation, and moral commitment to meet its financial obligations of interest and principal, in full, and in a timely manner. Credit ratings are not

- Recommendations to buy, sell, or hold a security

- Opinions about the general quality of a government or statements about the quality of life in a community

- Opinions about the correctness of a government's policy decisions.

A credit rating is determined by a credit rating agency, an independent appraiser of default risk associated with bond issues. With the growth of free market economies and the privatization of state-owned companies, rating agencies are increasingly used internationally. The four best known firms are Moody's Investors Service, Standard \& Poor's, Duff \& Phelps Credit Rating Company, and Fitch IBCA, Inc.

In some circumstances, credit ratings are performed not just by credit rating agencies, but also by national governments or quasi-governmental agencies in order to give the market greater faith in the issuer's repayment ability. The national government needs to consider whether the market will see such a rating as an implicit national guarantee of the debt issue, something that it may not want to give.

\section{Why Are Credit Ratings Important?}

Credit ratings are important from both the investor's and issuer's perspectives. Ratings provide information to the investment community and facilitate investors' access to debt offerings. They also have an effect on the costs of both buying and selling debt. This occurs because credit ratings indicate a level of default risk, which is the central factor for pricing bonds. High credit ratings indicate low default risk and therefore decrease the cost of borrowing. Low ratings, an indicator of higher default risk, increase the issuer's interest cost. Credit ratings are intended to equip investors with a consistent measure of credit, which provides reliable comparisons of debt and debt-like instruments in the capital markets. Usually the better the rating, the less interest an issuer will have to pay when it issues bonds.

In addition to influencing the interest rate issuers will pay to issue bonds, credit ratings can affect current and future debt offerings and other government behavior. For example, ratings can 
- Expand the number of investors available, as these investors understand the risks associated with the securities being offered

- Make debt more attractive to a wide range of investors, both domestic and foreign

- Provide a form of free publicity about SNG financial performance and make it politically easier for SNG officials to institute financial management techniques that could improve future ratings

- Influence government policies directly, because officials may avoid certain policies that might lower SNG credit ratings in the future.

Note that a credit rating can be useful even without borrowing, as argued in box 3.2.

\section{How Does the Credit Rating Process Work?}

The rating process involves several sequential steps. International rating agencies generally follow the rating process described here. Domestic rating agencies may use somewhat different procedures for conducting ratings.

CREDit PResentation. The rating agency, whose revenue comes from issuers and investors, begins the process by sending a rating team for a credit presentation. A credit presentation is the issuer's opportunity to describe the issue and make its case for a good rating. In addition to making an oral presentation, issuers often provide a written presentation with background materials (some of which are often provided prior to the rating team's visit). The information provided differs in accordance with the type of bond being issued, but frequently includes such items as

- Background and history of the issuer

- Official statement of the issuer

- Proposed terms and legal covenants for the issue

- Nature of existing bond issues, if any

- Five years of audited financial statements and annual reports and operating and capital budgets

- Summary of operating and statistical trends.

SITE VISIT. As part of its review, the rating agency visits the SNG or regional government and meets with senior officials to discuss economic and budget trends as well as any factors affecting credit quality.

RATING COMMITTEe. Once the analysis is complete, the lead analyst from the rating team convenes an internal rating committee to discuss and debate the entity's credit quality and

Box 3.2 The Role of Credit Rating without Borrowing Requests

After undergoing a capital planning process, an SNG may decide not to borrow. Nevertheless, it may want to employ a credit rating agency to issue a credit rating. A credit rating that is independent of immediate borrowing needs can serve the following purposes:

- It can alert the SNG to potential investor concerns, which it can then deal with through strategic planning initiatives and can result in an improved credit rating when the SNG does want to borrow.

- It can get the word out among investors that a particular SNG is "testing the waters."

- It can help influence government policies directly. For example, officials may avoid certain policies that might lower the SNG's credit rating in the future. 
determine its rating. Once the rating has been determined, the rating team contacts the issuer to report its decision.

OPPORTUNITY TO APPEAL. At this point the issuer is given the opportunity to appeal by presenting new or additional information that could lead to a change in the rating. If the issuer disagrees with the rating, the rating is not published and remains confidential. If the issuer accepts the rating, the capital markets are informed by means of a press release. If there is reason to reassess a previously issued rating, changes will be announced in a similar manner.

ONGOING REVIEW. The rating agency will expect to receive regular financial updates from the issuer and, in most cases, will visit the issuer annually. The rating agency reserves the right to upgrade or downgrade the rating based on new credit developments, such as

- Material changes in rating factors

- Significant change in the issuer or the project's financial position

- Shift in sovereign or subnational policy that will alter the credit profile

- Substantial economic downturn without sufficient governmental response.

\section{What Criteria Are Analyzed in Determining Credit Ratings for Individual Issuers and Bond Issues?}

The criteria analyzed to determine individual issuers' credit ratings vary according to the type of bond.

General Obligation Bonds. There are four broad criteria for this type of bond.

- Economic base, diversity, and growth. A diverse economy with no dominant employer and a healthy blend of manufacturing, agriculture, services, trade, natural resource processing, and government jobs is a positive credit factor. Dependence on a few primary employment segments in an economy makes the borrower more vulnerable to economic shocks and recessions. In addition, analysts look at how well developed private sector employment is compared with public sector employment. Economic prosperity and demographics are significant credit considerations. The competitiveness of local industries, infrastructure capacity, and the conduciveness of the environment to private sector investment and economic growth are other important factors.

- Analysis of outstanding debt. Debt analysis indicates what type of debt is owed, what the money has been borrowed for, and what has been pledged to repay the debt. For SNGs, their debt burden is measured by certain debt ratios, such as total outstanding debt to population and property valuation, as well as debt service to financial balances and revenues.

- Financial operations, revenue, and expenditure flexibility. Financial analysis begins with an examination of the issuer's financial statements. Balance sheets, income statements, and audits (if available), which display cash balances, intergovernmental borrowing, and current and long-term assets and liabilities, are fundamental to the credit rating process. Incomplete information will inhibit the credit rating.

- The government's administrative structure, legal factors, and political dynamics. Rating agencies must assess the regulatory and legal structures of the country's executive and legislative branches of government; the services provided by the central government, state enterprises, and administrative agencies; and the relationships among the central government and its SNGs to help determine the issuer's willingness to pay. In addition, rating agencies must consider the intergovernmental system's political and administrative stability and supportiveness. Part of this analysis will include consideration of the 
structure of intergovernmental transfers and the likelihood that such transfers will continue at current rates.

Project Revenue Bonds. The criteria for analyzing project revenue bonds are similar to the general obligation criteria, with two key differences. These differences can lead to the same issuer having different credit ratings for its general obligation debt and project revenue debt.

- Debt service for revenue bonds comes from the user fees generated by the project. The issuer does not pledge general revenues for debt service. Therefore, the key focus of credit analysis is not the issuer's financial stability, but the financial health of the project that will generate the revenues.

- Unlike general obligation debt, which generally has no bond covenants beyond the issuer's general pledge to service the debt, revenue bonds have a series of covenants dealing with such items as project maintenance, establishment of operating reserve and debt service reserve funds, debt service coverage levels, rate covenants, and additional bond issuance covenants. The legal strength and enforceability of these covenants has a direct impact on the issue's rating.

DEDICATED REVENUE BONDS. Rating agencies analyze criteria comparable to general obligation debt when determining a revenue bond rating. In general, agencies focus on four criteria:

- Economic feasibility of the project

- Credit risks during the project's development

- Efficient management and long-term economic health of the project

- Bond covenants in the context of the country's legal and policy framework.

\section{What Are the Challenges Facing Emerging Markets?}

Rating agencies have acknowledged particular concerns and challenges in rating emerging market SNG and regional debt. These challenges, which arise from the political, economic, and social pressures to which emerging markets are subject, include the following:

- Unpredictable legal and regulatory frameworks

- Risky debt profile

- Financial data that are not independently audited

- Burdens imposed by publicly-owned companies

- Shifting intergovernmental political and fiscal relationships

- Incomplete demographic data

- Inflation effects

- Enormous infrastructure needs

- Uncollected taxes and user fees.

\section{Conclusion}

The main points those concerned with SNG budgeting and finance should be aware of are the following. First, good financial information is necessary for both budgeting and borrowing activities and is derived from accounting information. Accounting conventions matter when measuring the financial health of an SNG. Even nonspecialists should be aware of the choices made in this matter (accrual or cash bookkeeping and so on). Second, the budget is one of the most important documents produced annually by a SNG. It is therefore crucial that it reflects residents' needs and the means available to satisfy them. Third, capital assets, such as sewers and roads, should be financed by all those who will benefit from them. Because these assets are 
long lived, borrowing to finance them is appropriate. Fourth, borrowing is done on the financial markets. The features of these markets vary among countries, both in terms of the institutions (banks, brokers, and so forth) and in terms of loan agreements (bonds, interest rates, role of credit ratings, and so on). The underlying economic rationale for borrowing and lending, however, remains the same. The amount borrowed must be used to finance capital assets and must be repaid on time. 


\title{
4
}

\section{The Structures and Conduct of Intergovernmental Relations}

\author{
Ronald H. Neumann and T. Russell Robinson
}

Federalism is a complex form of government that Canada, Russia, and a number of other countries have adopted. Such an approach helps countries achieve a politically acceptable and sustainable balance between national goals (including economic efficiency, social equity, and beneficial international relations) and the responsibilities and preferences of subnational regions and governments, often in the context of ethnic and cultural diversity. A related motivation, consistent with federalism although not confined to federal structures alone, is the widespread (although not universal) belief that decentralization can improve government efficiency and strengthen democratic practices (Martinez-Vasquez and Boex 2001).

Constitutions partly determine how federations function, as do laws that describe and delineate divisions of power and responsibility and sometimes prescribe elements of intergovernmental machinery and procedures. However, much also depends on the multitude of less formal structures and processes and on the conduct of the people who participate in them.

Martinez-Vasquez and Boex (2001) suggest explicitly that the Russian Federation required a well-functioning system of intergovernmental relations for Russia to meet its goals. This statement may be applicable to any federation. In his wide-ranging comparative analysis, Watts (1999a, p. 118) notes, "All federations have required intergovernmental processes and institutions to facilitate consultation and collaboration between their governments in the unavoidable areas of overlapping jurisdiction." Virtually all federations have found it necessary to build systems of intergovernmental collaboration, which sometimes include explicit and detailed rules and commitments and require high levels of policy understanding and professional competence from all participants. In this way, the intergovernmental structures in federationsincluding the various divisions of roles and responsibilities and the procedures for handling overlapping jurisdictions and common interests-represent a framework and regulatory regime for mediating conflicts, negotiating common goals, and collaborating on policy development, and even on program design and administration.

While specific mechanisms and procedures need to be tailored to each country's circumstances, there appears to be a significant set of common underlying structures, processes, and competencies for effective policymaking and public administration in federations. This chapter elaborates on such issues by examining a range of mechanisms and procedures by which governments in a federation conduct their affairs and pursue their responsibilities. In doing so, the chapter draws on specific examples from the content and conduct of Canadian intergovernmental relations (especially fiscal federalism) since World War II.

\section{Benefits from Differentiation and Common Understandings}

One advantage of a federal form of government is that it should, in principle, allow for a greater degree of differentiation than a unitary state through more formal decentralization of public sector policies, program design, and delivery. This differentiation is often useful when constituent parts of the federation have substantively different needs, tastes, or capacities. These 
differences arise because of the make-up of the constituent parts of the federation. The country's economic, fiscal, and social circumstances and conventions; the historical development of its constitutional and legal systems; different interpretations of appropriate principles governing roles for central, regional, and local governments; political considerations; and a host of other factors all come into play. Each of these factors can change over time, and the resulting formula of intergovernmental relations will similarly need to adapt. The participants in intergovernmental systems must have a good understanding of these differences and changes, along with an awareness of the areas in which a common perspective and solid consensus exists.

In a unitary state, the central government might face a constant stream of choices to balance these factors, each resulting in some degree of contention, whether the decision is to impose standard practice or to attempt different solutions for each set of circumstances. In a federal state the machinery of intergovernmental relations must provide options for addressing key common objectives while respecting the diversity within the federation.

A second advantage of decentralized activity is that it fosters the potential to address similar needs in different ways. This experimentation can lead to the development of new and better methods, healthy competition, and the confirmation of best practices (Breton 1990; Ostrom 1987).

However, a federal form of government also has potential disadvantages. More questions arise during the decisionmaking process, and jurisdictional "rights" of constituent governments can make issue resolution and clear decisions more complex and time consuming. The successful resolution of these matters may be essential to the efficiency of the state, and indeed to its very survival, should the constituent parts of a federation retain a degree of sovereignty.

\section{Flexible Frameworks to Accommodate Variety and Change}

Establishing an appropriate constitutional and legal framework is essential to the maximization of the value of a federal form of government. Noted scholars such as Bird (1986) and Bird, Ebel, and Wallich (1995) discuss in detail the principles and best practices for developing this framework, incorporating such matters as expenditure responsibilities and revenue assignments between and among national, regional, and local levels of government. However, a federal constitution, which balances various interests in the country, is likely to be difficult to change. For this reason, and because there are few absolutes in relation to principles and best practices, constitutions and legal frameworks usually provide parameters within which a wide degree of operational flexibility is practiced. Australia, Canada, and South Africa provide examples of such operational flexibility. There are no cookie cutter approaches to the design and operation of a federal state. Each state is likely to be unique and, furthermore, each is likely to evolve over time.

Intergovernmental relations are especially important for the operation of federal systems that can adapt, change, and remain flexible. Constitutional provisions, particularly for the assignment of expenditure and regulatory responsibilities, may have been made many decades ago (in Canada, for example, they date back to the 1860s) and do not always match contemporary needs. However, federal constitutions are by design difficult to amend. Thus policymakers use intergovernmental relations, including fiscal arrangements, to allow governments to achieve change more easily and less permanently. Central, regional, and local governments cooperate when dealing with naturally concurrent or overlapping responsibilities, such as environmental protection; coordinating local and national aspects of a policy area, such as economic development; and providing national frameworks for programs delivered by subnational governments, such as social programs (see, for example, Watts 1999b; Wright 1998).

Federations that are particularly complex and diverse have broad parameters for operational activity and face the need or potential for change must have intergovernmental processes 
that garner the benefits of the federal form of government while minimizing the potential for serious conflict (see Watts 1999a, chapter 5).

\section{Intergovernmental Processes that Apply to Virtually all Policy Areas and Ministries}

The conduct and structures of intergovernmental relations in a federation typically apply across the wide range of public sector responsibilities. Variations of these structures, processes, and practices develop among the major government ministries in which all levels of government have a role. Thus sectors and ministries of health, environment, energy, education, economic development, social protection, and so on will each develop mechanisms and patterns for the conduct of intergovernmental relations covering the range of functions outlined in this chapter (Watts 1999a).

In Canada, virtually all ministries have their own family of intergovernmental mechanisms, and they have developed their own practices of cooperation and collaboration between the federal and provincial (or territorial) levels. ${ }^{1}$ Although many of the concepts and functions are common across ministries, roles and structures vary for a variety of reasons. These include the differing roles and responsibilities of each level of government in various program areas, such as social services, housing, and energy (see, for example, Dupre 1985; Kernaghan and Siegal 1995; McRoberts 1985; Simeon 1979). This chapter uses finance ministry functions to provide examples of intergovernmental processes, focusing on the Canadian experience with fiscal relations.

\section{Fiscal Federalism's Core Issues}

Bird (2000) poses five questions that arise with respect to intergovernmental finance in any country, namely:

- Who does what? This refers to the assignment of expenditure responsibilities across levels of government.

- Who levies what taxes? This refers to the assignment of revenue capacity.

- How is any vertical imbalance addressed? A vertical imbalance exists when the expenditure responsibilities and the revenue capacities of subnational governments are not well matched.

- How are any horizontal imbalances addressed? A horizontal imbalance exists when different units of the same order of government, with similar expenditure responsibilities, have significantly differing fiscal capacities.

- What, if any, rules exist with respect to subnational borrowing?

Bird then adds a sixth question: what is the institutional framework whereby decisions are made and the technical and political problems of fiscal federalism resolved? Intergovernmental fiscal relations must have in place appropriate processes to deal with these fundamental questions whenever the answers cannot be found within the legal and constitutional framework. This is because a need may arise for interpreting or elaborating existing policies or for responding to changing conditions; contingencies, including external shocks; or new opportunities and challenges.

1. Canada's 10 provinces derive their basic powers and responsibilities from the Canadian Constitution, whereas federal legislation created the three northern territories. Although the territories are much more financially dependent on the federal government than are provinces, and are supported by means of a different fiscal formula, they have taxing powers and expenditure responsibilities similar to those of provinces. As such, the territorial governments participate in virtually all intergovernmental processes as independent jurisdictions. Thus in Canada (and in this chapter) references to intergovernmental operations include the territories. 
The remainder of this chapter discusses intergovernmental processes in the public fiscal area; intergovernmental machinery; examples from Canada and Russia; and a possible mechanism for evaluating the system with respect to needs, practice, and support for intergovernmental processes.

\section{Functions of Intergovernmental Structures}

Several factors determine how each federal system organizes itself for intergovernmental relations and the degree to which such mechanisms are formal and institutionalized or informal and ad hoc. The first factor is the degree of separation of powers in the federation, that is, whether the executive branch dominates intergovernmental relations as it does in Canada, or whether the legislative branch also plays an important role, as in the U.S. system (Watts 1989). The second factor is whether the legislative powers of the constituent governments are held concurrent with those of the central government, in which case broad cooperative schemes will be required to prevent centralization of policy, as in Australia. Alternatively, the constituent governments may have exclusive powers, enabling them to resist or avoid cooperative schemes (Painter 1998). The third factor is the value that society places on the degree of governmental competition versus cooperation. In Germany, for example, cooperation is seen as relatively important, and therefore intergovernmental relations are heavily institutionalized, whereas in the United States, where competition is valued, relations are more ad hoc. Finally, the fourth factor is the number of units in a federation. The smaller the number of units, the easier and more efficient it is to pursue ad hoc and informal bargaining of all governments as a group, because all the leaders can meet in a relatively small room, as with Australia and Canada. This is more difficult where the number of units is larger, as with Russia and the United States.

In any case, the structures of intergovernmental relations, whether explicitly as in Canada, or perhaps more informally in more recently-developing federations whose institutions are still being formed (perhaps including Russia), will normally carry out a number of activities that may be classified into several broad functional areas.

\section{Identification of Issues and Priorities for Intergovernmental Attention}

Federations respond both to central priorities and to regional and local priorities. The national government should have the ability to protect the common national interest and may promote the maintenance of national standards, where appropriate. Regions, in addition to having the ability to manage the areas within their own legal and constitutional competency, should be able to bring national attention to matters that may require the financial assistance or coordination of national or other regional and local governments. Bringing together these interests and competencies will likely raise a variety of matters that, though not necessarily unique to federations, must be addressed in patterns unique to the federal form of government.

To elaborate, one could consider the list of questions raised by Bird. Are there program and other expenditure responsibilities that might be new or might be desirably shifted to another order of government? Should tax assignment be changed? Must the total tax burden or the total tax burden on a particular segment of the population or a particular sector of the economy be changed and does this require coordinated action? In cases in which tax fields are shared, is the sharing appropriate? Are national standards with respect to public programs necessary or appropriate and, if so, will they be established by the national government or through coordinated action of all, or perhaps only a majority, of regional and local governments? Are there vertical or horizontal fiscal imbalances that need to be addressed? Must there be new rules or coordination with respect to borrowing?

If this identification function is not performed adequately, the intergovernmental system will be forced to deal with many matters simultaneously without sufficient focus to successfully 
address major challenges. It may be more responsive to immediate concerns than to any longerterm vision. The vital issues can be trivialized, while the importance of other issues is exaggerated. Achieving agreement on priorities - or adjustments to ongoing priorities-will not always be easy, but it is almost always worth the effort, and it can improve the prospects for progress and ultimate agreement.

\section{Development and Analysis of Relevant Information}

Data of acceptable quality are essential to the conduct and refinement of intergovernmental fiscal relations. The data must be accurate, current, appropriate, and sufficiently comprehensive for the purpose and must be accepted as such by the users (McEwin 2000). The development and use of a respected and independent statistical agency has proven to be a valuable tool in many federations, ensuring that needed data are prepared and accepted for policy development and administrative purposes. In this context, there should be an effective working relationship and consultative arrangements between the statistical agencies at the regional level (if they exist) and the central statistical agency, as well as a mechanism for information exchange and joint statistical planning and analysis among the finance officials of the governments in a federation.

In several federations, such as Australia, Canada, and South Africa, statistical agencies have been given the authority to develop the data underlying the calculation of federal transfer payments. In some federations, Nigeria, for example, available data are in dispute and therefore are not useful for administrative purposes. In Russia the data are less disputatious, but are not sufficiently current to capture the dimensions of a rapidly changing economy.

Whenever the facts are in question, the discussion of solutions to problems is jeopardized. Even when the facts are agreed on, separate interpretations can lead to support for different, even conflicting, positions. However, further joint analysis of the data can often lead to broader and more deeply shared perspectives on issues. Thus intergovernmental processes should have the capacity not only to receive data and analytical conclusions, but also to work toward a common and accepted interpretation of the data.

Necessary information may not be limited to economic and fiscal data. "Soft data" regarding political preferences; administrative capabilities; and the results of the monitoring, evaluation, and accountability exercises are examples of the range of other data requirements necessary for the analytical work underlying good, evidence-based decisionmaking.

\section{Development of Policy, Administrative, and Technical Options}

All governments require a competent cadre of administrative players who can take information; apply it to selected issues; and develop the policy, administrative, and technical options available to address a variety of issues. Knowledge of principles and best practices, practical experience, and professional objectivity are often the key characteristics of competent analysts.

Most often this type of expertise is concentrated in the national government. However, when it comes to the total number of competent staff or to experts on particular sectors of public finance-such as subnational program and expenditure responsibilities or revenue issues with respect to natural resources unequally distributed in regions of the country-more expertise may be available in the subnational governments. What seems to work most effectively is the development over time of "trust ties" among professional public servants across governments, creating good working relationships at the bureaucratic level (Dupre 1985).

It is important for intergovernmental processes to be able to access and consider the analysis and synthesis into options produced by policy development experts. Those experts may be located in the national or subnational levels of government-or even in the nongovernmental or quasi-governmental spheres, providing the system is open to such sources, as it is in Russia. 
Sufficient capacity within each level of government to understand, engage in, and challenge the analytical work will increase effectiveness. Without a capacity for critical analysis, federal systems may become mired in uninformed debates (Pollard 1986).

Even though the ultimate responsibility for the national interest may often reside at the federal level, participants in regional and local governments should have a good understanding of national policies and priorities, even when these policies and priorities may appear to be in conflict with local or regional preferences. Only then will maintaining a balanced dialogue between different levels of government be possible along with resisting the natural attitude of "them versus us," which can undermine productive intergovernmental processes.

\section{Development of Consensus}

Frequently in the conduct of intergovernmental fiscal relations, various camps will come to different conclusions about the best course of action. Relative power may play the decisive role in these situations; however, techniques are available for building consensus. As noted previously, making an appropriate forum for dialogue available and ensuring that the data and analysis are understood can be useful, particularly if the group members have become familiar with one another's perspectives.

The forum for resolution of intergovernmental fiscal issues should respect rules of successful negotiations, including

- The development of an appropriate agenda

- The role of the chair

- The establishment of deadlines

- The use of smaller and/or more focused working groups on subissues.

The introduction of outside facilitation, mediation, or conciliation may be considered, although such techniques are used infrequently. McRoberts (1985) provides a useful perspective on different approaches taken to resolve outstanding issues in the Canadian federation, including multilateralism, bilateralism, and unilateralism. When consensus is not achieved though structured processes, the balancing of political interests, establishment of alliances, trade-offs involving other issues, and other more political approaches are the common vehicles for maintaining viable intergovernmental relations, or at least for reducing antagonisms. ${ }^{2}$

\section{Policy Adoption and Implementation}

Officials must make decisions at the appropriate level in the governmental hierarchy. Technical matters may be resolved at lower levels, but policy must have political approval. Fiscal arrangements are frequently among the most important and contentious issues that the political system addresses. The intergovernmental machinery must be structured to enable the political approval process to function effectively.

Analytically based briefing material is an essential ingredient of the successful conduct of intergovernmental relations. In countries such as Canada and South Africa, forums of both officials and ministers strive to use common briefing materials that provide

- Background information and data that clearly and concisely provide the analytical framework

2. For a broad conceptual framework drawing on public choice theory, see Ostrom (1990). Ostrom's work is mainly rooted in the American experience. For a discussion more relevant to Australia see Painter (1998), and for Canada see Sproule-Jones (1993). 
- A succinct summary of the options

- The short- and longer-term consequences of the options

- A recommendation from staffers or a supporting body

- Strategies for implementation if the policy recommendations are accepted.

The material must be considered in an appropriate forum. This may consist of a meeting of heads of state of the federation, ministers of finance, perhaps others.

Processes that are overly cumbersome risk delay and may even jeopardize a plan of action. Strategies that assist the political process in reaching decisions in Canada include the following:

- The assignment of tasks with specific terms of reference and deadlines from political to administrative levels.

- A hierarchical system descending from the political level through senior officials to committees of technicians within the bureaucracy, with each level mimicking, or at least capable of representing, the various configurations of national and regional or local interests. Officials at each level attempt to focus their efforts toward the specific needs of the political decisionmakers, to the extent those are clear, or to identify and clarify those needs if there is ambiguity (which is often the case).

- The ability to resort to common briefing books rather than referencing separate materials developed by each jurisdiction. Although separate briefings will inevitably still occur, the structure of separate briefings will more likely focus on the degree of consensus that appears to be emerging and the differences of the specific jurisdiction from the consensus.

- Regular meetings that familiarize the players with each others' usual positions and perspectives and allow routine business to be concluded. In addition, the players should have the flexibility to meet when required to address urgent or exceptional business.

\section{Administration and Coordination}

Intergovernmental fiscal relations require a significant degree of coordinated activity. To move from policy to funding to actual program implementation, the role of each of the levels of government should be clear and accepted. Sometimes, by virtue of the constitutional or legal framework, the authority to take action is shared.

Even though bilateral action may suffice, a federation usually benefits from the creation of forums to guide and monitor the implementation of policy. Such forums may also assist in the development of appropriate rules and regulations under which policy is implemented. Standards may be set, but the boundaries may be more sensitive to regional considerations. For example, consider the regulations required for the provision of welfare in a poor, rural region compared with provision in a city. The overall policy objective of providing basic food, shelter, and clothing may be the same in the two settings, but the form of assistance provided, and its cost and delivery structure, may be substantially different. The development of a financing formula must consider these factors, and a common understanding of the necessity for specific elements within the formula reduces the potential for conflict. Experimentation and differentiation may be important benefits of the decentralized, federal system of governance. Sharing best practices helps to spread the benefits.

In some federal systems, such as Australia, Canada, and Germany, as well as the European Union, governments have developed (to varying degrees) intergovernmental machinery that enables them to make more substantive, collective decisions. This co-decision capacity-especially as seen in the European Union-requires intergovernmental councils to take binding votes in order to get past the lowest common denominator results of consensus rules. Even if such votes are not always taken, the ability to take them changes the behavior of the parties; 
one holdout cannot prevent forward movement by the rest. The European Union, which has no other form of central decisionmaking, uses such co-decision mechanisms routinely. In the more established federations co-decision is more restrained (especially in Canada) and confined to a few areas of public policy (Brown 2002).

\section{Transparency and Accountability}

In a democracy, transparency and political accountability to the electorate foster good governance. In a federation, however, even if information on monitoring, evaluation, and related activities is available to the media and the public, the lines are often blurred about who is accountable (for delivery or funding, for example) and to whom the reporting of information should be directed. Shared responsibilities among levels of government and conditions attached to shared-cost programs or to intergovernmental transfer payments can add to the difficulty of achieving public understanding and political accountability.

By way of example, national governments typically provide transfer payments to offset vertical and horizontal fiscal imbalances. The reasons for these imbalances within federations are rooted in the efficient distribution of taxation powers-which may not coincide with desirable distribution of spending responsibilities-and the need for the national government to make payments to address horizontal disparities (for example, to even out fiscal capacities between richer and poorer regions). In such circumstances, the national government will transfer funds to subnational governments. It will often seek considerable information from the recipient governments about program delivery, administration, and financial outlays to hold the subnational governments accountable for their performance.

Experience in established federations suggest that, as federal states develop modern governance practices, it may become appropriate to limit national accountability to the issues of whether program funding is adequate and whether it is effectively distributed. Regional authorities, responsible to their own electorate, can be held accountable for efficient and effective delivery of services. Of course when governments agree to conditions or performance commitments, or when national authorities threaten or impose penalties to enforce national standards, the national government often must be held at least partially accountable for program delivery and performance, if only because it is accountable to the electorate for the exercise of federal authority and the expenditure of federal funds.

In the context of contemporary Canadian political culture in which citizens, the media, and various organized social interests are much less deferential of governments than they once were, many observers have criticized intergovernmental relations on democratic grounds (Brock 1995; Dupre 1985; Smiley 1979). This criticism came to the fore during constitutional negotiations in the 1980s and 1990s, when the federal and provincial premiers were perceived as reaching deals behind closed doors on issues related to broad Canadian values and identity without adequate legislative scrutiny and public debate. The secrecy and suspected collusion of "executive federalism" became a liability and helped to turn public opinion against the proposed constitutional reforms.

The public and media usually seem to be less concerned about more routine, technical intergovernmental issues and discussions, even if the latter are closed to the public. Some would argue that governments are supposed to handle details competently, without continuous recourse to public debate. However, it is difficult to predict when a specific or apparently minor intergovernmental issue may assume a higher profile, with democracy issues (including accountability and transparency concerns) once again being raised by a critical media and public. Government officials and their political masters always face the challenge of finding an acceptable balance between the comfort, and sometimes the efficiency, of inside deliberations and the need for public input, understanding, and support. 
In Canada, the Auditor General's Office has written about these challenges of accountability in collaborative federal systems (Desautels 1999). In this complex environment many observers, including the auditor general, have identified key elements associated with strong accountability, including

- Clear and agreed-on expectations

- Clear roles and responsibilities

- Balanced expectations and capacities

- Transparency and credible reporting

- Reasonable review, program evaluation, and audit

- Ongoing scrutiny of intergovernmental arrangements by legislative committees

- Public hearings on major intergovernmental agreements prior to their completion.

Public debate is sometimes poorly informed about complex issues, and the simplistic solutions that are often presented in the popular media can create false expectations and unmanageable political pressures. Enabling independent researchers and arms-length organizations to obtain government data and to analyze it against the backdrop of adopted goals and policies can help provide greater credibility to the policy development process generally, and to intergovernmental policy activity specifically.

Thus public understanding and debate can be enhanced by a greater flow of facts and analysis from respected private, academic, and government organizations that have a credible structure and history. Modern democratic governments are increasingly seeking to make the policy process more accessible and transparent to outside organizations and the public at large. The ultimate benefit is government decisions that are better understood and ultimately better supported through democratic political processes than would be the case with more closed, or even secretive, decisionmaking processes.

\section{Issue Resolution}

After a course of action has been approved and adopted, disputes may still arise-and they often do. In some cases the administrative, evaluative, and accountability functions will function well, with the result that a subsequent cycle, beginning with the identification of issues to be addressed, will automatically unfold.

In other cases resorting to a third party, be it a political, judicial, or other type of forum for mediation, conciliation, or arbitration, may be necessary. A third party should be used only as a last resort, however, because its use can imply a failure to agree through the normal processes. Most intergovernmental issues are fundamentally of a political, rather than judicial, nature and require negotiated compromise and agreement. Effective governance of a federation will be demonstrated by political resolution of intergovernmental conflicts, at both bureaucratic and political levels. Thus appeals to an outside authority such as the courts should be avoided when possible.

Other typically Canadian devices that have frequently been used to achieve and sustain intergovernmental agreement or joint action-in other words, to avoid the occurrence of disputes in the first place-have included the following

- Having a co-decision by qualified majority vote that is binding on all parties, as discussed previously, such as the rules for the Canada Pension Plan (CPP)

- Allowing a party to opt out or opt in under certain specified circumstances

- Allowing one specific party to go its own way if its nonparticipation does not affect the other parties, such as the province of Quebec's handling of university funding (Kennett 1998). 


\section{Establishment of Intergovernmental Machinery}

Usually the mechanisms and structures to carry out the functions just outlined are the result of both formal and informal arrangements. The myriad of combinations used in federations around the world may reflect the need for certainty and continuity, for flexibility, or for differing combinations of both. These may evolve, responding to changing pressures and subject to intergovernmental negotiations and mutual agreement. However, structures may also be determined, at least in part, by constitutions; international obligations, such as treaties; and other more formal influences and requirements.

\section{Constitutional Provisions}

National constitutions often specify revenue and expenditure assignments, but they sometimes do so with a degree of flexibility or a lack of clarity. Constitutions generally do not institutionalize elements of intergovernmental machinery, though some countries have extensive constitutional intergovernmental provisions. For example, South Africa has a relatively recent constitution that

- Establishes rules for revenue and expenditure assignment and borrowing

- Sets out government operational objectives through the provisions of the justiciable Bill of Rights

- Provides that the National Council of Provinces, which consists of provincial and local government representatives, has oversight in relation to particular pieces of legislation that concern intergovernmental arrangements

- Proclaims a commitment to cooperative governance

- Provides for a financial and fiscal commission to advise the national parliament, provincial legislatures, and local governments on intergovernmental fiscal arrangements

- Provides for (while simultaneously discouraging) access to the Constitutional Court for dispute settlement. ${ }^{3}$

Usually a nation has to manage its intergovernmental relations with less explicit guidance-let alone instruction - from its constitution.

Some nations can alter their constitutional arrangements more easily and frequently than others. In Canada, constitutional change is difficult, and therefore rare. For example, constitutional changes were approved in 1951 and in 1964 to allow the development of old-age security programs. One part of the system, which administers old-age security pensions and guaranteed income supplements for low-income elderly Canadians, now falls completely under the aegis of the federal government. Another part, the CPP, a wage-based contributory program, is administered nationally, but both federal and provincial ministers provide policy stewardship. Even the government of the province of Quebec participates, while administering the Quebec Pension Plan (QPP) apart from, but in a generally harmonized fashion with, the CPP. Tax harmonization has allowed for the third part of the pension system, in the form of tax-supported employer-employee and private retirement plans, to be developed in a similar fashion across Canada.

\section{Legislative Arrangements}

Legislation can be used to add new elements to the fiscal machinery. For example, the creation of statistical and monitoring agencies and their roles may be formalized through legislation, as Australia and Canada have done. 
Legislators may also pass bills to develop intergovernmental arrangements. Such bills commonly include rules of procedure or the establishment of committees to manage prescribed matters or provide advice about them. South Africa's parliament passed legislation to establish both the Budget Council and Budget Forum. The council discusses transfer payments, fiscal coordination, and other related issues with respect to provinces; the forum discusses local government issues. Both are only advisory bodies to the national minister of finance, and both have ministerial representation from the national and provincial governments. The Budget Forum also has local government representatives. Both the council and the forum have established committees of officials that parallel the ministerial body in composition, but these committees are not provided for within the legislation.

The national government may promulgate legislation even when the national and subnational governments are not in a hierarchical relationship; however broad acceptance by independent constituent bodies is necessary to make the arrangement work well. Legislation is more readily altered than constitutional provisions, and may indeed be easier to change than arrangements resulting from agreements. Of all the federations, the German model is the most formalized. State governments administer almost all federal legislation. To ensure that administrative realities are taken into account in the federal lawmaking process, the upper house of the federal parliament- the Bundesrat, which is composed entirely of delegates of state governments-must approve all federal laws.

\section{Intergovernmental Agreements}

Intergovernmental agreements, which typically are used to implement funding and other policy decisions, may also be used to establish intergovernmental arrangements for the performance of a variety of functions. These include consultation on identifying issues; preparation of common data and policy option papers; coordination, administration, and monitoring of issues; and the establishment of rules of procedure.

Proceeding with agreements that do not have the full and active support of participants is less likely to produce satisfactory, well-functioning machinery. In Canada the 1998 Social Union Framework Agreement attempted to establish a system to manage federal involvement in certain areas of provincial jurisdiction; however, without the full participation of the province of Quebec or the sustained commitment of the national government, the agreement's potential has not yet been fulfilled (Lazar 2000; Mendelsohn and McLean 2000).

\section{Established Forums}

An intergovernmental political body or a group of officials may carry out one or more of the kinds of activities reviewed earlier on either a one-time or regular, continuing basis. When these bodies are established on a longer-term basis, the accumulation of knowledge and experience can ease the burden on the agencies administering the affected programs. More longstanding arrangements may encourage clarity about the mandate, clear rules of participation, established patterns of working arrangements, ability to foster greater participation, and mentoring of new participants; however, such longer-term structures may or may not be open to new mandates, more effective working arrangements, or other new approaches and ideas that are generated externally. As in other areas of public administration, regular public reporting and mandated periodic reviews can help offset these risks, while retaining the benefits of sustained expertise and continuity.

\section{Government-Funded Agencies}

Governments frequently find that funding an outside agency rather than carrying out an activity through a government department is expeditious. Perhaps Russia does this more commonly 
than other countries, although Canada and other federations provide many examples. Often such arrangements can build in greater real or perceived independence. An outside agency may be more flexible and able to bring in expertise on a short-term project. The agency may also be able to develop a governance structure that is supportive and reflects the intergovernmental milieu in which it operates.

In Canada both federal and provincial governments have experimented with a variety of government-funded agencies. In the 1960s and 1970s the Economic Council of Canada played an influential role by providing information and analysis and shaping debates, but the Canadian government ceased funding it in the late 1980s as part of a wide-ranging, cost-cutting budget review. Some controversy also existed about the council's analysis of the politically sensitive issue of Quebec separatism. This serves as a reminder of the balance that must be struck between the independence of such agencies and the roles they are expected to play. It also illustrates the potential vulnerability of agencies that rely on only one source of financial support. The provincial government of Ontario also sponsored the Ontario Economic Council, which functioned for several years until the sole source of funding ceased.

The provinces have a longstanding Council of Ministers of Education, with its own secretariat, which has had some success in maintaining a more cohesive education policy across the country than might otherwise have occurred with 10 independent provincial jurisdictions in charge of education policy. Recently, the federal government established the Canadian Institute for Health Information to monitor developments in the health care system, which is administered by the provinces. The institute is a federal creation, but its role is to advise both levels of government.

Pursuant to intergovernmental discussions and agreement, the federal government created the Canadian Food Inspection Agency as a joint body that brings together pertinent aspects of both federal and provincial activity-involving several ministries at each level of government-in a cooperative effort to reduce overlap and duplication, clarify roles, and improve the efficiency of the multifaceted food inspection system across the country. Currently Canada has few such jointly sponsored and financed organizations. However desirable these organizations may be in concept, they are complex to set up and manage because of the need to span a wide range of governmental interdependencies, both across jurisdictions and across ministries within governments, as in the food inspection area.

\section{Nongovernmental Organizations and Ad Hoc Activity}

In North America private, academic, and service organizations frequently play a significant policy development and monitoring role with respect to intergovernmental relations and other important issues. They are often invited into the government process of decisionmaking and management. They may or may not accept some government funding, but interpersonal relationships between nongovernmental organizations and government agency officials are frequently close.

Specific issues may trigger new organizational activity and sometimes will generate the development of coalitions of stakeholders. Such activity may extend beyond the usual lobbying efforts centered around individual concerns. This ad hoc activity, often with media coverage, has on occasion generated significant pressure in relation to the development and management of intergovernmental relations in Canada.

Like other countries, Canada has hundreds of large and small organizations and interest groups that seek to influence both federal and provincial governments. Coalitions of taxpayers form because of concerns about tax structures and distribution, representatives of health care providers urge their preferences on health ministers, associations of universities and colleges press the federal government to increase research funding and provincial governments to 
improve facilities and increase support for faculty and students, and so on. In relation to such input from interest groups Shultz (1977, p. 394)) concludes:

Given the significance of intergovernmental negotiations to policy processes, and consequently the political fortunes of the participants, interest group participation is not without its costs. Although the federal system does provide many access points, groups who exploit them run the risk of being embroiled in intergovernmental conflicts, of being caught, as it were, in the vise of federalism.

Despite these complexities-and perhaps partly in response to the challenges they implyadvocacy groups have become more ubiquitous and sophisticated, and they help stimulate public debate across the spectrum of government activity. Governments are increasingly obliged to respond, both in private consultations and in public discourse with such organizations. This increasingly open interaction takes time and effort on the part of policymakers, and it requires governments at all levels to build these interactions into their policymaking processes, including intergovernmental processes.

\section{Political Party Processes}

In many federations, party policies strongly influence intergovernmental relations. In the United States, for example, the Democratic and Republican political parties operate at both national and state levels, with significant linkages between them. In others, such as Canada, the relationships are weaker. Thus the debate on the appropriate role of the federal and provincial governments may be a side issue (as is currently the case of the federal Liberal government) or may be central to the policies of the party (as with the Bloc Quebecois, a party of parliamentarians from Quebec, that advocates the separation of that province from Canada).

In countries where one party has control of both national and most subnational governments, such as the African National Congress in South Africa, internal party processes can often play a significant role in managing intergovernmental issues. In Germany and the United States the political parties are integrated at the federal and state levels, that is, the same party exists at both levels, but with different branches. In Canada the party system has evolved to the point where it is not integrated, and the provincial party systems are quite separate from the federal system. Thus party linkages play less of a role in integrating the system. In other federations with coalition governments, the alliances struck could entail power sharing, the introduction of bargaining over the conduct of intergovernmental relations, or both.

The more the electoral fortunes of competing political parties ebb and flow so that governments or coalitions change frequently, the greater the need for independent, professional civil servants who maintain the processes of communication, interaction, and operational coordination across levels of government. In a sense, the expertise and continuity of intergovernmental relations at the level of civil servants permits more variable political change across a federation. Put another way, frequent changes in political leadership, especially at the regional or provincial levels where many governments may face elections at variable times, can create considerable disruption to intergovernmental policy development and cooperative management without the anchor of well-functioning processes maintained at the staff level.

\section{Judicial Processes}

When constituent governments resort to the courts, it is usually on matters of interpretation of laws. Courts rarely overturn nationally legislated decisions, with exceptions related to the application of rights or transgression of constitutional provisions. Governments in Canada, depending on the soundness of their legal advice, have tended to use the option of going to 
court as one among a variety of strategic instruments to achieve their goals. Nonetheless, courts tend to impose winner-take-all solutions, often with longer-term consequences in terms of constitutional balance. Thus Canadian governments will normally choose negotiated solutions if conditions permit. Court systems are often structured differently in different federations, which in turn probably influences attitudes toward and uses of them by governments as well as by citizens and organizations.

\section{Fiscal Federalism Mechanisms in Canada}

Canada has a well-developed set of intergovernmental institutions and arrangements that was built during the 20th century, especially during the second half of the century (after World War II), as government roles grew generally and subnational governments took on increasingly important roles. An examination of the institutions and processes as they relate to key functions in maintaining federal fiscal arrangements in Canada is useful, but note that intergovernmental relations on financial issues, although important, may not always be typical of intergovernmental relations across the board in Canada. They are more routine, more technical, probably more professionally oriented, and less overtly political than other areas of intergovernmental cooperation and conflict.

\section{Information}

Two specific institutional arrangements for the development and provision of information and data in Canada provide critical underpinnings for the work of government generally and for fiscal federalism issues specifically, namely: Statistics Canada and the federal-provincial Committee on Economic and Fiscal Data.

StATISTICS CANADA. Statistics Canada is a federal government agency with an international reputation for providing accurate and unbiased demographic, economic, and fiscal data. That reputation has been built on specific legal and institutional characteristics and policy norms, including

- A specific statutory basis for the statistical agency

- An executive director (with deputy minister status) who has control over the agency's budget and other matters

- The maintenance of autonomy over the statistical system, including data collection, system design, and data dissemination

- An adherence to internationally recognized scientific norms in data gathering and presentation

- A data gathering system that protects individual and corporate privacy and confidentiality

- A tradition of transparent decisionmaking

- A separate public profile

- A nonpolitical objectivity in relation to who has access to data, which is available to all the governments in the federation based on the provisions of the 2001 FederalProvincial Fiscal Arrangements Regulations.

In general, Statistics Canada data are essential for economic and fiscal management. More specifically, the chief statistician of Canada plays an important role in determining federal transfer payments to provinces. Under section 2 of the 1985 Federal-Provincial Fiscal Arrangements Act, the chief statistician has the authority to determine the populations of the provinces and territories for the calculation of transfer payments and to determine their gross domestic products for use in establishing escalator provisions. In the regulations accompanying the act, the chief statistician must present a certificate setting out data related to provincial revenues to 
be equalized, including population and gross domestic product figures, prior to a final computation being made with respect to the Fiscal Equalization Program. By meeting these information needs, Statistics Canada's independence is crucial in reducing or avoiding potential conflict between the provinces and the federal government.

Committee on Economic And Fiscal Data. The federal-provincial Committee on Economic and Fiscal Data meets twice a year and plays a useful role in ensuring that the framework for collecting and analyzing data is applied on a consistent basis across Canada. For example, its financial management system of accounts provides a system that takes disparate public accounts data of the federal and provincial governments and transforms them into a more comparable set of statistics. The committee also plays a role in projecting economic and fiscal results based on budgets and other information.

\section{Technical and Policy Options}

Federal and provincial finance departments maintain a number of joint committees to produce technical analyses and policy options with respect to fiscal arrangements. These include the Fiscal Arrangements Committee, which includes the Technical Committee on Transfers; the Taxation Committee; the CPP/QPP Committee; and the senior committee of deputy ministers, which is called the Continuing Committee of Officials.

Fiscal ArRangements CommitTeE. The Fiscal Arrangements Committee is composed of assistant deputy ministers from the federal government and all the provinces and territories and generally meets twice a year. Most participants enjoy direct access to their ministers and deputy ministers and can therefore present their governments' positions during discussions. Their task is to develop policy options for ministerial decisions with respect to major issues involving the Equalization Program, as well as the Canada Health and Social Transfer Program and other major transfer programs. They draw on the expertise of the Technical Committee, and some members participate in the meetings of both committees.

Issues that the Fiscal Arrangements Committee addresses include basic methodologies to be used for the distribution of transfers; adequacy and affordability issues that translate into standards, floors, ceilings and other parameters; and contentious technical issues that the Transfers Committee does not resolve. The Fiscal Arrangements Committee develops options that are usually considered by ministers, although some vetting might occur by deputy ministers through the Continuing Committee of Officials.

TeChNiCAl COMmitTEE ON TRANSFERs. The Technical Committee's primary responsibility is to consider the detailed operations of the Canadian Equalization Program. It meets approximately four times a year and circulates documents between meetings. Members discuss the methodology for the Equalization Program and, in particular, the modeling of the representative tax system. Therefore they must bring to the forum in-depth knowledge of the provincial tax bases and techniques for developing proxy or melded bases, necessary when provincial tax regimes have different profiles.

The national government has the largest staff involved in this work and generally prepares initial discussion papers; however, the provincial members frequently prepare alternative discussion papers or work with their federal counterparts to develop the discussion papers. All committee members participate in the consideration of these papers. Their specialized knowledge and expertise is concentrated within the committee, therefore the committee's decisions with respect to these technical aspects are rarely challenged.

The Technical Committee addresses administrative issues, such as payment schedules, when necessary. It provides guidance and advice to the more senior Fiscal Arrangements 
Committee regarding the effects or impacts of adopting different methodologies and standards and other issues requiring policy decisions.

TAXATIOn Committee. The Taxation Committee discusses issues of tax policy, administration, and harmonization. As many tax fields (income taxes, sales taxes, various commoditybased taxes, and so on) are shared between the national and subnational governments in Canada, the actions of one can have a significant effect on another. The national Canada Customs and Revenue Agency collects personal and corporate income taxes on behalf of most provinces, although three large provinces administer their own corporate income tax and Quebec administers its own personal income tax.

In the 1990s the Taxation Committee assisted in the transition of the federal manufacturers sales tax into a value added tax, named the goods and services tax. Federal leaders hoped provinces would join them and create a Canada-wide, harmonized sales tax by integrating their provincial retail sales taxes into a more comprehensive goods and services tax. Because of administrative and policy differences, however, only three Atlantic provinces joined the federal government in a harmonized sales tax. The federal government administers this tax. In Quebec the provincial government administers the harmonized sales tax system. Ontario and three of the four western provinces levying general sales taxes (Alberta has no such tax) did not choose to join in the harmonized system.

Effective tax administration requires some coordinated action between governments. The Taxation Committee addresses issues of tax sharing, tax evasion though loopholes, and smuggling with the objective of helping to achieve coherent and mutually compatible tax actions by the two orders of government. As with the Fiscal Arrangements Committee, the recommendations of the Taxation Committee are generally submitted directly to ministers for their decisions, with the Deputy Ministers' Committee participating somewhat more actively in this area than with Fiscal Arrangements Committee issues.

CPP/QPP COMMITTEE. Constitutional changes transferred the administration of old-age security programs-which had been an exclusively provincial jurisdiction-from the provinces to the federal government. Nevertheless, the subsequent legislation establishing the CPP provided for joint policy administration by the two levels of government. Quebec maintained its own pension plan, the QPP, but it has consistently harmonized rates and benefits, though not investment policy, with the CPP. Ministers created the CPP/QPP Committee to make recommendations with respect to rates, benefits, and other administrative policy matters. Recently the independent CPP Investment Board was created, with a process allowing for provincial input into the federal appointment of board members. Recommendations of the CPP/QPP Committee are also directed to the federal-provincial meetings of ministers. As noted previously, a co-decision rule under legislation establishing the CPP means that major features of the plan may be changed only with a qualified majority of the parties. In this case, there must be agreement from the federal parliament plus 7 of the 10 provinces, which must make up at least half of the Canadian population. The CPP/QPP Committee is the main formal forum for the exchange of views and provides an indication of how each government might vote on any proposed changes.

Continuing Committee of OfFicials. The deputy ministers of finance from the federal, provincial, and territorial governments form the Continuing Committee of Officials. The committee receives the reports and recommendations of the economic and fiscal data committees, the Fiscal Arrangements Committee, the Taxation Committee, and the CPP/QPP Committee. In the past, the Continuing Committee of Officials played a significant role in resolving issues arising in any of the aforementioned committees. In recent years, however, its primary role has been to prepare for meetings of ministers by establishing the agenda, rehearsing the positions 
to be taken into the meetings, and providing ministers with necessary information with respect to options, recommendations, and the positions of other jurisdictions. This work ensures that the limited time of ministerial meetings is used in the most productive fashion.

A recent development in the transfers area has been the holding of one-day workshops involving both officials and invited academic experts who present and discuss papers relating to the policy interests of the Continuing Committee of Officials. The committee then holds its regular meeting without the outside academics or other guests present, perhaps on the next day. This allows government officials to hear from the experts and debate issues without prejudice to the positions they might adopt inside their committee, while the academics gain a better appreciation of the current issues and priorities being examined inside government.

FunCtIONING OF THE COMMITTEES AND SubCOMMITTEES. The foregoing committees and subcommittees typically carry out their work behind closed doors. In contrast to the more open U.S. congressional committee processes, they are not part of the public policy dialogue among citizens, outside organizations, the media, and the government. However, they have access to, and are informed by, outside expertise from universities, private agencies, think tanks, and other organizations. The committees review the work of these groups, participate with them in public workshops and conferences, and sometimes consult with them on specific issues.

\section{Political Forums and Decisions}

The administration of Canada's major fiscal arrangements is generally the responsibility of the ministers of finance, who also deal with fiscal policy coordination and discuss monetary issues. However, with respect to major changes or new programs, first ministers (the prime minister and provincial and territorial premiers) may also be involved.

Federal, Provincial, AND Territorial Ministers MeEtings. Federal, provincial, and territorial ministers of finance traditionally met twice a year, and more frequently if major changes to programs were under consideration, but in recent years they have met less frequently. This may be because the 1990s became a period of severe fiscal restraint by most governments, and this included significant reductions in federal transfers to provinces. Relationships became strained, and political posturing over these cutbacks created a more difficult environment for meetings at the ministerial, and thus also the deputy minister, level. Recent improvements in the federal budget have resulted in some recovery of transfers, although not to the extent demanded by provinces. Under these conditions one might expect-or at least hope for-a return to more "normal" relations, with ministers and deputies resuming their former rhythm of more frequent and collegial meetings.

Traditionally, ministerial meetings held well in advance of the federal budget (normally announced each year in February) have been viewed as opportunities for provincial and territorial governments to influence federal budgetary decisions. Provincial budgets have usually followed the federal one, and they are often influenced by the federal budget and any consultative meetings that preceded it. Similarly, meetings after the passage of all budgets are regarded as opportunities to take stock of the aggregate set of decisions and the evolving state of the economy in preparation for the next budget cycle.

Officials at these meetings may address the options and recommendations arising from the work of the Technical, Fiscal Arrangements, Taxation, and CPP/QPP committees. Finance ministers attempt to reach consensus, although in most instances the final decisions lie with the federal minister of finance and the national government. Thus the ministerial meetings serve for the most part as an exchange of information and an attempt to coordinate broad policy goals or persuade others of a course of action. However individual governments almost always make 
final fiscal decisions in the context of provincial budget statements made in their own legislatures (or in parliament in the case of the federal government).

Separate Provincial and Territorial Ministers MeEtings. In recent years provincial and territorial ministers of finance have begun to meet frequently with each other. In the early 1990s western finance ministers also began to meet separately and prepare annual public reports on issues of common concern. These reports soon had an impact on the national agenda. After this development, the Atlantic provinces began to assert their interests as a block. More recently still, the provincial finance ministers have undertaken studies and arrived at consensus positions to be taken to the federal-provincial forum.

MEETINGS OF FIRST MiNISTERS. First ministers also maintain their own ongoing forums, but these have typically been less frequent and more ad hoc than the finance ministers' meetings. Their agendas and frequency depend on the political will and priorities of the prime minister. Some recent Canadian prime ministers, such as Brian Mulroney (1984-93), preferred intensive use of first ministers' meetings. Others, such as the current Prime Minister Jean Chretien, prefer to meet premiers in more informal circumstances or bilaterally. In addition to an irregular pattern of meetings involving all first ministers, annual premiers' conferences and regional premiers' conferences involve only the provinces and territories.

Each jurisdiction has an intergovernmental affairs office. In the provinces, this office is often within the office of the premier; in the federal government it is part of the Privy Council Office, which serves both the prime minister and a federal minister for intergovernmental affairs. The first ministers' meetings and the intergovernmental affairs offices deal with all matters of coordination of activity between the levels of government and among the provinces.

In 2000 federal improvements to funding for provincial social programs were offered by the prime minister at a first ministers' meeting, rather than by the federal finance minister, who had not met his colleagues except on a regional or bilateral basis in more than a year. Perhaps this was partly a reflection of the fact that the finance minister had become the bearer of bad news during the earlier fiscal restraint period, whereas the first minister was allowed the luxury of presenting good news. Whatever the case, this serves as an example that the availability of both first minister and finance minister forums provides useful flexibility in handling major-and sometimes contentious-issues of national importance.

ROYAL COMMISSIONS. The establishment of royal commissions by the federal government and the issuing of white or green papers on policy issues by federal or provincial governments are occasionally used to generate broad public policy debates. One major example was a recent multiyear royal commission on aboriginal affairs, and another, more recent, example concerned Canada's health care system, conducted by a former provincial premier, Roy Romanow of Saskatchewan.

\section{Administration}

The amounts and flows of funds resulting from intergovernmental fiscal arrangements in Canada are primarily formula driven. With excellent, reliable data from Statistics Canada, administrative issues have focused largely on estimations and timing. Advance payments for the Equalization Program, for example, rely on federal estimates of the coming year's revenues, based on economic and demographic forecasts. Adjustments are made when revised data, based on actual results and for up to a three-year extension period, become available. The same process of advance payments based on federal estimates, with adjustments for actual collections, applies to personal and corporate income taxes administered by the federal government on behalf of the provinces. These retroactive adjustments can be quite large, and they may have 
a somewhat destabilizing impact with either positive or negative surprises for provincial government financing. This has been an issue for intergovernmental discussion from time to time.

Another issue, which may fall into the administration category, is the treatment of tax room ceded by the federal government to provinces 25 years ago. (Tax room refers to tax reductions enacted by one government, with the idea that the other government could step in and increase its tax, that is, take up the "room" created by the reductions while preserving the same total tax burden as before.) Both levels of government claim credit for these revenues as part of their support for health care, postsecondary education, and other social programs. The federal government argues that its tax reduction was an agreed form of a federal de facto contribution to support the designated program areas, while the provinces claim that they are now raising the revenues as part of their own tax system. This lack of clarity-and conflicting political claimscreates some confusion, so that public understanding of who is responsible and accountable for what is sometimes blurred. Perhaps this provides a reminder that in any federation, clear information and public understanding are a challenge. The potential for ambiguity is always present, underlining the need to nurture an informed electorate.

\section{Government-Funded Agencies}

The government recently transformed the federal Department of National Revenue, which focuses on customs administration and tax collection, into an independent corporation. Renamed the Canada Customs and Revenue Agency, it has more flexibility than under the previous tax collection agreements to collect revenues for both the federal and provincial governments in accordance with provinces' increasingly independent tax policies and preferences.

\section{Nongovernmental Agencies}

Canada also has a significant number of private, academic, and social agencies that are influential in developing technical and policy options in the area of intergovernmental arrangements, including fiscal arrangements. Many of these institutes, such as the Institute of Intergovernmental Relations at Queen's University, the Economics Association of Canada, and the Saskatchewan Institute for Public Policy, are based in the academic community. Privately financed institutes, such as the C. D. Howe Institute, the Caledon Institute, the Fraser Institute, the Atlantic Institute for Market Studies, and the Canada West Foundation, may be national or regional in their perspective.

\section{Grassroots Associations}

Another interesting category of entity, which may be gaining in importance, is what might be referred to as grassroots or bottom-up associations. Such organizations include associations of municipal governments and school boards at the provincial or national levels and social planning councils. Should Canada mimic the worldwide trend toward a growing assignment of responsibilities to local governments, these associations may become increasingly influential.

\section{The Russian Context: Center-Regional Fiscal Relations in Transition}

Russia is still going through a period of transition in its center-regional fiscal relations. Officials continue to define expenditure responsibilities and make changes in the assignment of revenue sources. These changes in turn have required changes to the nation's Equalization Program and compensation fund to address vertical and horizontal fiscal imbalances. Each of these changes is being made as the country's fiscal circumstances begin to improve. As Martinez-Vasquez and Boex (2001) note, a rapid pace of transition and reform is being planned and implemented. This 
is apparently being managed by a cadre of officials in the national capital who have good knowledge of fiscal federalism principles and practices. These individuals work in both the formal government sector and in various high-quality institutes. However, they face a daunting challenge in trying to address the issues of intergovernmental fiscal relations in this vast country with its many and diverse regional and local governments. Moreover, it is clear that not all the regions match their expertise.

The establishment of seven federal districts and the appointment of presidential representatives to these districts by President Vladimir Putin add a new element to center-regional relations. Nevertheless, districts' legal status and roles are still somewhat vague and may be evolving (Avtonomov 2001).

As Russia proceeds through this period of transition, its center-regional fiscal relations may be shaped to a large degree by its emerging fiscal circumstances. If recent history is any guide, constitutional, legislative, and other less formal arrangements will continue to evolve. The institutional framework must be developed and professional bureaucratic capacities nurtured at both the national and subnational levels if the advantages of decentralization are to be realized.

\section{Checklists and "Audits" as Evaluation and Planning Tools}

This chapter has outlined a range of functions for intergovernmental institutions: development of issues; information gathering and analysis; preparation of technical and policy options; policy adoption and implementation; and coordination of tasks related to administration, monitoring, evaluation, and ensuring accountability. These tasks may be fulfilled by a number of intergovernmental institutions established by the constitution, legislation, agreements, or less formal means. There is no one best structure for all federations, but once all the constituent parts of the system have been set up, the job of managing federal fiscal arrangements must be carried out effectively and efficiently, and supportive mechanisms and expertise are essential.

Obtaining a full view of how a system functions in a federation may be difficult. To assist in an examination of a federal system, an intergovernmental audit could be useful. The audit would involve a review of the component parts of the system. It could also yield an assessment as to how well each of the functions is performed, bearing in mind that different people will have different perspectives concerning the system. In particular, there may well be differences between the perspectives of those in the regions and those working in the national government, as well as between those outside the formal government structure and those inside it. The discussion of such differences is a healthy step toward strengthening the intergovernmental processes.

No unique best system exists. The importance of doing an audit and discussing the results is to identify how constituent parts of the system might be added, strengthened, restructured, or made to fit with other parts more effectively to better address identified needs. In particular, there could be some potential to compensate for a deficiency in one area-be it constitutional vagueness, the lack of legislation, political discord, an inadequate civil service, or some other weakness-by using any other part of the available system. For example, a strong political forum, legislation, or agreements might satisfy certain needs of the system. Quasi or nongovernmental organizations might be equipped to do some of the data gathering, analysis, and development of policy options that elsewhere are done within national or subnational governments. It may not matter which part of the system carries out the function as long as the work is being done capably and is feeding into and from the rest of the intergovernmental system. The audit should determine whether the existing structure is up to doing the job or if functions need to be shifted, supplemented, or in other ways strengthened. 


\section{Conclusion}

Federations are complex and each is unique. The systems for conducting intergovernmental fiscal relations must reflect such complexity and diversity. Dupre $(1985$, p. 1) examined the Canadian system for the MacDonald Royal Commission and wrote that "federal-provincial relations have become so varied and complex that they defy generalization." However, officials in every system need to perform a range of common or "generic" functions, as described in this chapter. Many elements of a complete system may already exist, including institutions and expertise, and these can be drawn upon to help build or strengthen new structures.

There are no absolute prescriptions for the conduct of intergovernmental relations. However, assessing the role and effectiveness of the entire system against the list of tasks that must be accomplished could suggest areas that need to be strengthened and potential avenues for filling in gaps in the development, implementation, and administration of policy.

Canada's system of intergovernmental relations has evolved over a long period. With the possible exception of the year after World War II, when Canada's social programs grew rapidly, the pace of change in Canada has been much more gradual than that occurring today in Russia. The processes of policymaking in this changing environment may be as important to the cohesion of the nation as the content. A well-functioning system of intergovernmental relations will be staffed with competent participants, working with a common set of information, within known processes and structures.

Continuity of people and their efforts, mutual respect, and shared experiences create the teamwork to pursue the development of policy in an effective federal system. The gradual building up of working practices, along with expertise in all governments, is critical for the successful implementation of government mandates and policies. Clarifying those mandates and designing good policy constitute only one side of the good governance coin. Equally important and necessary for success are well-designed and well-attended structures and processes by which policies are interpreted, programs administered, disputes settled, and tensions resolved, competently and peacefully. In a federation, all levels of government must participate.

\section{References}

Avtonomov, Alexei. 2001. "Putin's Presidential Representatives: One Year Later." Federations: What's New in Federalism Worldwide. 1(4).

Bird, Richard A. 1986. Federal Finance in Comparative Perspective. Toronto: Canadian Tax Foundation.

- 2000. A Perspective on Fiscal Federalism in Russia. Toronto: C. D. Howe Institute.

Bird, Richard M., Robert D. Ebel, and Christine I Wallich, eds. 1995. Decentralization of the Socialist State: Intergovernmental Finance and Transition Economies. Washington, D.C.: World Bank.

Breton, Albert. 1990. Centralization, Decentralization and Intergovernmental Competition. Kingston, Ontario: Queen's University, Institute of Intergovernmental Relations.

Brock, Kathy. 1995. "The End of Executive Federalism?" In F. Rocher and Miriam Smith, eds., New Trends in Canadian Federalism. Peterborough, Ontario: Broadview Press.

Brown, Douglas, M. 2002. Market Rules: Economic Union Reform and Intergovernmental PolicyMaking in Australia and Canada. Montreal: McGill-Queen's University Press.

Desautels, L. Dennis. 1999. “Accountability for Alternative Service-Delivery Arrangements in the Federal Government: Some Consequences of Sharing the Business of Government." In 
Susan Delacourt and Donald G. Lenihan, eds., Collaborative Government: Is There a Canadian Way? Toronto: Institute of Public Administration.

Dupre, Stefan J. 1985. "Reflections on the Workability of Executive Federalism." In Richard Simeon, ed., Intergovernmental Relations. Toronto: University of Toronto Press.

Financial and Fiscal Commission. 2000. Recommendations for 2001. Halfway House, South Africa.

Kennett, Steven A. 1998. Securing the Social Union: A Comment on the Decentralized Approach. Kingston, Ontario: Queen's University, Institute of Intergovernmental Relations.

Kernaghan, Kenneth, and David Siegel. 1995. Public Administration in Canada, 5th ed. Toronto: Nelson.

Lazar, Harvey. 2000. "The Social Union Framework Agreement and the Future of Fiscal Federalism." In Harvey Lazar, ed., Canada: The State of the Federation 1999/2000: Toward a New Mission Statement for Canadian Fiscal Federalism. Kingston, Ontario: Queen's University, Institute of Intergovernmental Relations.

Martinez-Vasquez, Jorge, and Jameson Boex. 2001. Russia's Transition to a New Federalism. Washington, D.C.: World Bank.

McEwin, Marion. 2000. "Improving the International Statistical System." Occasional Paper. Academy of the Social Sciences in Australia, Canberra.

McRoberts, Kenneth. 1985. “Unilateralism, Bilateralism, and Multilateralism: Approaches to Canadian Federalism." In R. Simeon, ed., Intergovernmental Relations. Research Studies of the Royal Commission on the Economic Union and Development Prospects for Canada, vol. 63. Toronto: University of Toronto Press.

Mendelsohn, M., and John McLean. 2000. “SUFA's Double Vision: Citizen Engagement and Intergovernmental Collaboration." Policy Options 21(3): 43-5.

Ostrom, Elinor. 1990. Governing the Commons: The Evolution of Institutions of Collective Action. Cambridge, U.K.: Cambridge University Press.

Ostrom, Vincent. 1987. The Political Theory of the Compound Republic: Designing the American Experiment. Lincoln, Neb.: University of Nebraska Press.

Painter, Martin. 1998. Collaborative Federalism: Economic Reform in Australia in the 1990s. Melbourne: MacMillan.

Pollard, Bruce. 1986. Managing the Interface: Intergovernmental Affairs Agencies in Canada. Kingston, Ontario: Queen's University, Institute of Intergovernmental Relations.

Shultz, Richard. 1977. "Interest Groups and Intergovernmental Negotiations: Caught in the Vice of Federalism." In J. Peter Meekison, ed., Canadian Federalism: Myth or Reality, 3rd ed. Toronto: Methuen Publications.

Simeon, Richard, ed. 1979. Confrontation and Collaboration: Intergovernmental Relations in Canada Today. Toronto: Institute of Public Administration.

Smiley, Donald V. 1979. “An Outsider's Observations of Federal-Provincial Relations Among Consenting Adults." In Richard Simeon, ed., Confrontation and Collaboration: Intergovernmental Relations in Canada Today. Toronto: Institute of Public Administration.

Sproule-Jones, Mark. 1993. Governments at Work: Canadian Parliamentary Federalism and Its Public Policy Effects. Toronto: University of Toronto Press. 
Watts, Ronald L. 1989. Executive Federalism: A Comparative Analysis. Kingston, Ontario: Queen's University, Institute of Intergovernmental Relations.

. 1999a. Comparing Federal Systems. Kingston, Ontario: McGill-Queen's University Press.

1999b. The Spending Power in Federal Systems: A Comparative Study. Kingston, Ontario: Queens University, Institute of Intergovernmental Relations.

Wright, Deil S. 1998. “Federalism, Intergovernmental Relations and Intergovernmental Management: The Origins, Emergence, and Maturity of Three Concepts across Two Centuries or Organized Power by Area and Function." In J. Rabin, ed., Handbook on Public Administration. New York: Marcel Dekker. 



\title{
Fiscal Flows, Fiscal Balance, and Fiscal Sustainability
}

\author{
Richard M. Bird
}

The search for fiscal indicators to provide a shorthand, and preferably quantitative, picture of the size, direction, and nature of intergovernmental finance-and ideally some guidance for policy designed to improve outcomes-appears to be endless. For example, fiscal balance and fiscal sustainability are terms commonly heard in discussions of intergovernmental fiscal relations. These concepts sound like good things, and policymakers or analysts often suggest policies that are intended to achieve them. Fiscal flows are perhaps less prominent in policy discussions, but this notion too is often very much in the minds of some of those engaged in such discussions. Indeed, in practice much of the discussion of both fiscal balance and fiscal sustainability often reduces to assertions about the current and projected future course of fiscal flows. The aim of this chapter is to provide an overview of the uses and limits of these three approaches to measuring and interpreting the problems and progress of fiscal decentralization.

The next section argues that measuring fiscal flows is conceptually difficult, inherently subject to considerable political bias, and, in any case, is of surprisingly little use or relevance in determining good policy. I then go on to argue that the notion of fiscal balance is also seldom clearly defined; that it often seems to be confused with other, and quite separable, policy objectives; and that it is of surprisingly little analytical or policy relevance. In contrast, I note in the following section that fiscal sustainability can have a clear analytical meaning, and that if defined properly this concept can provide a useful, if limited, guideline or framework for policy. Unfortunately, even good fiscal sustainability analysis does not take us far along the road of analyzing and understanding intergovernmental fiscal relations. Thus in the concluding section I suggest that, while much can and should be done to improve the quantitative picture of intergovernmental fiscal relations, as a rule careful institutional and empirical analysis seems more necessary than such broad indicators, however carefully calculated, if we are to discover and fully understand the situation (for an illustration of the complexities involved even in industrial federal countries see Bird and Tarasov 2002).

Although some points in this chapter are illustrated by reference to particular countries, the chapter makes no attempt either to provide a full analysis of all the measures mentioned in this chapter for any one country or to provide comparable measures within or across countries. Its aim is less to tell analysts or policymakers what they should do to measure, say, fiscal balance, than to argue that looking to such simple quantitative indicators to reveal the directions of needed policies is inherently futile. Instead, much more specific institutional analyses focused on real policy goals and real policy problems are generally needed.

\section{Fiscal Flows}

Regional fiscal flows are usually intended to measure the redistribution of income among regions that results from tax and expenditure policies. In these terms, a region experiences a favorable fiscal flow if its income (in reality the income of its residents) is raised more by the impact of government spending than it is reduced by the taxes borne in the region. The most extensive discussion in English of intergovernmental finance in Russia (Lavrov and Makushkin 2001), for example, is concerned almost entirely with the analysis of inter-regional fiscal flows. 
The data presented in this study are interesting, and the study as a whole is an important contribution. Much the same can be said of a detailed study of flows at the subregional level in the Leningrad region (Bahl and others 1999). Similar studies have also been carried out in other countries from time to time, for example, see Advisory Commission on Intergovernmental Relations (1980) for the United States, Bird (1984) for Colombia, and Leslie and Simeon (1977) for Canada.

Fiscal flow data are not easy to obtain, and often require substantial effort to construct. ${ }^{1}$ It is thus perhaps understandable that once the hard work of estimating such flows has been accomplished, basing policy conclusions on them is tempting. The temptation to do so should, however, be resisted, because such numbers, though generally well used descriptively in the studies cited, can, unless care is taken, be highly misleading as a guide to policy. The balance of this section explains why this is so (portions of this section draw on an earlier discussion of some of these issues in Bird 1984, appendix II).

\section{Analyzing Geographic Incidence}

Fiscal flow analysis essentially has two levels of problems: conceptual and practical. Even though the task of measuring the size of regional fiscal flows might seem to be simple and straightforward, serious conceptual problems in the exercise and critical gaps in the database are common. As a rule, for instance, such analysis assumes, often implicitly, that taxes collected within a territory are paid by the residents of that territory. This assumption is often wrong. For example:

- Port cities do not pay-in the only economically meaningful sense of reduced private incomes for their residents-customs duties that are collected on shipments in transit to inland destinations.

- Those who live near a distillery that ships most of its product outside the jurisdiction do not pay the taxes the distillery remits to the government.

- Citizens of the region in which a company's headquarters is located do not pay all the taxes that company pays.

Tax incidence analysis is no doubt an arcane and arguable art, but its intricacies and inherent problems cannot be simply neglected, as is too often the case in flow analysis. Moreover, the data needed to trace the real inter-regional effects of product (and perhaps factor) taxes are seldom, if ever, available, largely because good data on cross-border flows of either products or factors within national boundaries are seldom available.

Similarly, on the expenditure side it should not simply be asserted that expenditures that take place in a particular geographic area actually benefit the residents of that area. For example:

- Are all the benefits (as measured by the cost of the project) of an interstate highway received by those who live beside the road?

- Do the benefits of expenditures on public sector activities accrue to those who receive incomes as a result (such as teachers) or to those who receive the services provided (in this case students)?

- Are the "benefits" received by the factors of production employed by the government only short run and those received by the presumed ultimate beneficiaries long run?

1. In many countries, even industrial countries, such information is often impossible to obtain below the level of intermediate (regional) governments. In the 1970s, for example, I worked for a trilevel commission on public finance in Canada that labored in vain for more than a year to carry out an acceptable fiscal flow analysis at the local level. 
- What is the time frame of the analysis?

- Are benefits equal to costs? ${ }^{2}$

- How does one allocate the benefits of public goods?

Such questions generally do not have easy or obvious answers and are even harder to answer in a regional context. A region is, in effect, a small, open economy that has extensive economic linkages with other regions. The central government may, for example, spend extensively in a certain region (directly or through transfers), but the effects of that expenditure may be felt throughout the economy as a result of the network of inter-regional trade and factor flows. Reliable data on such flows are rare. Even worse, spillovers from region to region of both expenditures (the factor incomes paid out, for example) and benefits (the services provided) may take place. Such spillovers are diffuse, complex, and difficult to measure even in principle, let alone in practice.

Such problems do not mean that measuring geographic incidence is impossible in principle or practice, but they do imply that doing so meaningfully requires more detailed data than usually exist as well as strong assumptions about issues that are inherently highly uncertain. One can certainly assign taxes and expenditures on a regional, or even a local basis, if one is willing to make such assumptions, but there are no universal rules that determine the appropriate assumptions for a particular country and time (for a recent interesting study of the United States that illustrates both what can be done and what assumptions are needed to do it see Sehili and Martinez-Vazquez 2002). The results of such analyses, even the most careful ones, are thus always suspect to some extent. More important, precisely because of its inherent subjectivity, flow analysis is all too subject to manipulation for political purposes.

To add to the problems, because of data limitations many flow studies, for example, Lavrov and Makushkin (2001), cover only part of the flow of intergovernmental revenues and expenditures. While understandable, this approach implicitly assumes that nonincluded flows have equal per capita effects everywhere, an assumption that is almost certain to be wrong. Ideally, one should also take into account the possibly offsetting regional effects of such "invisible" transfers as those through price controls and subsidies, tax expenditures, and controlled credit allocations (Bird and Chen 1998b), and a variety of nonfiscal public policies, such as regulation. To do so, however, is so difficult a task, even in the most data-rich countries, that apparently no one has ever managed to do it. The picture that even the best fiscal flow analysis paints of reality is therefore inevitably partial, and hence inherently flawed to an unknowable extent.

\section{Interpreting Regional Flows}

Even in the improbable case that the methodology of a flow study is beyond question, what do the results mean? Usually, as in the fiscal balance studies discussed in the next section, such studies are interpreted as showing that one region is paying too much or too little or receiving too much or too little. The usual policy recommendation drawn from such analysis is that this imbalance should be corrected, usually by allowing the generating regions to keep more of what they produce in terms in revenue. Attractive as such a conclusion may be to those regions, it is illogical. The aggregation of people into territorial units has little to do with the factors determining the allocation of most flows.

Suppose, for example, that each region were joined to one of its neighbors, that absolutely nothing else changed, and that fiscal flows were then re-estimated. The results would, of course, be quite different, generally with less measured inequality in the regional balance of revenues and expenditures, even though the reality has not changed. To illustrate, take this

2. Even if resources are optimally allocated, which is unlikely in reality, such equality prevails only at the margin, not in total terms. 
example to its limits and unify all territories into one. All regional differences have now been eliminated because there are no regions, but nothing has changed in reality because, by assumption, all spending and taxing is continuing in exactly the same way as before. Box 4.1 reinforces this point.

Despite its many methodological problems, fiscal flow analysis may nonetheless sometimes provide a useful framework within which to assemble data from diverse and scattered sources (which is essentially what Bahl and others 1999 and Lavrov and Makushkin 2001 do for Russia). From a policy perspective, however, the analysis of fiscal flows appears to be essentially a dead end. It is hard to see what one can learn from even the best fiscal flow analysis other than that the geographic incidence of taxes and expenditures-assuming one thinks, improbably, that such incidence is known with sufficient certainty-is unlikely to be neatly balanced within particular jurisdictional boundaries. Of course, why anyone would expect or want it to be so balanced is not obvious, which leads us to the next section.

\section{Fiscal Balance}

Some degree of fiscal imbalance seems inherent in countries with more than one level of government (much of the discussion in this section is based on Bird and Tarasov 2002). As a rule, central governments tend to collect most taxes while state and local governments are often responsible for more expenditures than they can finance from sources of revenue directly under their control. The resulting difference between expenditures and own source revenues at different levels of government is called vertical fiscal imbalance (VFI). At the same time, within each subnational level of government invariably some jurisdictions are richer than others. The resulting difference in the resources available to governments at the same level is called

\section{Box 4.1 Balance-Sheet Federalism in Canada}

In Canadian political debate adding up all the taxes paid by a region on one side and the transfers and services received on the other side and drawing conclusions from such calculations about who wins and who loses is common. For example, a prominent Alberta academic argued that Albertans are the major net contributors to Canadian federalism and that most other provinces-and by extension the people in them-were "on the take" (Flanagan 2001). Around the same time Quebec's premier argued that Quebec and its people were on the losing side of the federal fiscal equation, a view that the federal minister of intergovernmental affairs strongly rebutted (Dion 2001). (For earlier gorounds in this fight see Leslie and Simeon 1977.) As argued in the text, however, all such calculations are inherently theoretical and rely heavily on possibly prejudiced judgments. They often ignore, for example, upper-level government debt, deficits, and surpluses and also any economic flows of income back to the paying jurisdiction. Moreover, even if one believes all the numbers, they do not indicate whether any given person in any jurisdiction is better or worse off.

As no one has any objective measure of such fiscal balance sheets, the reality is that governments (and their opponents) use such numbers mainly for the purpose of scoring political points. In Canada the result is that people in every province except Ontario-the biggest and richest province-seem to think they pay more into federalism than they get out. However, if one takes a leap of faith and argues that such numbers have meaning, Ontario actually seems to be the biggest net loser in the system, with all other provinces except Alberta being net winners.

Reality is quite different than either of these pictures. As everyone in the same economic situation tends to pay the same taxes to the federal government and receive the same services regardless of where they live and the federal fiscal system appears on the whole to be mildly redistributive interpersonally, the biggest winners are likely to be poor people, of whom, by definition, there are relatively more in poor provinces, and the biggest losers seem to be rich people, of whom, again by definition, there are more in rich provinces. How provinces as such appear to fare reflects mainly how this works out in territorial terms given the level and distribution of income in a province relative to the national average. It has little or no independent meaning or policy relevance. Focusing on regional fiscal flows therefore hides rather than reveals the most important distributive outcome of Canadian fiscal federalism. 


\section{Box 4.2 How to Create a Fiscal Crisis}

A fiscal crisis for any local government occurs when its potential to raise revenues is insufficient to cover the expenditures that it is legally mandated to carry out. If maximum tax revenues are less than required expenditure (less transfers and other revenues), someone who is legally entitled to a claim on the local government loses and crisis ensues. Thus to see if a subnational government faces a crisis all one has to do is (a) calculate the maximum tax revenues, $\mathrm{T}^{*}$, that it can collect with its designated revenue structure; (b) calculate the cost of the expenditures, E, that it is legally required to carry out; (c) estimate the transfers to be received from other levels of government, TR; and (d) calculate how much the jurisdiction can expect to get from such other revenues as fees, OR. If $\mathrm{T}^{*}$ is less than $\mathrm{E}+\mathrm{TR}$ $+\mathrm{OR}$, there is a crisis.

Or is there? Obviously the credence one puts in this calculation depends on two things. One is the reliability of the estimates; what is maximum tax revenue, for example? The other is the critical assumption that no changes in required expenditures are feasible, for example, paying city workers less, reducing pension obligations, negotiating better prices for materials the city buys, or reducing service levels are all impossible. Only if one assumes that all the terms in the equation are both properly estimated and, more important, that the underlying assumption about the rigidity of the revenue and expenditure possibilities is correct, can one take such an equation as an indicator of crisis.

Source: This note was suggested by reading Inman (1995).

horizontal fiscal imbalance (HFI). Each of these concepts carries with it a fair amount of philosophical baggage. Each is also difficult to measure in an unambiguous way.

\section{Vertical Fiscal Imbalance}

If imbalance is the problem, then balance would seem to be the solution. It is thus not surprising that the concept of VFI-or the fiscal gap (Boadway and Hobson 1993)—is often discussed as though in an ideal governmental structure the own source revenues of each level of government should be sufficient to finance the expenditures for which it is responsible without recourse to intergovernmental fiscal transfers. ${ }^{3}$ Vertical fiscal balance, thus understood, seems to require that each level of government should have separate and independent revenue sources sufficient to finance the expenditures assigned to that level-no more and no less. In other words, given the assignment of expenditures, revenues should be assigned so that there is no imbalance between revenues and expenditures at any level of government. Proponents of this argument note that if this is not done, a fiscal crisis may ensue (see box 4.2).

In a world in which in many countries the most rapidly expanding expenditure sectorseducation and health, for example-have often been assigned to regional (state, provincial) governments, the implication of such analysis is generally taken to be that more revenues should be assigned to subnational governments. In Canada, for example, the province of Quebec has frequently used this interpretation of fiscal balance as an argument for more revenue authority. ${ }^{4}$ Among the advantages of such tax separation, in which every level of government "stands on its own bottom," are that local autonomy and accountability are strengthened and that the fiscal system is more transparent, with citizens being less confused by overlapping fiscal jurisdictions as to what they are paying for and to whom. ${ }^{5}$

3. This perspective is implicit in Wheare's (1963, p.93) classic statement that "both general and regional governments must each have under its independent control financial resources sufficient to perform its exclusive functions." It is explicit in Hunter (1977), the seminal work on vertical fiscal imbalance.

4. Compare, for example, the Tremblay report of 1954 (Kwavnick 1973, p. 215) with the Seguin Commission (2001, p. 4).

5. Another advantage of tax separation might be to make it more difficult for governments to form a cartel against citizens, thereby reducing governments' ability to exploit them unduly (Brennan and Buchanan 1980). 
By contrast, there is no reason why governments that are so inclined could not, if they wished, overcome taxpayer confusion and the inadequate attribution of political responsibility without recourse to strict revenue separation. Nor does even strict separation necessarily lead to such benefits. If governments really want citizens to understand what is going on, they can achieve this end without separate taxes. If they do not, separate taxes alone will do little to help matters. Moreover, even the strongest adherents of tax separation at the regional level sometimes seem strangely reluctant to apply similar reasoning to the local level of government, where it is surely equally applicable or inapplicable on logical (if not necessarily on constitutional) grounds. Finally, and perhaps most important, so long as governments at the same jurisdictional level have different levels of fiscal resources relative to their expenditure responsibility, even the most far-reaching attempt to resolve VFI by devolving revenue resources cannot succeed.

To make this last point clearer, it is important to understand that the two concepts of fiscal balance mentioned earlier-VFI and HFI-cannot be cleanly separated. One way to view VFI, for example, is that it might be thought of as being eliminated, that is, vertical fiscal balance is achieved, when expenditures and revenues (excluding transfers) are balanced for the richest local government, measured in terms of its capacity to raise resources on its own (Bird 1993). Even if this goal is achieved, however, fiscal gaps or VFI will, of course, still remain for all poorer local governments. More commonly, however, such gaps are instead discussed in terms of HFI, that is, as a problem of achieving horizontal fiscal balance within the regional or local government sector rather than vertical balance between levels of government. Regardless of how it is defined, whether and to what extent HFI (VFI for poorer jurisdictions under another name) is considered a problem is a highly political issue in many countries, and especially in formally federal countries. Box 4.3 illustrates some of the complexity of the notion of VFI in the Canadian setting.

While intergovernmental fiscal relations in most countries seem closer to those between Canada's provinces and its local governments than those between Canada's provinces and the federal government (for an extended discussion of these two very different models of fiscal federalism see Bird and Chen 1998a), vertical fiscal gaps may, in principle, be closed by reducing subnational expenditures or raising subnational revenues from existing sources, just as central governments may rectify any inverse imbalance or deficit (revenues exceeding expenditures) at the central level by increasing their expenditures or reducing their taxes. Central governments are seldom reluctant to expand their own expenditures or, less commonly, to lower their taxes. Often central governments also argue that subnational governments can both spend more efficiently and increase their fiscal effort. No doubt there is at least as much room for improvement in these respects at the subnational level in most countries as at the central level. Nonetheless, while each of these paths has been followed to some extent at some time in most federal countries, as a rule sufficient mismatch in the revenues and expenditures assigned to different levels of government remains so that some balancing role is invariably assigned to intergovernmental fiscal transfers.

\section{Measuring Vertical Fiscal Imbalance}

No matter what their stated purpose might be, intergovernmental fiscal transfers are thus often intended to help close the fiscal gap, and in any case have that result. Indeed, one way in which VFI is sometimes measured is simply as the ratio of transfers to subnational expenditures. This measure has the considerable virtue of being easy to calculate. Moreover, if one ignores borrowing, it may sometimes provide a useful measure of the actual level of VFI prevailing in a country in any given year in terms of fiscal flows. However, such a measure tells us nothing about the extent to which the fundamental concerns about political accountability and economic efficiency that presumably underlie the concept of VFI are legitimate. The 


\section{Box 4.3 The Meaning of VFI in Canada}

Consider how VFI might be eliminated, assuming that for some reason vertical balance is viewed as an appropriate or desirable policy goal. First, as just discussed, the assignment of expenditures can be taken as fixed and more revenue-raising powers can be devolved to subnational jurisdictions. Alternatively, revenue powers may be taken as fixed and some expenditure powers can be reassigned to the federal (or central) level. In Canada, for example, this is essentially how the gradually expanding social security system (unemployment insurance and old-age pensions) was initially dealt with in the middle of the 20th century (Bryden 1972), through constitutional amendments to "federalize" these expenditure functions. Subsequently, the later expansion of education, health, and social welfare expenditures was dealt with instead by increasing federal transfers to provinces, first in the form of broad conditional grants, and then in the form of essentially unconditional grants.

Norrie (2002) recently noted with respect to Canada: "The traditional interpretation of VFI does not apply to a federation in which both orders of government have equal access to the main revenue sources and both clearly exercise these powers to achieve economic and social objectives." His point is simply that projections of expected provincial and federal budget outcomes over some time period tell us nothing meaningful about fiscal balance. The distribution of both revenue sources and spending responsibilities in a flexible federation like Canada is therefore, and always has been, essentially a matter of political choice, not something carved in constitutional stone. As fiscal outcomes are not inevitable, but chosen, the ongoing and endless debate on VFI in Canada can largely be seen as nothing more than political posturing-part of the process of setting the stage for yet another reshuffle of exactly who is responsible for what and who pays for it and how (the recent review of tax sharing in Canada during the last 50 years in Vaillancourt and Bird 2002 broadly supports this interpretation).

Canadian cities, however, are not provinces, thus their fiscal futures are indeed largely cast in stone that is beyond their ability to cut (Bird and Slack 1993). The traditional concept of VFI therefore seems to be applicable at the lower level of subnational government even in Canada, and studies that argue that the fiscal needs of cities (driven largely by demographics) exceed their revenue prospects"(essentially the yields of the real property tax) are not uncommon (Vander Ploeg 2001), but such conclusions too are generally overstated. There is no iron law of local expenditure that says expenditure must always increase in step with population or with the growth of a particular client group. The alternative of reducing the amount spent per client is always an option. Moreover, although local governments' ability to raise property taxes may be genuinely limited, there is nothing to prevent provincial governments from, in effect, taking back responsibility for expenditures that cannot readily be financed from this source. Parenthetically, in Canada there cannot really be a fiscal crisis (box 4.2) at the local level simply because local governments are strictly held to balanced budgets; however, local levels can nonetheless face a sustainability crisis in the sense that the required balance is achieved only by reducing expenditures to below maintenance levels or by raising taxes so high that the tax base is chased away (for further discussion see Slack and Bird 2003).

transfer/expenditure ratio measure does not get to the heart of the matter, because it does not take into account the extent to which transfers, other subnational revenues, and indeed even subnational expenditures reflect central or subnational policy decisions.

Recognizing this problem, analysts have developed more refined measures of VFI. Hunter (1974, 1977), for instance, proposed three coefficients of vertical imbalance. Essentially, these measures took into account, to varying degrees, net borrowing by subnational governments, shared taxes, and the degree to which federal transfers were conditional. His intent in constructing these measures was to define more precisely the extent to which the basic allocation of revenues and expenditures was such that "governments at each level can command the financial resources necessary for them to carry out their expenditure responsibilities and to be held accountable for both spending and taxing decisions" (Mathews 1980, p.10). In other words, what Hunter was attempting to do was to distinguish between revenue sources that were under federal control and those that were under state control. He did so by assuming in one measure that unconditional transfers did not reduce state autonomy, in another that they did, and in a third that not only did such transfers (and borrowing) compromise state autonomy, but so did shared taxes to some extent. Naturally, Hunter's judgments as to how to assess 
such autonomy could be questioned, and soon were, for example, by Thimmaiah (1976). Nonetheless, despite its inherent subjectivity the literature still uses variants of Hunter's approach (see, for example, Bird and Tarasov 2002; Rezk 1998).

The defects of this approach are both conceptual and empirical. Conceptually, focusing on actual deficits and surpluses at different levels of government is a limited approach to the broad problem of VFI, however the data are manipulated. Hettich and Winer (1983), for instance, argue that ideally one needs a more logically consistent approach related to such fundamental concerns as maximizing social welfare. A less ambitious refinement would be to focus not on actual budget balances, but on structural budget balances, that is, the balances inherent in current expenditure and tax policies at each level of government. A recent Canadian study by Matier, Wu, and Jackson (2001), for example, first projects expenditures and revenues at each level of government under various demographic and economic assumptions, and then considers the extent to which the fiscal positions of each level are sustainable in the framework of an intertemporal budget constraint. Under this approach VFI exists if one level has room to reduce taxes or increase spending while satisfying its intertemporal constraint while another level would have to increase taxes or reduce spending to do so. The results of this more formal approach seem to be extremely sensitive to both model specification and empirical assumptions, and hence are unlikely to be accepted by all. ${ }^{6}$

In any case, undertaking such an ambitious dynamic analysis is seldom feasible in developing or transition countries. Even if one works only with historical data, one must be aware of important differences in the real significance of numbers purporting to measure the same thing in different countries, or even in the same country at different times. For example, shared taxes are an important source of subnational revenue in many countries. In some instances, however, such taxes may simply be central taxes, a share of which flows to subnational governments through a distribution formula, as is the case with VAT in Germany. Such tax sharing is in reality just an intergovernmental transfer in other guise. In other instances, so-called shared taxes may actually be subnational in the sense that the subnational governments set the tax rates even though the central government collects the taxes, as with most provincial personal income taxes in Canada. Thus those interpreting statistical comparisons must consider precisely how such data are recorded in statistical sources as well as the meaning of the measures provided. As Ebel and Yilmaz (2003) and the Organisation for Economic Co-operation and Development (1999) demonstrate, measures of fiscal decentralization and the interpretation of those measures are highly sensitive to assumptions about whether and to what extent each level of government controls state and local taxes. All measures of VFI based on internationally comparable fiscal data are thus invariably questionable to some extent.

\section{Horizontal and Vertical Fiscal Imbalance}

I noted earlier that HFI might be interpreted as the VFI that is "left over" when the VFI problem of revenue-expenditure imbalance is solved for the richest subnational government. As a rule, however, HFI is discussed in different terms than VFI, and indeed, close consideration of HFI raises serious questions about the meaning of VFI as that term is usually discussed. Essentially, VFI is generally measured in terms of the actual gap between subnational expenditures and subnational own source revenues available to finance those expenditures.

If horizontal fiscal balance is interpreted in the same gap-filling sense as vertical fiscal balance, the implication is that sufficient transfers are needed to equalize revenues (including transfers) and the actual expenditures of each subnational government. Such fiscal dentistry, as

6. This approach, in contrast to that which Quebec's Seguin Commission (2001) used, yields the result that Canada has no VFI. It is perhaps not entirely coincidental that the authors are employed by Canada's Federal Department of Finance. 
Rao and Chelliah (1991) refer to this approach, clearly makes no sense. Equalizing the actual outlays of subnational governments in per capita terms (raising all to the level of the richest subnational government) in effect ignores differences in local preferences, and hence one of the main rationales for decentralization in the first place. It also ignores local differences in needs, costs, and own revenue-raising capacity. Equalizing actual outlays would discourage both subnational revenue-raising efforts and subnational expenditure restraint, because under this system those with the highest expenditures and the lowest taxes would get the largest transfers.

Such problems are well recognized, but what seems to be noted less often is that just as any transfer, no matter what its rationale may be, helps resolve the VFI problem, so any transfereven one intended purely to close the gap-may have adverse incentive effects on subnational fiscal decisions. The appropriate incentive design of transfers, no matter what their stated rationale may be, is therefore a critical element in intergovernmental fiscal relations in any country.

\section{Equalization and Balance}

Three different topics are often confused when HFI, or equalization as it is often labeled, is discussed. First, many writers, especially in the United States-perhaps not coincidentally the only federal country that has no general equalization transfers-often discuss the equity aspects of intergovernmental transfers as though the principal objective of such transfers is to reduce disparities in per capita incomes in different regions (see, for example, Oakland 1994). Inter-regional equity is not interpersonal equity, however, and keeping the two concerns distinct is important (for further discussion of the distinction between interpersonal and interregional transfer objectives see Bird and Rodriguez 1999; Rao and Das-Gupta 1995). Sometimes transfers to poor regions may help poor people and sometimes they may not. If the principal objective of policy is to alleviate poverty, intergovernmental transfers are unlikely to be either the most appropriate or the most efficient way to achieve this aim. Nonetheless, such transfers have their own rationales and should not be judged solely or primarily in terms of their effects on individuals at different income levels.

Second, much public discussion of intergovernmental transfers focuses on the relationship between such transfers and regional disparity. While generally ill-defined, regional disparity is often interpreted in such a way that the supposed objective of transfers is to reduce such disparity, whether understood in terms of differences in per capita income between states or localities or in terms of differential regional growth rates, unemployment rates, or some other economic variable (Bird 1966 discusses the many facets of regional balance as a policy objective). Reducing such regional disparities may not always be a sensible policy objective, but naturally countries are free to attempt to do so if they wish, and they may use intergovernmental transfers as a policy instrument in any such attempt (Bird 1982 compares such transfers to other policy instruments, such as tax expenditures and direct expenditures). Thus finding that an important indicator of need in transfer formulas is some measure of the level of economic well-being in recipient regions, such as per capita regional income, is not uncommon. Basing intergovernmental transfers solely on such concerns, however, may produce undesirable economic incentives. Moreover, as with the case of viewing interpersonal equity as a policy objective, it is important to distinguish the aim of reducing regional disparity from the narrow concept of fiscal equalization between government income (or spending) that seems most directly relevant to transfer design.

Equalization transfers in the third sense just mentioned, namely, those intended to equalize government income, may have two distinct rationales. The first is to provide the necessary underpinning for decentralization in general (and, as discussed later, for matching transfers) by equalizing the fiscal capacity of territorial entities to some level, thereby putting all closer to the same footing with respect to incentives. A second rationale might be to provide sufficient resources to enable all local governments, even the smallest and poorest, to provide a basic 
package of local services. ${ }^{7}$ From a purely economic point of view, the second of these objectives may appear to make little sense. Often, however, small rural areas are simply unable to provide any significant local services without such transfers. ${ }^{8}$

In part to avoid the disincentive problem noted earlier, most countries with systems of formal equalization transfers avoid revenue pooling, and generally aim either to equalize local governments' capacity to provide a certain level of public services or to equalize local governments' actual performance of this level of service (Bird and Smart 2002). The performance criterion, which adjusts the transfer received in accordance with the perceived need for the aided service (and which may also allow for cost differentials) is often more attractive to central governments, because the level of service funded is then determined centrally, and transfers can be made conditional on the provision of that level of service. Unfortunately, unless adequate adjustment is made for differential fiscal capacity, once again the government that tries least will receive the most.

In contrast, under capacity equalization, which is more applicable to federal settings in which subnational governments have constitutional expenditure and revenue responsibilities, the aim is to provide each local government with sufficient funds (own source revenues plus transfers) to deliver a centrally predetermined level of services (differentials in the cost of providing services may or may not be taken into account). Transfers are based on a measure of each jurisdiction's potential revenue-raising capacity, such as assessed values for property taxes or measured tax bases for other taxes, and not on actual revenues. As long as revenue capacity is measured accurately, which is seldom an easy task in practice, such transfers will create no disincentive for local governments to raise revenues, because at the margin the local government still bears full fiscal responsibility for expenditure and taxing decisions, essentially because transfers are lump sum (inframarginal) in nature.

Full equalization (as defined earlier in the sense of closing all gaps) will be achieved only if the standard revenue-raising capacity that the grant is intended to provide is set at the level of the richest local government. In most countries, budgetary constraints lead to lower standards, such as the average revenue-raising capacity of local governments. In such cases, localities with below average capacities obviously remain disadvantaged. ${ }^{9}$ As even this brief discussion suggests, HFI is clearly a much more complex concept than VFI. Correspondingly, it is even more difficult to measure satisfactorily (for an interesting recent discussion of many of the relevant issues in the U.S. context see Chernick and Reschovsky 2000).

Thus even though fiscal balance analysis is not quite the analytical dead end that fiscal flow analysis generally is, for the most part it too is a relatively unproductive diversion from the real policy questions facing analysts in relation to intergovernmental fiscal relations. Perhaps the real answer lies in fiscal sustainability analysis?

\section{Fiscal Sustainability}

Sustainability, like balance, sounds good. At the very least unsustainability clearly seems to be not only undesirable, but, well, unsustainable (this section draws on an earlier, broader

7. The objective of providing similar public services regardless of location may conflict with the desirability of migration from less (privately) productive to more productive locations. This subject has been discussed extensively, if not conclusively, in the literature and is not considered further here.

8. Note that this lack of local resources need not necessarily imply a lack of local capacity to make and implement suitable expenditure decisions (see, for example, Fiszbein 1997).

9. An exception is when the positive transfers required to bring those below the average up to the average are financed by negative transfers from those above the average (as in the finanzausgleich of Germany and the similar system in Denmark and the Baltic states). Such transparent "Robin Hood" policies are inevitably controversial. More generally, the effects of any grant system are obviously determined in part by how the grants are financed (Musgrave 1961). 
discussion of fiscal indicators in Bird and Banta 2000). Like fiscal balance, however, fiscal sustainability is a term of art, not science. What it means depends largely on the interests and objectives of those who use it. How it is measured also depends on the information available. Sustainability may be assessed in terms of such structural factors as laws and institutions. Alternatively, and more plausibly, sustainability may be determined by the attainment of particular performance criteria, such as the reduction of deficits, or both structural and performance factors may be considered. Some factors taken into account may be quantifiable, others may be descriptive, and still others may reflect subjective judgment.

An obvious interpretation of fiscal sustainability, for instance, is simply that a government should cover public expenditures out of its own revenues, for example, reducing its dependence on transfers if it is a subnational government, on foreign assistance if it is a national government, or on borrowing regardless of its level. ${ }^{10}$ According to this simple definition, sustainability has three distinct quantifiable aspects: the level of taxes, the level of expenditures, and the difference between the two (the deficit), with the main relevant indicator of performance being the deficit. An example of this approach is the well-known Maastricht criteria for countries wishing to join the European Monetary Union: a budget deficit not exceeding 3 percent of gross domestic product (GDP) and a public debt level not exceeding 60 percent of GDP. McKenzie (2001) provides a useful simulation exercise showing how this approach can be used to illuminate some aspects of subnational finance (however, note the comment in box 4.2 on one possible limitation of this approach to sustainability at the local level, at least in some countries).

Even with this simple approach, however, in principle two distinct dimensions need to be considered: the static dimension (the relationship between levels) and the dynamic dimension (the relationship between growth rates). Suppose, for example, that the elasticity of public expenditures is unity, so that a 1 percent increase in GDP leads to a 1 percent increase in expenditures. If the budget were initially in deficit, fiscal sustainability would then require an elasticity of revenues that is greater than unity. However, if, for example, revenues depend largely on a VAT, the elasticity of which is unlikely to exceed unity over any prolonged period, then the only way to remove the initial deficit and achieve sustainability in the sense used here may be to reduce the size of the public sector relative to GDP (for an analysis along these lines see Bird 1989).

Focusing on such simple, quantifiable, budgetary measures can sometimes be an appealing and useful initial approach to the sustainability issue, but it is unlikely to prove fully satisfactory as a guide to policy for several reasons. First, the numbers available may not be either the right ones or the best ones. ${ }^{11}$ Second, they may not be comprehensive (on the importance of extrabudgetary funds in Russia see, for instance, World Bank 1996b). Third, they may not be

10. A variant, common in the literature on public debt, is to compare the actual deficit with the estimated sustainable deficit that would maintain a constant debt-to-gross domestic product ratio (for likely rates of growth, real interest, and inflation). A useful way to approach the question of how to move from theory to numbers in approaching the sustainability issue is to consider three quite distinct papers on this subject produced by the International Monetary Fund: Chalk (2002), Hemming and Petrie (2000), and Horne (1991). Reviewing these papers emanating from the world's leading institution charged with assessing the sustainability of national fiscal policies is impossible without concluding first, that the results appear to be very dependent on theoretical assumptions that often seem to be arguable, and second, that we still have a long way to go before we can use simple quantitative measures with much confidence, even at the national level. A review of some recent literature on appraising the creditworthiness (equivalent to sustainability) of subnational governments (for example, Fitch Ratings, Ltd. 2001; Moody's Investors Service 1998; World Bank 1996b) similarly suggests the continued importance of informed judgment over simple numerical measures.

11. Questions may be raised about, for example, the comprehensiveness of budgets and the appropriate measurement of deficits, particularly in transition countries in which the proliferation of such devices as mutual settlements, tax offsets, and the like make interpretation of the public sector's real fiscal situation difficult. 
comparable over time or across jurisdictions, particularly internationally. ${ }^{12}$ Finally, changes in budgetary outcomes may reflect not internal change and effort, but largely fortuitous external events. As different jurisdictions start in different initial positions, similar changes in outcome measures may mean completely different things.

Thus indicators of a government's relative degree of fiscal sustainability need to extend beyond outcomes to take into account both initial conditions and processes and structures. To do so satisfactorily requires establishing meaningful links between structures and processesfor example, the existence of a tax code, a functional organization of tax administration, or a single treasury ledger system-and the relevant outcomes to demonstrate that such outcomes are truly the result of the adoption of such policies and not simply reflections of exogenous influences. Such a task is far beyond the scope of our current knowledge. At best we may believe, from experience or theory, that a particular institution may be conducive to better outcomes. As an example, international experience may suggest that countries that systematically review and codify their tax systems are, on average, likely to do better over time than countries that do not, or theory may suggest that subnational governments subject to a hard budget constraint are more likely to tax and spend sensibly (Bird 2001). ${ }^{13}$

\section{Initial Conditions}

The policy choices governments make and the effects of those choices depend in part on initial conditions. A country, region, or locality that has few human or natural resources; no prior experience with an independent fiscal institutional structure; and also faces internal or external armed conflict is clearly completely different from a rich country, region, or locality with a strong tradition of independence that faces no serious disturbances. A country with a huge external debt, a large fiscal deficit, and raging inflation at the moment the transition process begins is not readily comparable with a country that faces none of these problems. Ideally, such contextual or environmental factors-ranging from the degree of public acceptance of the government's legitimacy to the extent of the development of the financial infrastructure-should be taken into account in assessing the efforts made and the success achieved (Bagchi, Bird, and Das Gupta 1995 develop this point with respect to tax administration).

Effort and success are therefore inherently relative concepts in the sense that both must be assessed in light of the scope and scale of the problems facing the country in question. For this reason, different indicators at different levels of detail may be appropriate for different jurisdictions, depending on such factors as the degree of development of the market economy, the extent to which the jurisdiction is engaged in fiscal reform as opposed to what may be called fiscal development (that is, the extent to which it has moved from changing the old to implementing the new), and perhaps also the level of outside technical and financial assistance it has received.

To illustrate, differences in levels of income and wealth are obviously relevant in assessing fiscal performance. It takes more effort for a poor country to raise an additional percentage point of GDP in taxes than for a rich country (Bird 1976). Similarly, the well-known convergence hypothesis suggests that increasing its growth rate may be easier for a country with below average growth performance than for one with above average performance. Another illustration relates to investor perceptions. With respect to foreign investment, for instance, as in politics, perception often is reality. If investors see a country as risky, the country pays the price in terms

12. The importance of, for instance, tax offsets in transition countries has varied considerably from country to country, and within any one country may change sharply from year to year.

13. For an interesting recent look at the sustainability issue in the broader environmental context see Stavins, Wagner, and Wagner (2002), who separate the problem into two components: the economic problem of dynamic efficiency and the political problem of intergenerational equity. One could conceive of a similar approach to the problem of public sector sustainability. 
of receiving less investment than it otherwise would and paying more for what it gets. Different perceived degrees of riskiness may therefore affect measured fiscal performance.

\section{Performance Assessment}

The nature of the problems a particular jurisdiction faces-the initial conditions-thus influence its performance. So, of course, may the institutional measures taken to deal with them. In other words, does the jurisdiction have a sustained, high-level commitment to change? Is there a coherent strategy for change? Without both a genuine desire to make changes and a welldeveloped plan for change, efforts at change are unlikely to prove either coherent or successful. The critical question to be considered here, however, is how to assess the extent to which a jurisdiction has achieved success.

Performance is a function both of exogenous conditions and institutional factors (including capacity). Unfortunately, many conceivable indicators measure inputs, not the policy outputs that are of ultimate concern. Some outputs, such as tax revenue, may easily be quantified. Other outputs may be more subjective, for example, what is the public's perception of the fairness of the tax system, and hence, perhaps, its long-term sustainability? On the whole, the fiscal indicators that may be assembled in practice in most countries almost inevitably constitute an extremely mixed bag. Aggregating or averaging such heterogeneous indicators meaningfully may be difficult, and sometimes not really possible, even with respect to any one area. As a rule, what analysts usually do, for example, in most bond rating analyses (see, for example, Fitch Ratings, Ltd. 2001; Moody's Investors Service 1998; World Bank 1996a), is little more than the pre-analytic step of collecting a series of indicators that, taken together, help profile some relevant aspect of the area.

To illustrate with respect to pension reform-a key component of the long-term fiscal sustainability issue in many countries-such indicators may be clustered under four headings: the system's structure, its viability, administrative issues, and other issues. The sustainability of pension systems may then be assessed either in terms of static short-run measures, such as pension payments to GDP ratios, or in light of longer-term measures, such as the present value of future commitments. Box 4.4 provides another example with respect to taxation (both the pension and tax cases are developed in more detail in Bird and Banta 2000, and Das-Gupta 2002 discusses the latter).

\section{Box 4.4 Tax Indicators in New Zealand}

As an example of the use and limits of quantitative measurement, consider what is perhaps the simplest case, the measurement of how well a jurisdiction does in collecting taxes. New Zealand recently made a notable attempt to assess its tax performance, estimating the optimal tax level and structure from the perspective both of maximizing economic growth and minimizing tax evasion (Caragata 1998). The conclusion was that tax levels mattered much more with respect to the attainment of these objectives than did tax mix, and that the prevailing level of taxation in New Zealand (37 percent of GDP in 1997) was much higher than the optimal level of at most 25 percent. This study underlines the importance of the sheer size of the tax share in appraising tax policy performance. Moreover, it suggests that success in increasing taxes, even if such increases seem necessary to cope with deficit problems, may well be a two-edged sword, relieving short-run fiscal pressures at the cost of long-run damage both to real economic growth and to the growth of the "official" economy.

The change in tax revenues compared with the change in GDP over the same period (tax buoyancy) may be the single most meaningful measure of tax effort in the absence of reliable measures of tax potential. A more refined measure might also encompass some measure of revenue stability, such as the coefficient of variation of the annual buoyancy measure. An additional measure that would be useful to assess the predictability and reliability of budgets would be to compare actual revenue outcomes with the amounts initially budgeted. Similar comparisons of the accuracy of budgeting could, of course, also be calculated for the expenditure side. Even the best figures must sometimes be interpreted with care, however. For example, what does high buoyancy mean when growth is negative? 
Raising taxes is undoubtedly hard. Unfortunately, spending hard-won fiscal proceeds sensibly and well seems to be at least as difficult in most developing and transition countries. Thus assessing expenditure performance at the subnational level is at least as important as assessing tax performance. In addition to comprehensiveness, perhaps the key factor in appraising budgetary policy in any country is discipline. As recent empirical studies in a variety of countries have suggested, budgetary institutions may have important effects on fiscal outcomes (Alesina and Perotti 1995). Important factors include the legitimacy, predictability, honesty, and effectiveness of the budgetary process and the related issues of the existence of a coherent strategy, for example, the budget's relationship to the macroeconomic policy framework through a coherent medium-term expenditure plan and the capacity of budgetary institutions in both the executive and legislative branches of government to analyze and implement policy (Campos and Pradhan 1996). As in the case of taxes, a well-grounded appraisal of fiscal sustainability therefore has to extend well beyond simple numbers to a thorough understanding of the sustainability of the institutional framework underlying the numbers.

\section{Conclusion}

Regardless of how carefully one assembles any set of fiscal indicators, at best the results constitute raw material for interpretative analysis. Fiscal indicators, such as those discussed in this chapter, may be compared with the information that consumer magazines assemble with respect to automobiles. Some of the indicators reported describe various mechanical and other features of the different vehicles, others report the results of specified performance tests, and still others report the subjective judgments of selected experts with respect to the vehicles' quality and general appeal. What the editors deem to be the best buy in terms of a particularly weighted set of criteria may also be indicated. In the end, however, readers must draw their own conclusions from all the information presented.

Even the best indicators are not, and cannot be, a substitute for analysis. Numbers are powerful. Good numbers, properly used, may illuminate reality and may not only permit meaningful assessment of certain aspects of performance, but may also suggest new and promising lines of inquiry. Measurement and quantification have long been essential ingredients in the development and application of scientific thought. Unfortunately, even good numbers may be misunderstood and misinterpreted, and bad numbers may all too easily pass for good among those who do not take the time to understand what the numbers can and do measure, and, equally important, what they cannot show. However, just because the unwary might cut themselves with sharp tools is no reason not to sharpen one's analytical tools as best as possible. Only careful study and appreciation of what can be measured, and with what degree of reliability, will advance knowledge of the world and how it works.

Therefore despite the inherent limitations and risks, attempting to develop meaningful and comparable fiscal indicators is worthwhile, particularly with respect to sustainability. Even the best such indicators will never provide a certain or clear guideline telling any country what to do, but they may, if done well, be helpful in understanding how a country or a subnational government is doing relative to others in roughly similar circumstances. Providing a base case against which to assess performance is no mean achievement in the complex and ongoing task of assessing how well particular governments are doing.

\section{References}

The word processed describes informally reproduced works that may not be commonly available through libraries.

Advisory Commission on Intergovernmental Relations. 1980. Regional Growth: Flows of Federal Funds, 1952-76: A Commission Report. Washington, D.C. 
Alesina, Alberto, and Robert Perotti. 1995. "Budget Deficits and Budget Institutions." Working Paper no. 5556. National Bureau of Economic Research, Cambridge, Massachusetts.

Bagchi, Amaresh, Richard M. Bird, and Arindam Das-Gupta. 1995. "An Economic Approach to Tax Administration Reform." Discussion Paper no. 3. University of Toronto, Faculty of Management, International Centre for Tax Studies, Toronto.

Bahl, Roy W., and others. 1999. "Intergovernmental Fiscal Relations in Leningrad Region." Working Paper no. 99-2. International Studies Program, Andrew Young School of Public Policy, Georgia State University, Atlanta, Georgia.

Bird, Richard M. 1966. "Tax-Subsidy Policies for Regional Development." National Tax Journal 19(2): 113-24.

. 1976. "Assessing Tax Performance in Developing Countries: A Critical Review of the Literature." Finanzarchiv 34(2): 234-55.

. 1982. "Expenditure Policy and Regional Development." Rivista di diritto finaziario e scienze delle finanze 41(December): 483-503.

. 1984. Intergovernmental Finance in Colombia: Final Report of the Mission on Intergovernmental Finance. Cambridge, Massachusetts: Harvard Law School International Tax Program.

. 1989. “Taxation in Papua New Guinea: Backwards to the Future?" World Development 17(August): 1145-57.

. 1993. "Threading the Fiscal Labyrinth: Some Issues in Fiscal Decentralization." National Tax Journal 46(2): 207-27.

. 2001. Intergovernmental Fiscal Relations in Latin America: Policy Design and Policy Outcomes. Washington, D.C.: Inter-American Development Bank, Sustainable Development Department.

Bird, Richard M., and Susan Banta. 2000. "Fiscal Sustainability and Fiscal Indicators." In A. Shapleigh, F. Andic, and S. Banta, eds., Transition Economies and Fiscal Reforms. Proceedings of the Conference on Central and Eastern Europe and the New Independent States, Istanbul, June 1999. Washington, D.C.: U.S. Agency for International Development.

Bird, Richard M., and Duanjie Chen. 1998a. "Federal Finance and Fiscal Federalism: The Two Worlds of Canadian Public Finance." Canadian Public Administration 41(1): 51-74.

1998b. "Intergovernmental Fiscal Relations in China in International Perspective." In Donald J. S. Brean, ed., Taxation in Modern China. New York: Routledge.

Bird, Richard M., and Edgard Rodriguez. 1999. "Decentralization and Poverty Alleviation: International Experience and the Philippines." Public Administration and Development 19: 299-319.

Bird, Richard M., and Enid Slack. 1993. Urban Public Finance in Canada, 2nd ed. Toronto: John Wiley.

Bird, Richard M., and Michael Smart. 2002. "Intergovernmental Fiscal Transfers: Lessons from International Experience." World Development 30(6): 899-912.

Bird, Richard M., and Andrey V. Tarasov. 2002. "Closing the Gap: Fiscal Imbalances and Intergovernmental Transfers in Developed Federations." Working Paper no. 02-02. International Studies Program, Andrew Young School of Policy Studies, Georgia State University, Atlanta, Georgia.

Boadway, Robin W., and Paul Hobson. 1993. Intergovernmental Finance in Canada. Toronto: Canadian Tax Foundation. 
Brennan, Geoffrey, and James M. Buchanan. 1980. The Power to Tax. Cambridge, U.K.: Cambridge University Press.

Bryden, W. Kenneth. 1972. Old Age Pensions and Policy Making in Canada. Montreal: McGillQueen's University Press.

Campos, Edward, and Sanjay Pradhan. 1996. “Budgetary Institutions and Expenditure Outcomes." Policy Research Working Paper no. 1646. World Bank, Washington, D.C.

Caragata, Patrick J. 1998. The Economic and Compliance Costs of Taxation: A Report on the Health of the Tax System in New Zealand. Boston: Kluwer Academic Publishers.

Chalk, Nigel A. 2002. "Structural Balances and All That: Which Indicators to Use in Assessing Fiscal Policy." Working Paper no. 02/101. International Monetary Fund, Washington, D.C.

Chernick, Howard, and Andrew Reschovsky. 2000. "The Long-Run Fiscal Health of Central Cities: The Impact of Devolution." State Tax Notes, November 27, pp. 1445-56.

Das-Gupta, Arindam. 2002. "Central Tax and Administrative Reform in the 1990s: An Assessment." In M. Govinda Rao, ed., Development, Poverty, and Fiscal Policy: Decentralization of Institutions. New Delhi: Oxford University Press.

Dion, Stephane. 2001. “Tell the Truth, Bernard." The Globe and Mail (Toronto), March 15, p. A15.

Ebel, Robert D., and Serdar Yilmaz. 2003. "On the Measurement and Impact of Fiscal Decentralization." In James Alm and Jorge Martinez-Vazquez, eds., Public Finance in Developing and Transitional Countries. Cheltenham, U.K.: Edward Elgar.

Fiszbein, Ariel. 1997. "Emergence of Local Capacity: Lessons from Colombia." World Development 25: 1029-43.

Fitch Ratings, Ltd. 2001. International Public Finance Special Report: Examining Canadian Provinces. New York.

Flanagan, Tom. 2001. "Why Canada Is a Kleptocracy." National Post, February 6, p. A14.

Hemming, Richard, and Murray Petrie. 2000. "A Framework for Assessing Fiscal Vulnerability." Working Paper no. 00/52. International Monetary Fund, Washington, D.C.

Hettich, Walter, and Stanley Winer. 1983. “Vertical Imbalance in the Fiscal Systems of Federal States." Working Paper no. 56-82-83. Carnegie-Mellon University, Graduate School of Industrial Administration, Pittsburg, Pennsylvania.

Horne, Jocelyn. 1991. “Indicators of Fiscal Sustainability." Working Paper no. 91/5. International Monetary Fund, Washington, D.C.

Hunter, J. S. H. 1974. “Vertical Intergovernmental Financial Imbalance: A Framework for Evaluation." Finanzarchiv 32: 481-92.

1977. Federalism and Fiscal Balance. Canberra: Australian National University Centre for Research on Federal Financial Relations.

Inman, Robert P. 1995. "How to Have a Fiscal Crisis: Lessons from Philadelphia." American Economic Review, Papers and Proceedings 85(2): 378-83.

Kwavnick, David, ed. 1973. The Tremblay Report. Toronto: McClelland and Stewart.

Lavrov, Alexei M., and Alexei G. Makushkin. 2001. The Fiscal Structure of the Russian Federation: Financial Flows between the Center and the Regions. Armonk, New York: M. E. Sharpe.

Leslie, Peter, and Richard Simeon. 1977. "The Battle of the Balance Sheets." In Richard Simeon, ed., Must Canada Fail? Montreal, Canada: McGill-Queen's University Press. 
Mathews, Russell. 1980. Revenue Sharing in Federal Systems. Canberra: Australian National University, Centre for Research on Federal Financial Relations.

Matier, Chris, Lisa Wu, and Harriet Jackson. 2001. "Analyzing VFI in a Framework of Fiscal Sustainability." Paper presented to the Canadian Economic Association, June.

McKenzie, Kenneth M. 2001. “A Note on the Sustainability of Fiscal Policy in Subnational Governments." World Bank Institute, Washington, D.C. Processed.

Moody's Investors Service. 1998. Subnational Governments: A Rating Agency Perspective. New York.

Musgrave, Richard A. 1961. "Approaches to a Fiscal Theory of Political Federalism." In Public Finances: Needs, Sources, and Utilization. Princeton, New Jersey: Princeton University Press.

Norrie, Kenneth. 2002. “On Fiscal Balance in the Canadian Federation.” In Robert D. Brown, ed., Canadian Conundrum: Views from the Clifford Clark Visiting Economists. Toronto: C. D. Howe Institute.

Oakland, William H. 1994. “Fiscal Equalization: An Empty Box?" National Tax Journal 47(1): 199-209.

Organisation for Economic Co-operation and Development. 1999. Taxing Powers of State and Local Governments. Paris.

Rao, M. Govinda, and Raja J. Chelliah. 1991. Survey of Research on Fiscal Federalism. New Delhi: National Institute of Public Finance and Policy.

Rao, M. Govinda, and Arindam Das-Gupta. 1995. "Intergovernmental Transfers and Poverty Alleviation." Environment and Policy C: Government and Policy 13(1): 1-23.

Rezk, Ernesto. 1998. “Argentina: Fiscal Federalism and Decentralization.” In Richard M. Bird and Francois Vaillancourt, eds., Fiscal Decentralization in Developing Countries. Cambridge, U.K.: Cambridge University Press.

Seguin Commission on Fiscal Imbalance. 2001. Fiscal Imbalance: Problems and Issues. Quebec.

Sehili, Saloua, and Jorge Martinez-Vazquez. 2002. "Fiscal Incidence at the Regional Level." Andrew Young School of Policy Studies, Georgia State University, Atlanta, Georgia. Draft.

Slack, Enid, and Richard M. Bird. 2003. "Fiscal Sustainability in the GTA." Paper prepared for the Neptis Foundation. Toronto.

Stavins, Robert N., Alexander F. Wagner, and Gernot Wagner. 2002. “Interpreting Sustainability in Economic Terms: Dynamic Efficiency Plus Intergenerational Equity." Faculty Research Working Paper no. RWP 02-018. Harvard University, John F. Kennedy School of Government, Cambridge, Massachusetts.

Thimmaiah, G. 1976. “Vertical Intergovernmental Financial Balance: A Restatement." Finanzarchiv 34: 497-508.

Vaillancourt, Francois, and Richard M. Bird. 2002. "Changing with the Times: Success, Failure, and Inertia in Canadian Federal Arrangements, 1945-2002." Federalism Project. Stanford University, Palo Alto, Calif.

Vander Ploeg, Casey. 2001. Dollars and Sense: Big City Finances in the West. Western Cities Discussion Paper. Calgary, Canada: Canada West Foundation.

Wheare, Kenneth C. 1963. Federal Government. 4th ed. London: Oxford University Press.

World Bank. 1996a. Argentina Provincial Finances Study: Selected Issues in Fiscal Federalism, vol.

II, Technical Annexes. Report no. 15487-AR. Washington, D.C. . 1996b. Fiscal Management in Russia. Washington, D.C. 



\section{Part II}

\section{The Provision of Services}





\title{
6
}

\section{Fiscal Aspects of Alternative Methods of Governing Large Metropolitan Areas}

\author{
Enid Slack
}

Large metropolitan areas or city-regions differ from other urban or rural areas in large part because of the size of their populations and because of the concentration of population within the metropolitan area. ${ }^{1}$ These differences are reflected both in the magnitude and complexity of the expenditures that local governments in metropolitan areas are required to make on municipal services and in their ability to pay for them. The type of governing structure in a large metropolitan area will have an effect on the efficiency with which local governments provide services and on the ability to share the costs throughout the entire region in a fair and efficient way. The governing structure also has an effect on citizens' access to local decisionmaking and the government's accountability for the expenditure and taxing decisions it makes.

This chapter reviews the fiscal aspects of the various ways to organize government structure in large metropolitan areas or city-regions. First, it reviews local government expenditures in metropolitan areas and describes how the size of these areas affects the nature and magnitude of expenditures. Next the chapter details the revenue sources of large metropolitan areas and how the size of the municipality affects these sources. The third section sets out the criteria for designing a government structure that will be used to evaluate alternative governance models. These include efficiency, equity, and accountability. The chapter then presents and evaluates alternative government structures used in city-regions around the world. The final part of the chapter sets out conclusions.

This discussion of governing structures in metropolitan areas shows that different structures have worked in different places at different times. Thus generalizing from the examples provided is difficult, because no one model stands out. The appropriate governing structure in any one municipality will depend on its specific characteristics: the nature of the services it provides, the revenue sources available to it, the size and location of the municipality, the size of the municipality relative to the state or province or the country as a whole, the nature of intergovernmental relations, the history of cooperation with neighboring municipalities, and other factors.

\section{Local Government Expenditures in Large Metropolitan Areas}

In terms of economic theory, the major role of local governments is to provide goods and services within a particular geographic area to residents who are willing to pay for them. ${ }^{2}$ If the

1. The term city-region generally refers to a defined urban center with smaller adjacent urban and rural areas.

2. The literature on fiscal federalism assigns three roles to government: stabilization, income redistribution, and resource allocation. Stabilization policy is generally not an appropriate function of local governments because they do not have access to monetary policy, and because capital and labor flow freely across local jurisdictions. In the case of redistribution, local efforts to address income disparities will likely result in the movement of high-income groups to low-tax areas and low-income groups to high-tax areas. Nevertheless, local governments do engage in redistribution through the act of taxing and spending. See Bird and Slack (1993) for a discussion of the role of local government. 
benefits of particular services are confined to local jurisdictions and the actions of one municipality have no effect on other municipalities, service provision will be efficient because the mix and level of services can vary according to local preferences. Some observers argue that local officials are in a better position to respond to local tastes and preferences than central government officials. Local governments generally have expenditure responsibilities for a wide range of services: roads and transit, water and sewer services, police and fire protection, garbage collection and disposal, recreation and culture, land use planning, and social services. However, this provision of local services does not mean that the municipality has to produce the goods and services itself. Rather, the role of local government is to make decisions about which services to provide and how to provide them. Municipalities could, for example, contract out service delivery to another government or to the private sector. As noted in Osborne and Gaebler (1992), local governments need to concentrate more on "steering" (policymaking) and less on "rowing" (service delivery).

This theory of the role of local governments does not distinguish among large metropolitan areas, intermediate-size cities, or towns and villages, yet making that distinction is important. According to Burki, Perry, and Dillinger (1999, p. 24): "A structure that fails to distinguish between major metropolitan areas and small villages makes it difficult to clearly define the functional responsibilities of local government." If all local governments are assigned the same responsibilities, the assignment is likely to reflect only that which the smallest municipalities can provide. Governments in large metropolitan areas may need to provide more and different services than governments in smaller urban areas, and they may have greater capacity to do so.

The magnitude and complexity of local government expenditures in large metropolitan areas differ from expenditures in smaller urban or rural areas because of the sheer size of the population in metropolitan areas (generally more than 1 million people), the high degree of concentration of population, and the presence of a heterogeneous population in terms of social and economic circumstances (Freire 2001; Nowlan 1994).

People and businesses are attracted to large metropolitan areas because they provide many of the benefits of close proximity, known as agglomeration economies. These benefits include face-to-face interaction, availability of business services, accessibility to a large skilled labor force, and accessibility to transportation and communications networks. Large metropolitan areas are able to achieve the critical mass required to attract and support high degrees of specialization: specialized labor, knowledge, businesses, services, infrastructure, institutions, and media. At the same time, large metropolitan areas attract low-income individuals and households that seek employment opportunities and can take advantage of a wider range of more specialized social services than are usually available in smaller municipalities.

Local governments in large metropolitan areas must provide a sophisticated transportation and communications network and services such as parks, recreational facilities, and cultural institutions that yield a high quality of life. The high concentration of special needs within large metropolitan areas also requires higher expenditures on social services, low-income housing, and public health. Expenditures per household in large metropolitan areas are therefore generally higher than in other municipalities. Large metropolitan areas tend to make expenditures on a wider range of services than do smaller cities and rural areas. For example, smaller cities may not have a public transit system because the urban densities are not sufficient for a transit system to be economically viable. Cultural facilities, such as opera houses and art galleries, are unlikely to be provided in smaller urban areas because they require a minimum size to make provision possible. Furthermore, people from outside the metropolitan area make use of the cultural facilities as well as other services, such as social services.

Opportunities may exist for lower expenditures per capita for metropolitan services to the extent that the local government can take advantage of economies of scale in service provision. Economies of scale occur when the per unit cost of producing a particular service decreases as the quantity of the service provided increases. Empirical evidence on the existence of 
Table 6.1 Expenditures Per Household in Toronto and Suburban Municipalities, 1999 (Can\$)

\begin{tabular}{lcc}
\hline Expenditure category & City of Toronto & $\begin{array}{c}\text { 24 lower-tier municipal governments } \\
\text { and regional governments combined }\end{array}$ \\
\hline Fire protection & 256 & 216 \\
Police & 675 & 453 \\
Roads & 192 & 366 \\
Transit & 983 & 207 \\
Water and sewers & 493 & 538 \\
Garbage collection and disposal & 151 & 151 \\
Public health & 89 & 118 \\
Social and family services & 1,505 & 820 \\
Low-income housing & 330 & 299 \\
Parks and recreation & 280 & 284 \\
Culture & 61 & 14 \\
Libraries & 130 & 87 \\
Planning and development & 77 & 82 \\
Total & 6,455 & 4,491 \\
\hline
\end{tabular}

Source: Ontario Ministry of Municipal Affairs and Housing, municipal analysis retrieval system database.

economies of scale is mixed, depending on the service in question and the units of measurement, for example, jurisdiction or facility size (Zoltán and others 1999). Some evidence exists that expenditures per capita decline with the quantity provided for so-called "hard" services such as water, sewers, and transportation, but not for "soft" services, such as police, garbage collection, recreation, or planning (Bird and Slack 1993).

\section{Expenditures of Large Metropolitan Areas: An Example from Toronto}

Table 6.1 compares expenditures per household in 1999 by category of expenditure for the city of Toronto, a metropolitan area with a population of 2.4 million, with expenditures per household in 24 neighboring suburban municipalities combined located in the surrounding regions of Halton, Peel, York, and Durham. ${ }^{3}$

Overall, expenditures per household are about 44 percent higher in Toronto than in the surrounding municipalities. An examination of some of the specific expenditure categories reveals some reasons why these expenditures are higher: ${ }^{4}$

- Expenditures on social and family services are much higher in Toronto than in the surrounding municipalities. This difference largely reflects higher poverty rates in Toronto. Based on the 1996 census, the poverty rate in Toronto was 27.6 percent, compared with 11.1 percent in Durham, 9.3 percent in Halton, 15 percent in Peel, and 12.9 percent in York. Poverty contributes to increased dependence on social assistance, individual health problems, and pressure on affordable housing. The pooling of costs for social services and social housing among Toronto and the surrounding municipalities has reduced the differential somewhat.

3. There are 24 lower-tier municipalities outside Toronto (contained within four upper-tier regions), with a total population of approximately 2.2 million. Municipalities range in size from 12,000 to 544,000, with the average being 94,000 people. Although the municipalities are largely urban, a few rural municipalities are also included.

4. Of course, expenditures may also be higher because the larger tax base, particularly the commercial and industrial property tax base, allows a metropolitan area to provide higher-quality services, whether required or not. 
- Transit expenditures per household are much higher in Toronto. Toronto operates an integrated transit system with subways, light rail lines, streetcars, and an extensive bus network. This system absorbs significant numbers of commuters on a daily basis. Expenditures on roads, however, are higher in the suburban municipalities where reliance on automobile use is much greater.

- Expenditures on policing are higher in Toronto. This reflects the higher crime rates of a large metropolitan area with a large, diverse population and a higher incidence of poverty. It also reflects the need for more specialization in police services.

- Expenditures on culture are higher in Toronto in part because it has the necessary size required for such facilities to be viable and in part because people come from outside the city and from outside the region to use these cultural facilities.

- Expenditures per household on fire protection are somewhat higher in Toronto. Fire protection is more costly to provide in large metropolitan areas with much higher population densities and greater concentrations of high-rise office buildings. These characteristics of large metropolitan areas require specialized training and equipment and full-time firefighters. A smaller urban or rural area may be able to rely on a volunteer fire department.

\section{Expenditure Assignment in Large Metropolitan Areas}

As noted, the characteristics of large metropolitan areas mean that the level and complexity of local government expenditures will be different than for other types of urban or rural areas. Furthermore, in addition to providing goods and services, local governments have to manage the local environment, structure land use to promote efficiency, and use financial tools in a way that promotes efficiency.

For these reasons, distinguishing among different types of municipalities in terms of expenditure assignment is important (Burki, Perry, and Dillinger 1999). For example, the German structure distinguishes among governments of different sizes, giving broader responsibilities to "city-states" such as Berlin, Bremen, and Hamburg and allowing other large municipalities to assume the responsibilities of counties (Burki, Perry, and Dillinger 1999).

Large metropolitan areas can and should be responsible for a wide range of municipal services, including hard services such as water, sewers, and transportation and soft services such as public health and some social services. To provide this wide range of services, however, they need appropriate revenue sources and governing structures.

\section{Financing Options}

Although the expenditure requirements are greater for local governments in large metropolitan areas, these local governments also have greater capacity to finance these expenditures. The types of revenue sources assigned to local governments in metropolitan areas should reflect the nature and level of services they provide and their ability to levy taxes. In particular, large metropolitan areas have greater fiscal autonomy than other urban or rural areas. This means greater responsibility for local services and greater ability to levy their own taxes and collect their own revenues (Bird 1984).

The sources of revenue available to and used by local governments include user charges; taxes such as property, income, and fuel taxes; and intergovernmental transfers.

\section{User Charges}

The efficient provision of goods and services requires local governments to charge directly for services wherever possible. Charges should be levied on those who receive the benefits from 
services wherever the government can identify such beneficiaries. User fees allow residents and businesses to know how much they are paying for the services that they receive from local governments. Based on the services provided and the costs incurred, residents and businesses can therefore make efficient decisions about how much to consume. User charges are appropriate for services such as water and public transit, because benefits are confined largely to individual consumers.

User fees are appropriate for large metropolitan areas, not only because they result in an efficient use of services, but also because they can potentially lead to efficient land use. If marginal cost pricing is used as the basis to charge for services, consumers of services that are far away from existing services would have to pay higher fees, while consumers of services that are closer would pay lower fees. However, if governments charged an average cost, consumers in outlying areas, where costs are relatively higher, would pay less than the marginal cost of the service and would therefore receive a subsidy. At the same time, consumers in the central, highdensity area would be paying more than the marginal cost of the service, in effect subsidizing the use of services by others.

\section{Taxes}

Where user charges cannot be used because the benefits of a particular service are not confined to individual consumers, but are confined within the municipal boundary, for example, policing, taxes that are borne by local residents are appropriate. These include property taxes and local income taxes. These taxes allow individuals to express their demand for services where benefits are consumed collectively.

In large metropolitan areas, the tax base is generally larger than in other urban or rural areas because of higher property values and a larger commercial and industrial presence in the municipality. A greater opportunity exists to share the costs of municipal services over a wider tax base in a metropolitan area, but this requires some form of governing structure encompassing the entire area or an intermunicipal agreement to share taxes.

PROPERTY TAXES. The property tax has an important role to play in funding local needs for municipalities of all sizes. It is the main source of revenue in 5 of the 27 Organisation for Economic Co-operation and Development countries (Australia, Canada, Ireland, New Zealand, and the United Kingdom), where it accounts for more than 90 percent of local tax revenue (OECD 2000).

The property tax is appropriate for financing local services for at least two reasons: first, real property is immovable, that is, it is unable to shift location in response to the tax. Second, a connection exists between the types of services funded at the local level and the benefit to property values. The property tax is like a benefit tax because it approximates the benefits received from local services. Residential property taxes, in particular, are appropriate to fund local governments because they are borne by local residents. Those who enjoy the benefits from services are required to pay for them.

The nonresidential property tax may be less appropriate for financing local government expenditures, because property owners may in part export this type of tax to residents of other jurisdictions who are consumers of the products or services produced in those properties. Tax exporting reduces accountability, because those bearing the burden of the tax are not the same as those enjoying the benefits. Thus an incentive exists on the part of local residents to demand greater expenditures, because some of the cost is borne by others. For this reason, restricting the use of nonresidential property taxes may be necessary.

Large metropolitan areas tend to have a larger proportion of commercial and industrial property than smaller urban areas because of the extent of economic activity. A larger commercial-industrial tax base permits local governments to make greater expenditures than 
smaller municipalities for reasons previously noted. Because of the ability to export these taxes, restrictions may also be needed in metropolitan areas.

INCOME TAXES. Income taxes represent the most important source of local tax revenues in 13 of the 27 Organisation for Economic Co-operation and Development countries including, for example, Belgium, the Czech Republic, Denmark, Finland, Norway, Sweden, and Switzerland (OECD 2000).

A strong case can be made for a local income tax (piggybacked onto the national tax) to supplement property taxes for large metropolitan areas. This source of revenue is justifiable on the grounds that governments in large metropolitan areas are increasingly required to address issues of poverty, crime, land use planning, regional transportation, and other regionwide needs (Nowlan 1994). To the extent that large metropolitan areas must provide social services, for example, an income tax is more appropriate than a property tax because it is more closely related to ability to pay. Furthermore, because mobility across jurisdictions in response to tax differentials will be lower for a larger geographic area, large metropolitan areas may be able to take advantage of tax sources such as income taxes. Finally, an income tax would permit local governments to be less dependent on grants from the central government (Bird 2001).

Another justification for income taxes for large metropolitan areas is on benefit grounds (Nowlan 1994). Some observers argue that the residential property tax is tied to the consumption of housing rather than the consumption of public goods. This means that the tax is a benefits tax only to the extent that housing consumption and local goods consumption are highly correlated across different households (Thirsk 1982). In large metropolitan areas with a heterogeneous population, income is more likely to be highly correlated with consumption of public services than with property value. This finding suggests that a municipal income tax may act more as a benefits tax than a property tax in large metropolitan areas. This argument only applies to large heterogeneous areas and not to municipalities where a strong relationship exists between income and property values. The choice between income and property taxes is less significant where housing values and income levels vary less.

Large metropolitan areas should be permitted to levy their own tax rates to ensure that they have fiscal autonomy. Even within metropolitan areas, however, a need to piggyback onto central government income taxes may exist. Piggybacking would significantly reduce the cost of administration.

FUEL TAXES. Governments levy municipal fuel taxes in many American jurisdictions and in a few of the larger Canadian municipalities, including Calgary, Edmonton, Montreal, Vancouver, and Victoria. Those cities that do levy a fuel tax generally piggyback onto state or provincial fuel taxes. The main reason is that the administrative costs of levying their own tax would be prohibitive. The revenues generated from these taxes are often earmarked for local roads and transit services in those cities, and, in some cases, these revenues are intended to replace previously provided provincial grants for these services.

A user charge on road users that reflects the marginal social cost of road use would result in an efficient use of the road. A share of the fuel tax for cities is not exactly the same as a direct user charge in the sense that it would not reflect the marginal social cost, but the fuel tax is nonetheless a benefits-based tax (Slack 2002). A municipal fuel tax is most appropriate for large metropolitan areas that have transit systems that would benefit from a dedicated source of revenue.

\section{Intergovernmental Transfers}

Transfers from senior levels of government are another source of revenue for local governments. The rationales for transfers include fiscal gap, externalities, and equity. In the case of large metropolitan areas, however, transfers may not be necessary. To reduce or eliminate the 
dependence of large metropolitan areas on intergovernmental transfers, governments may need to take other actions, such as assigning different revenue sources to large metropolitan areas than to other urban and rural areas and designing an appropriate governing structure.

FISCAL GAP. A fiscal imbalance exists when municipalities have inadequate revenues to meet their expenditure needs. Fiscal imbalance occurs at the local level essentially because local revenue sources tend to grow more slowly than income over time, while local expenditures tend to grow more quickly. Even though large metropolitan areas tend to have greater revenues than smaller cities, "few countries permit local governments to levy taxes capable of yielding sufficient revenue to meet expanding local needs" (Bird 2001).

Senior levels of government can address fiscal imbalance by increasing the sources of revenue at the local level or by reducing expenditure responsibilities. For example, if senior levels of government were to take over the funding of some services, then the local fiscal imbalance would be reduced. Alternatively, senior levels of government could allow local governments to raise revenues from additional tax sources. In particular, large metropolitan areas could be given access to more revenue sources, leaving unconditional grants for the smaller urban areas. Governing structure at the local level will also affect the size of the tax base and the capacity of a local government to meet expenditure requirements.

EXTERNALITIES. Where a service spills over municipal boundaries as, for example, in the case of regional highways, that service will receive an underallocation of resources, because the municipality providing the service bases its expenditure decisions only on the benefits captured within its jurisdiction. The municipality would not take account of the benefits to those outside the jurisdiction.

One way to provide an incentive to allocate more resources to the service generating the externality is a transfer from a senior level of government. The type of transfer appropriate for addressing externalities is a conditional matching grant (Bird and Slack 1993). It should be conditional in that it has to be spent on the service that generates the externality. It should be matching to reflect the extent of the externality. For example, if 50 percent of the benefits of highway expenditures spill over existing municipal boundaries, the matching rate should be 50 percent.

In the case of large metropolitan areas, externalities can be internalized within the jurisdiction if its boundaries are designed to reflect all the users of the service. For those services that generate externalities beyond the borders of the metropolitan area, providing a transfer may still be appropriate. These services may include, for example, education and health.

EQUITY. Some municipalities are unable to provide an adequate level of service at reasonable tax rates (Bird and Slack 1993). This may occur for three reasons: the costs of services may be too high, the need for services may be too high, and the tax base may be too small. Under these circumstances, an equalization grant is appropriate. The formula for a grant of this type reflects different per capita expenditures and different-sized tax bases in different municipalities.

The extent to which large metropolitan areas need equalization grants is unclear. In terms of the formula, a large metropolitan area generally does not qualify for equalization based on the size of its tax base because it is generally larger than the tax base of a smaller urban area. As noted earlier, the presence of economic activity and higher densities of residential, commercial, and industrial development all contribute to a larger tax base. On the expenditure side, however, the costs of services and the need for services may be higher than in other urban areas. ${ }^{5}$ If

5. The cost of services in remote areas tends to be even higher than in large metropolitan areas, however, because of higher transportation costs (greater distances), higher heating costs (climatic conditions), and so on. 
the equalization formula were to capture the higher costs, large metropolitan areas may be in a position to receive equalization grants.

Another way to achieve equity is to design the governing structure so that it covers the entire metropolitan area. By combining rich communities and poor communities, equalization can take place at least within the metropolitan area.

\section{Borrowing}

Borrowing is not a source of revenue, but is included here to show the differences in the ability of large metropolitan areas and other municipalities to access capital markets to finance capital expenditures. Local governments are generally not permitted to borrow to meet operating expenditure requirements. They are permitted to borrow to make capital expenditures, however. Where the benefits of a capital investment, for example, the construction of a water treatment plant, are enjoyed over a long period, say 25 years, paying for the project at least in part by borrowing may be fair and efficient. The stream of benefits matches the stream of costs through the payment of debt charges.

Local access to capital markets may be restricted, however, especially in developing countries (Bird 2001). Smaller municipalities, for example, may require a financing authority or state or provincial body to borrow on their behalf or to pool the borrowing requirements of several municipalities to reduce borrowing costs.

A municipality's bond rating largely dictates the rate of interest (and other features) necessary to make bonds marketable. This rating involves a detailed assessment of a municipality's capacity to bear debt and its capacity to raise revenue under normal and depressed economic circumstances. Generally the size of the municipality is negatively correlated with the interest rate attached to the debt instrument. This means that smaller local governments generally pay higher servicing costs than larger local governments.

Large metropolitan areas tend to have more access to bond markets than smaller municipalities, and debenture borrowing is therefore more prevalent in larger municipalities (and municipalities with higher bond ratings) than in small municipalities.

\section{Design of Local Government Structure}

Government structure should be designed to ensure that the local government provides the services that individuals and businesses want in a cost-effective manner. The main objective of designing the optimal government structure is usually to maximize the welfare of individuals. The welfare of individuals depends, at least in part, on the satisfaction they receive from local public goods and services. The optimal level of government is that which provides the desired level of local public goods and services at the least cost. Within this general framework, governments can use several criteria to design government structure: subsidiarity and local responsiveness, economies of scale, externalities, equity, access, and accountability.

\section{Subsidiarity Principle and Local Responsiveness}

The efficient provision of services requires that the level of government closest to the individual citizen carry out the decisionmaking. This is known as the subsidiarity principle and is needed for the efficient allocation of resources, accountability, and responsiveness. ${ }^{6}$ As long as

6. The Treaty of the European Union in 1992 originally included the subsidiarity principle in the context of the division of powers and responsibilities between European governmental bodies and their member countries. Governments have also applied the principle to the role and structure of government at all levels (Barnett 1997). 
local differences in tastes and costs exist, efficiency can clearly be gained from delivering services at the local level.

Higher levels of government should only take over expenditure responsibilities if they can demonstrate that they can carry out the function more efficiently than the lower level. With few exceptions, such as national defense and services that involve redistribution, almost all public services should be provided at the local level with local policymakers making decisions about what services to provide, how much to provide, and who should pay for them.

Public choice theory argues that small-scale, fragmented local governments have special advantages for local democracy because they maintain a quasi market. The proliferation of small government units in a metropolitan area results in competition among them. Tiebout (1956), for example, suggested that people vote with their feet, meaning that they move to the jurisdiction with the tax and expenditure package that most closely resembles what they want. ${ }^{7}$ This competition benefits citizens through increased efficiency in service delivery or through finding the municipality that has the basket of goods and services that most closely meets their tastes (Boyne 1992). A large urban government will be less efficient in meeting the demands of its residents because it will tend to provide a uniform level of public services to people who have different preferences for those services.

\section{Economies of Scale}

Economies of scale occur where the per unit cost of producing a particular service falls as the quantity of the service provided increases. However, using economies of scale as a criterion for designing government structure has problems. First, each urban service will likely achieve the lowest per unit cost at a different scale of production. For example, the optimal size of government may be different for fire services than for waste management. These differences mean that drawing boundaries for general-purpose local governments can be extremely difficult.

Second, the jurisdiction that provides the service is not necessarily the one that consumes it. If consumers are located in adjacent jurisdictions, then the producing jurisdiction could sell output to them. The producing jurisdiction could benefit from economies of scale in production without having to be part of a larger jurisdiction, that is, without requiring the larger population to be located within its own boundaries. A larger government jurisdiction is not necessarily required to achieve economies of scale because the demand and supply of local government services can be separated; economies of scale can be achieved even in a fragmented system.

Even if large government units can reap economies of scale for hard services, however, other ways are available to achieve these economies without having to create large jurisdictions. Furthermore, some evidence points to the higher costs from larger government units because of problems delivering services to remote areas within large jurisdictions or because of "bureaucratic congestion" (Boyne 1992, p. 336).

\section{Externalities}

The provision of some services results in externalities (spillovers) whereby the benefits (or costs) of a specific service in one local government jurisdiction spill over onto residents of another jurisdiction. One way to remove the resulting inefficiency is to design government jurisdictions large enough so that all of the benefits from a particular public service are enjoyed within the boundaries of that jurisdiction. Such boundary readjustments would internalize the

7. The Tiebout model assumes, among other characteristics, a large number of small, homogeneous local governments. Criticisms of the Tiebout model suggest that mobility has a cost that makes this adjustment less than automatic, that it excludes any discussion of externalities, and that it does not consider that people will vote other than with their feet. 
externalities, and those who benefit from the service will pay for it. As with economies of scale, however, the optimal size of a jurisdiction will be different for different services. Furthermore, the optimal jurisdiction from the point of view of internalizing externalities may conflict with the optimal size required to achieve economies of scale. Other ways to address externalities include provincial grants and coordination among municipalities.

\section{Equity}

Equity arguments are at least as important as efficiency arguments in designing government structure. Local government fragmentation means that some communities are likely to be rich and some poor. In these circumstances, the rich communities will have a more adequate tax base with which to provide services and may not have great demands for services, such as education or social services. However, the poor communities may require more services but have only a small tax base on which to levy taxes. The more municipalities within a metropolitan area, the greater this problem will be. One solution is to consolidate two or more areas into one jurisdiction, in effect taxing the rich municipalities and using some of the proceeds to subsidize the poor municipalities. An alternative approach is to shift the redistributive function to a senior level of government, or for the senior level of government to provide equalization transfers.

\section{Access and Accountability}

The access and accountability criteria suggest that citizens should have access to local government so that they can influence government policy. This is done through public meetings, hearings, elections, and direct contacts with officials (Bish 2001). Smaller government units can provide the average citizen with greater access to local decisions: "As the levels of consolidation and concentration in the local government system rise, so the capacity of the public to monitor policy makers' behavior falls" (Boyne 1992, p. 338). The larger the local government, the more likely that special interest groups will dominate citizen participation (Bish 2001).

Accountability is closely related to access: the more accessible politicians are to their constituents, the more easily they can be held accountable for their actions. A more fragmented system of local governments should increase public scrutiny and accountability and result in lower service costs. Accountability requires a link between expenditure and revenue decisions: the body making the decisions about how much to spend should be responsible for raising a large portion of the revenues it requires. "The costs of local decisions should be fully borne by those who make them" (Bird 2001, p. 117). If no accountability exists in decisionmaking, decisionmakers have no incentive to allocate resources efficiently across the competing services. Local governments must also be accountable to the central government to the extent that they receive transfers from it.

\section{Governance Models}

This section reviews four models-one-tier governments, two-tier governments, voluntary cooperation (including intermunicipal agreements), and special purpose districts and presents the advantages and disadvantages of each. Case studies from North American jurisdictions provide examples of how these models work in practice.

\section{One-Tier Model}

Under the one-tier model of urban governance, a single local government is responsible for providing the full range of local services and has a geographic boundary that covers the entire 
urban area. Large single-tier governments have generally been formed by amalgamation (merger of two or more lower-tier municipalities within an existing region) or by annexation (appropriation of a portion of a municipality by an adjacent municipality). Because only one level of government provides all municipal services, allocating expenditures among levels of local government (as in the two-tier model) is not necessary. In addition, only one political body makes taxing and spending decisions. One-tier governments can provide a wide range of services. These can be financed by a variety of user fees and tax sources that would be levied across the metropolitan area in the same way that the upper-tier municipality would finance services in the two-tier model.

One-tier cities can mean that the government provides uniform services throughout the metropolitan area, but this is not necessarily the case. Particularly where the amalgamation of several municipalities has created the one-tier municipality, maintaining the differential services and service levels that existed in different parts of the city-region prior to the creation of one tier is an option. For example, rural residents will not necessarily receive all the services available to urban residents.

For services financed by user fees, those who benefit from a service pay directly for it. Where property taxes finance services, special area rating can be used for those services where beneficiaries are restricted to specific areas. For example, if garbage collection is only provided in the urban parts of the municipality, then a special area rate for garbage would be levied on urban residents. All residents would pay the same general property tax rate; those in urban areas would pay both the general rate and the special area rate. ${ }^{8}$

In short, because services are not necessarily standardized across the new municipality, tax rates should also not be standardized. However, an opposing argument holds that one of the reasons for amalgamation is to create one jurisdiction that encompasses the entire city-region and that differences in service delivery and tax rates should not be maintained past a short transition period.

The main advantages cited for one-tier governments include better service coordination, clearer accountability, more streamlined decisionmaking, and greater efficiency (Boyne 1992). Furthermore, the funding of the provision of services is fair, because a wider tax base shares the costs of services that benefit taxpayers across the region. The larger taxable capacity of the onetier government increases its ability to borrow and to recover capital and operating costs from user fees (Bahl and Linn 1992).

The advantages of better service coordination, streamlined decisionmaking, and funding fairness are undisputed. From an efficiency perspective, municipal amalgamations have the potential to internalize externalities. For example, rural residents outside the original municipal boundary would now pay for the urban services that they use. ${ }^{9}$ Large one-tier governments can also take advantage of economies of scale in service provision.

However, some observers debate the success of a large one-tier government in achieving accountability and efficiency in terms of cost savings. In terms of accountability, some argue that a large-scale one-tier government reduces access and accountability because the jurisdiction becomes too large and bureaucratic. In some cases, community committees are established to address local issues, or satellite offices are distributed across the municipality where people

8. Special area rating has also been used to ensure that differences in reserves and debt of the constituent municipalities are reflected in their tax rates.

9. Municipal restructuring is only the first step in linking taxes to service benefits by ensuring that the beneficiaries are located within the jurisdiction providing the services. The second step is to identify the benefits received by residents and to tax residents accordingly. For example, while charging rural residents for their use of urban services such as recreation facilities and libraries is fair, charging them for garbage collection if they do not receive it is unfair (Vojnovic 2000). 
can pay tax bills, apply for building permits, and so on. ${ }^{10}$ These committees and satellite offices probably increase accessibility, but their effect on accountability is unclear. Furthermore, they remove any potential cost savings that might result from a larger government unit.

In terms of efficiency, evidence from municipal amalgamations suggests that cost savings are elusive (Slack 2000). Duplication of services tends to decrease when several municipalities are amalgamated, in particular, the number of politicians and bureaucrats decreases. However, a tendency for expenditure increases also exists when municipalities with different service levels and different wage scales merge.

As an example, when the fire departments of several municipalities are amalgamated, eliminating a number of fire chiefs, and maybe some deputy fire chiefs, is possible. Eliminating these positions will produce some cost savings. However, thousands of firefighters in the newly amalgamated municipality will now all be doing the same job, working for the same employer - the newly created city—and will want to be paid comparable salaries and benefits. Thus a tendency exists for salaries and benefits to equalize up to the highest-expenditure municipality. Although amalgamation presents potential cost savings, the harmonization of wages and salaries will likely outweigh the savings. ${ }^{11}$

Similarly, amalgamations result in the harmonization of service levels across the new municipality, and again these will equalize up to the highest service level enjoyed before the amalgamation (Slack 2000). The harmonization of service levels will also increase costs. These higher costs are not necessarily a bad thing. If some municipalities cannot afford to provide an adequate level of service because they do not have adequate resources, amalgamation allows them to provide a comparable level of service as that in other municipalities in the region. Such an amalgamation increases equity within the region.

A review of the empirical evidence in the United States on fragmented versus consolidated local governments concludes that lower spending is a feature of fragmented local government systems, while consolidated structures are associated with higher spending (Boyne 1992).${ }^{12}$ One reason is that amalgamation tends to reduce competition among municipalities because the government has less incentive to be concerned with efficiency and less incentive to be responsive to local needs. The lack of competition reduces efficiency in the delivery of services and results in higher costs. Boxes 6.1 and 6.2 provide examples of the one-tier model.

\section{Two-Tier Model}

The two-tier model consists of an upper-tier governing body, usually region, district, or metropolitan area, encompassing a fairly large geographic area and lower-tier or area municipalities, including cities, towns, villages, townships, and so forth. The upper tier provides regionwide

10. In 1971 the city of Winnipeg and its 12 area municipalities were amalgamated to form a single city. Even with its residents' advisory groups, observers felt that the city lacked responsiveness and accountability. These groups were subsequently abolished (Sancton 2000; Smith 1995). Montreal presents another example of amalgamation. The provincial government decided to merge the city of Montreal, with a population of 1 million, and 27 other municipalities on the island of Montreal, with a total population of 800,000, which took effect January 1, 2002. The new city was divided into 27 boroughs, each responsible for local services such as garbage collection, swimming pools, snow clearing, and libraries. Nine of the boroughs are located in the central city where no boroughs existed previously. Thus even though residents of the former suburbs lose control over some municipal services, residents of the former city of Montreal gain more autonomy.

11. Service delivery costs could also be reduced without changing government boundaries, for example, through the involvement of the private sector in municipal service delivery and the provision of services by one municipality to other municipalities.

12. Sancton (1996) reviewed municipal consolidations in three Canadian provinces and concluded that the evidence does not support the view that consolidations result in cost savings. 


\section{Box 6.1 Toronto after 1998: One-Tier Megacity}

On January 1, 1998, the new single-tier city of Toronto replaced the former metropolitan level of government and its constituent lower-tier municipalities (Toronto, Etobicoke, North York, Scarborough, York, and East York). This restructuring was not initiated locally, but by the provincial government through the passage of the 1996 City of Toronto Act. Indeed, opposition to the proposed amalgamation came from many different quarters, centered on the loss of local identity and reduced access to local government.

None of the studies of governance in the Greater Toronto Area (GTA) commissioned by the provincial government in recent years emphasized problems within Metropolitan Toronto or the need to create a megacity. Rather these studies identified problems with the coordination of transportation, planning, water provision, and waste management among the regions within the GTA and focused on the need for a GTA governing body to address these service coordination issues.

The stated rationale for creating a megacity was to achieve cost savings by avoiding waste and duplication. To the extent that two levels of government were involved in the provision of services, there was the potential for confusion and a lack of accountability, but, as noted earlier, whether a megacity would result in cost savings was not clear. Other reasons to create the megacity could have included the ability to coordinate services across municipal boundaries; the need to spread the costs of local government in general, and the costs of downloading in particular (downloading means that services previously funded, at least in part, by the provincial government now have to be funded at the local level), across a broader tax base; and the equalization of service levels. These were not mentioned at the time of the implementation of the megacity, however.

In terms of redistribution, the new city levies property taxes citywide to fund citywide services. The rates of property taxes on residential, commercial, and industrial properties are uniform across the new city. In those former municipalities that had a low tax base and high tax rate, a uniform rate across the new city has resulted in a property tax reduction. Similarly, for those municipalities with a large tax base and a low tax rate, a uniform rate has resulted in a tax increase. This result is similar to the kind of redistribution that occurred with the metropolitan portion of the property tax under the two-tier system. Now, however, 100 percent of the municipal property tax is pooled instead of only 50 percent.

Following the amalgamation of Toronto, the province also established the Greater Toronto Services Board (GTSB). The GTSB was given no legislative authority except to oversee regional transit. It was not designed to be a level of government nor was it given direct taxing authority. The GTSB comprised elected officials from each of the municipalities in the GTA. It has since been disbanded, however, and the provincial government has taken over the important function of regional transit.

Within the GTA, the costs of social services and social housing are pooled across the city-region through an equalization formula that measures the capacity of each municipality to contribute to these costs. Pooling means that the entire city-region is sharing the costs of these regionwide services. Each municipality that is part of the pooling, however, does not have a say over how the other municipalities spend their money on these services. Furthermore, the contributions of each municipality are uncertain from year to year because the service costs in other municipalities are beyond the control of any individual municipality.

The major concern about governance in the GTA has been the coordination of service delivery across the region. Neither the creation of the new city of Toronto nor the former GTSB has adequately addressed these fundamental regional problems. Evaluating the megacity in Toronto is probably premature. Nonetheless, some have argued that it is both too small and too big. It is too small to address regionwide spillovers related to transportation and planning and it is too big to be locally responsive and accessible (Slack 2000). Amalgamation has probably not resulted in cost savings, but it has resulted in a fairer sharing of the tax base and an equalization of local services so that everyone can enjoy a similar level of services across the city-region.

services characterized by economies of scale and externalities, whereas the lower tiers are responsible for services of a local nature. In this way, two-tier models help to resolve the conflict among the various criteria for designing government structure: economies of scale, externalities, and redistribution on the one hand and access and accountability on the other (Barlow 1994).

Redistribution throughout a city-region is achieved at the upper-tier level through a combination of tax and spending policies. On the tax side, governments generally levy tax rates at uniform rates across the region, and the contribution of each lower-tier municipality to the 


\section{Box 6.2 The Halifax Regional Municipality: Amalgamation to One-Tier with Special Area Rates}

In 1996 the Halifax Regional Municipality was created through the amalgamation of the cities of Halifax and Dartmouth, the town of Bedford, and Halifax County. Before the amalgamation, the former municipalities of the Halifax Regional Municipality had a complex tax system with four residential tax rates, four commercial tax rates, and more than 250 area property tax rates in Halifax County corresponding to the different levels of service provided (for a more detailed description of the Halifax amalgamation see Vojnovic 2000).

Following the amalgamation, policymakers recognized that services were provided at different levels in different parts of the new municipality, especially between the urban and rural areas, and that these differences should be reflected in property tax rates. The result is three base rates (urban, suburban, and rural), two additional customized rates for the two former cities, and more than 60 area rates in the new municipality. Urban rates differ from suburban rates to reflect the lack of public transit, sidewalks, and fire hydrants. Rural rates do not cover such services as public transit, streetlights, sidewalks, crosswalk guards, and recreation services. The 60 different area rates in the rural areas reflect the different standards of service in the various districts in the new municipality.

In designing the tax structure the Halifax Regional Municipality also considered the fiscal capacity of the former municipalities. An equalization transfer (50 cents per Can $\$ 1,000$ of assessment) is provided to the rural parts of the new municipality. The grant recognizes the rural areas' lack of fiscal capacity to provide adequate levels of service within their districts.

upper-tier municipality depends on the size of its tax base. The larger the tax base in any one municipality, the larger is its contribution to the upper-tier government.

On the spending side, the upper-tier government makes expenditures on regionwide services. These expenditures benefit the entire city-region and are not necessarily distributed among the lower-tier municipalities in the same way that the tax revenues are collected. The result is that a uniform property tax at the upper-tier level, combined with regionwide expenditures, serves to redistribute resources from the relatively large tax base municipalities to the relatively small tax base municipalities. Differentiation in service levels and tax rates for services provided by lower-tier municipalities will continue to exist.

Within the two-tier structure, the upper tier can charge user fees and levy property taxes, income taxes, and fuel taxes over the entire metropolitan area. It could also be responsible for borrowing for the entire area to achieve lower borrowing costs. The lower tiers could rely more on user fees and property taxes to pay for local services.

With two-tier governments, allocating functions among the tiers is necessary. To do this, the criteria for governing structure can be applied. The upper tier should be responsible for services that provide regionwide benefits, generate externalities, entail some redistribution, and display economies of scale. Services that provide local benefits should be the responsibility of the lower tier. Table 6.2 applies these criteria to the various public services provided at the local level to determine the appropriate level of government to provide them.

Two-tier systems permit any desired degree of redistribution, but also have potentially important advantages in terms of accountability, efficiency, and local responsiveness. Critics of the two-tier model argue that costs are higher because of waste and duplication in the provision of services by two levels of government. Furthermore, two-tier levels of government are less transparent and more confusing to taxpayers who cannot figure out who is responsible for what services. Finally, "critics assert that the existence of two councils leads to wrangling, inefficient decision making, and delays in implementing policies" (Kitchen 2002, p. 312). An example of the two-tier model is presented in box 6.3.

\section{Voluntary Cooperation}

Voluntary cooperation has been described as "minimal" government restructuring in which there is an "area-wide body based on voluntary cooperation between existing units of local 
Table 6.2 Allocation of Expenditure Responsibilities in a Two-Tier Model

\begin{tabular}{|c|c|c|c|}
\hline Function & Upper tier & Lower tier & Justification \\
\hline Welfare assistance & $\mathrm{x}$ & & Income redistribution and externalities \\
\hline Childcare services & $x$ & & Income redistribution and externalities \\
\hline Low-income housing & $\mathrm{X}$ & & $\begin{array}{l}\text { Income redistribution, economies of scale, and } \\
\text { externalities }\end{array}$ \\
\hline Public health & $\mathrm{X}$ & & $\begin{array}{l}\text { Income redistribution, economies of scale, and } \\
\text { externalities }\end{array}$ \\
\hline Ambulances & $x$ & & Economies of scale and externalities \\
\hline Roads and bridges & $\mathrm{X}$ & $\mathrm{X}$ & Local versus regional roads \\
\hline Public transit & $\mathrm{X}$ & & Externalities and economies of scale \\
\hline Street lighting & & $x$ & No externalities \\
\hline Sidewalks & & $x$ & No externalities \\
\hline Water system & $x$ & & Economies of scale \\
\hline Sewer system & $x$ & & Economies of scale \\
\hline Garbage collection & $x$ & & Economies of scale and externalities \\
\hline Garbage disposal & $x$ & & Economies of scale and externalities \\
\hline Police protection & $x$ & & Externalities and economies of scale \\
\hline Fire suppression & & $x$ & $\begin{array}{l}\text { Local responsiveness and scale economies for } \\
\text { specialized services }\end{array}$ \\
\hline Fire prevention and training & $x$ & & Economies of scale \\
\hline Local land use planning & & $X$ & Local access and responsiveness \\
\hline Regional land use planning & $x$ & & Externalities \\
\hline Economic development & $x$ & & Externalities \\
\hline Parks and recreation & & $x$ & Local responsiveness \\
\hline Libraries & & $x$ & Local responsiveness \\
\hline
\end{tabular}

Source: Author.

government in the agglomeration with no permanent, independent institutional status" (Sharpe 1995, p. 12). These are common in France and the United States, in part, because they are politically easy to create and also can be easily disbanded. The voluntary model is included under the governance of metropolitan regions even though it does not include an elected areawide government. It is included because it recognizes the inter-relationship of cities within the region with some form of areawide arrangement.

Cooperation can take different forms, which include consortiums, communities of communes, urban communities (France), joint intermunicipal authorities (Belgium and Spain), public bodies, joint agency, and core cities (the Netherlands) (Zoltán and others 1999). These forms of cooperation include administrative and political integration in that member local governments provide some form of representation on the boards. These organizations can levy taxes or collect contributions from the municipalities, or they can levy user fees to pay for services.

Voluntary cooperation is an alternative way of providing services across a region without resorting to amalgamation. Municipalities can retain their autonomy with respect to expenditure and tax decisions, but at the same time achieve economies of scale in service delivery and address externalities associated with service provision (Sharpe 1995). Problems of accountability can arise, however, when another jurisdiction provides services. Redistribution throughout the metropolitan area is not automatic in a system of voluntary cooperation, but could be agreed upon by the municipalities involved.

The voluntary model can work well when all policymakers in the various local governments share policy objectives. Thus any additional institutional arrangements would be unnecessary. 


\section{Box 6.3 Toronto 1954 to 1997: An Example of Two-Tier Government}

Metropolitan Toronto was created by provincial legislation on January 1, 1954. It had a two-tier government structure with a metropolitan tier that encompassed 13 lower-tier municipalities (reduced to 6 in 1967). The two-tier government structure was created for three reasons:

- Redistribution. The creation of a metropolitan level of government allowed for the relative wealth of the central city to be used to pay for services in the suburbs. By the mid-1950s, the central city had no vacant land for development. The suburban municipalities did not have sufficient resources to provide the infrastructure required for new development: educational facilities, roads, water, and other services. The creation of a metropolitan tier of government allowed the wealth of the central city (measured by the size of its property tax base) to be redistributed to the suburbs to provide needed services.

- Externalities. The metropolitan government could coordinate land use planning and transportation across the city-region. Fragmented local governments had meant that services such as transportation and land use planning were not coordinated across the city-region. As the benefits of these services spilled over into other jurisdictions, a governing body with wider jurisdiction was increasingly needed to coordinate the provision of these services.

- Responsiveness to local preferences: At the same time that the metropolitan government could be used to address issues of redistribution and spillovers, the lower tiers could provide the local services that they could afford. These lower tiers could be more responsive to local needs than could a large metropolitan government that provided uniform services across a broader area. Smaller governments also provided easier access for residents.

In the two-tier government structure in Metropolitan Toronto, both levels of government were involved in providing services. The metropolitan level was responsible for borrowing, transit, police services, social assistance, traffic control and operations, licensing, conservation, waste disposal, and ambulance services. Lower-tier governments were responsible for fire protection, garbage collection, licensing and inspection, local distribution of hydroelectric power, public health, recreation and community services, and tax collection. Both tiers shared responsibility for parks, planning, roads and traffic control, sewage disposal, and water supply.

Redistribution within the metropolitan area was achieved through a combination of tax and spending policies. On the tax side, the main source of local revenue to the metropolitan government was the property tax levied on residential, commercial, and industrial properties (the revenue sources for both levels of government are similar: property taxes, provincial grants, user fees, and other miscellaneous revenues). Because it was levied at a uniform rate across the metropolitan area (the rate was different on each class of property, but the same across the metropolitan area), the contribution of each municipality to the metropolitan government depended on the size of its property tax base. About half of the property tax for municipal purposes was returned to the metropolitan government, while the other half was kept at the local level. This means that about half of municipal property tax revenues were redistributed throughout the metropolitan area.

On the spending side, the metropolitan government made expenditures on regionwide services. A uniform property tax at the metropolitan level, combined with metropolitanwide expenditures, redistributed resources from the relatively assessment-rich municipalities to the relatively assessment-poor municipalities.

Early reviews of the two-tier government applauded its success at meeting its intended objectives: spillovers of benefits from transportation and planning were contained within the metropolitan area, redistribution from the central city to the suburbs allowed the latter to provide needed infrastructure, and lower-tier municipalities retained the ability to differentiate local services. More recently, however, some observers have expressed concerns about the metropolitan government's ability to address issues arising from growth outside its borders. Observers have also expressed concerns about overlapping responsibilities, confusion, and uncertain accountability in a two-tier structure.

It may not work so well, however, when objectives are divergent. Cooperation usually involves bargaining, and some municipalities may not have anything to bargain with. The problems metropolitan areas face are significant_-global competition, fiscal disparities, and sprawl—and the solutions may require them to rely on a structure with a permanent institutional status. Boxes 6.4 and 6.5 present examples of voluntary cooperation. 


\section{Box 6.4 Greater Vancouver Regional District: Voluntary Cooperation within a Two-Tier Structure}

The model of voluntary cooperation that is most often cited in the Canadian context is the Greater Vancouver Regional District (GVRD). Prior to 1965, special-purpose bodies, such as the Joint Sewerage and Drainage Board, the Greater Vancouver Water District, various health and hospital boards, the Lower Mainland Regional Planning Board, and the Industrial Development Commission of Greater Vancouver handled intermunicipal services in metropolitan Vancouver (Sancton 1994). These single-purpose bodies were completely voluntary.

The GVRD was created in 1967 as part of a system of regional governments being created by the provincial government in British Columbia at that time. The newly created GVRD took over the functions of the special-purpose bodies. It was originally responsible for hospitals and planning, but has grown to include borrowing for municipalities, air pollution control, parks, solid waste disposal, public housing, collective labor relations, and public transit. The GVRD was created to increase municipal cooperation, but not to introduce a new level of government.

The GVRD encompasses just over 1.8 million people and comprises 18 municipalities as full members and three unincorporated areas. The GVRD differs from regional government in a number of respects: (a) member municipalities can opt out of many district functions; (b) districts provide different functions for different areas within their boundaries, especially for unincorporated areas; and (c) all municipal representatives on the district board of directors are elected to their municipal councils and appointed by their respective governments to serve on the board.

The GVRD bills member municipalities for services. The cost of most services is apportioned among member municipalities on the basis of the property assessment base. Other regional costs are contained in municipal charges for water, sewer, and solid waste. GVRD services account for 12 percent of a property owner's tax bill, on average. The bulk of GVRD expenditures, 90 percent, are for capital costs of hospitals, water, sewerage, and solid waste disposal.

Voluntary participation by individual municipal governments and an approach of consensus building have always characterized regional organization in the Vancouver area. As Oberlander and Smith (1993, p. 333) note: "Metropolitan governance has emerged in place of metropolitan government in the Vancouver region; that is, metropolitanwide services and their spatial implications are managed regionally in the absence of metropolitan government." The difference between regional governance and regional government is that a government has the following characteristics: representation, revenue-raising capacity, autonomy, authority, and the capacity to coordinate multiple functions (Oberlander and Smith 1993).

The advantages of the Vancouver model are that it preserves local autonomy, diversity, and the distinct identity of its member municipalities. Problems have arisen, however, because of the lack of authority to implement policies. In the area of planning, for example, the 1994 master plan promised to slow down the disappearance of farmland, to concentrate housing, and to build rapid transit, but none of the municipalities are obligated to respect the plan. Another disadvantage is that the Vancouver model is ineffective in ensuring that regional concerns are taken into account in local decisions. No one speaks for the region (the chair and board members are part-time regional politicians); it can only do what its member municipalities delegate to it.

If a distinct upper-tier government directly accountable to residents is the goal, then the Vancouver model does not work as well as regional government. If, however, the goal is to have a flexible institution to help municipalities do things they cannot do themselves, then the voluntary cooperation model along the lines of the GVRD has some advantages. Some observers have argued that the intermunicipal confederation works best for consulting on goals and visions, but does not work so well for implementing those goals (Artibise 1999).

A further problem with voluntary cooperation in Vancouver is the inequitable sharing of costs and benefits. Even though the GVRD has developed a fair system for services such as water and sewers, which are charged for on the basis of the level of service provided, the same is not true for cultural and recreational facilities and municipally-funded social services. Taxpayers in the core (the city of Vancouver) fund the latter services in their entirety, even though the benefits of these services spill over to residents throughout the region. 


\section{Box 6.5 Minneapolis-Saint Paul Region: Property Tax Base Sharing}

In the early 1990s, some of the cities in the region had to raise their taxes dramatically and cut services because of increasing social responsibilities. At the same time, others were reducing taxes and maintaining high levels of service. The idea behind regionalizing the property tax base was to make the growing property wealth available to all parts of the region to meet social needs.

Under this system, each city contributes 40 percent of the growth in its commercial and industrial tax base acquired after 1971 to a regional pool. On an annual basis, this amounts to about 20 percent of the regional tax base. Money is distributed from this pool on the basis of inverse net commercial capacity. This method reduces the tax base disparities on a regional level from 50 to 1 to 12 to 1 (Orfield 1997).

Property tax base sharing also reduces the fiscal incentives for exclusionary zoning and urban sprawl. In the absence of sharing, communities have an incentive to increase their tax base and limit social expenditures by using exclusionary zoning. One way to achieve this objective is to encourage low-density development because it requires large lots and therefore expensive housing. Regional sharing of taxes on expensive houses weakens local fiscal incentives to create this type of housing.

Although tax base sharing can decrease intrametropolitan competition for tax base, apparently a lot of competition for tax base in the region still exists (Orfield 1997). Furthermore, cities with a higher than average commercial base, but with low-valued home and increasing social need, contribute tax base. Cities with high-valued homes and little commercial development receive money from this system.

\section{Intermunicipal Agreements}

Intermunicipal agreements are formal or informal agreements between municipalities to provide services. They are a type of voluntary cooperation, but they are less structured in that there is no official areawide body to oversee the arrangements. An example of an intermunicipal agreement is the contract services plan in Los Angeles, whereby Los Angeles County provides some services on behalf of municipalities in the Los Angeles metropolitan area on a contract basis. A city-county link occurs in other U.S. jurisdictions as well (Sharpe 1995).

These types of agreements have generally been effective for services such as firefighting and emergency dispatch, maintaining boundary roads, purchasing in bulk, and issuing debentures. Municipalities generally enter into agreements as a way to reduce costs or to set out joint obligations for different municipalities.

Intermunicipal agreements work well for small services that can be contracted out or for sharing costs. However, intermunicipal agreements provide no accountability except through the contract or agreement. If something goes wrong, citizens have difficulty knowing where to complain. Do they complain to their local government or the local government that has been contracted to provide the service? Intermunicipal agreements also increase the likelihood of intermunicipal litigation and conflicts (GTA Task Force 1996).

Although intermunicipal agreements are successful in achieving coordination and efficiencies for specific services, they are not suitable for achieving regionwide coordination. Intermunicipal agreements have been described as a second-best solution to reorganization that can lead to "an impenetrable jungle of $a d$ hoc commissions and complex arrangements that even the most conscientious municipal voter will never understand" (Sancton 1993, pp. 33-34).

\section{Special-Purpose Districts}

Special-purpose districts to deliver services that spill over municipal boundaries are another alternative to altering municipal boundaries. Single-purpose special districts provide similar municipal services for several municipalities or manage regional services with externalities. This form of cooperation among municipalities for regionwide services is common in 
countries with a history of strong and autonomous local governments. In the United States, for example, one-third of local governments are special districts or school districts that provide education, transportation, water and waste management, economic development, and other services. Joint boards of the special districts are responsible for managing these services and taxing, price setting, and other policymaking. The individual municipal councils indirectly control these districts.

One of the advantages of special-purpose districts is that each service spillover can be addressed individually. Because the spillover boundaries are unlikely to be the same for each service, municipalities could establish separate districts such as a regionwide transit districts or hospital districts. ${ }^{13}$ Other advantages include the delivery of services with decisionmaking somewhat removed from political influence, the ability to provide services with more professional expertise than may be available to the municipal government, and the ability to use dedicated revenues from user fees to finance capital expenditures (Bahl and Linn 1992).

Observers have identified several problems with special-purpose bodies. First, each body has responsibility for a single service and is not required to make the trade-offs between, for example, expenditures on transit and expenditures on water and sewers. Second, the proliferation of decisionmaking bodies has "created a diffuseness of government organizations that is difficult for citizens to understand." (Kitchen 1993, p. 14). Special-purpose bodies have no citizen control and confused accountability. Third, no direct link exists between the expenditure decisions the special purpose agencies make and the local council, which collects property taxes to fund them; for example, the local municipality accounts for upper-tier and school board taxes when it sets its own levy, but it has no control over upper-tire or school board levies (Locke and Tassonyi 1993). The absence of a link between expenditures and revenues reduces accountability. Fourth, where accountability is lacking, the incentive to be efficient is nonexistent. Fifth, when the number of independent special-purpose bodies is large, coordinating interrelated activities becomes difficult.

Bahl and Linn (1992) have suggested three ways to address the problems of coordination. The first is to encourage overlapping membership so that some of the same people are on a number of district boards. The second is to encourage multifunctional districts instead of single purpose districts. The third is to control the operations of the districts so that they remain separate authorities, but are still subject to political considerations in the decisionmaking process.

\section{Provincial or National Takeover}

Some observers have suggested that national or provincial governments should coordinate services that spill over municipal boundaries. For example, provincial or state governments could take over functions such as regional planning and regional economic development. They could also facilitate intermunicipal agreements to improve the coordination of services such as water, waste management, and transit. This coordination function could be done through a provincial ministry or department.

Although provincial or national takeover of regional services may effectively address the provision of services that exhibit externalities, it would violate the principle of subsidiarity that

13. Special districts are an example of functional, overlapping, and competing jurisdictions. The concept envisages that "welfare could be improved substantially by promoting competition between newly emerging jurisdictions that are organized along functions instead of territories" (Frey and Eichenberger 1996, p. 315). These would be governments in that they would have enforcement power and would be able to levy taxes, they would extend over areas defined by the functions they are responsible for, they would overlap geographically, and individuals and communities could choose which governmental unit they wanted to belong to (Frey and Eichenberger 1996). 
suggests that services are more efficiently and effectively delivered by the level of government closest to citizens. Based on this principle, regional coordination would be more effective and more accountable than provincial coordination.

\section{Concluding Comments on Governing Large Metropolitan Areas}

The size, concentration, and composition of the population of large metropolitan areas make such areas different from other urban or rural areas. From a fiscal perspective, these factors mean that these areas may have greater needs than other municipalities (although their costs may be lower) and greater ability to levy taxes. For this reason, granting them more fiscal autonomy - the ability to make expenditure decisions and set tax rates-than other urban areas may be appropriate. Large metropolitan areas will also be able to rely less on transfers from senior levels of government.

The governing structure of large metropolitan areas will affect their ability to provide services and raise revenues in a fair and efficient way. However, determining the best model of governance for large metropolitan areas is difficult. Out of the wide variety of existing metropolitan government structures "no model stands out as clearly superior in all respects" (McMillan 1997, p. 39). Application of the criteria for designing government structure to the various models presented, however, suggests the following:

- Some form of regional structure that encompasses the entire city-region is needed to address problems of a regionwide nature, such as fiscal disparities among municipalities and problems associated with externalities in service provision. Although the need for a regional structure is clear, the form it takes will vary with local circumstances. Intermunicipal agreements for the provision of services are effective for a small number of services, but do not provide a solution to the need for regional cooperation.

- A one-tier structure is simpler to understand and more transparent than a two-tier structure. For that reason, it appears to enhance political and fiscal accountability. Twotier structures, however, are inherently more complex and may result in undesirable duplication, overlap, and general confusion among citizens as to who is responsible for what and who is paying for it.

- Municipalities can achieve redistribution within a one-tier or a two-tier structure. In a one-tier structure with uniform tax rates across the city-region, all taxes are made available for redistribution. In a one-tier structure with special area rates or in a twotier structure, less than 100 percent of tax revenues will be available for redistribution.

- A two-tier structure may achieve greater efficiency than a more centralized one-tier structure is likely to achieve. Desirable economies of scale can be realized the upper-tier level, while the lower tier permits more responsiveness to local variations in preferences and maintains the close link between local financing and spending decisions.

- Where local autonomy is paramount and where policymakers in various local governments share objectives, voluntary cooperation can work. It works less well when objectives differ among local governments and when it comes time to implement those objectives.

City-regions face a number of fiscal and other challenges, unique to large metropolitan areas. What works best in terms of governing structure in particular circumstances depends on policy priorities, the scope and type of local responsibilities, the instruments of local finance, and the degree and nature of central-provincial presence in the metropolitan area in terms of service provision and financial support. "Any attempt to define one ideal size of a city-region or one ideal form of governance would be doomed to failure" (Sancton 2000, p. 7). 


\section{References}

Artibise, Alan F. J. 1999. "Regional Governance without Regional Government: The Strengths and Weaknesses of the Greater Vancouver Regional District." Report prepared for the Regional Municipality of Ottawa-Carleton, Ottawa.

Bahl, Roy, and Johannes Linn. 1992. Urban Public Finance in Developing Countries. New York: Oxford University Press.

Barlow, Max. 1994. "Centralization and Decentralization in the Governing of Cities and Metropolitan Regions." In Robert J. Bennett, ed., Local Government and Market Decentralization: Experiences in Industrialized, Developing, and Former Eastern Bloc Countries. Tokyo: United Nations University Press.

Barnett, Richard, R. 1997. "Subsidiarity, Enabling Government, and Local Governance." In Paul A. R. Hobson and France St-Hilaire, eds., Urban Governance and Finance: A Question of Who Does What. Montreal: Institute for Research on Public Policy.

Bird, Richard, M. 1984. "Intergovernmental Finance in Colombia." Final report of the mission on intergovernmental finance. Cambridge, Mass.: Harvard University Law School.

. 2001. "Setting the Stage: Municipal and Intergovernmental Finance." In Mila Freire and Richard Stren, eds., The Challenge of Urban Government: Policies and Practices. Washington, D.C.: World Bank Institute.

Bird, Richard, and Enid Slack. 1993. Urban Public Finance in Canada, 2nd ed. Toronto: John Wiley.

Bish, Robert L. 2001. Local Government Amalgamations: Discredited 19th Century Ideals Alive in the 21st. Toronto: C. D. Howe Institute.

Boyne, George. 1992. "Local Government Structure and Performance: Lessons from America?" Public Administration 70(Autumn): 338-57.

Burki, Shahid Javed, Guillermo E. Perry, and William Dillinger. 1999. Beyond the Center: Decentralizing the State. Washington, D.C.: World Bank.

Freire, Mila. 2001. "Introduction." In Mila Freire and Richard Stren, eds., The Challenge of Urban Government: Policies and Practices. Washington, D.C.: World Bank Institute.

Frey, Bruno, and Reiner Eichenberger. 1996. "FOJC: Competitive Governments for Europe." International Review of Law and Economics 16(3): 315-27.

GTA (Greater Toronto Area) Task Force. 1996. Greater Toronto. Toronto.

Kitchen, Harry. 1993. "Efficient Delivery of Local Government Services." Discussion Paper no. 93-15. Queen's University, School of Policy Studies, Government and Competitiveness Project, Kingston, Ontario.

2002. Municipal Revenue and Expenditure Issues in Canada. Toronto: Canadian Tax Foundation.

Locke, Wade, and Almos Tassonyi. 1993. "Shared Tax Bases and Local Public Expenditure Decisions." Canadian Tax Journal 41(5): 941-57.

McMillan, Melville. 1997. "Taxation and Expenditure Patterns in Major City-Regions: An International Perspective and Lessons for Canada." In Paul A.R. Hobson and France St-Hilaire, eds., Urban Governance and Finance: A Question of Who Does What. Montreal: Institute for Research on Public Policy.

Nowlan, David, 1994. “Local Taxation as an Instrument of Policy.” In Frances Frisken, ed., The Changing Canadian Metropolis: A Public Policy Perspective, vol. 2. Berkeley, Calif.: Institute of Governmental Studies Press. 
Oberlander, H. Peter, and Patrick J. Smith. 1993. “Governing Metropolitan Vancouver: Regional Intergovernmental Relations in British Columbia." In Donald N. Rothblatt and Andrew Sancton, eds., Metropolitan Governance: American/Canadian Intergovernmental Perspectives. Berkeley, California: University of California, Institute for Governmental Studies.

OECD (Organisation for Economic Co-operation and Development). 2000. Revenue Statistics 1965-1999. Paris.

Orfield, Myron. 1997. Metropolitics: A Regional Agenda for Community and Stability. Washington, D.C and Cambridge, Mass..: The Brookings Institution and Lincoln Institute of Land Policy.

Osborne, David, and Ted Gaebler. 1992. Reinventing Government-How the Entrepreneurial Spirit Is Transforming the Public Sector. Reading, Mass.: Addison-Wesley.

Sancton, Andrew. 1993. "Local Government Reorganization in Canada since 1975." Intergovernmental Committee on Urban and Regional Research, Toronto.

1994. Governing Canada's City-Regions: Adapting Form to Function. Montreal: Institute for Research on Public Policy.

. 1996. "Reducing Costs by Consolidating Municipalities: New Brunswick, Nova Scotia, and Ontario." Canadian Public Administration 39(3): 267-89.

.2000. Merger Mania: An Assault on Local Government. Westmount, Quebec: PricePatterson.

Sharpe, L. J., ed. 1995. "The Future of Metropolitan Government." In The Government of World Cities: The Future of the Metro Model. Chichester, U.K.: John Wiley.

Slack, Enid. 2000. "A Preliminary Assessment of the New City of Toronto." Canadian Journal of Regional Science 23(1): 13-29.

2002. Municipal Finance and the Pattern of Urban Growth. C. D. Howe Institute Commentary no. 160. Toronto: C. D. Howe Institute.

Smith, Patrick J. 1995. “Governing Metropolitan Change: Public Policy and Governance in Canada's City Regions." In James Lightbody, ed., Canadian Metropolitics: Governing Our Cities. Toronto: Copp Clark.

Thirsk, Wayne. 1982. "Political Sensitivity Versus Economic Sensibility: A Tale of Two Property Taxes." In Wayne Thirsk and John Whalley, eds., Tax Policy Options in the 1980s. Toronto: Canadian Tax Foundation.

Tiebout, Charles. 1956. "A Pure Theory of Local Government Expenditures." Journal of Political Economy 64(October): 416-24.

Vojnovic, Igor. 2000. "Municipal Consolidation, Regional Planning, and Fiscal Accountability: The Recent Experience in Two Maritime Provinces." Canadian Journal of Regional Science 23(1): 49-72.

Zoltán, Hermann, M. Tamás Horváth, Gábor Péteri, and Gábor Ungvári. 1999. Allocation of Local Government Functions: Criteria and Conditions-Analysis and Policy Proposals for Hungary. Washington, D.C.: Fiscal Decentralization Initiative for Central and Eastern Europe. 


\title{
Providing Public Services in Remote Areas
}

\author{
Harry Kitchen and Enid Slack
}

Governing remote areas raises different issues than governing urban areas because of the small size of the population, the lack of concentration of population, and the high cost of living. These characteristics mean that expenditures per capita are often much higher in remote areas than in urban areas. At the same time, the fiscal base tends to be smaller, because property is not privately owned and levels of employment and income are low. Governance of remote areas raises questions about local governments' ability to deliver services and the role of senior levels of government in funding and delivering local services. It also raises a more fundamental question of whether or not settlements in remote areas should be subsidized by senior levels of government.

The purpose of this chapter is to review ways to provide services in remote areas. The first section outlines the characteristics of remote areas and raises issues pertaining to the role of local government. The second section reviews local government expenditures in remote communities and indicates how the characteristics of these areas affect the nature and magnitude of expenditures. The third section looks at the revenue sources of remote areas and how they are affected by the size and remoteness of these communities. The fourth section presents and evaluates alternative government structures that can be used in remote areas, such as two-tier structures, one-tier structures, intermunicipal agreements, and special-purpose districts, and the role of senior levels of government.

\section{Characteristics of Remote Areas}

Although small or remote areas do not have universal characteristics, some common themes can be found (Dougherty, Klase, and Song 1999). Remote areas are characterized by geographic isolation and low population density. Communities tend to be sparsely populated, and the distance between them is considerable. In addition, they are generally noncontiguous. Often these communities have no publicly provided overland transportation system, such as roads and rail. Most municipalities in remote areas are subject to harsher climatic conditions than those living in the more populated and urbanized parts of the country. Many of these communities have higher unemployment rates because of fewer job opportunities and greater dependence on social service programs. As the second and third sections will show, the combination of these factors contributes to higher per capita costs of public services and a smaller tax base.

In some instances, remote communities are not organized into local government units and are called unincorporated areas. Any municipal functions that are required are generally provided by departments of senior levels of government, such as departments of regional affairs, transportation, natural resources, the environment, and so forth, in return for a small tax payment.

In some remote communities, municipal institutions have been slow to form because the communities were built and operated as company towns. In these cases municipal services are provided by the companies for their employees. This phenomenon has been common in Russia, where enterprises have provided services to their employees and their families that elsewhere are provided by local governments. For example, as Wallich (1994, p. 39) states: "Enterprises build and support hospitals, construct and maintain housing, build and run 
kindergartens and preschools, and make 'voluntary donations' toward financing public transport and to extrabudgetary funds of subnational governments." Although the extent to which the funding of services by enterprises varies across Russia, almost all social expenditures are made by enterprises in single-enterprise company towns.

Wallich (1994) identifies some of the problems with this practice. First, it is a form of hidden taxation, because enterprises are providing services rather than paying taxes and user fees for publicly provided services. Second, the provision of public services in this way does not allow local residents to reveal their preferences. Third, expenditures on public services place a burden on enterprises and put them at a disadvantage in the market economy. To the extent that these services are considered to be fringe benefits that are necessary to attract labor, however, the first and third points may be less relevant. In the sparsely settled areas of several countries (for example, Australia and Canada), communities are often characterized by a dual economy. On the one hand, the relatively stable native population is engaged for the most part in either low-wage occupations in line with their generally low skill and educational levels, are engaged in low-paying traditional occupations (hunting and trapping, for example), are engaged in some combination of these activities, or are unemployed. On the other hand, a highly mobile nonnative population is employed in remote communities whether they are full-time residents (like most government employees) or transitory workers (for instance, in mining and construction). In both cases, the highly mobile populations are well paid because of the nature of their occupations (skill and educational levels) and as compensation for enduring harsh living conditions. The concentration of income at the upper and lower ends of the income scale is the direct consequence of an economy characterized by a dual labor market.

Municipal governments in remote areas have generally been confined to population centers. Historically, communities in remote areas were established for a number of reasons. Some were based on a particular industry, such as mining, forestry, agriculture, fishing, or oil; some were regional service centers that provided a range of private and public services to the surrounding population; some were centers of indigenous peoples; and some were created for national security reasons. The existence of communities in remote areas today reflects these historical reasons even though, in some cases, they are no longer valid. For example, companies may have shut down, regional service centers may have moved, and national security in remote areas may no longer be an issue.

People continue to live in these communities, however. The issue is not whether they should continue to live there, but whether they should be subsidized. If a town loses the economic basis for its existence and no viable alternatives are available, continuing to subsidize these areas is not in the economic interests of senior levels of government (Graham 1963). These subsidies may prevent ghost towns from occurring, but they distort the allocation of resources. Although economic arguments would support the abandonment of these communities, political realities may keep them alive.

\section{Local Government in Remote Areas}

In terms of economic theory, the major role assigned to local governments is to provide goods and services within a particular geographic area to residents who are willing to pay for them (see Bird and Slack 1993, p. 16, for a discussion of the role of local government). If the benefits of particular services are confined to local jurisdictions (the actions of one municipality have no effect on other municipalities), efficiency is enhanced, because the mix and level of services can vary according to local preferences. The provision of local services does not mean that municipalities have to produce the goods and services themselves, however. Rather, the role of local government is to make decisions about which services to provide and how to provide them. Municipalities could, for example, contract out service delivery to another government or to the private sector (see Osborne and Gaebler 1992). 
A strong local government is one that is efficient and effective in service delivery, on the one hand, and accountable and responsive to its citizens on the other. Municipalities have to be small enough to provide access and large enough to be able to support a wide range of services in an efficient and effective way. If the municipality is too small and remote to deliver services effectively, however, political access is meaningless. In particular, municipalities need an adequate tax base and qualified personnel.

Some small municipalities do not have a large enough tax base to be economically viable. In particular, they often cannot finance major capital expenditures, such as road graders and fire equipment. Their limited debt capacity further inhibits their ability to make capital expenditures. Because the size of the population is small, these municipalities cannot take advantage of economies of scale in service provision. Furthermore, their remoteness prevents them from taking advantage of economies of scale by contracting out services to neighboring municipalities or to the private sector. As a result, small communities in remote areas tend to concentrate on providing a few basic services (Dougherty, Klase, and Song 1999).

Inadequate resources also mean that small and remote communities may face administrative difficulties, because they are unable to find suitably qualified full-time staff. These communities have limited training opportunities to develop and maintain qualified personnel (Dougherty, Klase, and Song 1999). Some municipalities operate with a part-time staff; others operate with a staff that is required to have a wide range of expertise because specialization is virtually impossible (Kurlyandskaya, Nikolayenko, and Golovanova 2001). The lack of qualified staff limits elected officials' ability to respond to their constituents' needs (Consultation Committee to the Minister of Municipal Affairs 1989). Some of these problems may be overcome, however, by contracting out to other governments or the private sector or by sharing expertise among municipalities. Technology can also improve efficiency and provide easy access to needed expertise.

In terms of access and accountability, the lack of mobility of large segments of the population in remote communities brings into question the role of local government. If residents are not mobile, they are unlikely to respond to taxes and expenditures by moving to other communities. To the extent that the efficiency of local government relies on it being responsive to local citizens, its role in remote areas is less significant than in urban areas (see Litvack, Ahmad, and Bird 1998 for a discussion of the limitations of "voice" and "exit" in smaller municipalities and rural areas in developing countries where mobility is limited).

\section{Local Government Expenditures in Remote Areas}

The role of local government in remote areas tends to be much weaker than in urban areas. Because of the vast distances involved, services such as police and fire protection are limited, garbage collection is non-existent, and land use planning is often performed by a senior level of government. Local services mainly comprise roads, sewer and water, garbage disposal, social services, and recreation. With respect to water and sewers in rural areas, public health considerations require that governments regulate and monitor the quality of water from private systems. With respect to garbage disposal, a need also exists to ensure that garbage is transported to landfill sites.

To illustrate the differences between per capita expenditures in remote areas and more populated areas, table 7.1 compares population density and per capita costs of providing government services in Canada's three northern territories, Yukon, Northwest Territories, and Nunavut, with the rest of Canada. This comparison is made for municipalities alone and for the consolidated territorial/municipal sector. Municipal expenditures per capita indicate the level of spending made by municipalities alone. Consolidated municipal/territorial expenditures indicate the level of spending by both sectors combined. The latter measure is appropriate where service responsibility is split between two levels of government. For example, social 
services are a territorial responsibility in the Yukon and are split between the municipal and territorial sector in the Northwest Territories and Nunavut.

Table 7.1 shows clearly that the population density is much lower in these remote territories than in the rest of Canada, and also that variation is considerable across the territories. The variation in population density accounts for a considerable portion of the variation in per capita expenditures. For the municipal sector alone, the following differences are noted with respect to expenditures per capita:

- Municipal spending on all services is considerably higher in remote areas than in the rest of Canada. Municipal spending is 41 percent higher in the Yukon, 173 percent higher in the Northwest Territories, and 171 percent higher in Nunavut.

- General government expenditures are considerably higher in the north than in the rest of Canada. This can be attributed to municipalities' small size and their inability to take advantage of economies of scale in administration.

- Fire and police expenditures are lower in the north, primarily because fire protection equipment is much less sophisticated than in more urban areas. In addition, the north does not have any high-rise buildings and has a relatively small geographical area to cover. The response time cannot compare with that in urban areas because of the distances involved, and the north does not have externalities, because the properties are so far apart. Policing is almost always the responsibility of a senior level of government because of economies of scale associated with the policing.

- Expenditures on roads, water, and sewers are higher in the north because of the harsh climatic conditions and terrain (tundra).

- Expenditures on recreation and culture are considerably higher in the north. Almost every municipality has an ice arena and a variety of recreational programs.

When consolidated territorial/municipal per capita expenditures are compared for the remote areas with the rest of Canada, the following are noted:

- Municipal/territorial spending on all services is substantially higher in remote areas: 129 percent higher in the Yukon, 188 percent higher in the Northwest Territories, and 224 percent higher in Nunavut.

- Administration expenditures are considerably higher in remote areas by a factor of close to 10 or more.

- Expenditures on fire, police, transportation, water, sewers, solid waste, housing, and recreation are significantly higher in remote areas.

- Spending on education, health, and social services significantly exceeds that in more populated and urban areas.

\section{Local Revenues in Remote Areas}

Under the benefit model of local government finance, charges should be levied to pay for services, wherever possible. Where user charges cannot be used because the benefits of a particular service are not confined to individual consumers, but are confined within the municipal boundary, taxes that are borne by local residents are considered to be appropriate. These taxes allow individuals to express their demand for services where benefits are consumed collectively.

As noted earlier, expenditures per capita are generally higher in remote areas than in other local communities. Indeed, they can even be higher in remote areas than in large metropolitan areas. Unlike large metropolitan areas, however, remote areas do not generally have sufficient capacity to finance these expenditures. To the extent that local governments in remote communities are responsible for delivering services, however, the local governments require some local 
Table 7.1 Expenditures Per Capita, by Municipal Sector, 2000, and Consolidated Provincial/Local or Territorial/Local Sector, 2000-01 (Can\$)

\begin{tabular}{|c|c|c|c|c|c|c|c|c|}
\hline \multirow[b]{2}{*}{ Expenditure } & \multicolumn{2}{|c|}{ Yukon } & \multicolumn{2}{|c|}{ Northwest Territories } & \multicolumn{2}{|c|}{ Nunavut } & \multicolumn{2}{|c|}{ Rest of Canada } \\
\hline & Municipal & Consolidated & Municipal & Consolidated & Municipal & Consolidated & Municipal & Consolidated \\
\hline General administration & 531 & 2,338 & 658 & 2,155 & 775 & 3,752 & 162 & 259 \\
\hline Protection & 164 & 1,627 & 167 & 1,713 & 124 & 2,217 & 237 & 457 \\
\hline Transportation & 383 & 2,811 & 675 & 2,790 & 562 & 1,968 & 295 & 482 \\
\hline Health & 4 & 2,527 & 411 & 4,657 & 63 & 4,868 & 29 & 2,207 \\
\hline Social services & 0 & 2,404 & 88 & 1,758 & 203 & 1,556 & 188 & 1,305 \\
\hline Education & 0 & 3,861 & 0 & 4,909 & 0 & 8,911 & 6 & 1,891 \\
\hline Resource conservation & 727 & 1,474 & 101 & 2,312 & 25 & 1,300 & 30 & 284 \\
\hline Environment & 329 & 545 & 829 & 756 & 1,036 & 1,643 & 207 & 240 \\
\hline Recreation, culture & 560 & 1,141 & 811 & 943 & 643 & 950 & 164 & 220 \\
\hline Housing & 1 & 659 & 91 & 1,749 & 444 & 2,394 & 38 & 94 \\
\hline Regional planning & 68 & 153 & 134 & 589 & 90 & 874 & 32 & 55 \\
\hline Debt charges & 24 & 130 & 57 & 368 & 11 & 278 & 89 & 962 \\
\hline Other & 5 & 36 & 40 & 57 & 54 & 159 & 8 & 133 \\
\hline Total & 2,796 & 19,706 & 4,062 & 4,756 & 4,030 & 30,870 & 1,485 & 8,589 \\
\hline Population & \multicolumn{2}{|c|}{29,900} & \multicolumn{2}{|c|}{40,900} & \multicolumn{2}{|c|}{28,200} & \multicolumn{2}{|c|}{$30,982,900$} \\
\hline Population per square ki & \multicolumn{2}{|c|}{0.063} & \multicolumn{2}{|c|}{0.035} & \multicolumn{2}{|c|}{0.015} & \multicolumn{2}{|c|}{5.63} \\
\hline
\end{tabular}

Source: Calculated from Statistics Canada (2001a,b); Financial Management Systems data. 
taxing authority to reinforce local autonomy and to promote accountability. Local governments in remote areas should therefore have access to revenue sources that can be exploited locally, and they should be encouraged to exploit them as much as possible. As Bird and Slack (1991, p. 84) state: "Unless local governments are given some degrees of freedom, including the freedom to make mistakes for which they are accountable, the development of responsible and responsive local government will remain an unattainable mirage." In theory, the sources of revenue available to local governments in remote areas are the same as local governments elsewhere. These include user fees, taxes (property, income, sales, fuel, and possibly poll taxes), and intergovernmental transfers. In reality, however, the characteristics of the tax base in remote areas restricts the use of many of these revenue sources, and the high cost of services means that user fees are less likely to cover the full cost of service provision.

\section{User Fees}

User fees recover at least a portion, if not all, of the costs of some services, such as water and sewers, in remote areas. Although reliance on these fees varies across remote communities, the proportion of total local revenues attributed to user fees is higher in two of three territories (Northwest Territories and Nunavut) than in the rest of Canada. This difference may be attributed to the higher cost of services for which user fees are charged in remote areas.

Charging user fees has many advantages. First, they promote efficiency in the consumption of goods and services. Users know how much it costs to provide services and can make an informed choice about how much to consume. When consumers do not know the cost, they are likely to consume more or less than what is efficient. Second, user fees allow the government to know the quantity and quality of goods and services that people want. Without direct charging, citizens do not have a mechanism (except for voting every few years) to register their demand for local goods and services. Third, user fees satisfy the equity principle when equity is based on benefits received. All individuals pay an amount that reflects the additional benefit they receive from a unit of the good or service.

Wherever possible, user fees should reflect the marginal cost of providing the service. A problem with charging the marginal cost in remote areas, however, is that costs can be significantly higher than in other communities. For example, the marginal cost of supplying water to people in remote areas is much higher than in urban areas. If the marginal cost is charged, some people might not be able to pay it and would likely leave these communities if they are not subsidized. In other words, charging a fee that reflects the true marginal cost of providing services to remote areas could reduce the number of people living there.

Subsidies provide an incentive to consume more water than is efficient. Furthermore, subsidies for water would benefit both low-income and high-income people. Although subsidizing the cost of services in remote areas is unlikely to result in an efficient level of service, it may nevertheless be justified to meet other objectives, for example, regional development, security, and so forth.

A problem with charging for services in remote areas concerns the cost of administration. Determining the appropriate amount of the charge and enforcing it can both be costly. If the administrative costs exceed the revenues collected, user charges may not be worthwhile.

User fees are appropriate for recreational services in urban areas, but may be less appropriate in remote areas. In remote areas externalities are associated with arenas and recreation centers, because the benefits of these services extend beyond the users of the facilities. One could argue, for example, that arenas and recreation centers provide a social service to the community, especially for youth, because remote communities have few alternatives. If full-cost pricing is charged, those who would use the facility might otherwise engage in less socially acceptable activities. In other words, significant external benefits call for at least some subsidization. Similarly, user fees for garbage (solid waste) disposal may act as a disincentive for using the 
service and may encourage individuals to dispose of their garbage on land outside the municipal boundary.

\section{Taxes}

Taxes borne by local residents might include property taxes; local income taxes; consumptionbased taxes, such as sales and fuel taxes; and poll taxes.

PROPERTY TAXES. As table 7.2 shows, property taxes represent almost 54 percent of total revenues of local governments for Canada as a whole. They only account for 5 percent in Nunavut, however, and 13.6 percent in the Northwest Territories. Property taxes are 44 percent of local government revenues in the Yukon. In some other countries with remote areas, property taxes are not important. For example, they are not used in Sweden and are used only minimally in Finland and Norway (Organisation for Economic Co-operation and Development 2000).

A tax on property is a good tax for municipalities. The tax base is immobile because only people move, so taxing property is relatively efficient. In addition, a local tax on all properties, owned or rented, is desirable to promote local autonomy, accountability, and fairness. If discrepancies exist in the size of the tax base across local communities in remote areas, these may be handled through an equalization grant.

Even though one could argue that local governments should be granted taxing authority to meet their expenditure requirements, some communities have difficulty levying a property tax, because the tax base is limited relative to local needs. One reason is the lack of private ownership of properties in remote areas, resulting in few properties to tax. Furthermore, the value of properties in remote communities tends to be much lower than the value in urban areas, and is often lower than the cost of construction. In Eastern European countries, where the market for housing is just developing in cities, assessing market value for properties in remote areas may be impossible. For this reason an alternative assessment base may be required. One possibility could include assessment on the basis of unit value, such as unit size and lot size (for a discussion of unit value assessment see Slack, LaFaver, and Shpak 1998). The proportion of property tax revenues levied on agricultural land, forests, mines, and pipelines is likely to be higher in remote areas than in urban areas. The nature of these properties requires different tax treatment than other commercial and industrial properties. For example, agricultural land and forests are often valued at current use rather than highest and best use, tax rates are often lower than for other properties, and in some countries farm properties and forests are exempt from property taxation altogether (Slack 2001a). Mines and minerals are generally exempt except for surface land and office buildings not connected with the mining operation. Mineral resources are usually taxed on the basis of profits, acreage, or assessment of mineral values (Kitchen 1992). Pipelines are usually assessed on the basis of pipe length and diameter.

Pipeline properties, unlike other commercial and industrial properties, have extensive linear networks that are not specific to any one municipality. Pipelines pass through urban areas, rural areas, and remote areas, and they receive limited services. Unlike the other special properties mentioned, pipelines have less of a link to the communities they traverse, so the municipal level does not have any accountability for the taxes levied.

For properties owned by senior levels of government in remote communities, as elsewhere, payments in lieu of taxes are required from the senior level of government to pay for local services. Failure to make these payments means that these properties receive services without paying for them, which puts senior government properties at an advantage compared with other commercial and industrial properties. Furthermore, the costs of these services will have to be picked up by other properties through higher taxes.

The levying of property taxes by municipal governments in remote areas does not mean that municipalities need to determine the assessment base. Assessment can be expensive and could 
Table 7.2 Revenues Per Capita, by Municipal Sector, 2000, and Consolidated Provincial/Local or Territorial/Local Sector, 2000-01 (Can\$)

\begin{tabular}{|c|c|c|c|c|c|c|c|c|}
\hline \multirow[b]{2}{*}{ Revenue source } & \multicolumn{2}{|c|}{ Yukon } & \multicolumn{2}{|c|}{ Northwest Territories } & \multicolumn{2}{|c|}{ Nunavut } & \multicolumn{2}{|c|}{ Rest of Canada } \\
\hline & Municipal & Consolidated & Municipal & Consolidated & Municipal & Consolidated & Municipal & Consolidated \\
\hline Own source revenue & 1,079 & 5,140 & 2,058 & 10,755 & 1,323 & 5,146 & 1,193 & 7,929 \\
\hline Income taxes & 0 & 1,396 & 0 & 4,054 & 0 & 636 & 0 & 2,201 \\
\hline Consumption taxes & 0 & 669 & 0 & 924 & 0 & 404 & 0 & 1,520 \\
\hline Property and related taxes & 688 & 760 & 568 & 953 & 197 & 311 & 776 & 1,335 \\
\hline Other taxes & 18 & 189 & 23 & 250 & 5 & 61 & 18 & 506 \\
\hline $\begin{array}{l}\text { Contributions to social } \\
\text { insurance }\end{array}$ & 0 & 202 & 0 & 394 & 0 & 224 & 0 & 262 \\
\hline User fees & 310 & 825 & 1,342 & 2,804 & 1,091 & 2,062 & 308 & 937 \\
\hline Investment income & 54 & 1,040 & 105 & 730 & 25 & 339 & 73 & 959 \\
\hline Other revenues & 11 & 59 & 20 & 649 & 5 & 1,109 & 17 & 141 \\
\hline Total grants & 504 & 13,439 & 2,104 & 14,243 & 2,537 & 21,208 & 255 & 1,021 \\
\hline Unconditional grants & 313 & 11,065 & 341 & 11,627 & 262 & 19,439 & 38 & 810 \\
\hline Conditional grants & 192 & 2,374 & 1,762 & 2,616 & 2,275 & 1,849 & 217 & 211 \\
\hline Federal & 2 & - & 12 & - & 10 & - & 11 & - \\
\hline Provincial & 190 & - & 1,751 & - & 2,265 & - & 206 & - \\
\hline Averages of all revenues & 1,583 & 18,583 & 4,162 & 24,996 & 3,861 & 26,434 & 1,448 & 8,949 \\
\hline
\end{tabular}

- Not available.

Source: Calculated from Statistics Canada (2001a,b); Financial Management Systems data. 
be the responsibility of a senior level of government, as it is in Canada and many other countries. A further advantage of centralizing the assessment function comes from the implementation of uniform assessment practices across all municipalities. Uniformity establishes a level playing field and permits municipalities to set their own tax rates to meet their financial and economic objectives.

In unincorporated communities in countries where property taxes are used, the property taxes have to be administered by a senior level of government because there is no local government. Tax proceeds are used to finance a portion of the costs of the limited number of services, for example, landfill sites and local roads, that are provided to residents of these areas.

INCOME TAXES. A potential source of revenue for local governments in remote areas is an income tax. For each local government in these areas to levy its own income tax would be far too costly; at most they could piggyback onto the income tax base of a senior level of government. Rates may be uniform across all municipalities, or they could vary by municipality. Uniform rates do not permit the same degree of local autonomy as locally determined rates.

Income taxes are the most important source of local tax revenue in a number of countries with remote communities. For example, income taxes account for 100 percent of all local tax revenue in Sweden, 96 percent of all local tax revenue in Finland, and 90 percent in Norway. Australia and Canada, other countries with many remote municipalities, do not use local income taxes at all (Organisation for Economic Co-operation and Development 2000).

While local income taxes have advantages in large metropolitan areas (Slack 2001b), some of these advantages disappear in remote communities, where problems exist in relation to the prevalence of a dual economy and more frequent worker mobility. In remote communities, many high-income workers are employed in seasonal occupations. They live in the community during the work season and relocate to urban and less remote areas in the off-season. The imposition of an income tax by a remote municipality becomes problematic if the tax is based on place of permanent residency, as it is in many countries. The municipality where the workers earned their incomes and benefited from municipally provided services for part of the year would not receive any tax revenue from them. A further impediment to levying income taxes in remote areas in developing countries arises from administrative and compliance problems (McClure 2001). Individuals in these countries have a history of never filing income tax returns. Furthermore, reliance on local income tax revenues to fund municipal services permits lowerincome individuals with no income tax liability to use these services at no cost. This creates the potential for overconsumption and waste in the provision of public services.

One possible solution might be to implement a payroll tax on all employers and selfemployed residents of the municipality, with the municipality retaining the tax revenue. This, however, also poses problems. The tax base would exclude higher-income individuals who use municipal services, but who are not in the labor force because they are retired or voluntarily unemployed. Because the tax base would be smaller than the income tax base, tax rates would have to be higher to generate the same amount of tax revenue.

When local property taxes are compared with local income taxes for remote communities, the former are likely to produce a closer link between taxes paid by individuals and the use of municipal services funded by these taxes. The closer this link, the greater the likelihood that some degree of local autonomy, accountability, and efficiency will be achieved in service provision. This view is often not shared by individuals who purchase rural properties for vacation use and argue that they receive fewer services and should therefore pay lower taxes than permanent residents. Although this argument may have some merit on the basis of benefits received, it is less defensible on the basis of ability to pay.

CONSUMPTION-BASED TAXES. This section considers two consumption-based taxes: a general sales tax and a municipal fuel tax. 
Some countries permit municipalities to tax businesses, for example, tourism facilities, through a crude gross receipts or categorical lump-sum tax. This section only looks at taxes on consumers. Reliance on a municipal sales tax tends not to be prevalent in countries with many remote areas, although it is used in several countries with relatively few communities in remote areas (Organisation for Economic Co-Operation and Development 2000). As with the income tax, the most feasible option for a general sales tax would be to piggyback onto the sales tax of a more senior level of government. The tax rate could be uniform across all municipalities, or it could be determined locally, with the latter providing more local autonomy than the former.

The rationale for a municipal sales tax in remote areas may be stronger than for a municipal income tax, mainly because the sales tax base is less mobile. Consumers in one municipality are unlikely to shop elsewhere to avoid the tax or tax differential because of distance and travel costs. Furthermore, the tax collects revenue from high-income and low-income earners and from permanent residents and visitors alike. As long as this revenue is used to fund local services, a somewhat closer link may be formed between the consumers of local public services and payment for these services than exists under a local income tax. This link, however, is not likely to be as close as it would be under a property tax.

Some Canadian and U.S. municipalities levy municipal fuel taxes (Slack 2001b). Generally these taxes are piggybacked onto state or provincial fuel taxes, because the administrative costs of a local tax would be prohibitive. The greatest amount of local autonomy would be achieved where municipalities were permitted to set their own tax rate. The revenues generated from these taxes are often earmarked for local roads and transit services.

Because the vast majority of roads in remote communities do not extend beyond the boundaries of the community, a tax on fuel could be viewed as a tax on residents and businesses that benefit from the local road system. The tax would increase local autonomy and be fair in terms of the benefits received principle. In addition, it might be more acceptable politically if the revenues are earmarked for funding local roads.

Those who support earmarking do so because it creates a link between the cost of a program and the tax rate necessary to fund it. Opponents argue that it can lead to rigidity in budgetary decisions and overspending, because of unwillingness to periodically review the relative benefits of spending on the earmarked service. Nevertheless, political acceptance of earmarked taxes for roads in remote areas may be higher if funded from a local fuel tax than from the general property tax or some other tax.

A potential disadvantage of a local fuel tax in remote areas is the increased cost of fuel that might result from higher taxes. Fuel costs are already considerably higher than in more urban areas, and an additional tax would likely raise them even further. Higher fuel taxes may serve to discourage businesses from locating in remote areas, although business location decisions in many of these communities are unlikely to depend on the price of fuel. Businesses are there because of a specific resource (mining, oil, or logging) or because they serve the local market (delivery of oil to homes, building construction, or operation of the few stores that serve the community). Distance from markets and cost of production, in reality, are simply too high to induce other firms or businesses to move to these areas.

POLL TAXES. The poll tax (or head tax) is a tax of a specific value that is imposed on each individual. It bears no direct relationship to property values, nor is it based on any concept of ability to pay. The local tax base is directly dependent on the number of residents in the community, usually adult residents only. A poll tax is considered to be the most efficient tax that local governments could adopt, because it is a fixed charge on all eligible taxpayers. Because a poll tax does not change the relative price of consumption or other types of activities, it does not provide an incentive for individuals to alter their behavior to reduce the tax.

Local government in the United Kingdom levied a poll tax (known as the community charge) for a short time, but it was replaced by a property tax (council tax) in 1993 (King 1988). 
The poll tax was extremely unpopular, because it was seen as regressive, that is, born relatively more heavily by low-income households than high-income households, and because it was costly to administer. Unlike property, which is highly visible and in a fixed location, individual taxpayers were able to escape full reporting of the total number of taxable occupants.

Although the poll tax may not be appropriate in large urban areas for the reasons previously noted, it may have some merit in remote areas. The lack of a sizable income, sales, or property tax base combined with the importance of having some local taxing authority and accountability might justify a poll tax in remote communities. Furthermore, it may be more difficult to escape full reporting in a small community.

\section{Intergovernmental Transfers}

Communities in remote areas generally rely more heavily on federal and provincial or state transfers than do communities in urban areas. In Canada, for example, municipalities on average receive 18 percent of their revenues from provincial grants (see table 7.2). This compares with 32 percent in the Yukon, 51 percent in the Northwest Territories, and 66 percent in Nunavut. The following paragraphs provide three economic justifications for intergovernmental transfers: the fiscal gap, externalities, and equity.

FISCAL GAP. When municipalities have inadequate revenues to meet their expenditure needs, they are suffering from a fiscal imbalance or fiscal gap. Fiscal imbalance occurs at the local level essentially because local revenue sources tend to grow more slowly than income over time, but local expenditures tend to grow more quickly. This is true in remote areas in the same way as in urban areas.

Fiscal imbalance can be addressed by increasing the sources of revenue at the local level or by reducing expenditure responsibilities. While large metropolitan areas could be given access to more revenue sources (Slack 2001b), this is unlikely to work as well for remote communities. Some increases in user fees and property taxes or poll taxes may be appropriate, as argued previously, but this is unlikely to be sufficient to eliminate the fiscal gap. This means either that the central government will either have to take over functions from the local governments or will have to provide unconditional grants. Grants to reduce or eliminate the fiscal gap would be unconditional in the sense that local governments could spend the funds on any function or use them to reduce taxes. In other words, the trade-off between expenditures and taxes and among different types of expenditures would remain with the local government.

EXTERNALITIES. Another rationale for central government transfers is externalities. Where services spill over municipal boundaries, an underallocation of resources to that service will occur, because the municipality providing the services would base its expenditure decisions only on the benefits captured within its jurisdiction. It would not take into account the benefits to those outside the jurisdiction (Slack 2001b). One way to provide an incentive to allocate more resources to the service generating the externality is a conditional, matching transfer from a senior level of government. It should be conditional in that it has to be spent on the service that generates the externality; it should be matching to reflect the extent of the externality. This rationale for central government transfers is not as applicable to remote areas as it is for urban areas. By definition, remote communities are isolated, and any spillover of service benefits to other jurisdictions is unlikely to occur. They are simply too far away to enjoy the benefits.

EQUITY. Some municipalities are unable to provide an adequate level of service at reasonable tax rates (Bird and Slack 1993). This may occur for three reasons: the costs of services may be higher, the need for services may be higher, and the tax base may be smaller. These three reasons are all relevant in remote areas. 
Under these circumstances, an equalization grant, which reflects both the fiscal capacity of the municipality and its expenditure needs, is appropriate. The definition and measurement of these two components presents a challenge, however. The formula must be designed in a way that does not discourage municipalities from collecting own source revenues or from finding other ways of balancing their revenues and expenditures (Martinez-Vazquez and Boex 2001), such as amalgamating communities, establishment of service boards to share costs, and so forth.

Perhaps the best national to subnational (municipal) grant equalization scheme is the one used in Australia. In each state or territory, calculations are made for both standard expenditures and revenues. Standard expenditures are calculated for each of 20 municipal functions by taking the product of the following (Commonwealth Grants Commission 2001):

- The council's relevant unit of need (such as population, number of households served, kilometers of roads

- The standard cost per unit of need (usually the average cost of that service or function within the state)

- A discount factor (total expenditure on the function discounted by revenue received from specific grants and certain other sources)

- A disability factor, which compensates the council for factors beyond its control, such as socioeconomic profile, possibly expressed as a percentage of the state average, physical terrain, or isolation

Within this basic framework, state to state differences may exist in the following:

- Measurement of disability factors

- Extent to which socioeconomic characteristics are emphasized and measured

- Degree of community isolation or remoteness that is recognized

- Number of qualitative factors included in measuring a particular service

- Weighting applied to improvements in local governments' management practices and structural reform

Standardized revenue for each municipality is obtained by multiplying the municipal tax base (property assessment) by the average (or implied) rate across all municipalities in the state. The difference between estimated expenditure needs and revenue potential is the basis for determining the municipality's share of equalization funds. The available funds, however, are generally less than the amount required to achieve full equalization.

In Australia, the Northern Territory, which contains the majority of remote areas and a high proportion of the aboriginal population, is included in the overall national government equalization formula. Higher expenditures of remote areas are recognized and compensated for in the equalization formula through the use of disability factors. For the Northern Territory, fewer categories of expenditures involve redistribution. Two categories-general administration and transportation-account for 90 percent of the total redistribution. One of the disability factors reflects the proportion of the population comprising aboriginal people. In the Northern Territory, the aboriginal factor accounts for one-third of the funds that are redistributed.

In Canada, the federal government provides equalization grants to the provinces and territories, which in turn use their own formulas to distribute funds to local governments. The federal grant to the territories is based on a different formula than the grant to the provinces. Box 7.1 compares these two formulas.

\section{Design of Government Structure}

A variety of options may be considered for structuring municipal government in municipalities in remote areas. These include two tier, single tier for all services, intermunicipal agreements, 
Box 7.1 A Comparison of Federal-Provincial and Federal-Territorial Equalization Grants in Canada

The federal-provincial equalization grant compares the per capita tax yield at national average tax rates for each province with the average per capita tax yield at national average tax rates for five representative provinces, for each of 34 provincial and local revenue sources.

The federal-territorial equalization grant is based on 1992-93 expenditures in the territories escalated in line with the growth in total provincial and local government expenditures and population in each territory. The base amounts are reduced to take taxes levied into account. These reductions are adjusted to reflect the tax effort in each territory in 1987-88. The grants are then adjusted by two special factors: the catch-up factor is equal to the ratio of territorial fiscal capacity relative to actual collections and has been set at 1.40, and the keep-up factor is the change in the provincial and local tax effort index for Canada since 1987-88.

A comparison of federal equalization grants to the provinces and the territories shows the following:

- Expenditures are explicitly included in the federal-territorial formula, but are proxied by revenues per capita in the federal-provincial formula.

- No allowance is made for differential needs or costs in the federal-provincial formula.

The tax rate in the provincial-territorial formula is fixed at a base-year level, whereas the national average tax rate in the federal-provincial formula changes each year.

special-purpose districts, senior levels of government responsible for funding some municipal services, and increased reliance on grants (for a discussion of similar options for metropolitan areas see Slack 2001b).

Each of these options is evaluated according to its ability to achieve a number of criteria. These include the capacity to benefit from economies of scale, the opportunity to internalize spillovers (external benefits and costs), the capacity for being accessible and accountable to citizens, the opportunity for citizens to satisfy local preferences, and the ability to fund expenditures in a fair and equitable manner (Slack 2001b).

The structure that may best satisfy these criteria in large metropolitan or urban areas with a number of contiguous municipalities (cities, towns, villages, and townships that are adjacent to each other) providing a wide range of services will likely differ from the structure that will meet the criteria in municipalities in remote areas. Municipalities in remote areas are generally far apart and deliver few services. Each of these structures is summarized in the following paragraphs along with a discussion of their applicability to remote communities.

\section{Two Tier}

A two-tier municipal structure is generally appropriate in large geographic and metropolitan areas where a number of contiguous municipalities are responsible for a variety of municipal services. In two-tier structures the upper tier is generally responsible for services that benefit the entire region, district, or area; that generate benefit or cost spillovers (externalities) across the entire area; that are primarily income redistributional (social services or social housing); that display economies of scale (water, sewer, and solid waste); and that are to be provided at uniform levels and standards across the entire area. For services that do not display these characteristics and where local responsiveness is important, responsibility generally rests with the local municipality. For an illustration of who should do what in a two-tier municipal structure based on allocation according to these criteria see Slack (2001b).

Within a two-tier structure, each level of government has its own revenue base (local taxes and user charges). For lower-tier services funding comes from a local revenue base that is contained within the local community. For upper-tier services the revenue base encompasses the entire area. Grants from a senior level of government can also play a role. 
In remote areas where municipalities are isolated from each other, distances are such that the benefits or costs of services provided by one municipality are unlikely to spill over into adjacent municipalities. Similarly, distances between municipalities and their isolation from each other prevent them from benefiting from economies of scale in the provision of services whose costs per unit decline as the number of residents served increases. Hence the rationale for a two-tier structure at the municipal level in remote areas is far less compelling than it is for larger metropolitan areas.

\section{Single Tier}

In a single-tier structure only one level of municipal government is responsible for all municipal services. Almost every country has a number of single-tier municipalities. Some exist in large metropolitan areas and some exist in small, isolated communities. Although a single tier is one of a number of potentially viable options for large metropolitan or urban areas, it is almost certain to be the only feasible one for municipalities in remote areas. These municipalities are generally small and isolated from each other. This means that there are no externalities from services they provide and that they cannot benefit from economies of scale. Hence there is no apparent role for an upper-tier level of municipal government.

What differentiates large metropolitan or urban areas from small, rural, and isolated municipalities in remote areas is the fiscal impact of their expenditure responsibilities. For example, higher per unit costs of service delivery are generally observed in the latter (see table 7.1). In addition, these municipalities almost always have a smaller and less diversified revenue base from which they can raise locally generated revenues. This combination of higher per unit costs and lower fiscal capacity raises the question of whether or not ways exist within this single-tier structure for providing local services in a less costly fashion or whether they should be funded differently than in larger metropolitan areas. The following subsections discuss some of these options.

\section{Intermunicipal Agreements}

An intermunicipal agreement exists when one municipality agrees contractually to buy a service from another municipality, generally an adjacent municipality. These agreements may exist for a variety of services, but are most common for water provision, fire and police protection, and maintenance of roads (snowplowing in particular). They are used more frequently in small municipalities (villages and townships, for example) than in large municipalities (cities and towns). The rationale for entering an agreement is almost always cost savings. Buying the service from an adjacent municipality is deemed to be less costly than for the municipality to provide it on its own, because the local municipality can achieve benefits from economies of scale.

Although these agreements have been used for a long time in many smaller, contiguous municipalities, they are unlikely to work or be appropriate where municipalities, such as those in remote areas, are isolated from each other. A municipality is unlikely to benefit from buying services from other municipalities where distances between them are large.

\section{Special-Purpose Districts}

In areas with a number of contiguous municipalities, some countries use special-purpose districts to provide a range of services for each municipality within the district. Although specialpurpose districts are not common in Russia, some examples exist, such as a specialized medical center in the Gatchina raion of the Leningrad oblast that provides services to more than one municipality (Kurlyandskaya, Nikolayenko, and Golovanova 2001). 
Service responsibilities of special-purpose districts generally include those that generate externalities, benefit from economies of scale, are income redistributional, and for which district-wide uniform standards are important. Where special-purpose districts exist, they play the same role and perform the same functions as an upper-tier level of municipal government in a two-tier structure. Special-purpose districts are less formal in terms of governing structure, however, because they generally have a board with members appointed from the different municipal councils. Even in metropolitan areas, issues of accountability exist around special districts. For reasons that are similar to the rejection of a two-tier structure for noncontiguous municipalities in remote areas, special-purpose districts are also rejected as being inappropriate and ineffective.

\section{Role for Senior Levels of Government}

Given that municipalities in remote areas are unable to take advantage of economies of scale in service provision, and given their smaller and less diversified tax base, one option is that senior levels of government provide local services instead of municipalities. Although this option could reduce local taxes and user fees, it would seriously hinder accountability, because there would be no direct link between individual consumption of a service and payment for it. When individuals receive a service for which they are not taxed or charged a fee, an incentive exists for them to consume more than they would if they paid for it. For example, in rural communities in Ontario, policing was provided by the provincial government at no charge until 1998. Failure to charge for policing provided an incentive to overuse the service.

The provision of services by a senior level of government raises concerns about local responsiveness. It may be less appropriate for a senior level of government to provide services because it is further removed from local residents. This makes determining the quality and quantity of output to provide in each municipality difficult. Senior levels of government are likely to be less responsive and less accountable to local residents than a local government.

\section{Grants}

Another option is for senior levels of government to provide grant assistance to communities in remote areas and have the municipalities deliver and fund local services themselves. If service provision is considerably more expensive (as shown in table 7.1, for example) and considerably higher levels of financial assistance are required (as shown in table 7.2), a question exists about the use of national or provincial/state resources to foster communities artificially in remote areas. The issue is not whether taxpayers in remote communities should be excluded from paying for municipal services. Clearly, they should pay at least some of the costs of services if accountability, fairness, and efficiency are to be achieved. An important issue is whether communities that cannot survive in the absence of disproportionate senior government funding (when compared with other urban areas) should exist at all.

Arguments can be made for and against government subsidization of remote areas. If a municipality in a remote area is essential for the provision of an important public service, such as national security, the public good benefit of this service and the externalities associated with it may justify higher grant assistance from senior levels of government to keep these communities viable. If the existence of municipalities in remote areas does not provide public good benefits, there may be less justification for large subsidies to these communities. For example, in the case of a company town where the municipality's existence is vital to the company's success, justification for grant funding is less obvious.

The argument against subsidizing remote areas is based on efficiency. Reliance on grant funding reduces the incentive for residents of these municipalities to leave and move to areas where with greater employment and educational opportunities. If national economic efficiency 
is an important objective, encouraging mobility of labor out of remote areas may be more appropriate than providing subsidies that encourage them to stay. That is not to say that they should not remain in these communities, but rather that there is no economic justification for higher subsidies. Politics sometimes leads to a different conclusion, however, because people form emotional attachments to communities and politicians are reluctant to move them, even though the long-term costs are high.

\section{References}

Bird, Richard M., and Enid Slack. 1991. "Financing Local Government in OECD Countries: The Role of Local Taxes and User Charges." In Jeffrey Owens and Giorgio Panella, eds., Local Government: An International Perspective. Amsterdam: North Holland.

1993. Urban Public Finance in Canada, 2nd ed. Toronto: John Wiley.

Commonwealth Grants Commission. 2001. Report on State Revenue Sharing Relativities. Canberra.

Consultation Committee to the Minister of Municipal Affairs. 1989. County Government in Ontario. Toronto.

Dougherty, Michael John, Kenneth A. Klase, and Soo Geun Song. 1999. "The Needs and Financial Problems of Small and Rural Localities: The Case of West Virginia." Public Budgeting and Finance 19(3): 17-22.

Graham, John, F. 1963. Fiscal Adjustment and Economic Development: A Case Study of Nova Scotia. Toronto: University of Toronto Press.

King, David, N. 1988. "Accountability and Equity in British Local Finance-The Poll Tax." Discussion Papers in Economics, Finance, and Investment. University of Stirling, Stirling, Scotland.

Kitchen, Harry. 1992. Property Taxation in Canada. Toronto: Canadian Tax Foundation.

Kurlyandskaya, Galina, Yelena Nikolayenko, and Natalia Golovanova. 2001. “Local Governments in the Russian Federation." Paper prepared for the Local Government and Public Service Reform Initiative/Open Society Institute. Budapest.

Litvack, Jennie, Junaid Ahmad, and Richard Bird. 1998. Rethinking Decentralization in Developing Countries. Washington, D.C.: Word Bank.

Martinez-Vazquez, Jorge, and Jameson Boex. 2001. Russia's Transition to a New Federalism. Washington, D.C.: World Bank.

McClure, Charles, E., Jr. 2001. “The Tax Assignment Problem: Ruminations on How Theory and Practice Depend on History." National Tax Journal LIV(2): 339-63.

Organisation for Economic Co-operation and Development. 2000. Revenue Statistics 1965-1999. Paris.

Osborne, David, and Ted Gaebler. 1992. Reinventing Government-How the Entrepreneurial Spirit Is Transforming the Public Sector. Reading, Massachusetts: Addison-Wesley.

Slack, Enid. 2001a. "Alternative Approaches to Taxing Land and Real Property." Washington, D.C.: World Bank. . 2001b. Fiscal Aspects of Governing Large Metropolitan Areas. Washington, D.C.: World Bank. 
Slack, Enid, John LaFaver, and Ihor Shpak. 1998. "Property Tax in Ukraine: Third Attempt."

Budget and Fiscal Review (Fiscal Analysis Office, Verkhovna Rada) (Second Quarter): 32-45.

Statistics Canada. 2001a. “CANSIM II, table 051-0001." Ottawa. Data provided on request. . 2001b. “Natural Resources Canada, GeoAccess Division." Ottawa. Data provided on request.

Wallich, Christine I. 1994. "Intergovernmental Fiscal Relations: Setting the Stage." In Christine I. Wallich, ed., Russia and the Challenge of Fiscal Federalism. Washington, D. C.: World Bank. 



\title{
8
}

\section{Local Government Enterprises}

\author{
Harry Kitchen
}

Local governments in many countries, but especially in developing countries, rely on a range of local government enterprises to finance a variety of public sector services. Nowhere is this more apparent than in Russia, where historically, Russia's state enterprises have financed many expenditures that the public sector shoulders in more market-based economies, for example, schools, hospitals, roads, and sanitation (Wallich 1994b). Of the 12,261 municipalities in Russia, 4,714 own municipal enterprises (Kurlyandskaya, Nikolayenko, and Golovanova 2001). This preponderance of enterprises raises a number of issues in relation to whether they should exist and their governance, structure, and control. This chapter attempts to address some of these concerns.

The chapter draws in part on experience in Canada and other countries. The discussion is organized in three main sections. The next section considers the possible role of local government enterprises and how the activity of such enterprises should be evaluated. The chapter then considers the difficult issue of the appropriate structure and control of local government enterprises, with special attention to financial aspects. Finally, the last section reviews the control of local enterprise expenditures and discusses alternative ways that local government services may be delivered other than directly by local governments or by enterprises owned by local governments.

\section{The Role of Local Government Enterprises}

Before local government enterprises are evaluated as a vehicle for financing and delivering local public services, a number of issues should be considered. In particular, what is a local government enterprise? Why do countries use local government enterprises? And finally, do local government enterprises have a unique role to play?

\section{What Is a Local Government Enterprise?}

While no single and uniform definition of what constitutes a local government enterprise is available, generally such enterprises are responsible for providing marketable goods or services for which they can charge a fee or a price per unit. This explains, at least in part, why local government enterprises are often responsible for electricity, water, sewers, and public transit, while locally elected councils are responsible for local streets and roads, street lighting, sidewalks, fire fighting, and neighborhoods parks, that is, services for which specific fees or per unit charges cannot be imposed.

Each public enterprise operates as a separate business entity, sometimes independent of the locally elected council and sometimes under some kind of governing control by or affiliation with the locally elected council. Each enterprise tends to be responsible for only one service. Each also usually has its own independent or quasi-independent (from the local council) governing body that is responsible for all policies affecting the enterprise. Each has its own accounting and financial system, frequently has its own workforce and capital equipment, and is responsible for monitoring and reporting on its own activities. 
Local government responsibility, by comparison, covers a range of public services for which fees or prices are not used. Local streets and roads, street lighting, fire fighting and the police force, and neighborhood parks are almost always funded from local taxes, grants, and other locally generated revenues. Local government staff share in the provision of all services, that is, each of these services uses a common staff and equipment complement. For example, accounting, auditing and legal services, municipal employees, and capital equipment are shared across a number of services. A locally elected council is responsible for making policy decisions for all services, including the trade-off between spending on one rather than another.

In New Zealand, Europe, and North America local government enterprises are responsible for relatively few local services. Furthermore, they generally provide almost all such services in an environment that lacks alternatives and competitors. Such services often include electricity, telephone services, water and sewers, municipal airports, and low-income housing. In other countries, by contrast, local government enterprises are responsible for many more services, some of which may compete with the private sector. For example, Russian subnational governments have long looked to state enterprises to finance many essential services. Estimates indicate that in 199240 percent of subnational budgetary outlays came from enterprises' contributions (Martinez-Vazquez 1994). In most one-company towns the percentage was much higher, sometimes reaching almost 100 percent. Revenues from local enterprises are important at the subnational level in Russia because they help finance basic services that might not be funded if left to the local tax base (Bahl and Wallich 1995). Bird (1984) reports a similarly important revenue-generating role for local government enterprises in Colombia. In short, the range of goods and services local government enterprises provide is vast and diversified, has been for some time, and likely will continue to be in the future.

Local government enterprises may be separated into those that operate in an environment lacking competitors and those that compete openly with the private sector. For the former, the only supplier is a public sector monopolist. For example, municipal water and sewers are the responsibility of one agency, a separate utility or business enterprise, sometimes under the direct governance of the municipality and sometimes under the governance structure of a special-purpose board or commission that tends to have characteristics similar to those of a separate business entity. Similarly, electricity is the responsibility of a single agency, as is public transit and so on. Furthermore, services with high infrastructure costs, such as water, sewers, and electricity, have characteristics of a natural monopolist, of which their predominant characteristic for analytical purposes here is that they exhibit decreasing per unit costs over the entire range of output, that is, they exhibit economies of scale. Other services, such as public transit, may not benefit from economies of scale over their entire output, that is, they are not natural monopolists, but they are, nevertheless, provided in a protected setting. In short, there is no competition for many of these services (electricity, water, and sewers) and limited and indirect competition for others (automobiles competing with public transit).

For publicly provided goods or services that compete with the private sector, the question arises whether the public sector should be involved at all. No solid economic rationale for public sector provision exists, though their provision has been defended on the basis of generating revenue for local governments. In Russia examples include public sector involvement in bakeries, paint shops, flower shops, sports clubs, mushroom growing, and handicraft businesses (Kurlyandskaya, Nikolayenko, and Golovanova 2001).

\section{Why Do Countries Use Local Government Enterprises?}

Defenders have put forward a variety of arguments for using local government enterprises for specific services. First, in some countries or regions within countries, legislated requirements stipulate that a separate enterprise must be responsible for providing specific services, generally under a governing structure referred to as a commission, board, or utility. This is the case 
for municipal electricity distribution in Ontario, Canada, where either a private corporation or a municipally appointed board of directors operating at arms length and independent of the local council makes all policy decisions (see box 8.1).

Second, where local governments are free to choose their governing structures for the provision of local goods and services, tradition often plays a role in relying on separate enterprises. The view is that it has always been done this way and there is no reason to change.

Third, local government enterprises have been defended on the grounds that appointed or elected officials governing single-purpose enterprises will make better decisions than directly elected municipal politicians who must make decisions, choices, and trade-offs over a vast range of local government functions. A single-purpose governing council, the argument goes, is more likely to consist of experts, and therefore be able to make better decisions than locally elected politicians and government officials who have heavy workloads and insufficient time to plan, administer, and oversee all governing functions. Those who support this view assert that financially independent public utilities are generally well run, honest, and efficient and allege that politically controlled utilities are markedly worse in each of these respects and likely to be run at a financial loss.

Fourth, some countries use enterprises as a way of escaping rigid controls by a senior level of government that apply to what and how local governments spend, whom they employ for what, how much they pay them, which revenues they can access, on what terms they may borrow, and so on.

Fifth, those countries where senior levels of government share in local tax revenues, but do not share in revenues generated by local enterprises, may prefer local government enterprises (Martinez-Vazquez and Boex 2001).

Sixth, some countries may use local government enterprises to provide employment.

Seventh, many politicians and residents perceive local government enterprises as more efficient and accountable than other municipally provided services that are not sold for specific fees or prices, because they are run more like a business, that is, they deliver a product, sell it, retain the revenue, and cover all their costs.

\section{Box 8.1 Governance of Municipal Electrical Utilities, Ontario, Canada}

In 2000, the provincial government in Ontario introduced legislation deregulating the provision and sale of hydroelectricity. For municipalities, this legislation required each of them to adopt one of the following options. The municipality could

- Sell its electrical utility to a private sector firm. Municipalities that sell their electrical utility to a private sector firm (the city of Cornwall is the only example of this so far) can use the proceeds for any purpose they wish. Private sector corporations operate under legislation and laws applicable to the private sector. This means that in the absence of a specific contractual agreement between the municipality and the private sector, the private sector operates entirely independently of the local council. However, the provincially appointed Ontario Energy Board must approve each rate increase.

- Sell or lease its electrical utility to another municipality or a provincial public sector agency. The implications of this are similar to selling to the private sector. Public sector responsibility for electricity provision is not, however, subject to the same freedom of information requirements applied to other public sector institutions.

- Retain ownership of the electrical utility. This is by far the most frequently chosen option. Legislation mandates that a board of directors appointed by the municipal council must govern the utility. This board has the power to make decisions independently and at arms length from local councils. The utility may be run as a nonprofit agency or the local council may require it to pay a dividend (rate of return) to the municipality. As with the other options, the Ontario Energy Board must improve rate increases. This, in turn, affects the rate of return paid to the municipality. The utility is not subject to the same freedom of information requirements applied to other public sector institutions. 
Finally, some local politicians and administrators prefer local government enterprises because fewer citizens complain about revenues generated from the sale of goods and services by what they perceive as a business enterprise than about local governments increasing local taxes to raise the same amount of money. More bluntly, setting up a local business enterprise and selling a good or service to raise revenues seems to be more acceptable politically than raising local taxes. Municipal governments may prefer generating revenues from the sale of goods and services by local government enterprises if the municipal governments face legislated requirements against their ability to raise taxes.

\section{What Are the Criteria for Evaluating Local Government Enterprises?}

The role of local government enterprises and how they should be structured should be evaluated based on the following criteria: allocative or economic efficiency, accountability, transparency, and ease of administration. Issues of fairness are important, but of little relevance in this discussion. Fairness is associated with how specific services are funded-benefits received arguments (for a discussion of the benefit model of local finance see Bird 1993; Kitchen 2000b) or with income distribution issues-ability to pay arguments (for a discussion of income redistribution and how to handle it see Boadway and Kitchen 1999, chapter 8)-and not with the enterprise or local government responsible for the service.

EFFICIENCY. The local public sector achieves efficiency when all service responsibilities are organized and allocated so that society gets the greatest possible gain from the use of all resources at its disposal. In other words, if reliance on local government enterprises leads to the use of fewer resources than would be required if the same service were provided directly by local government, then for a local enterprise to provide the service would be more allocatively efficient because society would be better off collectively. ${ }^{1}$ If, by contrast, the existence of one or more enterprises provides barriers or impediments to efficient local public sector decisionmaking and leads to a greater use (wastage) of resources, local enterprises could be deemed to misallocate resources and to be more costly to society collectively.

ACCOUNTABILITY. In the provision of local public sector services, accountability is achieved when the customer or taxpayer is able to identify who is responsible for what and is able to link the governing unit responsible for the service directly to its funding. Where there is only one governing unit, taxpayers know who is responsible for what and whom to contact if they wish to have an impact on decisionmaking. Where there are a number of local governing units responsible for a diverse range of services, customers or taxpayers may become confused and not know who is responsible for what and how to influence decisionmakers.

TRANSPARENCY. Transparency is achieved when taxpayers have access to information and decisionmaking forums so that they know what is happening and can judge whether it is appropriate. Vehicles or instruments for enhancing transparency should include legislation that requires public sector decisionmakers to consult with and report to the public annually on

1. Economic efficiency is more than technical efficiency: the latter is a necessary but insufficient condition for economic efficiency. Technical efficiency exists when a producing unit (firm, government, commission) operates in such a way that securing any additional output is impossible given the available inputs (labor, material, capital) and level of technology. In other words, technical efficiency is achieved when the output per unit of input is maximized or the cost per unit of output is minimized. Note that this does not concern whether one good or service generates more or fewer net benefits than another good or service. It simply concentrates on the efficient employment of inputs in the production of a specific good or service. Finally, as the level of technology advances, a technically efficient production process leads to increased output with the same inputs. 
planned activities, enforcement of regulations by officers, and purchase of inputs through contractual arrangements with internal staff or the private sector. A possible vehicle or instrument could include an annual publication of local public sector performance measures, thereby providing local residents with information for making intermunicipal efficiency and effectiveness comparisons. All this is intended to mitigate the risk of corruption by making information statutorily available and by ensuring that all public policy decisions are made in an open and transparent manner (see International Monetary Fund 2001).

EAse of Administration. Ease of administration is an extension of the efficiency and accountability criteria. The easiest system to administer is one that is not confusing and does not require an unnecessary amount of time and effort for consultations, correspondence, and meetings to reach decisions.

\section{Do Local Government Enterprises Have a Unique Role to Play?}

Do local government enterprises perform a unique role or offer something that improves local public sector governance, decisionmaking, and funding responsibilities? The foregoing criteria may shed some light on this question. The best and most socially desirable governing structure is achieved when locally elected councilors have decisionmaking responsibility for all local goods and services regardless of how they are delivered (for a discussion of the importance of distinguishing between decisionmaking for governance and service delivery see Batley 2001; Kolderie 1986; Osborne and Gaebler 1992; Ostrom, Schroeder, and Wynne 1993; Savas 1987; World Bank 1994; Wunsch 1991). Perhaps this is best illustrated by pointing out a variety of problems - real and potential— that frequently emerge when local government enterprises are responsible for some local public sector decisionmaking. For example, if a local government enterprise can make policy decisions and has funding control over specific goods and services, and if it operates independently or semi-independently of the locally elected council that is responsible for a range of other goods and services, there are fewer incentives and it is less likely that local public sector efficiency, transparency, and accountability will be achieved. Indeed, the potential for problems of this sort exists in the newly created governing structure for municipal electricity in Ontario (box 8.1). In addition, if additional resources and time are wasted on reaching agreements and coordinating policies between these competing governing units, the system will be more expensive to administer than it should be.

As noted earlier, support for local government enterprises rests, at least in part, on the assertion that individuals appointed or elected to an enterprise's governing board can govern more efficiently and effectively than locally elected politicians who are responsible for a range of local public sector goods and services. These services, the argument goes, must be kept free from political interference. This approach to municipal government as basically corrupt and unrepresentative of consumer demands, however, is a poor principle upon which to organize municipal service responsibility.

Furthermore, arguments supporting removal from politics seem to be an attempt to substitute special politics for general politics or to withdraw from the struggle to change the community's political decisions. If politics is understood in the pejorative sense of partisan or personal patronage and influence, the independence of local government enterprises does not guarantee freedom from spoils, but rather opens possibilities for their own methods of self-enrichment. Technical specialists in many functions and their respective supporting groups of citizens may believe that their function is so important to the general welfare and the methods involved so technical that their objectives can be accomplished only if they are protected against interference by nonprofessionals (Bird 1980). In a democracy, however, practical politics involves compromise in the decisionmaking process. Experts and special interest groups should be available for advice on such decisionmaking, but they need not be responsible for policy. In cases in which an activity's proponents find the existing political situation distasteful, they should resist 
the tempting alternative of avoiding involvement in favor of seeking basic political improvements.

Another dubious contention by advocates of local government enterprises is their assertion that funding specific goods and services from user fees or prices is more businesslike, and therefore preferable, if conducted by an independent or semi-independent business enterprise rather than if funded in the same manner but under the governance of a locally elected council. Such an argument overlooks the essentially political nature of decisionmaking with regard to many services supported in whole or in part by user charges or public sector prices. There is no reason why a user-supported service cannot be operated on a businesslike and self-sustained basis under a department at city hall.

The existence of a number of independent and semi-independent enterprises complicates local government to the point where citizens cannot understand its structure or determine who is responsible for what. The weakening of municipal councils by removing some responsibilities, combined with citizens' inability of to understand government (who is responsible for what), results in a loss of accountability, a lack of transparency, and a reduced public interest in local government. As the municipal organization becomes more diffuse it becomes less accessible to political control. Also the agencies into which local government is fragmented are often only indirectly responsible to the public, particularly if its members are appointed. Fragmentation of government into separate enterprises further complicates the problems of administrative integration and coordination.

Bringing all governance and policymaking decisions for local enterprises under local council governing responsibility (day-to-day management should be left to the managers regardless of the governing structure) may be criticized, however, because local politicians in some countries apparently use these enterprises as places of employment for relatives, friends, and cronies. Some have suggested that if governing responsibilities for enterprise operations were left with local enterprises, these potentially inefficient and unfair employment practices could be minimized; however, this might not be true for at least two reasons. First, there is nothing inherent in the governing structure of either a local government enterprise or local council operation to suggest that either agency is more or less susceptible to this type of employment abuse. Second, where this is a problem, its resolution should involve the implementation of fair, effective, and transparent employment policies that prevent this kind of nepotistic behavior.

Many local government enterprises enjoy considerable autonomy and financial independence. Indeed, they tend to become little governments in themselves with the inherent characteristic that they are independent and in no way subordinate to the elected municipal politicians. This can lead to an environment over which taxpayers have little control, and one that is therefore politically inefficient. For those that are funded partially by grants or local taxes, there is often no direct link between the policymaking body (the body making the expenditure decisions) and revenues (local taxes) that are collected by municipal councils and must be used to fund the agencies. Whenever expenditure and revenue decisions such as these are made independently, the system is likely to be less accountable or transparent and unable to allocate its resources efficiently across all competing municipal services (for a discussion of the importance of this link between revenues and expenditures see Bossons, Kitchen, and Slack 1993). Those that are fully funded from sales of their output are more likely to become independent and be more removed from the governing decisions of local councils.

When a large number of independent, single-purpose enterprises exists, coordinating interrelated activities is difficult, and in some instances impossible (Kitchen 1989, chapters 8 and 9). Attempts by locally elected politicians to provide services are frequently thwarted or made more difficult because of decisions made by these independent enterprises over which the politicians have little, if any, control. For example, actions taken by electrical utilities, water and sewer utilities, or public transit authorities may conflict with the local council's overall planning effort (Tindal and Tindal 1988). 
This institutional structure, which may be referred to as a localized monopoly, creates a potential impediment for pursuing competitive forces if municipal councils are prevented from making all decisions affecting the local municipality in the most accountable, transparent, and efficient manner. This may happen when a municipality defers all decisions over spending and funding until a local government enterprise has determined its level of spending and funding. For example, a decision by a separate water utility enterprise to replace or rehabilitate a water line or sewer main may affect a municipality's timing for resurfacing or improving a local road or street. This, in turn, may affect both the timing and choice of competing alternatives whereby the municipality allocates its resources to other municipal services. ${ }^{2}$ Similarly, if a decision by a local enterprise to borrow in order to finance the rehabilitation or provision of new capital infrastructure crowds out or inhibits the local council's ability to borrow for other capital projects, perhaps because of debt limits, then resources are not allocated efficiently.

In general, where municipal councils are directly responsible for a service pressures for public accountability (Kitchen 1975) and political responsibility are greater. Greater public accountability, in turn, leads to greater pressure to reduce costs (Kitchen 1976a), ${ }^{3}$ improve efficiency, and justify expenditure increases. When compared with governance under a municipal council, most enterprises are free from the limelight of major municipal elections, and consequently are further removed from these important political pressures. The elections of commissioners, where elections rather than appointments occur, are generally dull affairs that go virtually unnoticed by the public and often result in acclamations. Voter apathy develops in municipal elections, but the general desire to control costs at city hall extends to all departments, whereas such pressure is less frequently exerted on a separate enterprise. Partly for this reason, many governing boards for local enterprises slip into "rubber stamp syndrome" and allow many policy decisions to stem from dominant, technically competent managers.

Connected with the idea of political accountability is the financial flexibility available to each type of organization. A sufficient degree of political leverage and direct accountability to the public must be maintained over the governance of local public services, otherwise these organizations are strongly tempted to try unwarranted expansion or to invest in new resources to an extent far out of line with investment in other municipal functions. Municipal council operations appear to satisfy such a condition much more than separate enterprise operations, and the latter's financial freedom may permit greater indulgence in empire building (Kitchen 1975) and wasted expenditures.

An important source of economies available to operations run by municipal councils and often not available to single-purpose enterprises comes from the opportunity for certain personnel, facilities, and capital equipment to be engaged in multiple functions. Some of these economies are as follows. First, council-operated services may share office space at city hall, whereas separate enterprises are generally established in separate buildings. Second, a municipally governed service easily shares administrative and operational tasks with other departments at city hall, for example, accounting and legal services, whereas separate enterprise operations tend to set up their own administrative and operational facilities. Economies of

2. Information gathered from interviews with municipal officials in Ontario. Similar results have been observed for school board (Tassonyi and Locke 1994) and police spending (Knapton 1993) in Ontario (both are under governing structures that are independent of municipal councils), where expenditure decisions and ensuing property tax requirements for these two independent local bodies frequently crowd out municipal expenditures over which the municipal council has control. Kitchen (2002, chapter 11) argues that crowding out occurs because municipal councils are reluctant to raise property taxes to cover municipal expenditures and incur the wrath of local citizens if the expenditure decisions of school boards and police boards have resulted in higher property taxes for their specific services.

3. The results of this study indicated that the cost of supplying water through a separate water utility or enterprise was significantly higher than the costs of supplying it through a department directly responsible to the municipal council. 
scale and cost savings are less likely to be achieved in the latter structure than in the former structure. Third, opportunities exist for pooling capital equipment and labor in city-governed operations. This permits a reduction in idle hours for capital and labor through the opportunity to transfer personnel and equipment to different functions as the need arises. As with many of its departments, city hall can achieve economies of scale in the use of unspecialized personnel and equipment. This source of savings is more important for smaller than for larger municipalities, because the smaller-scale operations are much more likely to encounter indivisibilities in capital and labor inputs. Local government enterprises, by contrast, tend to acquire a separate complement of labor and equipment, and as a rule these inputs are not used for other municipal government functions. In many instances, especially for capital equipment, there is considerable down time and lack of use of some of the capital equipment (see Kitchen 1975, and for a more recent illustration and discussion see Armstrong and Kitchen 1997).

Thus the economic and political arguments in support of independent and autonomous or semi-independent and semi-autonomous local government enterprises are generally weak. Local government enterprises do not appear to contribute anything that is unique. Their existence creates or has the potential to create decisionmaking problems and unnecessary costs for both local governments and local residents. Eliminating local government enterprises should improve the extent to which local public sector efficiency, accountability, and transparency could be improved. It would certainly remove the confusion about who is responsible for what and allow local councils to set priorities and weigh and consider the trade-offs necessary in making decisions on the relative merits of spending on water and sewer systems versus roads versus public transit and so on.

All this assumes, of course, that we are operating in a first-best world and that the current decisionmaking structures can be changed. Unfortunately, this may not be possible for many enterprises and in many countries. Local government enterprises are solidly entrenched in local public sector services, and they will continue to be used even though they have declined in importance in some countries over the past decade, ${ }^{4}$ largely because of the types of decisionmaking problems described earlier.

\section{Governance, Structure, and Control of Local Government Enterprises}

The remainder of this chapter therefore takes a different slant and accepts the likelihood that local government enterprises will continue to be responsible for a range of local goods and services for some time and in many countries. In particular, the discussion concentrates on policies designed to improve the efficiency, accountability, and transparency of the local government sector without unnecessarily increasing its administrative costs.

\section{How Should Local Government Enterprises Be Governed?}

The governance of local government enterprises depends on local views regarding the separation of politics or governance from management. ${ }^{5}$ The governance structure refers to the political body responsible for making all policy decisions. It does not refer to the day-to-day management of local government or its enterprises and it does not refer to service delivery, because this may be handled in a variety of ways. As a major objective of the local government sector should be to design an overall governance structure that, in principle and as closely as possible

4. In Ontario, reliance on utility commissions (local enterprises) for water provision declined from 112 separate utilities in 1990, to 41 in 2000, and 15 in 2001 (Sancton and Janik 2001, table 3).

5. In New Zealand, for example, legislation mandates that the policymaking responsibilities of elected municipal councils must be "decoupled" from day-to-day management of the authority (Pallot 2001). 
in practice, meets the criteria described earlier, it is best achieved if a democratically elected local council retains all local public sector decisionmaking powers. In effect, a local enterprise should be governed by the same body that governs city hall. This would create an environment where it would be easier to coordinate all municipal services and functions and would minimize instances where the policies of local enterprises conflict with the policies of local councils. In principle, a system whereby local councils are responsible for making decisions about the appropriate trade-offs to be made in relation to all local expenditures reduces the possibilities of conflict between local enterprises seeking to promote their own special interests and the municipality attempting to hold the line on taxes, restricting expenditures, or altering expenditure choices among those services over which it does have substantial control.

Putting all municipal public policy decisionmaking powers, including those that are politically sensitive and those that are not as politically sensitive, under council control should improve local accountability and responsiveness to the taxpaying public (Municipality of Metropolitan Toronto 1988; Stenning and Landau 1988). An independent enterprise in charge of a basic service, such as water, sewers, electricity, and so on, that can set its own rates or prices, determine its own policies, and formulate and approve its long-range plans has considerable control over a number of other municipal services; how a community is governed; and how and where it develops residentially, commercially, and industrially.

\section{How Should Prices Be Set?}

Given that services traditionally provided by local government enterprises or their substitutes (separate business units under local council responsibility) tend to have many characteristics associated with private goods except that they are generally provided in a monopolistic environment, the pricing structure should reflect the specific circumstances under which each service is supplied. Allocative efficiency, fairness, and accountability in the provision of enterprise services are generally achieved if the fee or price per unit equals the extra cost of producing the last unit. This is the well-known marginal cost pricing principle for public sector goods and services. While this principle is straightforward in theory, its application is considerably more difficult and almost always requires modification. For example, municipal officials frequently cannot determine marginal costs. Even where they can do so, problems arise in setting prices when economies of scale are present, when capacity constraints exist, when demand differs at peak and nonpeak periods, when second-best considerations are prevalent, and when externalities exist (for more detail see Bird 2001; Bird and Tsiopoulos 1997; Kitchen 1997, 2002). The options for achieving marginal cost pricing are described briefly in the following paragraphs. To satisfy the criteria for efficiency and accountability, one or more of the following types of pricing should be implemented. The actual choice will depend on the characteristics of the specific good or service and the circumstances under which it is provided.

Average Cost Pricing. Either the inability to calculate marginal cost or the likelihood that financial losses will result where marginal cost can be calculated has led to considerable reliance on average cost pricing. Average cost pricing (total cost divided by the units of output equals price) is relatively easy to calculate, especially if only financial costs are considered, as is usually the case. Average cost pricing, however, produces some important differences when compared with marginal cost pricing. If average cost is declining (marginal cost is lower than average cost), too little of the good is provided (in the allocative efficiency sense) and the price is too high. If average cost is rising (marginal cost is above average cost), too much of the output is produced and the price is too low. In either case, an inefficient level of output results. Average cost will only generate the efficient level of output if marginal and average costs are constant (the same regardless of the level of output). Despite potential efficiency deficiencies, average cost pricing is the most common structure for funding many municipal services that rely on prices or fees. 
Average incremental cost pricing is a variant of average cost pricing. Like marginal cost pricing it attempts to calculate the cost incurred as a result of an additional user, but it does so in a way that is computationally easier for public managers to estimate. Briefly, it includes all the additional costs of providing an increased level of service divided by the anticipated number of additional users. Each user is charged the average of the incremental total cost. This does not amount to marginal cost pricing, which refers to the additional cost for each user, in the strict sense, but it may be about as close as one can get in practice (Bird 2001).

PRICING FOR ECONOMIES OF SCALE. For utility services that have characteristics of a natural monopolist, an efficient pricing policy involves more than simply setting price equal to marginal cost. Here equating price with marginal cost results in a loss that must be subsidized from another local revenue source, a solution that is highly improbable for political reasons and almost certain to be allocatively inefficient, because the subsidy will come from taxes that create distortions elsewhere. Setting price equal to average cost or some variant of it is also inefficient as described in the preceding section.

An economically (allocatively) efficient and generally politically acceptable solution in this case involves the use of a multipart tariff. In its simplest form, this would include a

\section{Box 8.2 Application and Problems with Pricing for Water and Sewer Provision in Canada}

Water provision in Canadian municipalities is characterized by five basic rate structures: a flat-rate charge, a charge based on property assessment, and three volume-based charges. A flat-rate water charge is the most commonly used residential rate structure, and a number of municipalities also use it for commercial properties. Flat-rate charges are unrelated to water consumption, and while some flat-rate systems have become somewhat complex, their structure is typically simple. The rate often varies for residential versus commercial customers. In addition, flat rates may vary by the characteristics of customers' property, for example, number and types of rooms, number of water-using fixtures, number of residents, size of lot, presence of a swimming pool, size of service connection, and so on.

Some indirect methods of charging for water are equivalent to a flat-rate charge. These are based on property assessment and come in the form of an addition to the property tax bill, frontage charges, or special assessments. However, only a few municipalities use these methods.

Volume-based charges require the use of meters and take one of three forms: constant unit rate, declining block rate, or increasing block rate. A constant unit rate is an identical charge per unit of consumption (cubic meter, for example) and seldom differentiates among customer classes. It is the most common type of volumetric charge used in Canada. A declining block rate structure generally includes a basic or fixed service charge per period combined with a volumetric charge that decreases in discrete steps or blocks as the volume consumed increases. Typically one or two initial blocks cover residential and light commercial water use, with subsequent blocks covering heavy commercial and industrial uses. The fixed component of the charge often varies with the size of the service connection. Minimum charges corresponding to a minimum amount of water consumption in each billing period are common in these systems. Environmentalists generally do not favor declining block rates because they do not capture the social costs associated with water consumption. An increasing block rate structure, which only a few municipalities use, is similar to the decreasing block rate structure except that the volumetric charge increases in steps as consumption increases and there is no minimum charge.

Sewage collection and treatment expenses are almost always recovered through surcharges on water bills. For residential and most commercial and industrial customers, rates are not based on sewage flow and flat-rate charges are the most common type. Not only are these used in municipalities with flat-rate water charges, but they are sometimes used in municipalities with metered water rates. For other municipalities the sewer charge is a percentage of the water bill.

Because efficiency is achieved when the price is set to cover marginal cost, municipalities must use water meters. Yet according to the Economic and Regulatory Affairs Directorate of Environment Canada in Ottawa, as of 1996 fewer than 45 percent of all Canadian municipalities were metered for residential water and almost 60 percent were metered for commercial and industrial water. In 
variable charge equal to the marginal cost of the last unit consumed and a fixed charge for the privilege of using or gaining access to the service. More complicated versions may include more than two pricing variables. This multipart pricing policy is particularly appropriate for local utility services that have significant fixed (capital) production costs and a declining average and marginal cost structure. A variant of this that many water and sewer enterprises and electrical utilities use is variable block pricing (for an illustration and explanation of these possibilities see Strategic Alternatives, Inc. and others 2001, chapter 6). Box 8.2 describes this type of pricing practice along with other pricing practices for water and sewer enterprises in Canada.

PRICING WITH CAPACITY CONSTRAINTS. Capacity constraints arise when the level of service provided by a given capital asset or infrastructure is limited. In the context of marginal cost pricing, problems arise if capacity is uneven and can only be expanded in discrete amounts. In such cases services are typically under- or overprovided relative to the efficient level. When the service is underprovided, marginal benefits exceed marginal costs, hence the price will exceed marginal cost and total revenues will exceed total costs. Where the service is overprovided, marginal benefits will be less than marginal costs, the price will be less than marginal costs, and

addition, prices are generally based on average costs. Peak load demand is not taken into consideration and distance from source of supply is not captured. Not only does this lead to an inefficient allocation of resources, it is unfair on the basis of benefits received, because customers whose price exceeds marginal cost subsidize those whose price is below marginal cost.

A recent study based on 77 water utilities in Ontario concluded that the marginal cost of water supply and sewage treatment exceeded the price for water output and sewage treatment in every municipality studied (Renzetti 1999). Specifically, the average price of water for residential customers was Can $\$ 0.32$ per cubic meter while the estimated marginal cost was Can $\$ 0.87$ per cubic meter. By comparison, the average water price for the commercial and industrial sector was Can $\$ 0.73$ per cubic meter and the estimated marginal cost was Can\$1.49 per cubic meter. At the same time, the average marginal cost of sewage treatment was Can\$0.52 per cubic meter while the average price was Can $\$ 0.13$ per cubic meter. When small versus large utilities were compared, the discrepancy between price and marginal cost was higher for the small utilities. For instance, the five smallest municipalities in the sample reported average price and marginal costs for residential water of Can\$0.12 and Can\$1.15 per cubic meter, respectively. Conversely, the five largest municipalities in the sample reported average price and marginal costs of Can $\$ 0.21$ and Can $\$ 0.45$ per cubic meter. Similarly, when the sample was separated into those with meters and those without meters, the discrepancy between price and marginal cost was greater for nonmetered municipalities.

This large deviation between marginal cost and price generates noticeable deadweight loss estimates per unit of output. Underpricing water and sewage generates a higher level of consumption than is allocatively efficient, primarily because there is no incentive to restrict consumption and to consume in an efficient manner. It has also led to an investment in water and sewage treatment facilities that is larger than would exist under a more efficient pricing policy. Finally, some have suggested that underpricing water supply and sewage treatment has discouraged innovation in developing alternative water and sewage treatment technologies (Gardner 1997; Postel 1993).

Similar studies in other countries also indicate that water and sewer rates are significantly lower than the marginal cost of production (Easter and others 1993; Munasinghe 1992). The results from these studies, as with the Ontario study cited, typically use the utilities' own cost accounting procedures as the basis for their estimates. Other costs, such as the value of raw water withdrawn from the natural environment, the opportunity cost of landholdings, the opportunity cost of invested capital, and the harm caused by pollution, are not included. The presence of these costs implies that the gap between price and the full marginal cost of supply is larger than previously estimated. Indeed, a recent study that included a competitive rate of return on assets, pollution externalities, and the value of raw water supplies as costs for the Regional Municipality of Niagara (a region in southern Ontario) estimated that the wholesale price for water would have to increase by at least 15 percent, and possibly by as much as 45 percent, if all social costs were to be recovered (Renzetti and Kushner 2001). 
total revenues will be less than total costs. The decision as to the size of facility is therefore one for benefit-cost analysis.

In the presence of capacity constraints, an efficient pricing policy will result in revenues exceeding costs for a facility that is too small—the project is self-financing-whereas for a facility that is too large, supplementary financing beyond revenues from sales will be required, perhaps some kind of fixed charge such as noted earlier.

PRICING DURING PEAK PERIODS. A further issue revolves around the pricing of services during peak and off-peak periods of demand. Efficient pricing may call for higher fees during peak periods and lower fees during off-peak periods. This arises because peak demand strains capacity and only lasts for part of the demand cycle. Marginal benefit to peak users only occurs over a portion of the demand cycle, whereas the marginal cost of capacity expansion is incurred over the entire demand cycle, which means that the marginal benefits to peak users exceed their marginal costs. In addition, as off-peak users gain no additional benefit from capacity expansion, peak users should shoulder all the additional capacity costs. In other words, the off-peak price should be set equal to marginal operating costs, while the peak price should be set equal to the sum of marginal capacity and operating costs.

PRICING AND DistANCE FROM THE SOURCE OF SUPPLy. If distance from the source of supply affects marginal cost and if the price is not differentiated to reflect this, users with lower marginal costs subsidize users with higher marginal costs. If this subsidy is capitalized into land values (this is an empirical question, and some uncertainty exists as to the extent of capitalization), then those properties furthest from the source will be priced higher than would otherwise be the case. One way to handle this is to impose zone charges or differential fees on customers in areas where the costs of servicing are higher because of their distance from the source.

PRICING AND SECOND-BEST CONSIDERATIONS. Second-best considerations arise in the presence of inefficient pricing policies (prices set at levels other than marginal social cost) elsewhere in the system. Such is the case, for instance, when a municipality implements a price for a particular service, say public transit or buses, while other services that are considered substitutes, such as urban expressways or roads, are not subjected to a specific charge. Here road and expressway users pay nothing per trip other than their vehicle operating costs, while transit users are charged for each trip. In this instance efficiency gains can be achieved if price is set below marginal cost in the controllable sector (public transit), and if this results in an increased use of transit services and a decreased use of roads and expressways (uncontrollable sector). This pricing solution is known as second best (Boadway 1997).

\section{Should Prices Be Regulated?}

There are two opposing views on whether or not prices or user fees charged by local government enterprises should be regulated. Those who oppose the regulation of prices suggest that concerns about price increases by local monopoly enterprises may be no different than concerns about tax increases. In democratically elected local councils where all decisionmaking responsibilities rest with the local council, taxpayers have the ultimate control or power in that they have the opportunity to vote the politicians out of office at the next elections. Furthermore, if cost efficiency in service provision, and hence control of prices, is the objective, this is likely to be achieved by introducing competitive elements in the production and delivery of each public good and service.

In contrast, those who support price regulation contend that it is necessary to protect consumers from inefficient and unfair price increases where decisions about service responsibility and funding are made in an environment that lacks competition. Setting up a regulatory system 
is a complex task, however. When should prices be regulated? Who should regulate them? How should they be regulated?

When Should Prices Be Regulated? Current practice in many countries is inconsistent in relation to local price regulation. For example, prices are regulated for specific local government enterprises in some countries (electricity, for instance), but not for other enterprises in the same countries (water and sewer, public transit). The rationale behind this differential treatment is far from clear. The practice appears to be based on tradition and what is done elsewhere rather than on any solid economic rationale. Presumably, the case for price regulation is strongest in instances where competitive pressures both in terms of decisionmaking (lack of opportunity for the local council to make decisions on the trade-offs for all local goods and services) and production or delivery are weakest, such as in noncontestable markets.

Who Should Regulate Prices? Should regulation be the responsibility of the local council, of an independent body set up by the local council, of a senior level of government, or of a separate agency set up by a senior level of government? If it is a local council responsibility, the advantages of this have been noted already. If it is a separate independent body set up by the local council, it has the potential to take on a life of its own and create the kinds of problems that tend to be created by special-purpose bodies (Kitchen 1993). Similar concerns arise if it is a body set up by a senior level of government or if it is a senior level of government itself. In either case, a senior level of government has considerable control over the behavior of local governments that may restrict their ability to be independent and autonomous governing units working in the best interests of their local citizens. Of these possible options, the creation of an independent regulatory body operating at arms length from all levels of government, with experts appointed jointly by local and senior levels of government and fully versed in financial, budgetary, and operational details, may best serve local citizens.

How SHOuld PRICES Be Regulated? What is the benchmark or criterion that should be used to determine the appropriate price? Should it be based on the financial or economic costs of the enterprise in each municipality? Should it be based on a defined standard of service for all municipalities, and if so, what standard? These are not easy questions to answer.

In general, price regulatory schemes have two common prototypes: rate of return and price cap regulation (Szalai 2001). Where rate of return is used, the regulator defines a fair and reasonable profit level and the company has the opportunity to increase the price to the point where it reaches its maximum profit level. Because reasonable profit is counted as a percentage of the asset base, the company has an incentive to overinvest to increase its asset base, and hence its profit. Further concerns with this regulatory pricing scheme exist because it does not depend on costs, and hence the enterprise has little incentive to be efficient and vigilant in controlling costs. Monitoring of this price would require regulators to check the usefulness of all investments so that unnecessary ones could be dropped from the asset base-a formidable task.

Price cap regulatory schemes concentrate on creating incentives for the enterprise to increase efficiency. This scheme adjusts the regulated price each year by the rate of inflation minus the rate of the expected efficiency gain. If the company reduces its costs through technological innovation or production efficiencies, it earns extra profits. If it does not, it incurs a deficit. A major difficulty with this scheme is establishing a measure of efficiency. The practice has been to compare relevant performance indicators for an enterprise with similar indicators from enterprises in other municipalities or to take the average for all similar enterprises within a country adjusted for geography and other factors that affect cost. The difference between an enterprise and the comparator group may be referred to as the efficiency deficit (gap). Where a deficit arises, it is not always expected to be corrected immediately. It may take a few years, with a condition that a specific percentage of the deficit be removed each year. For example, the water regulator in the United Kingdom requires that less efficient companies close 50 percent 
of the gap yearly. Again, to be effective and efficient such regulation requires a high degree of knowledge and competence on the part of the regulator.

Where the costs are less than expected under price cap regulation, the enterprise will yield unexpectedly high profits. One solution in such a case is to give each customer a refund at the end of the fiscal year equal to that customer's share of the profit, which could be referred to as a patronage dividend. Another possibility, although less preferable economically because it would reward those customers who did not consume the service in the year when the profit was earned, would be to use the profits to reduce prices in the following year.

\section{Should Local Government Enterprises Earn Profits?}

Perhaps this discussion should start by asking what is meant by profit. Here profit is defined as the difference between annual operating revenues and annual operating costs. Annual operating revenues come from the sale of goods or services provided by the enterprise. Annual costs should include all financial or explicit costs and all implicit or opportunity costs. Financial costs include wages, materials, insurance, utilities, and bank interest on borrowed money, and opportunity costs include the annual costs of asset replacement (depreciation) and a normal profit defined as the opportunity cost associated with putting resources into this enterprise rather than into a viable alternative.

In some countries, it is common practice for a local government enterprise to generate a profit and for the enterprise to transfer this profit to the local government so that the latter can use it to fund a range of municipal services. This raises an important question. Should profit generation be an objective of a local government enterprise? If a municipality relies on user fees or charges and local taxes to fund a range of municipal services, what is the rationale for overcharging consumers of goods and services provided by enterprises and undercharging taxpayers for services funded from local taxes? In principle, there is no solid rationale why local taxpayers should be subsidized from revenues generated by selling a specific good or service or why the users of a specific good or service should be subsidized by local taxpayers. This encourages citizens to overconsume subsidized services and underconsume the overpriced or overtaxed services.

While one could argue that profit maximization should not be an objective of a public enterprise, so that monopoly (as opposed to normal) profits should not arise, this is not to say that allocative efficiency and cost minimization should not be objectives. Clearly they should be. This is where implementation of expenditure controls and monitoring activities such as those discussed later are critical.

\section{Should Revenues Be Earmarked?}

If local government enterprises earn profits, especially above normal profits (greater than the cost of capital), what should be done with such profits? Should they be earmarked or not? (For an extensive discussion and analysis of earmarking, including reference to Russia, see Bird 1997.) Earmarking occurs when specific revenues are set aside for funding certain goods or services, for example, earmarking exists if the costs of providing a specific good or service are funded by revenues generated from the sale of that good or service. Earmarking can be efficient, accountable, and fair for local public sector services that resemble privately supplied services in that each taxpayer's consumption can be recorded, the extra cost of providing the service can be measured, and correct prices or user fees can be charged. Earmarking can also be a disaster when it channels funds into activities that do not have high public priorities.

Earmarking is supported for a number of reasons. First, when there is a close link between the cost of a good or service and the revenue that funds it. This permits residents to associate the benefits received as reflected in the price paid with the costs of providing the good or 
service and to decide for themselves whether the good or service is worth the price or fee. This in turn leads to a greater likelihood of achieving efficiency and accountability in local service provision.

Second, earmarking is likely to improve local decisionmakers' motivation and efficiency. If funds are not earmarked, surplus revenues from the sale of goods and services could be used to lower local tax rates. This may discourage management from improving efficiency and reducing costs, because excess revenues would go elsewhere. It could also discourage the introduction of innovative techniques and future investment that could lead to cost savings and efficiencies.

Third, there is no solid economic reason why local taxpayers should be subsidized from revenues generated by selling a specific good or service or why the users of a specific good or service should be subsidized by local taxpayers. Such cross-subsidization may lead to undesirable distortions and a departure from efficient and accountable pricing and investment practices.

Fourth, this type of cross-subsidization is almost certain to lead to a great deal of unplanned and implicit income redistribution, much of which would be unacceptable if it were made explicit (Bird 1976). More specifically, when consumers of specific goods and services are subsidized by local taxpayers or vice versa, lower-income individuals all too frequently subsidize higher-income individuals. Indeed, this has been observed in both rich and poor countries, for example, Bird (1997) notes that flat-rate water charges favor households with large lawns to water and multiple vehicles to wash.

Fifth, as generating local revenues by raising user fees or public prices is often more politically palatable than raising local taxes, failure to earmark these fees provides an incentive for the governing body to generate excess revenues and use them to fund services that ought to be funded from local taxes or grants (Kitchen 2000a). If governing bodies responsible for local service rely properly on user fees or prices, local taxes, and grants, one opportunity for abuse of power by such governing bodies may be removed.

Sixth, rational earmarking is fair because consumers pay for identifiable services they use and no one either receives a service without paying for it or pays without receiving it. Properly designed user fees should therefore be earmarked for use by the enterprise producing the service. However, to the extent that such fees are used to levy a tax (in the form of a monopoly profit) on service users, such profits should flow into general revenues and not be earmarked either for the enterprise or for other specific uses.

Thus good earmarking can be beneficial, but all too often it can be criticized, because it can shield expenditure programs from the critical assessment that budgetary authorities might otherwise impose. Even though criticism may be muted as long as proper expenditure controls and monitoring practices are in place, it arises, at least in part, because of the absence of good financial practices that leads to much earmarking in the first place.

\section{How Should Capital Investments Be Financed?}

Local enterprises generally finance their capital expenditures from current operating revenues (user charges), capital reserves, borrowing, and more recently, public-private partnerships because of the potential opportunities for gaining access to new sources of revenue. Borrowing is generally favored as a way to fund large capital infrastructure projects where the beneficiaries of the asset can be identified and prices or fees can be charged for the goods or services provided (for arguments for and against borrowing see Peterson 2001). Borrowing in this instance satisfies the benefits-based model of local public finance, because those who benefit from the facility (the users over the next few years) pay for it. Furthermore, the practice of earmarking revenues has much to offer when there is a strong benefit link between the payment of an earmarked fee or price and the use of revenues to finance capital expenditures. In these instances, local preferences can be reflected in the level and quality of service provided. Fairness is 
achieved as long as the projects' beneficiaries pay for it. Optimal and efficient investment decisions will ensue as long as the price or fee charged is efficient and fair. In short, the "interdependence of pricing and investment decisions, and the potentially important role of earmarking in linking revenues and expenditures deserves careful consideration when it comes to financing local infrastructure" (Bird 1994, p. 20).

The arguments against borrowing and in support of pay-as-you-go financing from current revenue sources include the savings in annual interest costs (available for spending on other projects), the creation of debt capacity for more important projects in the near future, and the avoidance of the situation whereby future users have no say in the issuance of debt yet are required to pay for projects approved by those in power today. These criticisms of borrowing, however, essentially ignore the benefits-based principles of funding local public services.

The way in which an enterprise raises long-term capital funds through borrowing can affect its cost of raising money. If the local government enterprise issues its own debt, then its transaction, interest, and administration costs are almost certain to be higher than if it raised the same debt through a provincial, state, or regional borrowing body. Furthermore, this borrowing authority might include other public sector bodies, such as municipalities, local schools, and hospitals, in which case the enterprise could borrow from the authority, which would total up all requests for funds and issue long-term debentures against itself. When it received the proceeds from the sale of these debentures, it could disburse the funds to the requesting participants under a loan agreement.

The advantages of pooling municipal debt through a regional authority can be substantial. Administration costs would be lower, because one contract with an underwriter could be substituted for separate contracts between each borrower and debt issuer. Transaction costs could be reduced, because an authority would be prepared to issue debentures more frequently than would an enterprise on its own. This is important when capital markets are volatile and considerable savings may be incurred by being able to take advantage of lower interest rates. Because of its size a large borrowing authority can exercise greater flexibility over issue terms and offer lower interest costs to participants (Gilbert and Pike 1998).

\section{Should Local Government Enterprises Pay Taxes?}

The issue of whether a local government enterprise should pay taxes is more complicated than whether private sector firms should pay taxes. While arguments for taxing the latter are fairly clear (Boadway and Kitchen 1999, chapters 4 and 7), arguments for taxing the former are more complicated. To illustrate, if local enterprises are responsible for goods and services that local governments would otherwise be responsible for, then arguments for taxing them may be no different than arguments for taxing a municipality. Otherwise taxing enterprises with the tax revenues going to municipal governments means that some public services are taxed while others (those provided by the municipal council) are not. Such differential treatment can lead to distortions and income distribution consequences identical to those discussed earlier. If, however, local enterprises provide goods and services that compete with the private sector, the case for taxation is the same in both cases. ${ }^{6}$

\section{Controlling Enterprise Behavior}

Where local government enterprises exist, local governments should control them. One approach is through expenditure controls, such as the implementation of appropriate budgeting, reporting,

6. Note that there is never a case for nonpayment of bills by or to local enterprises. All too often, local governments do not pay their electricity bills and local electricity enterprises reciprocate by not paying their taxes or not paying dividends to local governments. 
and accounting practices and the adoption of performance measures. A quite different approach may be to consider alternative ways of delivering certain services.

\section{Budgets}

Local enterprise budgets should be designed to achieve the following objectives (Solano and Brams 1996): (a) to provide for the maintenance of financial control, (b) to provide information essential for efficient management decisions, and (c) to improve program and financial planning.

In practice, local enterprise budgets tend to be input oriented as opposed to goal or output oriented and far from ideal. Input-based budgets are almost always based on incrementalism, for example, last year's line-by-line expenditure item plus 2 or 3 percent. Budgets of this type are deficient, because they lack a mechanism for assessing benefits from existing expenditures. They lead to a narrow and cumbersome financial management system characterized by paperwork, detail, duplication, complexity, and inflexibility. They lack the information necessary for proper planning and efficient management of local enterprise activities. Finally, the information provided is frequently incomprehensible to all but the most sophisticated readers.

To facilitate policymaking and managerial decisions, budgets should be designed to reflect both past and projected expenditures on outputs (rather than inputs) or goals achieved or to be achieved. This may be a tall order, yet one that is necessary if operational efficiencies are to be achieved. Such identification of expenditures on outputs involves the establishment of workloads or targets, for example, the policy decision may be to achieve a 5 percent reduction in water line breaks at an average cost of $X$ person-hours per incident, or the aim may be for all garbage to be collected with a minimum amount of inconvenience to all residents at an average cost of \$Y per ton. Similar targets may involve a reduction in per capita fire losses of a fixed percentage at an average cost of $\$ \mathrm{Z}$ per alarm or the completion of road maintenance that ensures smooth riding at a cost of $\$ \mathrm{~K}$ per kilometer.

Establishing targets or workloads permits decisions to be made on the basis of both costs (efficiency) and some measure of returns (effectiveness). Budgets should be built around the kind of work to be undertaken in the next fiscal year and beyond, expenditures required, and revenues tapped. Workload targets should include the scheduling of work, the development of an organizational structure, and the procedures to achieve the proposed plans (Solano and Brams 1996). Any local government or local government enterprise should also consider alternative methods of achieving the volume of work to be undertaken. Decisionmakers should undertake impact studies and cost-benefit analysis of all options before a path of action is chosen.

Once such targets or objectives have been established, the task of achieving these objectives begins. Workloads or targets must be defined in quantifiable terms. Such quantification requires data on both inputs and outputs, because it is the ratio of inputs to outputs that defines the target to be achieved.

Workload and other performance indicators should be measured, established, and monitored periodically to make certain that targets are adhered to and that justifiable changes are being incorporated into the budget. Periodic reporting also provides a basis for evaluating improvements or discovering deviations that must be corrected. These deviations might exist because of unplanned inflationary cost pressures, inadequate financial controls, unrealistic revenue or expenditure estimates, and/or foolish management decisions. Once decisionmakers have determined the basis for the deviation, enterprise managers should either alter the targets or adjust their operations to achieve the previously stated objective. Finally, an independent audit by a firm or individual(s) not employed directly by the enterprise is necessary to guarantee that the enterprise has achieved its objectives or goals in an effective and efficient manner. 


\section{Accounting and Reporting}

The focus of accounting and reporting is to document, classify, and summarize transactions so that users of financial reports can understand and evaluate the operations of municipal enterprises (Holder 1996). Enterprises must fulfill a number of financial management functions to meet these objectives. Accounting systems are needed to record revenues and expenditures in a way that permits comparisons between budgets and actual figures. Financial audits are needed to determine whether the financial statements provide an accurate and reasonable picture of the financial position and activities for the reporting period. The financial audit must be designed to detect deficiencies in the system of internal financial control, failures to comply with accounting principles and standards or with reporting requirements of a senior level of government, and instances of errors or the misappropriation of funds. As financial audits focus on financial statements, they do not address the issues of efficient resource utilization and the achievement of performance standards, which are reviewed by means of management and performance audits or special audits, such as an environmental audit.

Accounting information should be presented in a way that satisfies a number of users. One group includes constituents, creditors, suppliers, and others engaged in business transactions with the enterprise. This group is external to the operation and generally lacks any effective control over the type of financial information available. Information on performance measures would be particularly useful. This would permit an intermunicipal and intramunicipal comparison of enterprises' unit costs, efficiency, and effectiveness of service provision. This group would also benefit greatly from information on such things as the impact of current capital projects on future operating budgets; the enterprise's ability to draw on future resources; and the impact of inflation on future expenditures, and hence on revenues to be collected.

A second group of users includes all individuals involved in the enterprise's managerial and administrative functions. Specifically, it includes policymakers, managers, and administrators. The financial information needs of these users are more comprehensive. In addition to the foregoing, they require cost estimates for alternative ways of achieving specific goals. Cost-benefit analyses of proposed and existing ways of providing services, forecasts of current and capital expenditures, and the impact these will have on current and future revenues are important.

Fund accounting is particularly appropriate for local government enterprises. It features self-balancing, double-entry accounts from which a balance sheet and statement of operations can be prepared. The fund basis of accounting recognizes that most assets are not fungiblethat is, they are not available for purposes other than those budgeted-and that data on budgeting compliance are an important part of an enterprise's stewardship responsibility. Fund accounting and reporting is necessary to control resources so they are used for their designated purpose and to demonstrate compliance with legal and budgeting constraints (Holder 1996).

Cash, accrual, and modified accrual accounting are the three possible accounting bases that may be used. Cash accounting involves recording expenditures and revenues when funds are actually disbursed or received. Accrual accounting records transactions when they occur regardless of when expenditures are made or funds received. For example, the cash expenditure to finance an investment in a fixed asset may take place within one year, but the associated expenses reported in the financial statement of operations takes the form of annual depreciation charges incurred over the life of the asset. As depreciation is a charge that is used to recover the original cost of an asset and associates the annual flow of benefits with costs, interpreting depreciation as a charge to cover replacement costs is incorrect, because this would entail double counting. Moreover, the cost of asset maintenance and repair is recovered directly as an expense.

Modified accrual accounting is somewhat different. It adopts the same principles and approach as accrual accounting except that depreciation and return on capital are not included as costs. Instead, interest costs and principal repayments on debt are recovered directly in the year in which they are due through revenues the enterprise generates. Modified accrual 
accounting often generates revenue in excess of expected operating, maintenance, and debt service costs, resulting in operating surpluses that are transferred to a capital fund to finance ongoing investments or into reserves or reserve funds to finance planned future investments. Because principal repayments are recovered directly each year as chargeable expenses, enterprises are less likely to face cash flow problems. Capital finance does not therefore depend on the flow of funds from a depreciation charge and a return on equity

The adoption of accrual or modified accrual accounting does not suggest that absolutely every revenue source or expenditure item be accrued. For extremely small revenue and expenditure items, a simple recording on a cash basis along with a proper notation of the approach followed may be sufficient.

Interest in full accrual-based accounting is generally motivated by concerns about the state of aging infrastructure and a lack of reliable information that could be used to evaluate this concern. In New Zealand, the 1996 Local Government Amendment Act requires local governments to adopt fixed asset accounting and to prepare and approve a long-term financial strategy every three years, thereby providing long-term financial and asset management plans (Pallot 2001). Under the act, depreciation charges are estimated and funded through locally generated revenues. The depreciation charge provides an estimate of the decline in the service potential of assets, while its funding assures that users of the service pay its real cost (1999 report to parliament by the Office of the Controller and Auditor General of New Zealand). Currently, local authorities are allowed to use the long-run average cost of asset renewals as an alternative to depreciation charges. To make this approach work, local authorities must develop a 20-year capital plan. In the case of long-life assets, the 20-year plan has not provided a realistic estimate of the average annual renewal cost. Conversely, where a realistic depreciation charge is set and funded, local authorities have complained that extremely large reserve funds will accumulate long before they are needed.

Accounting reforms in the United States are similar (International City/County Management Association 2000). The requirement for full accrual accounting by local government was established by the U.S. Government Accounting Standards Board, which concluded that reporting information on infrastructure assets is essential for assessing municipalities' financial position and changes in their financial position and for reporting the costs of programs or functions (Johnson and Bean 1999). Governments may choose to report expenses for repairing and maintaining infrastructure instead of depreciation expenses for that infrastructure if they manage the infrastructure using a suitable asset management system, including an assessment of the assets' physical condition every three years, and if they establish a minimum condition level for those assets and demonstrate that they are maintaining those assets at or above that condition through appropriate investments (Government Accounting Standards Board 2001; Patton and Wardlow 1999).

Asset management figures prominently in both the New Zealand and U.S. approaches. In New Zealand it is mandatory, and in the United States it is mandatory so long as depreciation is not charged for infrastructure. As a source of information on the condition of infrastructure, asset management planning goes well beyond fixed asset accounting, because it requires an assessment of the physical condition of the infrastructure and includes a strategy and financing plan for asset maintenance and replacement.

\section{Performance Measures}

Performance measurement is relatively new for public goods and services, although the importance of performance measures has been widely recognized for some time (Hatry 1999). If correctly set, a performance measure records the output of, rather than the input to, municipal spending on specific programs or services As an example, table 8.1 describes performance measures used in Ontario. 
Table 8.1 Examples of Performance Measures Used in Ontario, Canada

\begin{tabular}{|c|c|c|}
\hline Types of municipal services & Intended results & Definitions \\
\hline \multicolumn{3}{|l|}{ Solid waste management } \\
\hline $\begin{array}{l}\text { Operating cost for waste } \\
\text { collection }\end{array}$ & $\begin{array}{l}\text { Efficiency of municipal waste } \\
\text { collection services }\end{array}$ & $\begin{array}{l}\text { Operating cost for waste } \\
\text { collection per tonne or } \\
\text { household (if tonnage } \\
\text { information is not available) }\end{array}$ \\
\hline Operating cost for waste disposal & $\begin{array}{l}\text { Efficiency of municipal waste } \\
\text { disposal services }\end{array}$ & $\begin{array}{l}\text { Operating cost for waste } \\
\text { collection per tonne or } \\
\text { household (if tonnage } \\
\text { information is not available) }\end{array}$ \\
\hline Operating cost for recycling & $\begin{array}{l}\text { Efficiency of municipal recycling } \\
\text { services }\end{array}$ & $\begin{array}{l}\text { Operating cost for recycling per } \\
\text { tonne or household (if tonnage } \\
\text { information is not available) }\end{array}$ \\
\hline Test results & $\begin{array}{l}\text { Effectiveness: municipal solid } \\
\text { waste services do not have an } \\
\text { adverse effect on the } \\
\text { environment }\end{array}$ & $\begin{array}{l}\text { Test results for solid waste } \\
\text { disposal sites }\end{array}$ \\
\hline $\begin{array}{l}\text { Complaints concerning garbage } \\
\text { collection and recycling }\end{array}$ & $\begin{array}{l}\text { Effectiveness: municipal solid } \\
\text { waste services meet household } \\
\text { needs }\end{array}$ & $\begin{array}{l}\text { Number of complaints } \\
\text { concerning the collection of } \\
\text { garbage and recycling per } \\
\text { tonne or per } 1,000 \text { households }\end{array}$ \\
\hline Waste diversion rate (a) & $\begin{array}{l}\text { Effectiveness: municipal waste } \\
\text { reduction programs divert } \\
\text { waste from landfills and/or } \\
\text { incineration }\end{array}$ & $\begin{array}{l}\text { Percentage of residential solid } \\
\text { waste diverted for recycling } \\
\text { and tonnes of waste recycled } \\
\text { Percentage of commercial, }\end{array}$ \\
\hline Waste diversion rate $(\mathrm{b})$ & $\begin{array}{l}\text { Effectiveness: municipal waste } \\
\text { reduction programs divert } \\
\text { waste from landfills and/or } \\
\text { incineration }\end{array}$ & $\begin{array}{l}\text { industrial, and institutional } \\
\text { solid waste diverted for } \\
\text { recycling and tonnes of waste } \\
\text { recycled }\end{array}$ \\
\hline
\end{tabular}

Sewage

Operating costs for collection

Operating costs for treatment and disposal

Sewer main backups

Test results

Untreated sewage released
Efficiency of municipal waste collection services

fficiency of municipal waste disposal services

Efficiency of municipal recycling

Effectiveness: municipal solid waste services do not have an adverse effect on the environment

Effectiveness: municipal solid waste services meet household

Effectiveness: municipal waste croms diver

Effectiveness: municipal waste waste from landfills and/or incineration

Efficiency of municipal sewage and storm water collection

Efficiency of municipal sewage treatment and disposal services

Effectiveness: municipal sewage management practices prevent environmental and human health hazards

Effectiveness: municipal sewage management practices prevent environmental and human health hazards

Effectiveness: municipal sewage management practices prevent environmental and human health hazards
Operating costs for collection of sewage and storm water per kilometer of sewer lines Operating costs for treatment and disposal of sewage and storm water per cubic meter treated

Number of sewer main backups per kilometer of sewer line

Test results for sewage treatment operations

Number of hours when untreated or partially treated human sewage was released into a lake or natural water course 
Table 8.1 (continued)

\begin{tabular}{|c|c|c|}
\hline Types of municipal services & Intended results & Definitions \\
\hline \multicolumn{3}{|l|}{ Water } \\
\hline $\begin{array}{l}\text { Operating cost for water } \\
\text { treatment }\end{array}$ & $\begin{array}{l}\text { Efficiency of municipal water } \\
\text { treatment services }\end{array}$ & $\begin{array}{l}\text { Operating costs for water } \\
\text { treatment per million liters of } \\
\text { water treated }\end{array}$ \\
\hline $\begin{array}{l}\text { Operating cost for water } \\
\text { distribution }\end{array}$ & $\begin{array}{l}\text { Efficiency of municipal water } \\
\text { distribution services }\end{array}$ & $\begin{array}{l}\text { Operating costs for water } \\
\text { distribution per kilometer of } \\
\text { distribution pipe }\end{array}$ \\
\hline Approximate water loss & $\begin{array}{l}\text { Effectiveness: minimize water } \\
\text { loss }\end{array}$ & $\begin{array}{l}\text { Percentage of water produced } \\
\text { that is not billed }\end{array}$ \\
\hline Test results & $\begin{array}{l}\text { Effectiveness: water is safe and } \\
\text { meets local needs }\end{array}$ & $\begin{array}{l}\text { Test results for water treatment } \\
\text { plants and distribution systems }\end{array}$ \\
\hline Water leaks & $\begin{array}{l}\text { Effectiveness: water is safe and } \\
\text { meets local needs }\end{array}$ & $\begin{array}{l}\text { Number of breaks in water } \\
\text { mains per kilometer of water } \\
\text { pipe }\end{array}$ \\
\hline Boil water advisories & $\begin{array}{l}\text { Effectiveness: water is safe and } \\
\text { meets local needs }\end{array}$ & $\begin{array}{l}\text { Number of days when a boil } \\
\text { water advisory issued by the } \\
\text { medical officer of health and } \\
\text { applicable to a municipal water } \\
\text { supply was in effect }\end{array}$ \\
\hline \multicolumn{3}{|l|}{ Transportation } \\
\hline Operating cost for paved roads & $\begin{array}{l}\text { Efficiency of municipal paved } \\
\text { road maintenance services }\end{array}$ & $\begin{array}{l}\text { Operating costs for paved roads } \\
\text { per lane kilometer }\end{array}$ \\
\hline Adequacy of roads & $\begin{array}{l}\text { Effectiveness: safe and secure } \\
\text { roads }\end{array}$ & $\begin{array}{l}\text { Percentage of paved lane } \\
\text { kilometers of roads rated } \\
\text { adequate }\end{array}$ \\
\hline $\begin{array}{l}\text { Operating cost for unpaved } \\
\text { roads }\end{array}$ & $\begin{array}{l}\text { Efficiency of municipal unpaved } \\
\text { road maintenance services }\end{array}$ & $\begin{array}{l}\text { Operating costs for unpaved } \\
\text { roads per lane kilometer }\end{array}$ \\
\hline $\begin{array}{l}\text { Operating costs for winter } \\
\text { control of roadways }\end{array}$ & $\begin{array}{l}\text { Efficiency of municipal winter } \\
\text { road maintenance services of } \\
\text { roadways }\end{array}$ & $\begin{array}{l}\text { Operating costs for winter } \\
\text { control maintenance of } \\
\text { roadways per lane kilometer }\end{array}$ \\
\hline $\begin{array}{l}\text { Effective snow and ice control } \\
\text { for roads in winter }\end{array}$ & $\begin{array}{l}\text { Effectiveness: safe and secure } \\
\text { roads }\end{array}$ & $\begin{array}{l}\text { Percentage of winter event } \\
\text { responses that meet or exceed } \\
\text { municipal road maintenance } \\
\text { standards }\end{array}$ \\
\hline $\begin{array}{l}\text { Conventional transit ridership } \\
\text { per capita }\end{array}$ & $\begin{array}{l}\text { Effectiveness: maximum } \\
\text { utilization of transit services }\end{array}$ & $\begin{array}{l}\text { Number of conventional transit } \\
\text { passenger trips per person in } \\
\text { service areas }\end{array}$ \\
\hline $\begin{array}{l}\text { Operating costs for conventional } \\
\text { transit }\end{array}$ & $\begin{array}{l}\text { Efficiency of municipal transit } \\
\text { services }\end{array}$ & $\begin{array}{l}\text { Operating cost for conventional } \\
\text { transit per regular service } \\
\text { passenger trip }\end{array}$ \\
\hline
\end{tabular}

Source: Ministry of Municipal Affairs and Housing (2001).

The implementation of a performance measurement system has a number of advantages. First, it permits enterprise officials and consumers of enterprise services to monitor the latters' activities over time and in relation to each other (referred to as benchmarking). Second, it strengthens accountability, because taxpayers are in a better position to evaluate the services provided by an enterprise given the costs of producing those services, and are therefore in a better position to judge whether service provision is effective and efficient. Third, it enhances transparency, because citizens will be able to observe and monitor enterprises' activities more closely. Fourth, it reinforces managerial accountability (Solano and Brams 
1996) and often provides an incentive to stimulate staff creativity and productivity. Finally, it helps enterprises develop budgets based on realistic economic costs and benefits rather than on historical patterns.

Performance measures are also used to determine the effectiveness of service delivery. Effectiveness measures the extent to which an activity contributes to the achievement of stated goals, objectives, or targets. For example, an activity such as building a road may be efficient in terms of cost per kilometer, but its effectiveness will depend on the road's usefulness in providing convenient, safe, and economic vehicular transportation. When a direct evaluation of the benefits arising from local services is impossible, the demand for services subject to quality standards could be measured using surveys, studies of local economic conditions, reports on the number of applications, requests or complaints received, expert evaluations of specific needs, and so on. In this way, a measure of the value of the service provided can be estimated.

As noted earlier, not only are performance measures now required for all municipalities and their agencies in the province of Ontario, Canada, and all local governments in New Zealand, municipalities and their enterprises are required to report the results to their taxpayers (Ministry of Municipal Affairs and Housing 2001; Pallot (2001). While this information is intended to improve efficiency and productivity in the provision of each local service, it should be linked to the budgetary process. The tighter financial environment facing local enterprises everywhere, along with the greater pressure for public accountability, should provide an incentive for them to clearly outline their budgetary targets, goals, or objectives and to relate these to performance measures. At the same time, enterprises should employ cost-benefit analysis to evaluate alternative means of achieving their stated objectives to determine those that yield the greatest returns given revenue constraints.

\section{Monitoring}

In order to monitor enterprises' behavior, a senior level of government must mandate budgeting, accounting, and reporting requirements. In addition, requirements that enterprises report all budgetary information, the extent to which they met budgetary goals, and information about performance measures to local citizens on an annual basis should improve the efficiency, accountability, and transparency of enterprise activities. This reporting could take a variety of forms, including mailings to all residents included with property tax and/or utility bills, notices in local newspapers, and postings on the municipality's Web site.

\section{Service Delivery}

So far the discussion of local government enterprises has concentrated on governance and managerial issues rather than on actual service delivery. Instead of relying on local government enterprises to deliver specific public services, municipalities can choose the private sector as their delivery agent while retaining all ownership rights through contractual arrangements that spell out the terms and conditions for delivery, including quantity, quality, frequency, standards to be met, and so on. Indeed, Wallich (1994a) suggests that with competitive markets being introduced in Russia, all governments and their agencies stand to realize significant cost savings by privatizing service delivery in some form or other without relinquishing governing responsibilities.

As discussed in the following subsections, private sector delivery could take the form of contracting out, franchising out, or public-private partnerships.

CONTRACTING Out. Local authorities in the United Kingdom are now required to enter into competitive tendering for the provision of municipal services. Recent legislation in New Zealand has had a significant impact on the way services are provided, but it does not go as far 
as the United Kingdom in requiring mandatory competitive tendering. In New Zealand, delivery exclusively by local council departments declined from 70 percent in 1989 to 26 percent in 1994, while delivery by business units rose from 2 to 18 percent (Department of Internal Affairs 1994). Business units delivered the core services of water supply, sewage systems, storm water removal, and drainage in more than 50 percent of the councils surveyed, and most councils that provided legal services, refuse collection, and refuse disposal and engaged in commercial forestry used external providers (Pallot 2001).

The current trend is to advocate privatization of local public services, primarily through contracting out, on the basis of a number of claimed efficiency advantages. In essence, proponents of contracting out allege that the use of competitive tendering improves the competitive environment and leads to lower per unit operating costs for the delivery agent. Contractors face positive incentives to be efficient and negative sanctions if they are not. Note that contracting out need not apply only to contracting out to the private sector. Indeed, it could equally apply to enterprises and governments that contract with each other and with nonprofit and voluntary organizations as well (Bish 1986).

Contracts are typically awarded on a competitive tendering system whereby the lowest bidder is normally chosen. In addition, some jurisdictions have adopted a policy whereby regions, counties, or cities are subdivided and contracts are tendered for a number of subregions or areas for those services where economies of scale do not exist. The purpose of this is to encourage smaller firms to bid on contracts and in some cases to permit municipal crews to compete with the private sector in securing a contract. Such action provides a stimulus for increased competition, ultimately promoting cost savings and greater efficiency, as has occurred in some U.S. cities (Goldsmith 1997, 1998).

The most successful contracts tend to be those based on outputs that can be measured (solid waste, recycling, and so on), primarily because monitoring the quality of the output is easier. In addition, writing contracts in terms of outputs rather than inputs leaves contractors free to organize their operations to attain output goals or targets in the most efficient way possible (Bish 1986).

Many local government politicians and administrators who are not strong advocates of contracting out have argued that service quality is inevitably lower in the private sector. This concern has led to suggestions that a monitoring system be established to ensure that quality is maintained at an acceptable level. However, public sector monitoring is unlikely to be any more effective or efficient than a policy of competitive tendering for service delivery on a relatively frequent basis, for example, annually, biennially, or every three years. Tendering can create incentives for a firm to maintain quality if it wants the contracting agency to consider renewing its contract at the time of rebidding.

Most of the empirical work on contracting out suggests that per unit operating costs are lower in privately run operations. While the bulk of these studies have been completed in the United States and Europe (Borcherding, Pommerehne, and Schneider 1982; Hike 1992), similar studies have been conducted elsewhere. In New Zealand, for example, cost savings from contracting out reportedly range from 45 to 60 percent in the case of refuse collection in the city of Dunedin to 15 to 30 percent for other services in Dunedin and the city of Christchurch (Douglas 1994; Williamson 1994). A number of Canadian studies on a variety of services (solid waste collection, recycling and garbage disposal, public transit operations, and electrical utility maintenance) are also available that provide similar results (see table 8.2). Investigators have obtained similar results in an examination of private sector involvement in three urban services (waste collection, water, and electricity supply) in developing countries (Batley 2001).

These studies conclude that most of the efficiency gains from contracting out have resulted from increased scope for competition rather than from the fact that a private contractor provided the service (Bish 2001; Donahue 1989; Johnson 1988). In addition, the results suggest that where economies of scale are not prevalent, the creation of delivery zones creates a more 
Table 8.2 Private Versus Public Sector Delivery, Canada

\begin{tabular}{|c|c|}
\hline $\begin{array}{l}\text { Services studied, } \\
\text { author, and year }\end{array}$ & Delivery alternatives \\
\hline \multicolumn{2}{|l|}{ Bus service } \\
\hline Kitchen (1992) & $\begin{array}{l}\text { Municipal department versus } \\
\text { privately contracted service in } \\
\text { Ontario municipalities }\end{array}$ \\
\hline \multicolumn{2}{|c|}{ Electric utility maintenance } \\
\hline Kitchen (1986) & $\begin{array}{l}\text { Utilities contracting out utility } \\
\text { maintenance versus in-house } \\
\text { maintenance in Ontario } \\
\text { municipalities }\end{array}$ \\
\hline \multicolumn{2}{|l|}{ Refuse collection } \\
\hline Kitchen (1976b) & $\begin{array}{l}\text { Municipal versus privately } \\
\text { contracted firms in } 48 \text { Canadian } \\
\text { cities }\end{array}$ \\
\hline $\begin{array}{l}\text { McDavid, Richards, } \\
\text { and Doughton } \\
(1984)\end{array}$ & $\begin{array}{l}\text { Comparison of costs before and after } \\
\text { Richmond, British Columbia, } \\
\text { switched from private to public } \\
\text { collection }\end{array}$ \\
\hline McDavid (1985) & $\begin{array}{l}\text { Survey of private collection versus } \\
\text { municipal collection of residential } \\
\text { solid waste in } 107 \text { Canadian } \\
\text { municipalities }\end{array}$ \\
\hline
\end{tabular}

Tickner and

McDavid (1986)

McRae (1994)

McDavid and Eder (1997)

Landfill sites

McDavid and

Laliberte (1998)

Residential recycling

McDavid and

Laliberte (1999)
Detailed survey information on output, inputs, and costs for of residential waste obtained from 100 municipalities

Comparison of charges for collection of commercial/industrial solid waste in three communities in central Vancouver Island

327 questionnaire responses to survey on solid waste collection services in Canadian municipalities

Comparison of operational costs of 72 public and private landfill sites across Canada

Private versus public sector comparison of 132 recycling agents private versus public collection
Significantly lower costs per kilometer under privately contracted operation

Contracted out service significantly less expensive

Municipal suppliers more expensive than private firms.

Residential solid waste collection fell from Can\$46 per household in 1982 to Can\$31 in 1983

In municipalities with sole delivery agents (public versus private) collection was 51 percent more expensive in municipal operations, and in municipalities with a mix of public and private services the public sector was 12 percent more expensive; differences attributed to much higher productivity in private operations

On average, private collectors were 28 percent less expensive

Depending on the size of container and frequency of pickup, municipal services were between 16 and 67 percent higher than private sector prices

For all of Canada, government collection was 22 percent more costly per household than private contractors

Operational costs of privately run operations was lower: Can $\$ 15.75$ per tonne compared with Can\$23.48 per tonne

Net cost per tonne is virtually identical for public and private service providers except in seven communities where public and private providers compete directly; here substantial cost savings were reported for private providers when compared with public providers 
competitive environment than exists when there is only a single delivery agent for an entire municipality (Bartone 2001). Introducing or increasing rivalry, however, may not be possible without the existence of some private ownership. In other words, some degree of privatization through contracting out may be a necessary, but insufficient, condition for substantial performance improvements (Vickers and Yarrow 1991). For a recent and practical example of the importance of competition see the discussion in box 8.3.

Although most of the studies have concentrated on contracting out individual services, some U.S. cities have experience with contracting out most of their service responsibilities. These cities have formed the Association of Contract Cities and are mainly concentrated in California. This group has generated a highly competitive local service environment with a vast network of producers and contract arrangements. Cities buy and sell to one another, and private firms compete actively among themselves and with government producers for contracts (Bish 1986, 1997). One empirical analysis of these contract cities indicated that they received services at lower cost than the noncontract cities in Los Angeles County (Deacon 1979).

While many municipalities have apparently achieved cost reductions from increased competition, unions are generally opposed to contracting out (Canadian Union of Public Employees 1985). In particular, they are concerned about their members losing jobs and the extent to which contracting out would undermine the union, fragment the workforce, side-step provisions of collective agreements, and reduce labor costs with resultant profit-taking opportunities for businesses (Cassidy 1994). In addition, cost savings and increased efficiencies noted in the empirical studies have not been universally accepted by a few critics, because they allege that some important cost items have been excluded. In particular, critics have argued that contracting out results in additional costs because of the time and money spent on drafting,

\section{Box 8.3 The Impact of Competition}

Recent experience in pricing for garbage in Clinton, a small town in southwest Ontario, provides an example of the importance of competition in affecting costs, and hence the price or tax paid. Nearly a decade ago, the town implemented a per bag charge for garbage collection. The initial impact, as in most jurisdictions that have implemented "pay-as-you-throw" garbage collection, was that the number of garbage bags households put out declined by roughly 50 percent, while the weight of their garbage fell by about 25 percent. Households reduced their garbage collection charges by packing garbage bags fuller and tighter, but they also began recycling more of their bottles, cans, cardboard, plastic, and newspapers.

The initial charge for the pay-as-you-throw program was Can $\$ 2$ per bag. Residents had to buy stickers from the town hall and affix them to their garbage bags. Shortly after this started, an enterprising resident figured he could make a profit by collecting town garbage for only Can $\$ 1$ per bag as long as he had access to the town's landfill site on the same terms as everyone else. The town was not pleased with this challenge to its monopoly. It tried several ways to thwart this entrepreneurial effort, but to no avail. Finally the simple threat of market competition forced the town to lower its charges to only Can $\$ 1$ per bag, the same fee the private collection service charged.

In 2000 town officials realized that they had more important uses for some of their employees than collecting garbage and announced that Clinton was terminating its garbage collection service, and that residents would be obliged either to take their garbage to the landfill site themselves at a cost of approximately Can $\$ 15$ per load or to hire a private contractor to collect their garbage. Within a few weeks three different private collection services surfaced. One firm offered garbage tags for an introductory price of only $80 \notin$, another offered its tags for $90 \notin$, and the existing private service promised to donate 5 percent of its revenues to the local hockey program. Prices for garbage collection services fell as each firm courted new customers. Furthermore, residents no longer had to go to the town hall to buy garbage tags during town hall business hours. The competing collection services arranged for local convenience stores to be their outlets, and even offered to bring tags to the homes of residents who could not get to the store. While this is a small-town story, it illustrates the importance of competition in affecting the costs of providing a service and the price charged for it.

Source: Palmer (2001). 
negotiating, and monitoring contracts (for a discussion of contract design and efficient monitoring systems see David 1988); the contractees' costs for training and overseeing contractors' employees to ensure productivity; and the costs incurred in laying off employees after their services have been contracted out (Sauter, Weisman, and Percy 1988).

FRANCHISING OUT. A franchise may exist when a private firm provides a service to residents within a specific geographic area and when the supplier is paid directly by the service recipients. Franchises may be exclusive (one producer) or nonexclusive (many producers).

If an exclusive franchise provides the service, then prices will likely have to be regulated. Further regulations may be imposed to guarantee that the franchise adheres to quality standards or performance measures and that all consumers within the specific area served by the franchise have access to the service if they pay for it. For exclusive franchises that are largely capital intensive, not tendered on a frequent basis, and not subject to competitive forces (such as water and wastewater), adherence to performance standards along with carefully drawn up contracts spelling out the terms and conditions of the agreement are essential. For services that are not capital intensive, refuse collection, for example, frequent tendering for the right to provide the service should help maintain the necessary competitive forces to ensure high-quality and low-cost services.

For services provided by nonexclusive franchises, price regulation and monitoring activities are less likely to be necessary. The attractiveness of this organizational structure is mainly a function of the number of firms involved, and hence the degree of competition created. The larger the number of firms, the greater the competitive environment and thus the greater the incentive for improved efficiency, lower costs, and good quality services.

A possible problem with franchise operations is that some users, such as low-income families, may discontinue the consumption of certain services if they view the price of the service as being too high. This has occurred, primarily in smaller communities, where solid waste collection has been privatized and franchised. Not only could this be unsanitary and impose externalities on those who pay, it could lead to lower-quality service and/or greater costs for existing users if economies of scale disappear. Use of a franchise operation in place of contracting out may therefore be undesirable on efficiency grounds, especially for services where negative externalities might be created because individuals choose not to use the service.

Where franchises are considered, a franchise agreement between the local council and the supplier is critical, because it is the core legal document by which both parties are bound and which can be enforced. This agreement should include the following:

- The terms of payment for a franchise fee

- The principles and practices to follow in setting prices

- The standards and performance measures that the franchise is to meet

- A list and description of all financial and performance reports that the franchise is to provide on a regular basis to the local council and the public

- Procedures to follow in renegotiating standards and conditions in the agreement

- The conditions for the return of any capital assets whose ownership is retained by the local council at the end of the agreement period.

PUBLIC-PRIVATE PARTNERSHIPS. Relatively recent developments in the financing of municipal infrastructure involve public-private partnerships, particularly for services with substantial capital or infrastructure costs. Indeed, 85 percent of government respondents to a survey by the Canadian Council for Public-Private Partnerships noted that their governments were increasing their reliance on public-private partnerships (Martin 2001). Szalai (2001) notes similar trends in many other countries. This kind of partnership can take different forms, including private involvement in project initiation or planning, construction, operation, ownership, and 
financing. These public-private partnerships are a form of contracting out and involve the direct participation of one sector in a venture controlled by the other sector (for more information see Slack (1996). Both partners contribute funds or services in exchange for certain rights or future income.

Public-private partnerships can take the following forms:

- Operate: the private sector operates the facility for a fee. The public sector retains responsibility for capital costs.

- Lease or purchase and operate: the private firm leases or purchases the facility from the public sector, operates the facility, and charges user fees.

- Lease or purchase, build, and operate: this option is similar to the previous one except that the private sector firm is required to build or develop a new facility or enlarge or renovate an existing facility and then operate it for a number of years.

- Build: this is a turnkey partnership in which the private sector is paid a fixed fee to build a facility according to government specifications and turns the facility over to the public sector when it has been completed.

- Build, operate, and transfer: the private sector develops and builds the required infrastructure, operates the facility for some specified period of time, and then transfers it back to the government.

- Build and operate: the private sector builds and operates the facility and is responsible for capital financing. The public sector regulates and controls the operation.

- Build and transfer: the private sector builds the infrastructure and then transfers ownership to the public sector.

The way in which the risks of partnerships are shared will depend on their structure (for a more detailed discussed see Martin 2001; Tassonyi 1997). Public-private partnerships have three main benefits. First, private sector capital may be viewed as a way of gaining new sources of capital, freeing up municipal resources, reducing current debt, and increasing debt capacity (De Luca 1997). The opportunity to gain new sources of capital is especially important where modernization of decrepit and crumbling infrastructure is necessary (Huang 2001). Reliance on private sector financing means that the private sector must incur all associated risks (see table 8.3 for possible types of risks). The greater the risk, the greater the rate of return expected. The private sector may also be concerned that the government could change the rules of the game in midstream because of changes in regulation or in the political climate or that the public sector may terminate contractual arrangements without having to compensate private sector participants.

Second, public-private partnerships enable the public sector to draw on the private sector's experience and skill to minimize costs. This may be more important to smaller municipalities that may have greater difficulty in attracting the necessary expertise.

Third, private sector involvement tends to lead to more innovative and efficient operations than if the public sector provides the service on its own (Probyn 1997).

As with most options, private sector involvement also entails some disadvantages. First, there may be some uncertainty that the private sector will be able to carry its role through to completion. Second, the public sector faces a potential loss of control to the private sector. Third, there may be a trade-off of up-front capital costs for future operating costs, for example, this could happen if the private sector's annual cost of financing a municipal project is greater than if the public sector financed it (De Luca 1997; Probyn 1997). Finally, private sector financing may include government financial or credit backing, thereby continuing to impose a potential burden on the public sector.

Experience with public-private partnerships in Canada suggests that most have produced cost savings for the public sector (table 8.4). Experience with public-private partnerships has led to the identification of a number of issues. One issue relates to the respective roles of the 
Table 8.3 Types of Risks and Possible Solutions

\begin{tabular}{|c|c|c|}
\hline Risk & Meaning & Possible solution \\
\hline Market risk & $\begin{array}{l}\text { Future demand is uncertain, but } \\
\text { the provider plans investment } \\
\text { based on the expected growth } \\
\text { in demand }\end{array}$ & $\begin{array}{l}\text { Contractual guarantee that all } \\
\text { relevant information is } \\
\text { provided }\end{array}$ \\
\hline Financing and economic risk & $\begin{array}{l}\text { Interest and inflation rates } \\
\text { fluctuate }\end{array}$ & $\begin{array}{l}\text { Some kind of indexing } \\
\text { mechanism, but the provider } \\
\text { should also be responsible for } \\
\text { restructuring and reducing } \\
\text { costs }\end{array}$ \\
\hline Exchange rate risk & $\begin{array}{l}\text { If investment is financed in } \\
\text { foreign currency }\end{array}$ & $\begin{array}{l}\text { Adjust prices according to } \\
\text { exchange rate fluctuations }\end{array}$ \\
\hline Performance risks & $\begin{array}{l}\text { Reaching the standards set by } \\
\text { law depends on many factors, } \\
\text { for instance, on the quality and } \\
\text { quantity of inputs }\end{array}$ & $\begin{array}{l}\text { Define the circumstances within } \\
\text { which the performance can be } \\
\text { below standards }\end{array}$ \\
\hline Natural resource risk & $\begin{array}{l}\text { Quality of service depends on } \\
\text { natural resources such as raw } \\
\text { water }\end{array}$ & $\begin{array}{l}\text { Government may be responsible } \\
\text { for the quality of these } \\
\text { resources. }\end{array}$ \\
\hline Operation and maintenance risk & $\begin{array}{l}\text { Providers are responsible for } \\
\text { operation and maintenance, but } \\
\text { if they are forced to transfer the } \\
\text { assets back to the government } \\
\text { at a low price they have no } \\
\text { incentive to invest }\end{array}$ & $\begin{array}{l}\text { Guarantee a fair valuation } \\
\text { process at the end of the period }\end{array}$ \\
\hline Technology risk & $\begin{array}{l}\text { New technology can appear on } \\
\text { the market during the contract } \\
\text { period; the provider is } \\
\text { responsible for working as } \\
\text { efficiently as possible }\end{array}$ & $\begin{array}{l}\text { Price adjustment (incentive } \\
\text { regulation); the requirements to } \\
\text { use the best technology are not } \\
\text { relevant because of monitoring } \\
\text { difficulties }\end{array}$ \\
\hline
\end{tabular}

Source: Szalai (2001, table 2).

public and private sectors. Basically, the private sector can handle delivery, but governments should handle governance. A second issue relates to the services that might qualify for publicprivate partnerships. Considerations include the degree to which objective standards and performance measures can be described, the presence of competition, the ability to replace the private provider if the service is below standard or if the firm goes out of business, the degree to which the government can monitor the contractor's performance, the impact on current government employees, the degree of potential opposition to the partnership arrangement, the legality of contracting out, and the time needed to structure and implement the partnership arrangement (Bartone 2001; Carr 1996). Whether the function has been outsourced elsewhere is an additional consideration.

According to Carr (1996, p. 24): "The key criterion is that you must know what it is you wish to achieve as the result of contracting out. The benefits and barriers then can be accommodated and addressed throughout the process." As to whether or not municipalities should proceed with public-private partnerships, they should evaluate each service for which this is a possibility separately and thoroughly, taking all the benefits and costs of each project into consideration.

SUMMARY. While ranking the order in which local governments should consider alternatives for providing specific government services is difficult, they should consider a number of factors 
Table 8.4 Examples of Canadian Case Studies of Public-Private Partnerships

\begin{tabular}{lll} 
Municipality & \multicolumn{1}{c}{ Nature of project } & \multicolumn{1}{c}{ Impact } \\
\hline Hamilton-Wentworth, Ontario & Water and wastewater treatment & $\begin{array}{c}\text { Cost savings guaranteed to } \\
\text { the municipality }\end{array}$ \\
Paradise, Newfoundland & Public works & Cost savings \\
Alberta Highway 14 Water Project & Water supply system & Cost savings \\
Rockland, Ontario & Sewage treatment plant & Proposal did not proceed \\
Ottawa-Carleton & Service delivery for sewage treatment & Cost savings \\
Sainte-Marie-de-Beauce, Quebec & Operation of water treatment plant & Cost savings \\
Peel region, Ontario & Operation of water treatment plant & Cost savings \\
\hline
\end{tabular}

Source: Slack (1996); correspondence with municipal officials.

before implementation takes place. These include the extent to which each alternative will improve the efficiency of service delivery, the differences in monitoring costs associated with the alternatives, and the improvements in the choice of services available to consumers. In evaluating the alternatives, local governments should not address income distribution issues, which are handled more appropriately through income transfer schemes.

Improved efficiency, expanded consumer choice, and enhanced mechanisms for monitoring the activities of producing and delivering agents are achieved through the introduction of competitive elements. This may involve the introduction of additional production and delivery agents with their inherent tendency to be competitive with each other, and therefore more efficient. For services not displaying economies of scale, it should involve the creation of service delivery zones. Or it may involve the introduction of incentives for managers of public sector departments or corporations to be more efficient in the delivery of public services. In New Zealand, this is attempted by legislation requiring that local councils hire their chief executive officer on a performance-based contract for up to five years. The chief executive offer is the employer of all other staff. The council's job is to set policy and monitor the performance of the chief executive officer, and the latter and other officers are to manage within that policy (Pallot 2001).

While injecting more competitive incentives into public sector organizational structures may be possible, growing taxpayer unrest and criticism about growth in government expenditures and possible tax increases has led to increased calls for the privatization of a variety of public services. Privatization, as it is often used in discussions of delivering government services, does not mean that governments forego their ownership. Indeed, it is implicitly assumed that governments would retain the right to set standards, specify conditions, and generally retain overall responsibility through the use of contractual arrangements.

As for the future of private sector delivery of public services, the debate will continue. Some will advocate greater privatization and others will oppose it. In reality, however, political pressure to reduce government expenditures and lower or restrict tax and user fee increases will force governments to resort to private sector delivery, in one form or another, for a variety of what are currently referred to as municipal services. Indeed, this is even legislated or mandated in some countries.

\section{References}

The word processed describes informally reproduced works that may not be commonly available through libraries.

Armstrong, W. Douglas, and Harry Kitchen. 1997. Peterborough County/City Municipal Review. Joint Restructuring Committee of the City and County of Peterborough, Ontario. 
Bahl, Roy, and Christine I. Wallich. 1995. "Intergovernmental Fiscal Relations in the Russian Federation." In Richard M. Bird, Robert D. Ebel, and Christine I. Wallich, eds., Decentralization of the Socialist State. Washington, D.C.: World Bank.

Bartone, Carl R. 2001. "The Role of the Private Sector in Municipal Solid Waste Service Delivery in Developing Countries: Keys to Success." In Mila Freire and Richard Stren, eds., The Challenge of Urban Government: Policies and Practices. Washington, D.C.: World Bank.

Batley, Richard. 2001. "Public-Private Partnerships for Urban Services." In Mila Freire and Richard Stren, eds., The Challenge of Urban Government: Policies and Practices. Washington, D.C.: World Bank.

Bird, Richard M. 1976. Charging for Public Services: A New Look at an Old Idea. Toronto: Canadian Tax Foundation.

1980. Central-Local Fiscal Relations and the Provision of Urban Public Services. Canberra: Australian National University, Centre for Research on Federal Financial Relations.

1984. Intergovernmental Finance in Colombia. Cambridge, Massachusetts: Harvard Law School, International Tax Program.

1993. "Threading the Fiscal Labyrinth: Some Issues in Fiscal Decentralization." National Tax Journal XLVI(2): 207-27.

1994. Decentralizing Infrastructure: For Good or Ill? Policy Research Working Paper no. 1258. Washington, D.C.: World Bank.

1997. “Analysis of Earmarked Taxes.” Tax Notes International 14(25): 2096-2116.

2001. "User Charges in Local Government Finance." In Mila Freire and Richard Stren, eds., The Challenge of Urban Government: Policies and Practices. Washington, D.C.: World Bank.

Bird, Richard M., and Thomas Tsiopoulos. 1997. "User Charges for Public Services: Potential and Problems." Canadian Tax Journal 45(1): 35-37.

Bish, Robert L. 1986. "Improving Productivity in the Government Sector: The Role of Contracting Out." In David Laidler, research coordinator, Responses to Economic Change. Studies of the Royal Commission on the Economic Union and Development Prospects for Canada, vol. 27, pp. 203-37. Toronto: University of Toronto Press.

1997. “California Contract Cities." Policy Brief. Winnipeg, Manitoba: Frontier Centre for Public Policy.

2001 "Local Government Amalgamations: Discredited 19th-Century Ideals Alive in the 21st." C. D. Howe Institute Commentary, no. 150. Toronto: C. D. Howe Institute.

Boadway, Robin. "Public Economics and the Theory of Public Policy." 1997. Canadian Journal of Economics 30 (4):753-772.

Boadway, Robin, and Harry Kitchen. 1999. Canadian Tax Policy, 3rd ed. Toronto: Canadian Tax Foundation.

Borcherding, T. E., W. Pommerehne, and F. Schneider. 1982. "Comparing the Efficiency of Private and Public Provision: The Evidence from Five Countries." Nationalokonomie, Journal of Economics 42(Supplement 2): 127-56.

Bossons, John, Harry Kitchen, and Enid Slack. 1993. “Local Government Finance: Principles and Issues." Ontario Fair Tax Commission, Toronto.

Canadian Union of Public Employees. 1985. “Contracting Out: It's a Trend CUPE Must Continue to Oppose." Facts 7: 14-15. 
Carr, Glenna. 1996. "Promoting Entrepreneurial Municipalities." Background paper for the Greater Toronto Area Task Force. Toronto.

Cassidy, Gordon. 1994. Contracting Out. Discussion Paper no. 94-06. Kingston, Ontario: Queen's University, School of Policy Studies.

David, T. 1988. Privatization in America. Washington, D.C.: International City Management Association.

Deacon, R. T. 1979. "The Expenditure Effects of Alternative Public Supply Institutions." Public Choice 34(3-4): 381-97.

De Luca, L,. ed. 1997. Labour and Social Dimensions of Privatization and Restructuring-Public Utilities, Water, Gas, Electricity: Part II Europe. Geneva: International Labour Organization, Interdepartmental Action Program on Privatization, Restructuring, and Economic Democracy.

Department of Internal Affairs. 1994. Territorial Authority Service Delivery 1993-1994. Wellington, New Zealand.

Donahue, John. 1989. The Privatization Decision: Public Ends, Private Means. New York: Basic Books.

Douglas, M. 1994. "New Zealand Paths to Competitive Tendering." In Introducing Competitive Tendering in Local Government in Australia. Melbourne: Royal Melbourne Institute of Technology, Department of Management, Foundation for Local Government Education and Development Fund.

Easter, K.W., G. Feder, G. Le Moigne, and A. Duda. 1993. Water Resources Management. Policy Paper. Washington, D.C.: World Bank.

Gardner, G. 1997. Recycling Organic Waste. Paper no. 135. Washington, D.C.: Worldwatch Institute.

Gilbert, M., and R. Pike. 1998. "Financing Local Government Debt in Canada: Pooled Versus Stand-Alone Issues-An Empirical Study." Canadian Public Administration 41(4): 529-52.

Goldsmith, Stephen. 1997. “Can Business Really Do Business with Government? The Answer Is Yes, Just Ask the Mayor of Indianapolis." Harvard Business Review (May-June): 110-21. . 1998. “Smaller Government Prescriptions for Big City Problems.” Fraser Forum (September): $6-15$.

Government Accounting Standards Board. 2001. New Rules for Reporting Infrastructure Information Enacted for State and Local Governments. Available on:

http:/ / www.rutgers.edu/Accounting/raw/gasb/repmodel/infrastructure.html.

Hatry, Harry. 1999. Performance Measurement. Washington: D.C.: Urban Institute Press.

Hike, John. 1992. Competition in Government Financed Services. Westport, Conn.: Quorum Books.

Holder, William W. 1996. "Financial Accounting, Reporting, and Auditing." In J. Richard Aronson and Eli Schwartz, eds., Management Policies in Local Government Finance, 4th ed. Washington, D.C.: International City Management Association.

Huang, Mel. 2001. “From Monopolies to Markets: Privatizing Public Utilities in the Baltic States." Local Government Brief: Quarterly Journal of Local Government and Public Service Reform Initiative (Budapest) (Fall): 1-3, 6-12.

International City/County Management Association. 2000. GASB: What It Means for You. Service Report 332(12). Washington, D.C. 
International Monetary Fund. 2001. Code of Good Practices on Fiscal Transparency. Washington, D.C.

Johnson, Christopher, ed. 1988. Privatization and Ownership. London: Lloyds Bank Review.

Johnson, L. E., and D. R. Bean. 1999. “GASB Statement No. 34: The Dawn of a New Governmental Financial Reporting Model." CPA Journal 69(12): 14-24.

Kitchen, Harry. 1975. "Some Organizational Implications of Providing an Urban Service: The Case of Water." Canadian Public Administration (Summer): 18(2): 297-308. . 1976a. "A Statistical Estimation of an Operating Cost Function for Municipal Water Provision." Journal of Urban Analysis (January): 5(1): 56-76.

. 1976b. "A Statistical Estimation of an Operating Cost Function for Municipal Refuse Collection." Public Finance Quarterly (January): 4(1): 56-76.

1986 Local Government Enterprise in Canada. Discussion Paper no. 300. Ottawa: Economic Council of Canada.

1989. Report and Recommendations: A Review of Regional Government in Niagara. Toronto: Queen's Printer for Ontario.

1992. "Urban Transit Provision in Ontario: A Public/Private Sector Cost Comparison." Public Finance Quarterly 20(1): 114-28.

. 1993. Efficiency Delivery of Local Government Services. Discussion Paper no. 93-15.

Kingston, Ontario: Queens University, School of Policy Studies.

1997. "Pricing of Local Government Services." In Paul A. R. Hobson and France StHilaire, eds., Urban Governance and Finance: A Question of Who Does What. Montreal: Institute for Research on Public Policy.

. 2000a. "Municipal Finance in a New Fiscal Environment." C. D. Howe Institute Commentary, no. 147. Toronto: C. D. Howe Institute.

. 2000b. "Provinces and Municipalities, Universities, Schools, and Hospitals: Recent Trends and Funding Issues." In Harvey Lazar, ed., Canada: The State of the Federation 1999/2000. Kingston, Ontario: Queen's University, Institute of Intergovernmental Affairs.

. 2002. Municipal Revenue and Expenditure Issues in Canada. Toronto: Canadian Tax Foundation.

Knapton, David. 1993. “Police Commissions: Do They Crowd Out Other Municipal Expenditures?" Honors economics essay, Trent University, Economics Department, Peterborough, Ontario.

Kolderie, T. 1986. "Two Different Concepts of Privatization." Public Administration Review 46(2): 285-91.

Kurlyandskaya, Galina, Yelena Nikolayenko, and Natalia Golovanova. 2001. “Local Governments in the Russian Federation." Open Society Institute, Local Government and Public Service Reform Initiative, Budapest.

Martin, Stephen. 2001. "Public-Private Partnerships: An Effective Tool for Providing Best Value." Paper presented at the Insight Information conference on Managing the New Realities of Municipal Amalgamation, February 13-14, Toronto.

Martinez-Vazquez, Jorge. 1994. "Budgeting in the Russian Federation." World Bank, Europe and Central Asia Department, Washington, D.C. Draft.

Martinez-Vazquez, Jorge, and Jameson Boex. 2001. Russia's Transition to a New Federalism. Washington, D.C.: World Bank. 
McDavid, James. 1985. "The Canadian Experience With Privatizing Residential Solid Waste Collection Services." Public Administration Review: 45(4): 602-08.

McDavid, James, and K. Anthony Eder. 1997. The Efficiency of Residential Solid Waste Collection Services in Canada: The National Survey Report. Victoria, British Columbia: University of Victoria, School of Public Administration, Local Government Institute.

McDavid, James, and Verna Laliberte 1998. The Efficiency of Canadian Solid Waste Landfills: National Survey Report. Victoria, British Columbia: University of Victoria, School of Public Administration, Local Government Institute.

1999. The Efficiency of Residential Recycling Services in Canadian Local Governments: National Survey Report. Victoria, British Columbia: University of Victoria, School of Public Administration, Local Government Institute.

McDavid, James, P. L. Richards, and B. E. Doughton. 1984. "Privatization of Residential Solid Waste Collection in Richmond, British Columbia." University of Victoria, School of Public Administration, Victoria, British Columbia. Processed.

McRae, James J. 1994. Efficient Production of Solid Waste Services by Municipal Governments. Discussion Paper no. 94-11. Kingston, Ontario: Queen's University, School of Policy Studies.

Ministry of Municipal Affairs and Housing. 2001. Municipal Performance Measurement Program. Ontario: Government of Ontario.

Munasinghe, M. 1992. Water Supply and Environmental Management: Developing World Applications. Studies in Water Policy and Management. Boulder, Colorado: Westview Press.

Municipality of Metropolitan Toronto. 1988. "First Report of the Subcommittee on Special Purpose Bodies." Toronto, Ontario. Processed.

Osborne, David, and Ted Gaebler. 1992. Reinventing Government: How the Entrepreneurial Spirit Is Transferring the Public Sector. Reading, Massachusetts: Addison Wesley.

Ostrom, E., L. Schroeder, and S. Wynne. 1993. Institutional Incentives and Sustainable Development: Infrastructure Policies in Perspective. Bolder, Colorado: Westview.

Pallot, June. 2001. "Local Government Reform in New Zealand: Options for Public Management as Governance." Available on http:/ /www.willamette.org/ipmn/test/papers/ pallot.htm.

Palmer, John. 2001. “Clinton Garbage: Pay as You Throw." University of Western Ontario, London, Ontario. Processed.

Patton, T. K., and P. S. Wardlow. 1999. "Why Infrastructure Reporting?" GASB Action Report, vol. 16, no. 5. Available on: http://www.rutgers.edu/Accounting/raw/gasb/repmodel/viewpoints.html.

Peterson, J. E. 2001. Subnational Debt, Borrowing Process, and Creditworthiness. Washington, D.C.: World Bank Institute.

Postel, S. 1993. “Facing Water Scarcity." In L. Brown, ed., The State of the World. New York: W. W. Norton.

Probyn, S. 1997. "Public-Private Partnerships on the Way to Nowhere." Financial Post, April 16, p. B-5.

Renzetti, Steven. 1999. "Municipal Water Supply and Sewage Treatment: Costs, Prices, and Distortions." Canadian Journal of Economics 32(3): 688-704.

Renzetti, Steven, and Joseph Kushner. 2001. “The Underpricing of Water Supply and Sewage Treatment." Brock University, Economics Department, St. Catharine's, Ontario. Processed. 
Sancton, Andrew, and Teresa Janik. 2001. "Provincial-Local Relations and Drinking Water in Ontario." Issue paper commissioned by the Walkerton Inquiry.

Sauter, R. W., R. D. Weisman, and R. W. Percy. 1988. “Union View: Subcontracting the Work of Union Members in the Public Sector." Labor Law Journal 39(8): 487-96.

Savas, E. S. 1987. Privatization: The Key to Better Government. Chatham, New Jersey: Chatham House.

Slack, Enid. 1996. Financing Infrastructure: Evaluation of Existing Research and Information Gaps. Ottawa: Central Mortgage and Housing Corporation.

Solano, Paul L., and Marvin A. Brams. 1996. "Budgeting." In J. Richard Aronson and Eli Schwartz, eds., Management Policies in Local Government Finance, 4th ed. Washington, D.C.: International City Management Association.

Stenning, Philip, and Tammy Landau. 1988. The Niagara Regional Board of Commissioners of Police: Its Role and Accountability. Background study. Niagara Region Review Commission, Niagara Falls, Ontario.

Strategic Alternatives Inc., Michael Fortin, Enid Slack, Mike Loudon, and Harry Kitchen. 2001. "Financing Water Infrastructure." Issue Paper no. 14. Commissioned by the Walkerton Inquiry, Toronto.

Szalai, Akos. 2001. "New Models of Privatizing Public Utilities: Highlights of Reform in PostSoviet Countries." Local Government Brief: Quarterly Journal of Local Government and Public Service Reform Initiative (Budapest) (Fall): 18-24.

Tassonyi, Almos. 1997. “Financing Infrastructure in Canada's City-Regions" In Paul A. R. Hobson and France St-Hilaire, eds., Urban Governance and Finance: A Question of Who Does What. Montreal: Institute for Research on Public Policy.

Tassonyi, Almos, and Wade Locke. 1994. "Shared Tax Bases and Local Public Expenditure Decisions." Canadian Tax Journal 41(5): 941-57.

Tickner, Glen, and James McDavid. 1986. “Effects of Scale and Market Structure on the Costs of Residential Solid Waste Collection in Canadian Cities. Public Finance Quarterly 14(4): 371-93.

Tindal, C. R., and S. Nobes Tindal. 1988. Local Government in Canada. Toronto: McGraw-Hill Ryerson.

Vickers, John, and George Yarrow. 1991. "Economic Perspectives on Privatization." Journal of Economic Perspectives 5(2): 111-32.

Wallich, Christine I. 1994a. "Intergovernmental Fiscal Relations: Setting the Stage" In Christine I. Wallich, ed., Russia and the Challenge of Fiscal Federalism. Washington, D.C.: World Bank. . 1994b. "Russia's Dilemma." In Christine Wallich, ed., Russia and the Challenge of Fiscal Federalism. Washington, D.C.: World Bank.

Williamson, J. 1994. “The Christchurch Case Study on Competitive Tendering." In Introducing Competitive Tendering in Local Government in Australia. Melbourne: Royal Melbourne Institute of Technology, Department of Management, Foundation for Local Government Education and Development Fund.

World Bank. 1994. World Development Report 1994: Infrastructure for Development. New York: Oxford University Press.

Wunsch, J. S. 1991. "Institutional Analysis and Decentralization: Developing an Analytical Framework for Effective Third World Administration Reform." Public Administration and Development 11(5): 431-52. 


\section{Part III \\ Revenues}



9

\title{
Local and Regional Revenues: Realities and Prospects
}

\author{
Richard M. Bird
}

The traditional theory of fiscal federalism prescribes a limited tax base for subnational governments. According to the theory, the only good local taxes are those that are easy to administer locally, are imposed solely (or mainly) on local residents, and do not raise problems of harmonization or competition between subnational-local or regional-governments or between subnational and national governments. (For the classic tax assignment arguments see Musgrave 1983 and for a recent restatement see McLure 1999.) The only major revenue source that usually passes these stringent tests is the property tax, with perhaps a secondary role for taxes on vehicles and user charges and fees. As central governments are in any case generally reluctant to provide subnational governments with access to more lucrative sales or income taxes, that traditional theory has become conventional wisdom is not surprising. Almost everywhere, central governments and experts alike therefore urge subnational governments to make more use of property taxes and user charges and criticize them when they do not do so enthusiastically.

Up to a point, this view has much to recommend it. Unfortunately, that point falls short of the task facing subnational governments in many countries for a number of reasons. First, the conventional case for user charges and property taxes is somewhat flawed. Property taxes, for example, are often costly and difficult to administer well, and such problems are greatly exacerbated as the tax burden increases. Moreover, political realities mean that increases in property taxes are often concentrated primarily on those nonresidential properties that most readily permit tax exporting, that is, the shifting of taxes to nonresidents, thereby undercutting one of the principal arguments for local use of property taxes in the first place.

Second, even a well-administered local property tax cannot finance major social expenditures (education, health, social assistance) except perhaps to a limited extent in the richest, and usually largest, communities (user charges should be used only with caution in such social areas; see Bird 1976). Because, to the extent possible, governments should finance the services they provide from their own revenues, either local governments that depend on property taxes are essentially confined to providing local services (street cleaning, refuse removal, and the like), or they are inevitably heavily dependent on transfers from higher levels of government. This pattern persists even in the industrial countries. ${ }^{1}$

Third, the conventional argument does not take adequately into account the existence in many countries of important regional or intermediate levels of government, especially these governments' often major role in financing social expenditures. Local governments may to a considerable extent be able to finance purely local services through property taxes and user fees

This is a substantially revised and updated version of a paper originally prepared for the 1999 Annual World Bank Conference on Development in Latin America and the Caribbean and subsequently published in Burki and Perry (2000).

1. Relatively few industrial countries have significant local property taxes. In most countries of the Organisation for Economic Co-operation and Development, to the extent that local governments are not dependent on national transfers, they either impose significant direct taxes on business or levy surcharges on national income taxes (Bird and Slack 1991). Bahl (2002) shows that property taxes are even less important in developing and transition countries. 
on residents. Regional governments responsible for social services, however, cannot rely solely on this narrow base for financial support. The conventional approach to tax assignment has traditionally held that the best additional source of finance for regional governments is retail sales taxes. Such taxes are usually assumed to fall mainly on residents, a desirable feature of a subnational tax. In reality, most retail sales taxes, even in industrial countries, fall to a considerable extent on business inputs. For example, one Canadian study found that between a third and a half of the retail sales tax base in different provinces consisted of such inputs (Kuo, McGirr, and Poddar 1988). ${ }^{2}$ Moreover, as Canada and the United States have long demonstrated, retail sales taxes can be administered at the regional level, at least in industrial countries, although this cannot simply be carried over to developing countries, which have universally found that administering such taxes is impossible, even at the national level.

Given the recent moves toward decentralization in many countries (Litvack, Ahmad, and Bird 1998) and the frequently expressed concerns about the resulting strain on intergovernmental fiscal relations and the possibility of irresponsible behavior by subnational governments expressed by authors such as Tanzi (1996), some rethinking of the appropriate revenue structure for regional and local governments seems to be needed.

Both theory and international experience suggest that governments are more likely to spend responsibly the more they are responsible for raising the revenues they spend. While intergovernmental transfers will obviously always have an important role, especially in countries with wide regional economic disparities, in principle, there seems to be no reason why at least the wealthier regions, for example, large urban areas, should not be able to raise and spend most of their budgets themselves. Thus there are good reasons to strengthen subnational tax regimes. The balance of this chapter reviews the various sources usually considered for this purpose.

An important implication of strengthening subnational own revenues should first be noted, however. The resources accruing to different states or provinces will obviously differ greatly depending on their access to the tax base in question. While in principle, transfer systems can be adjusted as desired to prevent unduly penalizing poor regions, the extent to which such adjustments will actually be made is always country specific-compare, for example, the cases of Canada versus the United States and Germany versus Switzerland (Bird 1986) - and the incentive effects of transfer design need to be considered with care (Bird and Smart 2002).

Multitiered governments work best when taxes and the benefits of public spending are as closely related as possible, that is, when citizen-voter-consumers residing in a particular political jurisdiction both pay for what they get from the public sector and get what they pay for, or in other words, when they benefit from the expenditures financed by the taxes they pay. Obviously when citizens reside in several overlapping jurisdictions (local, regional, national), this so-called principle of fiscal equivalence (Olson 1969) suggests that they should pay taxes to each level corresponding to the benefits they receive from each jurisdiction.

In this framework, the only rationale for intergovernmental transfers is to restore this equivalence, for example, by providing a compensatory payment when some benefits flow from one jurisdiction to another or when some taxes levied by one jurisdiction are actually paid by people residing in another jurisdiction. Such transfers would, of course, be horizontal, between regions or municipalities, and not between levels of government. In addition, however, considerations of administrative efficiency and feasibility may require that higher or lower levels of government impose certain taxes or make certain expenditures, even when doing so is not appropriate on equivalence grounds. The vertical intergovernmental fiscal transfers found in most countries are motivated largely by this consideration. However, if, as suggested here, more adequate subnational taxes are made available, this fiscal gap (Boadway and Hobson 1993) argument for transfers disappears with respect to richer jurisdictions, because the richer

2. The situation in the United States appears to be broadly similar (Ring 1999). 
units of government at subnational levels should be essentially self-sufficient. Any grants from higher levels of government that are made to the poorer subnational units for reasons of regional equalization should be clearly inframarginal, so that, as McLure (1999) notes, all subnational governments, rich and poor alike, will face the full marginal tax price of the spending decisions for which they are responsible. Only in this way can the hard budget constraint critical to good intergovernmental fiscal and financial policy be achieved (see Bird 2001 for more detail and Rodden, Eskeland, and Litvack 2003 for a useful recent review of experience with hard budget constraints in a variety of countries).

Therefore good subnational taxes should, in principle, satisfy two main criteria. First, they should provide sufficient revenue for the richest subnational units to be essentially fiscally autonomous. Of course this objective does not preclude intergovernmental fiscal transfers not only to achieve the usual spillover objectives, but also, in some circumstances, to ensure the adequate provision of certain services to national standards (for a suggested design for such a system in Colombia, for instance, see Bird and Fiszbein 1998). Second, good subnational taxes should clearly impose fiscal responsibility at the margin on subnational governments. The simplest and probably best way to achieve this goal is by allowing those governments to establish their own tax rates with respect to at least some major taxes.

The most immediate issue facing many large countries is undoubtedly the need to develop a satisfactory revenue base for regional governments, that is, one for which those governments are politically responsible. One possibility is to permit regional surcharges on personal income taxes. Another potentially promising approach may be to establish subnational value added taxes (VATs). Such taxes work well in Canada (Bird and Gendron 1998), and implementing them in some circumstances may be feasible even in countries with less well-developed tax administrations.

The following sections review the major tax sources experts usually suggest for local and regional governments in developing countries, more or less in order of preference.

\section{User Charges}

Perhaps the most obvious, and in many ways the most sensible, recommendation with respect to revenue at any level of government is that governments should employ appropriate user charges whenever possible. From an economic point of view local, and to some extent regional, governments may be viewed as firms delivering packages of local public services to residents. As with any economic activity, people should want what they deliver enough to be willing to pay for it. From this perspective, the first rule of subnational finance should therefore be: wherever possible, charge. While officials are likely to view user charges solely as a potential additional source of revenue, their main economic value derives from ensuring that citizens value what the public sector supplies, at least at its marginal cost. In addition, user charges promote economic efficiency by providing demand information to public sector suppliers. This efficiency objective is particularly important at the subnational level, because the main economic rationale for subnational government in the first place is to improve efficiency. Whenever possible, local governments should charge for local public services properly rather than giving them away.

Most countries have at least the following three types of user charges:

- Service fees. These include such items as license fees (marriage, business, dog, vehicle, and so on) and various small charges local governments levy for performing specific services-registering this or providing a copy of that-for identifiable individuals or businesses. In effect, such fees constitute cost reimbursement from the private to the public sector. Charging people for something they are required by law to do may not always be sensible, however, for example, if the benefit of registration is general and the 
cost is specific, but on the whole there is seldom much harm, or much revenue, in recovering the cost of providing the service in question. Note, however, that imposing unnecessary regulatory requirements, whether accompanied by a fee or not, may result in considerable harm, both by imposing additional obstacles to and costs on new business activities and by providing more opportunities for corrupt practices.

- Public prices. These consist of the revenues local governments receive from the sale of private goods and services other than from service fees. All sales of locally-provided services to identifiable private agents-from public utility charges, to admission charges, to recreation facilities-fall under this general heading. In principle, local governments should set such prices at the competitive private level, with no tax or subsidy element included, unless doing so is the most efficient way of achieving public policy goals. The best approach is to account for the tax subsidy element separately.

- Specific benefit taxes. Such revenues are distinct from service fees and public prices because they do not arise from the provision or sale of a specific good or service to an identifiable private agent. Unlike prices that those who obtain services voluntarily pay, but like fees that people must pay for services that are legally required, taxes are compulsory. Nonetheless, specific benefit taxes are, at least in theory, related in some way to benefits that specific taxpayers receive, in contrast to such general benefit taxes as fuel taxes levied on road users as a class or local general business or property taxes viewed as a price paid for local collective goods. Examples of specific benefit taxes abound under many different names: special assessments, land value increment taxes, improvement taxes, front footage levies, supplementary property taxes related to the provision of sewers or street lighting, development exactions and charges, delineation levies, and so on. Most such charges are imposed either on the assessed value of real property or on some characteristic of that property such as its area, its frontage, or its location.

The importance of user charges is greater in principle than the relatively small amounts of money that most countries collect from this source. The appropriate policy in setting user charges is simply to charge the correct price. Only then will local governments provide the correct amounts and types of service to the right people, that is, those willing to pay for them. Such user charges should be levied wherever feasible to ensure that scarce public resources are used as efficiently as possible. Critics often suggest that equity considerations mitigate against user charges. Although in principle the incidence of user charges is no more relevant than the ultimate incidence of the price of something someone obtains from the private sector, a number of studies in different countries suggest that in many instances the distributive consequences of charging for local public services may even be progressive (Bird and Miller 1989). The rich, for example, use more water-for washing cars, watering lawns, filling swimming pools, and so on-than the poor. In any case, attempting to rectify fundamental distribution problems by inefficiently pricing scarce local resources is almost always a bad idea that results in little, if any, improvement in equity and a high price in efficiency terms.

Most countries make much less use of charging at the local level than seems to be desirable, and many of the charges they do levy are poorly designed from an efficiency point of view. The province of San Juan, Argentina, for example, levies a wide range of charges for an enormous number of specific services rendered by the judiciary, the registry of commerce, the registry of real property, the inspection of juridical persons, the civil registry, the mining department, the transport directorate, the bus station, the local transport enterprises, the police, the irrigation department, the general administration, and even the tax department. Many of these charges probably cost more to administer than they yield and are little more than nuisance levies that impede normal transactions, while none of the rates imposed appear to be based on any rational principle.

Thus even though the rational use of user charges in subnational finance has a number of advantages, finding much rationality in the systems in use in most jurisdictions is hard. 
Probably 90 percent of the levies now existing in San Juan, and in all likelihood in many other subnational governments throughout the world, could be abolished with little loss in revenue and some gain in efficiency. The remaining 10 percent probably need to be revised to accord with appropriate charging policy.

In most countries user charges are seldom employed to the extent that is both possible and desirable, and those charges that do exist are seldom well designed, and consequently rarely produce any significant economic benefits. Even in the industrial countries, designing and implementing good user charges is often surprisingly difficult, and as a rule even good charges are not popular with either administrators or citizens (for further discussion of the theory and practice of user charges, with extensive examples from Canada, see Bird and Tsiopoulos 1997). In short, user charges are a good idea in principle, but one that appears to be surprisingly difficult to implement well in practice. Such charges therefore seem unlikely to provide anything close to adequate finance for subnational activities in any country.

\section{Property Taxes}

As already mentioned, for decades, local governments have been told that the only appropriate general tax source for them is the real property tax. A property tax is indeed an excellent local tax. ${ }^{3}$ Unfortunately, such advice is often not helpful in the circumstances of many countries. Land and buildings cannot easily run away and hide from tax officials, but nonetheless, a standard, market value property tax can be sometimes difficult and costly to administer well. Valuation is an art, not a science, and the determination of the tax base offers much room for discretion and argument. Moreover, even though the assessment and collection of property taxes can and should be improved in most developing and transition countries, administering this tax equitably is difficult in a rapidly changing environment, and increasing revenues from this source very much or quickly is always hard. ${ }^{4}$

Despite such problems, however, a low-rate, uniform property tax almost always has an important role to play in financing local governments in most countries, especially in rural areas, in which land is often the only possible tax base (see Bird 1974). Moreover, other landbased subnational taxes, for example, betterment levies, and even transfer taxes, are both feasible and, within limits, desirable in certain circumstances (for further discussion of such levies see Bird and Slack 2002). In general, however, subnational governments in most countries will do well if they can finance "hard" (property-related) services, such as local roads and refuse removal and disposal out of property taxes. If such governments are expected to play any significant role in financing "soft" services (education, health), as a rule they will need to have access to more elastic revenue sources.

The current state of land and property taxes in most countries leaves much to be desired, and countries usually can and should collect more local revenue from this source. In Argentina, for example, a few years ago regulations imposed maximum property tax rates, differentiated by rural and urban locations, and further decreed that the tax base could in no case exceed 80 percent of market value. The maximum nominal rates that can be established are little more than 1 percent of market value. The nominal property tax rates currently in force in most of Argentina are well below these limits, and the effective rates are even lower given the high degree of undervaluation of even those properties recorded on the rolls (see, for

3. One important economic argument for local property taxation is as a sort of generalized user charge financing activities that benefit local residents. See Netzer (1973) and Vickrey (1963) for the classic arguments for the property tax as a user charge. For a modern view see Fischel (2001).

4. As with the other condensed reviews of alternative subnational revenue sources in this chapter, such statements may appear to be unsupported assertions. For the most part, however, they are grounded in decades of experience and dozens of specific examples; see, for example, Bird and Slack (2002) and the references cited therein. 
example, the data on undervaluation in the cities of Santa Fé, Mendoza, and Buenos Aires reported in World Bank 1996). Moreover, the structure of the tax is, as a rule, too complicated, economically perverse, and basically unenforceable. In the province of San Juan, for instance, urban properties are taxed at nominal rates from 0.55 to 0.75 percent depending on their fiscal value, rural properties are subject to a similar scale ranging from 0.9 to 1.3 percent, and vacant land is allegedly taxed at 3 percent. Every aspect of this tax is both structurally wrong and unduly complicates administration. Progressive rates make no sense (Bird 1974), nor does differentiating between different classes of property or penalizing vacant land through high tax rates (Bird and Slack 2002).

Countries can and should do much to strengthen such deficient property taxes. Ideally the tax should be simplified and applied uniformly. Cadastral maps should be updated; valuations should be made more consistently and at regular intervals; and better use should be made of flows of information from property registries, local building license authorities, public utilities, and the like. As Dillinger (1991) argues, from a revenue perspective, in upgrading property taxes most attention should be paid to improving collection and enforcement rather than the technically more costly (and less immediately productive in terms of revenue) mapping and surveying of the traditional cadastral approach.

Property taxes are not easy to administer well, however, especially in countries where inflation is endemic, and they are never politically popular, perhaps because of their visibility as well as a certain inherent arbitrariness in the process of assigning values to individual properties. Even in the most sophisticated countries, local property taxes can seldom yield enough to finance local services. No industrial country that depends significantly on property taxes for local fiscal resources has a local government sector that accounts for more than 10 percent of total public spending (Bird and Slack 1991). Despite substantial efforts in some countries and considerable foreign assistance, property taxes seldom account for more than 20 percent of local current revenues-or less than 1 percent of total public spending-in developing countries (Bird 1995).

In short, even though the property tax is a useful, even a necessary, source of local revenue, in most countries it cannot easily provide sufficient resources to finance a significant expansion of local public services. Indeed, many countries have often been hard-pressed to maintain even the currently low relative importance of property tax revenues in the face of varying price levels and political difficulties.

One reason for widespread resistance to the property tax is simply its visibility. Taxpayers usually have to pay it directly in periodic lump-sum payments. Taxpayers who pay taxes directly to the government tend to be more aware of the size of their tax bills than those whose take-home pay is reduced by weekly or monthly tax deductions or those who pay small amounts of tax on each purchase. The need to make such large periodic payments may increase governments' accountability and responsibility, but it also greatly increases taxpayers' sensitivity to even nominal increases in taxes.

The inelasticity of the property tax has a similar effect. As the base of this tax does not increase automatically over time, the periodic nominal increases in property tax bills needed to maintain real revenues when price levels rise require increased tax rates. In terms of political accountability, the need to confront people with the cost of government represents a virtue of the property tax; however, the downside, at least from the government's point of view, is the heightened visibility of nominal tax increases and the accompanying political resistance.

Finally, property taxes finance such services as roads and garbage collection. The quantity and quality of these services (or their absence) is thus readily linked to the property tax. When potholes develop in their street, taxpayers are understandably quick to question the taxes that supposedly finance street repair. Again, the very features that make the property tax a good source of local government revenue in principle make it especially vulnerable to political resistance in practice. 
Other problems result from property tax administration. As a rule, property is supposed to be assessed on the basis of its market value, usually defined as the price struck between a willing buyer and a willing seller in an arm's-length transaction. Substantial technical efforts are therefore needed before much revenue can be expected from property taxes. Even in countries with well-developed property tax systems, discrepancies arise between assessed values and market values within classes of property, between classes of property, and across municipalities for both political and technical reasons (Bird and Slack 1993). As taxpayers can easily compare their property taxes with those of similar properties in their neighborhoods, such discrepancies lead both to specific assessment appeals and to general pressure for tax relief.

For such reasons, experience around the world suggests that the political costs of relying on property taxes are so high that no government with access to "cheaper" sources of finance will willingly increase property taxes. That academics tend to be fonder of recommending increased use of the property tax than politicians are of actually doing so is thus not surprising.

If property taxes are to become a relatively more attractive source of local finance, and if local decisionmakers are to confront the true economic and political costs of their decisions, central governments must curtail politically cheaper sources of finance such as unconditional intergovernmental transfers, which local governments can spend as they wish, and access to taxes on business, which local governments can export to a substantial degree. Even if they succeed in doing so, a number of other policy reforms are also needed to turn the property tax into a responsive instrument of local fiscal policy. First, local governments must be allowed to set their own tax rates. Few developing or transition countries currently give local governments much freedom in this respect. Second, the tax base must be maintained adequately. In countries with inflation some form of index adjustment may be advisable. In other countries the assessing agency must sometimes be provided with direct financial incentives to keep the tax base up-to-date. Finally, a series of procedural reforms is often needed to improve collection efficiency, valuation accuracy, and coverage of the potential tax base. None of these steps is easy, but countries that want to have local governments that are both responsive and responsible must follow this hard road.

Property tax revenues are low in many developing and transition economies, in part because of the way in which the tax is administered. The coverage of the tax is not comprehensive, assessments and nominal tax rates are low, and collection rates are also often low. Low tax rates are sometimes imposed by higher-level governments and sometimes by local governments themselves, which find rate increases in this most visible of taxes difficult to sell politically.

Simply raising the legal tax rate would seldom be appropriate, however, because it would place the burden of the increase on "those few individuals whose properties are on the tax rolls, accurately valued, and from whom taxes are actually collected" (Dillinger 1991). Increased nominal rates are likely to be acceptable only along with improvements in tax administration, such as more comprehensive coverage, better assessments, more frequent assessment revaluations, and enforced penalties for late payment. In general, revenues from this source are higher if the property tax is based on the value of land and buildings instead of just on land, if exemptions are few and no particular property classes are given favorable treatment, and if the scope for local tax competition is limited.

Despite its problems, the property tax remains the predominant option for raising local revenues in most developing and transition countries. The potential yield of land and property taxes is unlikely to be huge, revenues from this source will not be very elastic, and administrative costs are substantial. Nonetheless, an expanded property tax is both a logical and a desirable objective for many countries, particularly those in which local governments are expected to play an increasing role in allocating public sector resources. Nevertheless, significant additional revenues from this source can seldom be expected in the short run, and even though property taxes are often relatively more important in smaller communities, most 
additional revenues will likely be found in, and accrue to, the larger urban areas. A good property tax is a good thing, but it is seldom enough to do the whole job.

\section{Excise Taxes}

The property tax is undoubtedly the pre-eminent local tax. Taxes that might be considered as regional sources of funds include excises, payroll taxes, corporate income taxes, personal income taxes, retail sales taxes, and VATs. McLure (1997) suggests that excise taxes are a potentially significant source of regional revenue largely on administrative and efficiency grounds. He argues that such taxes are both easy for regional governments to administer and lend themselves to regionally-differentiated rate determination. Moreover, in terms of efficiency, such taxes, applied on a destination basis, should have little distortionary effect. Finally, a general benefit argument can be made for some regional excises, for example, on alcohol and tobacco to the extent that regional governments are responsible for health expenditures and on vehicles and fuel to the extent they are responsible for roads.

All these arguments have some validity, although in some instances the case is weak. The benefit case for "sin" taxes, for example, is weak in general (Bird 1998), and imposing regionally differential taxes without serious distortions, as well as substantial administrative and compliance costs and dangers of evasion, is not always easy, as demonstrated by Canada's recent experiences with cross-border smuggling and provincial tobacco taxes (Bird, Perry, and Wilson 1998). Indeed, even though countries such as Canada and the United States derive a significant proportion of regional government revenues from excises, tying regional finances to such inelastic levies when the pressure on those finances for the most part comes from elastic expenditure demands for health and education does not seem particularly desirable. Such a mismatch of revenue and expenditure elasticity is a serious problem in Colombia, for example, where regional governments' revenues depend largely on excise taxes (Acosta and Bird 2003).

The strongest economic and administrative case for regional excises is with respect to vehicle-related taxes (Bahl and Linn 1992). The most important tax on automobiles from a revenue perspective is the fuel tax, which is also the simplest and cheapest form of automotive taxation from an administrative perspective. Fuel taxes can be levied at the regional level. Different regions could impose different tax rates if they chose to do so, subject to the constraint that they would probably not be able to differ much from the rates imposed by their neighbors given the mobility of the tax base. Administratively, differential regional fuel taxes could easily be imposed at the refinery or wholesale level, with the refiner or wholesaler acting as the collection agent for the regional governments and remitting taxes in accordance with fuel shipments.

Fuel taxes are also related to road usage and to such external effects of vehicles as accidents, pollution, and congestion, although not in any precise way. To the extent that automotive taxation is intended to price either the use of publicly provided services or externalities, fuel taxes are at best a crude instrument. Toll roads and an appropriate set of annual automobile and driver license fees can serve this benefit tax function much better. For example, these fees might be based on such features as vehicles' age and engine size (older and larger cars generally contribute more to pollution), location of vehicle (cars in cities add more to pollution and to congestion), driver records ( 20 percent of drivers are responsible for 80 percent of accidents), and vehicles' axle weight (heavier vehicles do exponentially more damage to roads and require roads that are more costly to build).

To the extent that policymakers wish to achieve some redistributional goal through automotive taxation, a national excise tax at the time of initial sale is the best way to achieve this. In contrast, the situation in Argentina, in which every province levies an array of annual taxes that vary with vehicles' year and model, apparently in an attempt to levy a progressive tax, makes little sense. In San Juan province, where it takes three newspaper-sized pages to set out the details of vehicle tax rates, the tax is imposed at a rate of 3 percent on automobiles, but the 
values to which this rate is applied vary with vehicles' make, model, age, and weight. This approach is administratively complex and costly, is not related in any consistent way to any distributional objective, unduly penalizes newer and more efficient vehicles, and does not price public services or externalities in any meaningful way. As with most provincial taxes and charges in Argentina, the automobile tax suffers from undue refinement in terms of fine discrimination between similar bases. The result is arbitrary differentiation with consequent economic distortion and considerable leeway for administrative and compliance slippage. A commendable desire to make fine distinctions for social purposes may underlie this complex system, but the reality is that such complexity makes the system both economically undesirable and impossible to administer properly.

Subnational taxation of automobiles is fundamentally a good idea, but requires careful study of the appropriate design of any automobile tax system (Smith 1991). Most countries could raise more revenue and achieve better economic effects through a revised system of automotive taxation. Subnational revenues could be boosted still further by giving regions access to the fuel tax, perhaps through regionally determined surcharges. Indeed, automotive and fuel taxation appear to be the only commonly available subnational revenue sources that should demonstrate more than unitary income elasticity, thereby matching this aspect of some of the key services (education, health) for which regional, and sometimes perhaps local, governments are increasingly responsible in many countries. Nonetheless, even when fully exploited automobile taxation alone seems unlikely to do the job of financing social services such as education and health to any significant degree. Moreover, as with most of the tax sources discussed in the following sections, fuel and vehicle taxes are much greater potential revenue sources in large urban areas than in poor rural areas. Consequently, to the extent that regional finances rely on such levies, regional fiscal inequalities are likely to be exacerbated unless they are offset by an adequate system of equalization transfers.

\section{Personal Income Taxes}

Because property taxes can only be pushed so far and user charges and taxes on vehicles and fuels seem unlikely to be extremely productive in most regions, if countries wish their subnational governments to have more own source revenues, either to expand the size of subnational activities or to make subnational governments more self-reliant, experience in countries of the Organisation for Economic Co-operation and Development points to supplementary (piggybacked) local income taxes (Bird and Slack 1991). Like the property tax, such a tax would be visible and would therefore satisfy the criteria of political responsibility and accountability. Many such taxes exist in the industrial countries, as follows:

- The Nordic countries are among the few in which subnational governments have large expenditure roles and are largely fiscally autonomous. It is no coincidence that the best known examples of local income taxes are in those same countries (Soderstrom 1991). These local income taxes are levied at a flat, locally-established rate on the same tax base as the national income tax and are collected by the central government.

- In Belgium, and until recently in most Canadian provinces, the local surcharge is levied as a percentage of the national tax liability rather than the national tax base. A similar system exists in Switzerland, where most cantons-the intermediate level of government-allow local governments to levy surcharges at locally-established rates on the cantonal income taxes, which as with most U.S. state income taxes are not harmonized with the federal income tax (Bird 1986).

- Japan has a unique system of local income taxation. Corporations are subjected to a municipal tax assessed largely on the basis of national corporate taxes paid in the previous year, with the tax base being allocated to different jurisdictions in proportion to the 
number of employees. In addition, corporations are subject to a progressive municipal enterprise tax based directly on income. When this enterprise tax is applied to individuals operating businesses, its rate varies with the category of business activity (like the local professional tax in France). Individuals are also subject to both a progressive local income tax levied on the same base as the national income tax and a poll tax (like the former British community charge) levied at a nationally determined per capita rate that varies with the size of the municipality. Only the latter is levied on nonresidents working in the municipality. All these taxes are assessed and collected locally.

Even though developing countries have occasionally levied local income taxes (Bahl and Linn 1992), they are not common. In contrast, in many transition economies subnational governments have been assigned significant shares of income tax revenues. For example, in Russia at one time a few years ago subnational governments received all personal income tax revenues, in Bulgaria they received 50 percent, in Poland 30 percent, and in Hungary 25 percent (Bird, Ebel, and Wallich 1995). In none of these countries, however, did local governments have any freedom in establishing the tax rate. In such cases the resulting distribution of revenues is therefore closer to an intergovernmental fiscal transfer based on locally collected national tax revenues than a truly local source of revenue. If local governments are not politically responsible for the revenues they receive, such revenues should not be viewed as local taxes (Ebel and Yilmaz 2003). In contrast, locally determined surcharges are clearly local own taxes in that local governments are accountable for both imposing the taxes and spending the revenues.

One reason local governments have seldom been given access to income taxes in the industrial countries is because of central governments' reliance on this source of revenue. In the developing countries even central governments often have trouble collecting much from the income tax. Shome (1999), for example, depicts the weak, and weakening, state of personal income taxes in a number of Latin American countries. In most developing and transition countries, no quick fix for subnational revenues is likely to be available from this quarter given the combination of weak personal income taxes at the central level, the apparent difficulty of strengthening these taxes in the near future, and the general reluctance of central governments to share productive taxes with local governments.

Nonetheless, several developing and transition countries, such as Hungary and South Africa, have recently proposed local surcharges on a central personal income tax (Bird, Wallich, and Peteri 1995), and others have recently favorably reviewed this revenue source (see, for example, McLure 1999). Most countries should therefore explore further the possibility of imposing regional, and in some instances perhaps even local, surcharges on personal income taxes, but subnational revenues from this source are unlikely to be significant in the near future.

\section{Payroll Taxes}

Payroll taxes have been important sources of regional government finance in Australia and, to a considerably lesser degree, in some other countries such as Mexico and South Africa. Such taxes have several advantages and at least two disadvantages. Their advantages are that they are easily administrable, at least when imposed on large enterprises, and relatively productive at relatively low rates. Their disadvantages are, first, that they act as a tax barrier to employment in the modern sector and introduce distortions into the factor mix decision (Bird 1992), and second, that in most countries the payroll tax basis is already heavily exploited to finance the central government's social security systems. Note that some countries use the payroll tax base for many additional purposes (see, for example, the discussion of the Colombian system in Alm and López-Castaño 2002).

To the extent that payroll taxes can be made effective on a regional basis, so can flat-rate personal income taxes, which are likely to be levied on much the same base without the factor bias 
inherent in payroll taxes. Moreover, again in principle if not as clearly in practice, subnational personal income taxes can more easily be levied on a destination (resident) than origin (employment) basis (Bird and Wallich 1992), an important factor in considering the potential distortionary aspects of subnational factor taxes. Thus on the whole, in economic terms, surcharges on a nationally uniform personal income tax base would seem to be a more appropriate way for subnational governments to tax wages in most developing and transition countries than payroll taxes. In administrative terms, however, a payroll tax, levied as a final tax on payrolls at the enterprise level, is undoubtedly simpler, unless the so-called personal income tax is itself levied in much the same way on total wages and salaries at the enterprise level and is not aggregated with other forms of income on an individual basis.

\section{General Consumption Taxes}

In many countries the search for a regional revenue source that is economically significant, administratively viable, and reasonably elastic comes down to a general sales tax. Given the disadvantages of the taxes already discussed, the only "big" tax that remains-apart from business taxes as discussed in the next section-is the general sales tax.

The general sales tax now found in most countries is a VAT. According to Ebrill and others (2001), 123 countries had a VAT in 2001. The future of the retail sales tax, once favored as a regional tax (Musgrave 1983), and still in place in most U.S. states, now seems dim; however, the dominance of the VAT poses a serious problem for the finance of regional governments. Most tax analysts consider independent, subnational VATs to be either infeasible or undesirable for a number of reasons (Bird 1993a). Some emphasize high administrative and compliance costs. Others stress the possible loss of macroeconomic control and central governments' general reluctance to share the sales tax base. Still others emphasize the problems arising from cross-border (interstate) trade, arguing that if levied on an origin basis, subnational VATs are distortionary, and if levied on a destination basis, they are unworkable. ${ }^{5}$

Critics generally took Brazil's experience as supportive of this negative appraisal. Brazil was the first country to introduce a fully fledged VAT (Guérard 1973). Indeed, Brazil liked the idea of a VAT so much that it introduced not one VAT but several, one for the federal government and one for each of the state governments. The central government levies the federal VAT on industry and the states levy state VATs on agriculture, industry, and many services. Brazil's enthusiastic adoption of this new tax soon resulted in a series of complex technical and administrative problems with respect to how to apply different VATs in different states (although all are levied at a uniform rate) in addition to a federal VAT. Over the years these problems were partly resolved in various, ultimately unsatisfactory, ways, for example, the overlap in taxes was reduced by confining the federal VAT essentially to the manufacturing stage. In part, the problems were simply ignored, perhaps because the resulting distortions in resource allocation seemed unimportant compared with those resulting from inflation. In part the issue was fudged by means of various unsatisfactory administrative fixes, such as introducing some border controls between states (for further discussion see Purohit 1994; Shome and Spahn 1996). Not surprisingly, the resulting patchwork has become increasingly unsatisfactory, and sales tax reform has again risen high on Brazil's fiscal agenda in recent years, although as yet no reform has proved possible (Varsano 2000).

Fear of difficulties similar to those encountered in Brazil has perhaps been one reason why neighboring Argentina has delayed desirable sales tax reforms following a 1993 federalprovincial agreement that required the abolition of provincial gross receipts taxes and their

5. Poddar (1990), in the most thorough early discussion of this issue, demonstrates that the destination base is technically feasible, although the particular approach he discusses seems unlikely to work well in developing countries. 
replacement by a retail sales tax by 1996 (World Bank 1996). Even though the process was postponed, the ensuing debate led to proposals from the most important province, Buenos Aires, for a provincial-level VAT and to considerable discussion on the advantages and disadvantages of this approach.

The major revenue source of Argentine provinces has long been an antiquated gross receipts tax levied at various rates on different activities and an even more antiquated stamp tax. In San Juan province, for example, the basic rate of the gross receipts tax was 3 percent, with rates of 0.83 percent on fuel production; 1.67 percent on fuel sales; 2 percent on construction; 4 percent on tourist services and certain financial activities; 5 percent on certain other financial activities, lotteries and gaming, sales of tobacco, and advertising agencies; 10 percent on pubs, night clubs, and similar activities; and 15 percent on electronic games, pool, cabarets, and places that rent rooms by the hour. In addition, minimum fixed taxes were established for certain activities, including cabarets, parking lots per space (depending on the size of the space), and places rented by the hour (depending on the rate they charge).

This gross receipts tax provides an excellent illustration of what is wrong with provincial consumption taxes in Argentina and similar taxes found in other countries. It taxes a significant number of intermediate business activities, such as fuel, construction, advertising, insurance, and finance; it creates a variety of unenforceable distinctions between disfavored activities, ranging from cabarets versus night clubs to the sizes of parking spaces; and it imposes ridiculous rates on the latter activities. Such provisions may make legislators feel good, but they create a nightmare for tax administrators and serve no useful economic or social purpose.

Thus the requirement of the 1993 federal-provincial agreement that the gross receipts tax be changed to a retail sales tax is quite understandable. Indeed, Argentina took some steps in this direction. By 1995, for example, taxes on primary production had been eliminated completely in 6 of the 24 provinces and reduced to rates of 1 percent or less in most of the rest, while the tax on industry had generally been lowered to 1.5 percent (compared with the general rates of 2.5 percent on wholesale trade and roughly 3.5 percent on retail trade and services). From the point of view of reducing the economic distortion caused by the tax system, the need to complete the reforms and replace the antiquated taxes with a more modern retail sales tax seemed obvious. From the point of view of strengthening provincial revenues, however, the effects of replacing the existing stamp and gross receipts tax seemed less obviously desirable to most provincial governments. Estimates of the revenue-neutral rate of a retail sales tax ranged from 3.5 percent to 10 percent. Adding a retail sales tax at these rates to the then existing federal VAT of 21 percent was clearly not a politically attractive alternative.

Some commentators, such as Gómez Sabaini and Gaggero (1997), suggested that imposing either independent provincial VATs or a more uniform joint federal-provincial VAT, subject to an overall 20 percent rate limit, would be better. They indicated that such subnational VATs could be imposed like any national VAT essentially on a destination basis, with the problem of interprovincial sales dealt with by allocating revenues in accordance with macroeconomic consumption indicators. Such an approach would clearly be more feasible with the joint version of the tax and would resemble the so-called harmonized sales tax in force in three small Canadian provinces (Bird and Gendron 1998). It would also require a high degree of agreement between the federal and various provincial governments. In contrast, the compensating VAT (CVAT) proposal discussed briefly later requires less agreement and affords more provincial revenue autonomy.

The only functioning, destination-based, subnational VAT now in existence is that in the province of Quebec in Canada (Bird and Gendron 1998). The Quebec sales tax and the federal VAT (known as the goods and services tax) constitute a dual VAT system with none of the problems usually associated with such systems. The respective governments set the rates of the two taxes quite independently. The tax bases are also determined independently, although they are essentially the same. Since the beginning a single administration, the Quebec Department of 
Revenue, has collected both taxes. Taxes on interprovincial sales from one business to another are handled through a deferred payment system similar to that applied with respect to sales between member countries in the European Union. Exports from Quebec, whether to another province or another country, are zero rated. Imports into the province from other provinces or from abroad are taxable, but the tax is assessed on interprovincial imports only when there is a sale by a registered trader to an unregistered trader or consumer in the province. Although special regimes apply to automobiles and a few other cases, in general no attempt is made to collect tax on interprovincial purchases made directly by final consumers.

What makes this system work, Bird and Gendron (1998) argue, is the existence of the overriding federal goods and services tax as an enforcement mechanism. In effect, the existence of a federal sales tax on a more or less uniform base provides some control over interjurisdictional sales for purposes of both provincial and federal taxes. Reportedly the system is working quite well.

Thus Canada has demonstrated that with good tax administration operating a VAT at the subnational level on a destination basis is feasible, at least for large regional governments. In principle, it is immaterial whether there are two separate administrations or one, or if there is one, which level operates it. A single central administration and a common base, as in Canada's personal income tax system, is probably most efficient, but this degree of convergence is not essential. What seems to be critical is either a unified audit or a high level of information exchange. Most important, from the perspective of improving accountability each taxing government should be able to determine its own VAT rate independently.

What is the alternative for countries with no realistic prospect of "good" tax administration at the subnational level in the near future? As Varsano (2000) demonstrates, a promising approach is to impose what is in effect a supplemental central VAT, which McLure (2000) labels the CVAT. This approach has the major virtue of protecting revenues when tax administration (at all levels of government) is far from well developed. Specifically, it reduces the risk that households and unregistered traders in any state can dodge state VAT by pretending to be registered traders located in other states.

To implement this kind of CVAT (see Bird and Gendron 2001), states would zero rate not only international, but also interstate sales, but the latter would be subject to the central CVAT (as well as the central VAT). Domestic sales would therefore be subject to central VAT and either state VAT or central CVAT. There would be no need for any state to deal explicitly with any other state nor, generally, would there be any need for interstate clearing of tax credits. ${ }^{6}$ Registered purchasers in the other state would be able to credit CVAT against central VAT. The results of this procedure are twofold. First, the central government, which first levies CVAT and then credits it, would gain no net revenue from it (it could receive some kind of fee for its services as in Canada). Second, the state VAT applied to resale by the purchaser would be that of the destination state. In other words, the results are exactly the same as in the goods and services tax and Quebec sales tax case described earlier: a destination, subnational VAT is applied, but the CVAT now acts to protect state revenues from some obvious frauds. This approach appears to make subnational VATs potentially feasible, at least in large countries in which states have major expenditure roles, the VAT is the principal source of actual and potential revenue, and tax administration is not up to Canadian standards.

As Bird and Gendron (2001) note in a review of experience around the world, however, the debate on how best to design and implement a subnational VAT is far from settled. The final answer may turn out to be, as might be expected, that different contexts call for different

6. This assumes that the state VAT rates are lower than the central rate. If, as in Brazil, the state rates are substantially higher, there might be some residual need for a clearing house, though on an aggregate, not transaction basis, but this would not seem to be a difficult problem if there is central administration of state VATs. 
solutions. What a country can, should, and will do depends on many factors, including its trade patterns, the location and size of the country and its subnational jurisdictions, the relative importance of business to business versus business to consumer transactions in the tax base, the quality of administration, the degree of trust and feasible coordination, the desire for local autonomy, the tolerance for asymmetry, the offsetting nature of equalization, the extent and nature of revenue shifts, and the existing sales tax structure. The road to feasible subnational VATs may be long and winding in many countries, but the longest journey starts with a single step, and with respect to subnational VATs, a few countries such as Brazil and Canada are already much further down this path than a few steps.

\section{Business Taxes}

Most countries have regional and local business taxes in such forms as corporate income taxes, capital taxes, nonresidential property taxes; such ancient levies as octroi and patente; and various forms of industry and commerce taxes. Whether or not an economic case for such taxes exists, the political realities of governing in a democratic society are such that virtually any subnational government will wish to impose such a tax. Subnational business taxes are not only widespread, they are also generally popular with officials and citizens alike for at least two reasons. First, they often produce substantial revenue, and they also tend to be much more elastic than, for example, property taxes. Second, as no one is quite sure of the incidence of such taxes, assuming or asserting that they are paid by someone other than local residents is easy.

As a rule, experts have tended to look at the distortions and problems arising from such taxes, advised against them, and moved on to other topics (see, for example, McLure 1994). As local business taxes are likely to continue to exist no matter what economists may say, an important consideration is whether the problem is with the very idea of subnational governments taxing business or rather with the way in which they now generally do so.

The economic case for local business taxation is simply as a form of generalized benefit tax. Such benefit taxes are essential to the attainment of efficiency. Where possible, specific public services benefiting specific business enterprises should be paid for by appropriate user charges, as argued earlier, but where recouping the marginal cost of cost-reducing public sector outlays through user charges is not feasible, some form of broadly-based, general levy on business activity may well be warranted. Finding any support along these lines for taxing any one input is difficult, however, whether labor (payroll tax) or capital (corporate income tax). Instead, what this line of reasoning suggests is that a broadly based levy neutral to factor mix should be imposed, such as a tax on value added.

As discussed in chapter 11, the most appropriate form of VAT for this purpose would appear to be a value added income tax or a VAT levied on the basis of income (production, origin) rather than on consumption (destination). A business value tax (BVT) would improve subnational tax systems in several ways. First, it would be more neutral than most existing local business taxes, which often discriminate against certain forms of investment. Second, it would probably be less susceptible to base erosion. Third, it should be more sensitive to cyclical realities than most other forms of business tax. All these advantages would apply even if the rate of the BVT were set to produce the same revenue as existing business taxes. Of course, if the rate were set to more or less match the benefits received basis suggested earlier, it would generally be lower, and the tax would have the additional important advantages of eliminating inefficient spillovers and encouraging more responsible and accountable subnational governments. As with the subnational VAT, while many technical issues need further thought and discussion, moving toward a local business tax of the BVT type as, for example, Italy did recently (Bordignon, Gianni, and Panteghini 2001) would clearly be a substantial improvement in many countries. 
Alternatively, in some countries simply rationalizing the existing set of (often presumptive) levies imposed on business may prove simpler administratively and almost equally beneficial economically, as discussed in more detail in chapter 11. As shown there, local business taxation is characterized by great variety around the world. Some countries rely mainly on taxes on profits and property, some on various forms of sales taxation, and some on a variety of specific charges and fees. Few existing local taxes on business are equitable; almost none are neutral; most accentuate rather than reduce disparities between localities, giving most to those who have most; most also lend themselves to tax exporting, thereby violating the correspondence principle that those who pay should be those who benefit; and all too many are costly to administer, especially taking into account the cost of compliance and the facility with which the tax can serve as the basis for corrupt transactions. Nevertheless, local business taxes thrive around the world because they score highly on some of the other criteria. For example, business taxes are highly politically acceptable; provide an important, and relatively elastic, source of revenue, particularly for larger cities; and in many countries, despite defects in design and execution, provide one of the few ways in which local governments have any degree of fiscal autonomy.

The question is therefore to what extent the virtues of local business taxation can be realized while minimizing such vices as economic distortions and administrative costs. While the low rates of most such taxes dampen these problems, a more systematic approach to the problem is the BVT. Note, however that that no form of local business taxation can overcome certain fundamental problems. First, any tax on business will obviously give more revenues to those who have more tax base. It will therefore accentuate fiscal disparities among regions and localities. Second, although one of the advantages of local business taxation is that it is politically acceptable, this "virtue" is inescapably accompanied by two potential vices: the weakening of the correspondence principle and a consequent increase in the lack of clarity about the equity of local taxation. The first of these weaknesses is much more important. Although most local business taxes are probably somewhat regressive, the equity of local taxation is, in general, a less important question than some think. Indeed, as noted earlier, from many perspectives local governments can be viewed as entities that provide services to residents, and the appropriate equity perspective is the benefit principle rather than the ability to pay principle (Bird 1993b).

\section{Conclusion}

Table 9.1 summarizes many of the arguments of this chapter. The general approach this chapter has taken in relation to subnational taxation in developing and transition countries is based on three simple principles: (a) more attention should be paid to matching expenditure and revenue needs, (b) more effort should be made to ensure that all governments bear significant responsibility at the margin for financing the expenditures for which they are politically responsible, and (c) subnational taxes should not unduly distort the allocation of resources.

If regional governments have significant expenditure responsibilities, in most countries they are apparently only able to satisfy these criteria through a surcharge on personal income tax or a surcharge on VAT. Few developing countries have sufficiently robust central income taxes to offer much hope that subnational governments will soon be able to derive much revenue from this source. A potentially promising alternative answer for subnational revenues, at least in the larger countries, particularly those with federal features, may better rely on the VAT.

A second feature of subnational taxation that this chapter has emphasized is the importance of developing a less harmful form of subnational business taxation. Most forms of local and regional business taxes found in developing countries introduce serious economic distortions in a variety of ways. Nonetheless, there is an economic (benefit) case for some regional and local taxation of business and local leaders often face an overwhelming political need to impose 
Table 9.1 A Preliminary Evaluation of Local Revenues

\begin{tabular}{|c|c|c|c|c|c|c|c|}
\hline Criterion & User charges $(R)$ & Property tax (L) & Excises (R) & $\begin{array}{c}\text { Personal } \\
\text { income tax }(R)\end{array}$ & Payroll tax $(R)$ & Sales tax $(R)$ & $\begin{array}{c}\text { Business } \\
\text { taxes }(L, R)\end{array}$ \\
\hline Revenue adequacy & $\begin{array}{l}\text { Yes, for some } \\
\text { activities; not in } \\
\text { general }\end{array}$ & $\begin{array}{l}\text { Yes, for general } \\
\text { local } \\
\text { government }\end{array}$ & $\begin{array}{l}\text { Unlikely to } \\
\text { suffice }\end{array}$ & Unlikely & $\begin{array}{l}\text { Yes, if industrial } \\
\text { area }\end{array}$ & Yes & Not likely \\
\hline Revenue buoyancy & No & Not much & Varies & Yes & Yes & Yes & $\begin{array}{l}\text { May be } \\
\text { adequate }\end{array}$ \\
\hline $\begin{array}{l}\text { Correspondence of } \\
\text { payers and } \\
\text { beneficiaries }\end{array}$ & $\begin{array}{l}\text { Excellent if } \\
\text { well designed }\end{array}$ & $\begin{array}{l}\text { Fair if properly } \\
\text { done }\end{array}$ & Not high & Not high & $\begin{array}{l}\text { Depends on } \\
\text { employment } \\
\text { pattern }\end{array}$ & $\begin{array}{l}\text { Depends on } \\
\text { mobility }\end{array}$ & $\begin{array}{l}\text { Depends on } \\
\text { design }\end{array}$ \\
\hline Local accountability & Excellent & Low & $\begin{array}{l}\text { Not good unless } \\
\text { rate set regionally }\end{array}$ & $\begin{array}{l}\text { Low (depends on } \\
\text { rate discretion) }\end{array}$ & $\begin{array}{l}\text { If have rate } \\
\text { discretion }\end{array}$ & $\begin{array}{l}\text { May be } \\
\text { adequate }\end{array}$ & Usually low \\
\hline Administrative cost & Sometimes high & Fairly high & Low & $\begin{array}{l}\text { Reasonable if } \\
\text { imposed as a } \\
\text { regional } \\
\text { surcharge }\end{array}$ & Not high & Moderate & Sometimes high \\
\hline Compliance costs & $\begin{array}{l}\text { Irrelevant, in } \\
\text { principle }\end{array}$ & Vary, but not high & Low as a rule & Medium & Not high & Moderate & Often high \\
\hline $\begin{array}{l}\text { Latitude for } \\
\text { corruption }\end{array}$ & Low & Moderate & Low & $\begin{array}{l}\text { Probably high in } \\
\text { most countries }\end{array}$ & Low & Moderate & High \\
\hline Political acceptability & $\begin{array}{l}\text { Not high in most } \\
\text { countries }\end{array}$ & Moderate & $\begin{array}{l}\text { High in some } \\
\text { instances }\end{array}$ & Low & High & Perhaps & High \\
\hline Distortionary impact & None & Moderate & Can be low & Moderate & Not too high & Moderate & Usually high \\
\hline Progressivity & Irrelevant & Possibly & $\begin{array}{l}\text { Regressive in } \\
\text { general, except } \\
\text { fuel }\end{array}$ & Largely unknown & Not very & No & $\begin{array}{l}\text { Usually } \\
\text { unknown }\end{array}$ \\
\hline $\begin{array}{l}\text { Reduces regional } \\
\text { disparities }\end{array}$ & $\begin{array}{r}\text { May do so to } \\
\text { some extent }\end{array}$ & No & No & No & No & No & No \\
\hline
\end{tabular}

\footnotetext{
L Local.

R Regional.

Source: Author.
} 
such taxes. One approach to this problem might be to introduce another form of value added tax such as the BVT.

Suppose that a given country accepted both these proposals for subnational revenue reform. The result would then be a family of VATs, with a standard invoice credit, destination principle, consumption type of VAT imposed at the central government level, similar VATs imposed at varying rates on the same base by regional governments, and a BVT levied on all VAT registrants by regional governments, and perhaps even larger local governments, at relatively uniform rates. In addition, all levels of government should apply appropriate user charges; some excise taxes, particularly those related to vehicles, might be appropriate at the regional level; a strong case exists for more effective local property taxation in most developing countries, especially of residential property; and the central government may continue to levy both a corporate and a progressive personal income tax, perhaps with regional governments imposing flatrate personal income taxes on the same base if they so choose.

Even major reforms along these lines would not solve all the problems of establishing sound and workable subnational tax regimes in developing and transition countries. Such reforms would, however, would at least move matters in the right direction.

\section{References}

The word processed describes informally reproduced works that may not be commonly available through libraries.

Acosta, Olga Lucia, and Richard M. Bird. 2003. "The Dilemma of Decentralization in Colombia." Mision de Ingresos, Bogota, Colombia. Processed.

Alm, James, and Hugo López-Castaño. 2002. "Payroll Taxes in Colombia." Mision de Ingresos, Bogota, Colombia. Processed.

Bahl, Roy. 2002. “The Property Tax in Developing Countries: Where Are We in 2002?" Land Lines (newsletter, Lincoln Institute of Land Policy, Cambridge, Mass.).

Bahl, Roy W., and Johannes Linn. 1992. Urban Public Finance in Developing Countries. New York: Oxford University Press.

Bird, Richard M. 1974. Taxing Agricultural Land in Developing Countries. Cambridge, Mass.: Harvard University Press. . 1976. Charging for Public Services. Toronto: Canadian Tax Foundation. 1986. Federal Finance in Comparative Perspective. Toronto: Canadian Tax Foundation. . 1992. Tax Policy and Economic Development. Baltimore, Md.: Johns Hopkins University Press.

. 1993a. "Federal-Provincial Taxation in Turbulent Times." Canadian Public Administration 36(Winter): 479-96.

. 1993b. "Threading the Fiscal Labyrinth: Some Issues in Fiscal Decentralization." National Tax Journal 46(2): 207-27.

. 1995. Local Finance: Problems, Perspectives, and Possibilities. Major Report no. 31. Toronto: University of Toronto, Centre for Urban and Community Studies.

. 1998. “Analysis of Earmarked Taxes.” Tax Notes International, June 23, pp. 2095-2116.

. 2000. "Rethinking Subnational Taxes: A New Look at Tax Assignment." Tax Notes International 20(19): 2069-96. 
2001. Intergovernmental Fiscal Relations in Latin America: Policy Designs and Policy Outcomes. Washington, D.C.: Inter-American Development Bank, Sustainable Development Department.

Bird, Richard M., and Ariel Fiszbein. 1998. "The Central Role of Central Government in Decentralization: Colombia." In Richard M. Bird and Francois Vaillancourt, eds., Fiscal Decentralization in Developing Countries. Cambridge, U.K.: Cambridge University Press.

Bird, Richard M., and Pierre-Pascal Gendron. 1998. "Dual VATs and Cross-Border Trade: Two Problems, One Solution?" International Tax and Public Finance 5(3): 429-42.

. 2001. "VATs in Federal Countries: International Experience and Emerging Possibilities." Bulletin for International Fiscal Documentation 55(7): 293-309.

Bird, Richard M., and Barbara D. Miller. 1989. "Taxation, Pricing, and the Poor," In Richard M. Bird and Susan Horton, eds., Government Policy and the Poor in Developing Countries.

Toronto: University of Toronto Press.

Bird, Richard M., and Enid Slack. 1991. "Financing Local Government in OECD Countries: The Role of Taxes and User Charges." In Jeffrey Owens and Giorgio Panella, eds., Local Government: An International Perspective. Amsterdam: North-Holland.

1993. Urban Public Finance in Canada. Toronto: John Wiley.

. 2002. "Land and Property Taxation around the World: A Review." Journal of Property Tax Assessment and Administration 7(3): 31-67.

Bird, Richard M., and Michael Smart. 2002. "Intergovernmental Fiscal Transfers: Lessons from International Experience." World Development 30(6): 899-912.

Bird, Richard M., and Thomas Tsiopoulos. 1997. “User Charges for Public Services: Potentials and Problems." Canadian Tax Journal 45(1): 25-86.

Bird, Richard M., and Christine Wallich. 1992. "Financing Local Government in Hungary." Working Paper no. WPS 869. World Bank, Washington, D.C.

1993. "Fiscal Decentralization and Intergovernmental Relations in Transition Economies.” Working Paper no. WPS1122. World Bank, Washington, D.C.

Bird, Richard M., Robert Ebel, and Christine Wallich, eds. 1995. Decentralization of the Socialist State. Washington, D.C.: World Bank.

Bird, Richard M., Christine I. Wallich, and Gabor Peteri. 1995. "Financing Local Government in Hungary," in Richard M. Bird, Robert Ebel, and Christine Wallich, eds., Decentralization of the Socialist State. Washington, D.C: World Bank.

Bird, Richard M., David Perry, and Thomas A. Wilson. 1998. "Canada." In Ken Messere, ed., The Tax System of Industrialised Countries. London: Oxford University Press.

Boadway, Robin W., and Paul A. Hobson. 1993. Intergovernmental Finance in Canada. Toronto: Canadian Tax Foundation.

Bordignon, Massimo, Silvia Gianni, and Paolo Panteghini. 2001. "Reforming Business Taxation: Lessons from Italy?" International Tax and Public Finance 8: 191-210.

Burki, Shahid Javed, Florence Eid, Maria Emilia Freire, Victor Vergara, and Guillermo E. Perry. 2000. Annual World Bank Conference on Development in Latin America and the Caribbean: 1999 Proceedings. Washington, D.C: World Bank.

Dillinger, William. 1991. Urban Property Tax Reform: Guidelines and Recommendations. Washington, D.C.: World Bank. 
Ebel, Robert, and Serdar Yilmaz. 2003. "Fiscal Decentralization: Is It Happening? How Do We Know?" In James Alm and Jorge Martinez-Vazquez, eds., Public Finance in Developing Countries. Cheltenham, U.K.: Edward Elgar.

Ebrill, Liam, Michael Keen, Jean-Paul Bodin, and Victoria Summers. 2001. The Modern VAT. Washington, D.C.: International Monetary Fund.

Fischel, William. 2001 "Homevoters, Muncipal Corporate Governance, and the Benefit of the Property Tax," National Tax Journal, 54(1): 157-73.

Gómez Sabaini, Juan Carlos, and Jorge Gaggero. 1997. “Lineamientos para una Reforma del Sistema Tributario Argentino." No. T-37. Inter-American Center for Tax Studies, Buenos Aires. Processed.

Guérard, Michele. 1973. "The Brazilian State Value-Added Tax." International Monetary Fund Staff Papers 20: 118-69.

Kuo, C.-Y., T. McGirr, and S. Poddar. 1988. "Measuring the Non-Neutralities of Sales and Excise Tax in Canada." Canadian Tax Journal 36(3): 655-70.

Litvack, Jennie, Junaid Ahmad, and Richard M. Bird. 1998. Rethinking Decentralization. Washington, D.C.: World Bank.

McLure, Charles E., Jr. 1994. "The Tax Assignment Problem: Ends, Means, and Constraints." Australian Tax Forum 11: 153-83.

1997. "Topics in the Theory of Revenue Assignment: Gaps, Traps, and Nuances." In Mario J. Blejer and Teresa Ter-minassian, eds., Macroeconomic Dimensions of Public Finance. London: Routledge.

. 1999. "The Tax Assignment Problem: Conceptual and Administrative Considerations in Achieving Subnational Fiscal Autonomy." Paper presented and the seminar on Intergovernmental Fiscal Relations and Local Financial Management, February 24-March 5, National Economic and Social Development Board of the Royal Thai Government and World Bank, Chiang Mai, Thailand.

2000. "Implementing Subnational VATs on Internal Trade: The Compensating VAT (CVAT)." International Tax and Public Finance 7(6): 723-40.

Musgrave, Richard A. 1983. "Who Should Tax, Where and What?" In Charles E. McLure, Jr., ed., Tax Assignment in Federal Countries. Canberra: Australian National University, Centre for Research on Federal Financial Relations.

Netzer, Dick. 1973. The Property Tax. Washington, D.C.: The Brookings Institution.

Olson, Mancur. 1969. “The Principle of 'Fiscal Equivalence': The Division of Responsibilities among Different Levels of Government." American Economic Review 59: 479-87.

Poddar, Satya. 1990. “Options for a VAT at the State Level." In M. Gillis, C. S. Shoup, and G. Sicat, eds., Value Added Taxation in Developing Countries. Washington, D.C.: World Bank.

Purohit, Mahesh C. 1994. "Value Added Tax in Brazil." Working Paper. National Institute of Public Finance and Policy, New Delhi.

Ring, Raymond J. Jr. 1999. "Consumers' Share and Producers' Share of the General Sales Tax." National Tax Journal 52 (1): 79-90.

Rodden, Jonathan, Gunnar Eskeland, and Jennie Litvack, eds. 2003. Decentralization and Hard Budget Constraints. Cambridge, Mass.: MIT Press.

Shome, Parthasarathi. 1999. "Taxation in Latin America: Structural Trends and Impact of Administration." Working Paper no. WP/99/19. International Monetary Fund, Washington, D.C. 
Shome, Parthasarathi, and Bernd Spahn. 1996. "Brazil: Fiscal Federalism and Value Added Tax Reform." Working Paper no. 11. National Institute of Public Finance and Policy, New Delhi

Smith, Roger S. 1991. “Motor Vehicle Taxation.” In Roy W. Bahl, ed., The Jamaican Tax Reform. Cambridge, Mass.: Lincoln Institute of Land Policy.

Soderstrom, Lars. 1991. “Fiscal Federalism: The Nordic Countries' Style." In Remy Prud'homme, ed., Public Finance with Several Levels of Government. The Hague/Koenigstein: Foundation Journal Public Finance.

Tanzi, Vito. 1996. "Fiscal Federalism and Decentralization: A Review of Some Efficiency and Macroeconomic Aspects." In Michael Bruno and Boris Pleskovic, eds., Annual World Bank Conference on Development Economics 1995. Washington, D.C.: World Bank.

Varsano, Ricardo. 2000. "Subnational Taxation and Treatment of Interstate Trade in Brazil: Problems and a Proposed Solution." In S. J. Burki and G. E. Perry, eds., Decentralization and Accountability of the Public Sector. Washington, D.C.: World Bank.

Vickrey, William. 1963. "General and Specific Financing of Urban Services." In Howard Schaller, ed., Public Economic Decisions in the Urban Community. Washington, D.C.: Resources for the Future.

World Bank. 1996. Argentina: Provincial Finances. Washington, D.C. 


\title{
10
}

\section{Alternative Approaches to Taxing Land and Real Property}

\author{
Enid Slack
}

Almost all local governments worldwide rely, at least to some extent, on property taxation. Dependence on property taxes as a source of local government revenue has varied over time and across jurisdictions depending on the expenditure responsibilities assigned to local governments and the other revenues available to them, such as intergovernmental transfers, user fees, and income and sales taxes. In many countries local governments also levy other landbased taxes, such as land value increment taxes, land transfer taxes, and development charges.

This chapter reviews elements of property taxes and other land-based taxes at the local level. A standard list of criteria for evaluating taxes provides the background to the discussions of property taxes and other land-based taxes that follow. These criteria include

- Fairness based on benefits received: taxes should be related to the benefits received from government expenditures.

- Fairness based on ability to pay: taxes should be related to the ability to pay taxes. Horizontal equity requires that taxes be similar for those with similar ability to pay. Vertical equity requires that taxpayers with greater ability pay relatively greater taxes. ${ }^{1}$

- Neutrality: taxes should not distort economic behavior, including people's decisions about where to live and work and what improvements to make to their property. Negative side effects should be minimized.

- Accountability: taxes should be designed in ways that are clear to taxpayers, so that policymakers can be made accountable to the taxpayers for the cost of government.

- Ease of administration: taxes should be fairly easy to administer. The simpler the system, the easier it will be to administer.

Achieving all these principles at the same time is often difficult, so governments have to make choices. For example, a tax system that is designed to be equitable may not be simple to administer.

\section{Taxing Real Property}

The property tax is historically associated with local government, in part because real property is immovable, that is, it is unable to shift location in response to the tax. Although a change in

1. This criterion raises definitional questions with regard to the measure of ability to pay. Ability to pay has been measured by income (current income in some cases and permanent income in others), property value, and wealth. For a discussion of different measures of ability to pay property taxes see Kitchen (1992). 
property tax may be capitalized into property values in a particular community, ${ }^{2}$ and in the long run may affect where people locate, these effects are of a smaller magnitude than those that would occur with income and sales taxes at the local level.

Another reason why property taxes are appropriate as a source of revenue for local governments is the connection between the types of services funded at the local level and the benefit to property values. Fischel (2000), for example, has argued that the property tax is like a benefit tax, because taxes approximate the benefits received from local services. Under these circumstances, the property tax promotes efficient public decisions, because taxpayers will support those measures for which the benefits exceed the taxes. Both the benefits derived from local services (for example, good schools, access to roads and transit, and so on) and the taxes are capitalized into property values. Because taxpayers are willing to pay more for better services and lower tax rates, this translates into higher property values. A competing view sees the property tax as a tax on capital. For example, Zodrow (2000) argues that the property tax results in distortions in the housing market and in local fiscal decisions. According to this view, the property tax (based on market value) discourages building and results in the underutilization of land. The amount of capital per unit of land is less than what is economically efficient. Both of these approaches have some validity. The property tax is not purely a benefits tax, because homeowners who improve their houses will face higher taxes and will therefore be discouraged from doing so. At the same time, the benefits and costs of local programs are reflected in local property values.

\section{Characteristics of the Real Property Tax}

The following characteristics of the property tax differentiate it from other taxes:

- Visibility: the property tax is a highly visible tax. Unlike the income tax, for example, the property tax is not withheld at source. Rather, taxpayers generally have to pay it directly in periodic lump-sum payments. This means that taxpayers tend to be much more aware of the property taxes they pay. ${ }^{3}$ The property tax also finances services that are highly visible, such as roads, garbage collection, snow removal, and neighborhood parks. Visibility is desirable from a decisionmaking perspective, because it makes taxpayers aware of the costs of local public services. This awareness enhances accountability. The ability to raise property taxes (or to reform the tax), however, is more constrained than with other taxes.

- Inelasticity: the base of the property tax does not increase automatically over time, because property values respond more slowly to annual changes in economic activity

2. Property taxes are capitalized into the value of a property if, other things being equal, a higher property tax results in a lower property value. Because property owners pay property taxes each year, estimating the present value of the property tax payments is necessary. The present value of a future flow is the amount that someone would pay today in exchange for receiving that flow in the future. The present value of US $\$ 1$ to be received next year is $1 /(1+i)$, where $i$ is the discount rate (the return on an investment other than housing). The present value of a dollar received in two years is $1 /(1+i)^{2}$ and so on. The present value of avoiding property taxes every year from now until the expected lifetime of the house is $\Sigma 1 /(1+i)^{n}$, which is closely approximated by $1 / i$. For example, consider two houses, A and B, identical except for the property taxes. The annual property taxes on house A are $\$ 1,000$ higher than on house B. Suppose that the discount rate is 5 percent. The present value of the stream of future property taxes would thus be US $\$ 20,000$ (that is 1,000/0.05) higher on house A than on house B. Property taxes would be fully capitalized if the market value of house A were US $\$ 20,000$ less than house B. Anything less than US\$20,000 would mean that the property taxes were only partially capitalized.

3. In some cases, however, mortgage institutions include property tax payments with monthly mortgage payments. This reduces the visibility of the property tax for taxpayers who pay their taxes along with their mortgage payments. 
than incomes. Furthermore, few jurisdictions update property values for taxation purposes on an annual basis. This means that to maintain property tax revenues in real terms or to raise property tax revenues, taxing authorities have to increase the rate of the tax. As with visibility, inelasticity leads to greater accountability (taxing authorities have to increase the tax rate to increase tax revenues), but it also leads to greater taxpayer resistance.

- Local autonomy: usually only local governments levy the property tax. This means that it can be an important instrument of local autonomy, because property taxes do not compete with taxes the central government levies. To ensure local autonomy, however, tax rates must be set locally and not by a senior level of government. Some local government revenues are linked to taxes at other levels of government. For example, owners of multiresidential, commercial, and industrial properties can write off their property taxes against income for income tax purposes. In the United States, homeowners can also write off property taxes against income. User charges, however, cannot be written off against income, and are therefore not linked to income taxes at other levels of government. This difference might bias the choice of revenues at the local level in favor of those that can reduce taxpayers' income tax liability.

- Favorable treatment of single-family, owner-occupied, residential property: the property tax commonly favors single-family, owner-occupied, residential properties over apartments and commercial and industrial properties in most North American jurisdictions. Similarly, in most transition economies, enterprises tend to pay higher property taxes than individuals (Malme and Youngman 2000). Favorable treatment of single-family residential properties is achieved in three ways. First, the assessment system deliberately underassesses single-family residential property compared with apartments and commercial and industrial property of comparable value. Many jurisdictions have legislated lower tax rates on single-family residential property. Second, governments often provide property tax relief measures to residential property owners (and in some cases to tenants) in the form of tax credits, homeowner grants, or tax deferrals. These measures are not generally available to nonresidential properties. At the same time, this differential treatment does not necessarily reflect the differential use of services by different property types. ${ }^{4}$

\section{Property Identification}

Several steps are involved in the process of taxing real property: identifying the properties being taxed, preparing an assessment roll that contains a description of the property and the amount of assessment, setting the tax rate or series of rates, issuing tax bills, responding to assessment appeals, collecting taxes, and addressing arrears. This chapter focuses on property identification, assessment, and tax rates. For information on the other steps in the process see Dillinger (1992).

The first step in levying a property tax is to identify ownership and assemble a complete list of properties. A fiscal cadastre requires the following for each property: a description, a definition of its boundaries (using cadastral maps), a notation of ownership, and the value of land and improvements. The preparation of cadastral maps is an essential element of property identification. Establishing a complete inventory of all properties and assigning a unique property identification number to each parcel is necessary to permit the tracking of all parcels. Property identifiers also allow for the linking of assessment, billing, and property transfer records.

4. Some observers have suggested that nonresidential properties use fewer services than residential properties, but pay more in taxes. For example, users of nonresidential property often provide their own garbage collection, security, and fire protection (Kitchen and Slack 1993). 
The process of property identification is often more difficult in developing countries and transition economies. Dillinger (1992) and Malme and Youngman (2000) present examples of some of the types of problems that have occurred, which include the nonexistence of base maps for property identification, the absence of data on property ownership because of disputed ownership, the incomplete information on improvements, and the poor sharing of information on building permits. Further problems include land and building records being maintained separately by different agencies and not linked, tax records being identified by taxpayer and not by property, records being considered secret, and official prices not being true indicators of market value.

Property identification requires that existing information on properties within the jurisdiction be updated and made consistent. Information that needs to be collected for each property includes, for example, the assessment roll number of the property, the address, the owner(s) of the property, the area in square meters, the age of the unit, and a description of any renovations. ${ }^{5}$ Jurisdictions must report the information collected in a consistent way and establish a process for updating it on an annual basis (Slack, LaFaver, and Shpak 1998).

\section{Composition of the Assessment Base}

The property tax is levied on residential, commercial, and industrial properties. The base of the tax is the assessed value of real property. Some properties in all countries are exempt from the property tax base. Exemptions may be based on ownership, such as government-owned property; on the use of the property, such as properties used for charitable purposes; or on the basis of the characteristics of the owner or occupier; such as age or disability (Youngman and Malme 1994).

Although the use of exemptions varies widely, some properties are exempt in most jurisdictions. For example, property owned and occupied by the government is generally exempt from property taxes. Other property types that are often exempt include colleges and universities, churches and cemeteries, public hospitals, charitable institutions, public roads, parks, schools, libraries, foreign embassies, and property owned by international organizations.

Governments often make payments in lieu of taxes. These payments are generally negotiated between governments and are often much less than the property taxes would be. In Canada, for example, the federal government, and not the taxing authority, determines the values and rates to be used for the payment in lieu calculation.

Critics have questioned exemptions and payments in lieu of taxes on a number of grounds. First, to the extent that people working in government buildings or institutions use municipal services just as workers do in other buildings, they should be taxed (Bahl and Linn 1992). Second, the differential treatment means that owners or managers in payment in lieu or taxed properties face higher costs than owners or managers of exempt properties. This differential will have implications for economic competition among businesses and between businesses and the government (Kitchen and Vaillancourt 1990). Third, differential tax treatment affects location decisions, choices about what activities to undertake, and other economic decisions. Fourth, exemptions narrow the tax base and thereby increase the taxes on the remaining taxpayers. Fifth, the proportion of tax-exempt properties varies by municipality, thereby creating disproportionate tax burdens across communities.

A case may exist for favoring certain property holders, such as churches and charitable organizations, to encourage their presence in the local community. If such a case can be made for

5. The cost of collecting the information could be added to the tax bill. In Ontario, Canada, for example, a corporation representing municipalities in the province performs the assessment function. The cost of the assessment function is passed on to municipalities, which add this cost onto tax bills. 
preferential treatment, then some argue that these organizations should be rewarded directly with a grant rather than on the basis of their property holdings (Kitchen 1992). Unlike a property tax exemption, a grant is open and subject to review by elected representatives. If exemptions are to be continued, all exempt property should be assessed in the same way as other properties so that the value of the exemption is known. Furthermore, payments in lieu of taxes should be based on the assessed value and should reflect the taxes that could have been collected.

\section{Assessment Systems}

Two general assessment methodologies are used for property taxation: area-based assessment and value-based assessment (for a review of the characteristics of property tax systems around the world see McCluskey 1999; Youngman and Malme 1994).

AREA-BASED ASSESSMENT. Under an area-based assessment system, the tax jurisdiction levies a charge per square meter of land area, per square meter of building, or some combination of the two. Where both measures of area are included, the assessment of the property is the sum of an assessment rate per square meter multiplied by the size of the land parcel and an assessment rate per square meter multiplied by the size of the building. Assessment rates can be the same for land and buildings or they can be different. For example, if a policy existed to encourage development, a lower assessment rate could apply to buildings.

A strict per unit assessment results in a tax liability that is directly related to the area of the land and buildings. With unit value assessment, the assessment rate per square foot is adjusted to reflect location, quality of the structure, or other factors. Market value has an indirect influence on the assessment base through the application of adjustment factors. For example, the assessment rate per square meter might be adjusted to reflect the location of the property within a particular zone in the city. Even though the specific location of the property within the zone is not taken into account, properties in different zones will have different values.

The adjustment factors derive from average values for groups of properties within each zone and do not reflect the characteristics of each individual property. When the groups are defined narrowly enough, however, unit value begins to approximate market value. For example, a zone could be defined anywhere from an entire city to specific neighborhoods to properties on one side of a street.

Unit value assessment is used in Israel and until recently was used in Rotterdam in the Netherlands. Governments in transition economies also use it, because the absence of mature property markets makes determining market value difficult. A study of property taxes in economies in transition by Malme and Youngman (2000) indicates that with the exception of Estonia, the countries studied-Armenia, the Czech Republic, Poland, the Russian Federation, and Slovakia-levy taxes on an area basis. In the Czech Republic, for example, tax jurisdictions assess land and tax it on the basis of land area and assess buildings and tax them on the basis of floor space. The assessment of land and buildings is adjusted by factors that reflect location and land use, but these differentials do not reflect market data. ${ }^{6}$ The major tax base influence is location, and urban areas have higher assessed values than rural areas.

In Estonia, the area-based system has been adapted to reflect actual market influences. The land tax combines an area-based pricing system with market evidence on location, quality, and use. These values were originally determined using survey data. With the development of the real estate market, these values have been able to reflect market information.

6. Market value assessment has been under discussion in the Czech Republic since 1993. The government is considering moving in the direction of market value assessment by incorporating ad valorem elements into the area-based system using information on approximate pricing for location and types of use gathered by the real estate industry (see Bryson and Cornia 2000). 
In Tunisia, the rental tax requires communes to use national values for covered square meters to establish the rental tax roll. The values set by presidential decree vary from D 2 to D 8 per square meter, depending on the size of the house and the neighborhood. ${ }^{7}$ The communes apply four tax rates on an area basis. Areas are classified according to the availability of six services: garbage collection, street lighting, paved roadway, paved sidewalk, sanitary sewers, and rain water sewers. The tax rate is set at 8 percent for one to two services, 10 percent for three to four services, 12 percent for five to six services, and 14 percent for additional services or better quality services.

VALUE-BASED ASSESSMENT. Value-based assessments use market value (including site value assessment), rental value, and self-assessment. Market value is defined as the price that would be struck between a willing buyer and a willing seller in an arm's-length transaction. Market value assessment estimates the value that the market places on individual properties. The following are three methods used to estimate market value:

- The comparable sales approach looks at valid sales of properties similar to the property being assessed. Assessors use it when the market is active and similar properties are being sold.

- The depreciated cost approach values the property by estimating the land value as if it were vacant and adding the cost of replacing the buildings and other improvements to that value. Assessors use the depreciated cost approach when the property is relatively new, no comparable sales exist, and the improvements are relatively unique. They also use the cost approach to assess industrial properties.

- The income approach uses the assessor's estimate of the potential gross rental income the property could produce and deducts operating expenditures. The assessor then converts the resulting annual net operating income to a capital value using a capitalization rate. Assessors mainly use this approach for properties with actual rental income.

Canadian and American municipalities generally use some form of market value assessment. Variations of market value to address property tax volatility can be found in California and the United Kingdom. In California, assessors update the property assessment to reflect market value only at the time of sale. After that, assessment is frozen and increased annually by a 2 percent inflation factor. The stated advantage of time of resale assessment is that property taxes are stable and predictable over time. The disadvantage is that assessors will assess similarly valued properties differently depending on whether or not the properties have been sold recently. This difference violates the principle of horizontal equity (fairness based on ability to pay for comparable properties).

In 1993 the U.K. government implemented the council tax to replace the community charge (poll tax). ${ }^{8}$ The Valuation Office Agency, which is part of the Department of Inland Revenue of

7. Two main sources of own revenues exist in Tunisia: direct taxes and indirect taxes and fees (including market fees). Direct taxes comprise mainly the rental tax, the business tax, the hotel tax, an electricity tax, and the tax on unbuilt land. The rental tax and the business tax each account for about 40 percent of direct tax revenue (Vaillancourt 1998).

8. The community charge in the United Kingdom was a poll tax of a specific dollar value applied to each adult. The local tax base therefore depended solely on the number of residents in the community. Economists consider a poll tax to be the most efficient tax that local governments can adopt, because it is a fixed charge on all eligible taxpayers. Because a poll tax does not change the relative price of consumption or other types of activities, it does not provide an incentive for individuals to alter their behavior to reduce the tax. The community charge was unpopular in the United Kingdom, however, because it was perceived as regressive (borne relatively more heavily by low-income households than high-income households), and because it was costly to administer. Unlike property that is highly visible and in a fixed location, individual taxpayers can escape full reporting of the total number of taxable occupants (see King 1988). 
the central government, assessed the value of homes. The agency placed each property on a valuation list in one of eight valuation bands. The value assigned to each property only indicates the valuation band and not the actual value of the property. Tax rates vary among different bands according to proportions laid out in statute. In particular, higher rates apply to properties with higher band values.

The value for each dwelling is based on its market value, which is an estimate of the sale price on April 1, 1991, and takes into account any significant changes that have occurred since that time, such as an extension to the property. The government did not intend to revalue all dwellings in the future, which means that any change in value because of a change in house prices has generally not affected the banding. Individual properties could be rebanded only under two circumstances. First, if the local area changes for the worse, all homes in the area may be placed into a lower band. Second, if a house is expanded it will be rebanded only after it is sold. If a home decreases in value because part of it is demolished, it may be rebanded immediately.

By assigning properties to broad categories rather than assigning a taxable value to each one, the council tax achieves simplicity and stability at the price of accuracy. Furthermore, because the council tax uses an estimate of market value at a particular point in time (April 1, 1991) and then freezes assessments for the foreseeable future, it has the same implications as any out-of-date assessment system, namely, inequities will increase over time. The government recognizes this problem and has proposed a reassessment in 2007.

Site value taxation is a special case of market value taxation where only the land portion of the property is taxed; the assessment base excludes any improvements to the land. George first proposed the method in 1879 , which gave rise to the single tax movement in the United States in the 1890s. Land is sometimes taxed directly. In other cases, market value taxes are levied, but they exempt improvements or tax them at a lower rate. Site value assessment has been used in parts of Australia and in Jamaica, Kenya, New Zealand, and South Africa.

The main advantage of site value taxes is their potential for improving the efficiency of land use. Site value, in principle, taxes the location rents (the returns from a particular location regardless of the improvements to the site). If improvements are not taxed, the owner has an incentive to develop the land to its most profitable use. Compared with a property tax that discourages investment in property, a site value tax will encourage building and improvements.

Assuming land is in fixed supply (the supply of land offered for development is unresponsive to price changes), the tax falls on landowners and cannot be shifted to others. Increased site value taxes will be capitalized into lower property values. Because landowners bear proportionately more of the tax than in the case of a property tax, the tax should be more progressive (borne relatively more heavily by high-income taxpayers than low-income taxpayers).

The use of site value taxation has two potential disadvantages. The first relates to the administration of the tax. Accurate land valuation presents a challenge to assessors, because urban real estate sales combine the value of land and improvements. Site value requires the assessor to subtract the value of the improvements from the property value to derive an assessed value for the land. Some authors have argued, however, that valuation of land is probably easier than valuation of property (Netzer 1998). Rather than assessing the property value and subtracting the value of improvements, site values per square meter could be estimated from sales and demolition records. Although this debate has not been resolved in the literature, Bahl (1998) has argued that valuing land separately may be more of a problem in industrial countries than in developing countries, where separate assessment of land and improvements takes place anyway. Where a uniform tax rate exists and taxpayers can only appeal the total value, however, the division between the two components becomes arbitrary.

The second disadvantage concerns the potential revenues that can be collected using a site value tax. Because the tax base is considerably smaller than the value of land and improvements combined, site value taxation can only produce comparable revenues at high tax rates. Bahl (1998) notes that levying a lower property tax rate on land and improvements is politically 


\section{Box 10.1 Equivalence between Rental Value and Market Value Property Taxes}

The following shows the equivalence between a tax on rental value and a tax on market value. This equivalence is important if moving from one tax base to the other and if private investors are familiar with one system when the other is being used.

\section{Tax Rates}

Tax rates are usually expressed in terms of a given amount per 100 units of value, such as US\$2 per US\$100 of taxable value. The term "mill rate" refers to the rate per 1,000 units. In this example, the mill rate would be US\$20.

\section{Tax Bases}

Rental value and market value are linked, because in well-functioning markets a relationship exists between the returns to various types of investments. Thus if one can earn 10 percent interest on an investment such as a bond, then the rental value of a property worth US $\$ 100,000$ should be US $\$ 10,000$ $(100,000 \times 0.1)$, neglecting maintenance, repair, and risk. Otherwise, investors should either sell properties (if the return is less) or buy properties (if the return is more).

This means that the tax rates in the two systems can be compared. A tax rate of 2 percent on property value is equivalent to a tax rate of 20 percent on rental value, because a property worth US\$100,000 will (a) have a property tax burden of US\$2,000; (b) rent for US\$10,000; and (c) consequently have a rental tax burden of US\$2,000 if the rate is 20 percent on rental value.

Source: Based on Vaillancourt and Renneberg (2000).

easier than levying a higher tax rate on the land portion only. Under the rental value (or annual value) approach, property is assessed according to an estimate of rental value or net rent. One rationale for using rental value is that taxes are paid from income (a flow) rather than from wealth (a stock), and thus taxing the net rental value of real property is appropriate. In theory, however, no difference should exist between a tax on market value and a tax on rental value (see box 10.1). When a property is put to its highest and best use and this is expected to continue, rental value will bear a predictable relationship to market value: the discounted net stream of net rental payments is approximately equal to market value.

This relationship does not always hold, however. Most assessors tend to assess rental value on the basis of current use, and thus a difference exists between market value and rental value. A property that is underutilized would be assessed much lower under rental value than under market value. Furthermore, gross rents are often used rather than net rents that build in an allowance for maintenance expenditures, insurance costs, and other expenses.

The use of rental value assessment has some problems. First, estimating rental value is difficult when rent control is in place. Controlled or subsidized rents cannot be directly used to assess market rents unless most properties are rent controlled. Second, vacant land causes problems. Because vacant land is not taxable under a tax based on rental value in current use, an incentive exists for low return uses over high return uses and to withhold rental properties from the market altogether. ${ }^{9}$ If governments do not tax vacant properties, the tax has to be higher on occupied properties to yield the same amount of revenue. These higher taxes discourage investment.

In terms of tax administration, using rental value poses further difficulties (Netzer 1966). First, rental value is difficult to estimate, because little information is available on the annual rents of comparable properties for unique commercial and industrial properties such as steel mills, for example. Second, calculating net rents is difficult, because the distribution of expenses

9. As noted previously, if rental value were based on highest and best use, then vacant land would be taxable; the value would have to be estimated on the basis of other properties. Even if rental value were based on current use, assigning a nonzero value to vacant land might be possible. 
between landlords and tenants differs for different properties. Third, assessors may not have access to rental income information, because rental income is not always in the public domain in the same way as sales prices.

Rental value assessment is used in several countries, including France, India, and Morocco. In India, which has rent controls, the assessed value is not related to the market value because it is tied to the controlled rent. Revaluation is also irrelevant, because the rent control sets the maximum assessment.

Self-assessments require property owners to place an assessed value on their own property. In Turkey, for example, property owners are required to file property declarations with the taxing authority every three years and when a property changes ownership or when a building is constructed or improved (Dillinger 1992). Owners must also provide information on location, use, measurements, and characteristics of land and buildings. Based on these characteristics and price factors provided by the taxing authority, owners are required to calculate their property value. If their estimate is below the minimum value, they pay a penalty if the property is later sold for more than the estimated value. Turkey relies on field audits and tax clearances to enforce compliance. When owners sell their properties, they are required to obtain clearance from the tax authority before submitting their applications to the registrar of deeds. While this system is effective for properties that are being sold, it does not affect properties that are not.

In some countries, Taiwan (China), for example, the taxing authority has the right to buy the property at the assessed value (see Dillinger 1992). A system where the taxing authority can buy the property will only be credible if it can and will buy property, but this right has rarely been exercised, partly because of the political impossibility of large-scale purchases of residences.

Another similar proposal is that people should assess their own properties and then make their assessments public (Tanzi 2001). Anyone who wanted to buy a property at a price that exceeded the declared price by some margin, such as 40 percent, could make an offer. If the owner refused the offer, the bid plus a penalty would become the new assessment.

Self-assessment does not require an assessment staff, and it appears to be easy to implement. To minimize the problems associated with self-assessment, however, the government has to be prepared to obtain expert assessments of individual properties in cases where it believes the self-assessment is inaccurate. Expert assessments significantly increase the cost of collecting the tax.

Self-assessment can lead to inaccurate estimates of property values, and there is a tendency to underestimate the value of the property. Self-assessment violates the principle of fairness on the basis of ability to pay, because people with comparable properties will not necessarily pay comparable taxes. Generally lower-valued properties have a lower rate of underestimation than higher-valued properties, making this assessment approach regressive (taxes are relatively higher on low-valued properties). Underestimation also erodes the size of the tax base. Furthermore, the potential exists for self-dealing and fraud, for example, if non-arm's length transactions determine values.

Table 10.1 summarizes the different assessment methodologies and presents examples of where they are used. Note that in a number of countries taxing authorities have a choice of tax base. For example, in New Zealand the site value system is the most popular among local authorities, but they can also use rental value, market value, and, in a few instances, land area.

COMPARISON OF AREA-BASED AND VALUE-BASED AsSESSMENT. Where possible, experts generally regard market value as a better tax base. First, the benefits from services are more closely reflected in property values than in the size of the property. For example, properties close to transit systems or parks enjoy higher property values. The benefits from these services are not reflected in the dimensions of the property, but rather in the value of the property. Even for those services where benefits may relate more closely to property dimensions (such as sidewalks and street lighting, for example), front footage, rather than lot size or building size, is 
Table 10.1 Base for Property Taxes

\begin{tabular}{|c|c|c|c|}
\hline Tax base & Definition & Measure used & $\begin{array}{c}\text { Examples of } \\
\text { countries where used }\end{array}$ \\
\hline Market value & $\begin{array}{l}\text { Price that would be } \\
\text { struck between a } \\
\text { willing buyer and } \\
\text { seller in an arm's- } \\
\text { length transaction }\end{array}$ & $\begin{array}{l}\text { Comparable sales, } \\
\text { depreciated cost, or } \\
\text { income method }\end{array}$ & $\begin{array}{l}\text { Australia, Canada, } \\
\text { Indonesia, Japan, } \\
\text { United States }\end{array}$ \\
\hline Site value & $\begin{array}{l}\text { Price that would be } \\
\text { struck between a } \\
\text { willing buyer and } \\
\text { seller in an arm's- } \\
\text { length transaction }\end{array}$ & $\begin{array}{l}\text { Comparable sales } \\
\text { subtracting } \\
\text { improvements value } \\
\text { from total property } \\
\text { value }\end{array}$ & $\begin{array}{l}\text { Jamaica, Kenya, New } \\
\text { Zealand, South Africa }\end{array}$ \\
\hline Rental value & Value in current use & Net rental income & France, India, Morocco \\
\hline Unit value & $\begin{array}{l}\text { Size of property } \\
\text { adjusted to reflect } \\
\text { location, quality, or } \\
\text { other factors }\end{array}$ & $\begin{array}{l}\text { Square meters of land } \\
\text { and building area, } \\
\text { adjusted }\end{array}$ & $\begin{array}{l}\text { Armenia, Czech } \\
\text { Republic, Israel, } \\
\text { Poland, Russia, } \\
\text { Slovakia }\end{array}$ \\
\hline Self-assessment & Sales price & $\begin{array}{l}\text { Determined by owner } \\
\text { of property }\end{array}$ & Peru, Turkey \\
\hline $\begin{array}{l}\text { Transitional or mixed } \\
\text { systems }\end{array}$ & $\begin{array}{l}\text { Combination of area and } \\
\text { market value }\end{array}$ & $\begin{array}{l}\text { Market-priced zones for } \\
\text { land or land and } \\
\text { buildings }\end{array}$ & Estonia, Latvia \\
\hline
\end{tabular}

Source: Author.

more relevant. Table 10.2 shows how the costs of different services might be allocated among properties.

Second, market value has the advantage of capturing the neighborhood's amenities, which have often been created by government expenditures and policies. Area-based assessments, particularly unit assessments, are unlikely to capture these amenities, because they do not take into account differences in the quality of buildings or their location. Consider, for example, the taxes paid by two properties of identical size and age but in different locations. Specifically, one is located next to a park and the other is adjacent to a factory. Under an area-based assessment system, both properties would be levied the same property tax. Under a value-based assessment system, the property next to the park would pay higher property taxes. In this example area-based assessments would not be fair.

Third, unit assessment results in a relatively greater burden on low-income taxpayers than high-income taxpayers when compared with a value-based assessment, because average

Table 10.2 Examples of Allocation of Costs among Properties

\begin{tabular}{ll}
\hline Service & Allocation method \\
\hline Transit & Property value \\
Parks & Property value \\
Fire protection & Property value \\
Police protection & Property value \\
Sidewalks & Front footage \\
Street lighting & Front footage \\
Water and sewers & Front footage \\
Roads & Front footage \\
\hline
\end{tabular}

Source: Author. 
household incomes in high-value neighborhoods are higher than in low-value neighborhoods. A tax on square footage taxes all properties that are the same size the same amount whether they are in high-income or low-income neighborhoods. Similarly, older houses in a bad state of repair but with a large floor area will pay relatively higher taxes.

Furthermore, if a relatively poor neighborhood becomes richer, no relative tax change would occur. A tax system that fails to take account of changes in relative values over time will result in inequities among houses. If one value per square foot is chosen for all single-family homes, for example, and the relative property values change over time as some locations become more desirable, then over a period of years, if the value per square foot is not changed, inequities in the assessment system will result (Bird and Slack 1993).

One of the stated advantages of unit value assessment is that property taxes based on it tend to be less volatile than under market value assessment, because they do not change when property values change. In any event, unit value assessment can easily evolve into a market value system by defining zones more narrowly over time.

Some experts have also argued that unit value assessment is easier to understand and cheaper to administer than value-based assessment. This is particularly true where the real estate market is not well developed. Although unit value may be easier to administer for singlefamily residential properties, using it for multiresidential rental, residential condominium, commercial, and industrial properties is difficult. One problem is what to include for tax purposes. For example, one question is whether spaces such as atrium floors, servicing shafts, and elevator spaces should be taxed even though they have no revenue-producing space. Issues arise about whether to include structural elements, such as decorative beams that project outside the glass line, as is the case with some office towers. A second problem is how to allocate shared facilities, such as common entrances, halls, exits, aisles, atriums, or malls, between owners and tenants. For example, common areas can be shared on the basis of the size of each unit relative to the total, the rent charged to each unit, or some other measure. A third problem in market economies has been the tendency toward the proliferation of multipliers that are applied to the area of improved property to reflect the relative differences in value. In the Netherlands, for example, the system became so complex that it was abandoned (Youngman and Malme 1994).

NEED FOR A UNIFORM ASSESSMENT SYSTEM. Whichever assessment method is used, fair property taxes have to be based on assessments that are uniform within each jurisdiction. In this way, taxpayers share the costs of local government fairly. Furthermore, because the property assessment base is sometimes used as the measure of fiscal capacity for equalization grants from senior levels of government, as is the case in Morocco, the assessment base needs to be uniform across jurisdictions.

Uniform assessment systems are easier to achieve where the assessment function is centralized. Strauss and Sullivan (1998), for example, found that the use of county rather than local assessors resulted in more uniform residential assessments in U.S. jurisdictions. Furthermore, to the extent that economies of scale exist in the assessment function, these are more likely to be achieved at the central government level (Sjoquist and Walker 1999). When assessment is performed at the local level, an incentive exists to undervalue properties to increase the equalization grant.

Much of the criticism of the property tax stems from a lack of credibility in the fairness of the assessment base. Fair and productive property taxes require periodic revaluation to reflect changes in the market. Frequent valuations maintain the legitimacy of the tax and reduce the risk of sudden, dramatic shifts in tax burdens caused by large increases in assessed values. For these reasons the valuation cycle needs to be fairly short.

Many countries use a three- to five-year cycle, and in some cases they index values in the intervening years using a price index (Bell 1999). In a market in which property values are 
changing, a shorter time frame for re-assessments would obviously be better for reflecting current market conditions. Indexing is not as good as re-assessment, because property values change at a different rate in different neighborhoods and for different property characteristics. Fairness is not achieved when property assessments are merely increased by a common factor on an annual basis. Indexing can be used, however, where financial resources are insufficient to carry out regular reassessments. Indexing over a three- to five-year period that reflects relative price changes among locations and property markets can ameliorate taxpayers' discomfort with large assessment changes and improve information about market trends for assessment administrators.

\section{Tax Rates}

To determine the tax liability, the assessed value is multiplied by the tax rate. Given the size of the tax base, the tax rate determines how much revenue the property tax will generate. In most North American jurisdictions, local governments first determine their expenditure requirements. They then subtract nonproperty tax revenues available to them, for example, intergovernmental transfers, user fees, and other revenues, from their expenditure requirements to determine how much they need to raise from property tax revenues. The resulting property tax requirements are divided by the taxable assessment to determine the property tax rate.

By contrast, in many transition economies, the national government sets the rates for property taxes. Two exceptions are Estonia and Poland, where municipalities are allowed to determine tax rates within fixed limits (Malme and Youngman 2000). In Poland local governments determine the tax rates on land and buildings through the annual budgetary process, but the central government sets upper and lower limits.

To be a truly local tax, local governments must set tax rates. If a local government is to make efficient fiscal decisions, it needs to weigh the benefits of the proposed services with the costs of providing them. If local governments do not finance these services themselves, then the link between expenditures and revenues is lost and the choice of services will not be based on their cost. Setting tax rates at the local level places accountability for tax decisions at the local level. Local determination of tax rates is particularly important where a senior level of government determines the tax base.

Local tax rates may have to be set within limits, however, to avoid distortions. A minimum tax rate may be needed to avoid distorting tax competition. For example, richer local governments may choose to lower tax rates to attract more business. A maximum rate may be needed to prevent distorting tax exporting, whereby local governments levy higher tax rates on industries for which nonresidents will bear the ultimate tax burden (for a discussion of tax exporting see Boadway and Kitchen 1999).

Local governments may levy a series of rates that differ by property class. Property tax rates can also vary according to the services received. For example, in some jurisdictions a general tax rate applies across the city and a special area rate or additional surcharge applies in those parts of the city that receive services provided only to them, for example, garbage collection, street lighting, or transit. Special area rates, which are earmarked for services in those locations, approximate a benefit charge.

Variable tax rates are different tax rates for different classes of property, for example, residential, commercial, and industrial. Generally where variable tax rates apply, properties are assessed at a uniform ratio (100 percent or less) of market value. Another way to differentiate among property classes is through a classification-based assessment system. Under this system, tax jurisdictions differentiate classifications or types of property according to ratios of assessed value, but apply a uniform tax rate. In terms of accountability, variable tax rates would be more visible and easier to understand for taxpayers than a classified assessment system. This system gives local governments the power to manage the distribution of the tax burden across various 
property classes within their jurisdiction in addition to determining the size of the overall tax burden on taxpayers.

Variable tax rates may be justified on a number of grounds as follows:

- On the basis of fairness with respect to benefits received, some could argue that the benefits from local public services are different for different property classes. In particular, a case can be made on benefit grounds for taxing nonresidential properties at a lower rate than residential properties.

- On efficiency (neutrality) grounds, some have argued that property taxes should be heavier on those components of the tax base that are least elastic in supply. Because business capital tends to be more mobile than residential capital, efficiency arguments lead to the conclusion that business property should be taxed more lightly than residential property. In reality, however, tax jurisdictions generally apply lower rates to residential properties.

- On the basis that higher property taxes on buildings tend to slow development and that lower taxes speed up development, a municipal policy to develop some neighborhoods instead of others would call for differential taxes in different locations as well as for different property classes. In this case variable tax rates are used to deliberately distort decisions to achieve certain land use objectives.

\section{Taxation of Nonresidential Property}

Nonresidential properties include a wide variety of property uses, including commercial uses such as offices, banks, retail outlets, restaurants, and hotels; industrial uses such as mines, manufacturing plants, and shipyards; and special uses such as pipelines and railway rights-of-way. As noted earlier, effective property tax rates (property taxes relative to market value) are generally higher on nonresidential properties than on residential properties. As also noted, the higher taxation of nonresidential properties cannot be justified on the basis of benefits received or on efficiency grounds. Notwithstanding all the reasons for taxing nonresidential property at a lower rate than residential property, most jurisdictions do the opposite. Local governments tend to favor residential properties largely on political grounds: residential homeowners vote in elections.

The ability of nonresidential property owners to export property taxes to residents of other jurisdictions may require limits on the local government's ability to determine tax rates on this class of property. At least to some extent, the consumers of the products or services produced in nonresidential properties bear the burden of nonresidential property taxes. To the extent that the product or service is exported outside the jurisdiction, consumers in other jurisdictions may bear part of the tax. Tax exporting is inequitable, because the same benefits of local expenditures require different tax prices in different jurisdictions depending on the degree of exporting. It tends to induce inefficient, additional local expenditures to the benefit of local residents who may not be willing to bear the cost of such expenditures themselves. Finally, tax exporting does not enable accountability, because those bearing the burden of the tax are not the same as those enjoying the benefits.

Within the category of nonresidential properties, linear properties, such as railway rights-ofway and gas pipelines, present unique challenges. Unlike other commercial and industrial properties, these properties have extensive linear networks that are not specific to any one municipality. They pass through urban and rural areas and areas where no people live. They receive limited services. Because they have no links to the communities they traverse, no accountability exists at the municipal level for the taxes levied. Indeed, the tax revenues that accrue to municipalities along the route are simply windfall revenues for which no services are provided. For these types of properties, a province-wide or nationwide tax rate may be appropriate. 


\section{Taxation of Farm Properties}

Tax jurisdictions usually favor farm properties in the property tax system as part of a more general policy of protecting farmland. A common way to favor farm properties is through assessment. Rather than using market value to assess farms, which reflects the highest and best use, farms are often assessed at their value in current use. This means that the value of a farm is determined by its selling price if it were to continue to be used as a farm. Alternative uses of the farm, or its speculative value, are not considered in the determination of value.

Many Canadian and New Zealand jurisdictions use value in current use for farmland. In Ontario, Canada, tax rates on farmland pending development can be phased in over stages. The triggers for tax increases are when the land is used solely for farm purposes but has been registered for subdivision, and when the land is used solely for farm purposes but a building permit has been issued. In New Zealand, if the highest and best use exceeds current use, tax jurisdictions record both values. The difference between the taxes as assessed on the two values may be postponed until the land is sold or no longer used for farming.

Other ways of favoring farm properties include providing exemptions for part or all of the farm property, lowering tax rates on farms, or providing farm tax rebates. Tax jurisdictions give full exemptions in Cyprus and Ireland, for example, whereas they provide partial exemptions in Jamaica and the Netherlands. Lower tax rates apply in Ontario, where the farm tax rate and the rate for managed forests are legislated to be 25 percent of the residential tax rate. Lower rates replaced the earlier system of farm tax rebates in Ontario.

\section{Incidence of the Property Tax}

The statutory incidence of the tax (the taxpayers legally liable to pay the tax) is not necessarily the same as the economic incidence (the taxpayers who bear the final burden of the tax) (for a review of the incidence of the property tax see Bird and Slack 1993). The reason for the difference is that those who are liable for the tax can shift the burden onto others by altering their behavior. For example, the tax may be levied on an apartment owner (statutory incidence), but the final burden may be borne by the renter (economic incidence), because the owner passes the tax onto the renter as part of the rent.

The two views of property tax incidence are the "old" view and the "new" view. According to the old or traditional view of property tax incidence, the tax is divided into a tax on land and a tax on improvements. Because the supply of land is fixed, it follows that the landowner bears the tax on the land component. Because the quantity of land supplied cannot be reduced, the landowner cannot shift the burden onto others. However, because the supply of structures can be altered through investment decisions, the portion of the tax that falls on structures may be shifted forward onto the consumers of the services provided by the structures. For rented residential property, this means the tax can be shifted onto tenants; for nonresidential property the tax can be shifted to consumers of the goods and services produced by commerce and industry. For owner-occupied properties, owners bear the entire tax on structures in proportion to their imputed housing expenditures. If the supply of structures is perfectly elastic in the long run, all the tax can be shifted forward to tenants and consumers.

The new view of property tax incidence takes a different perspective on the property tax. The old view provides a partial equilibrium approach to property tax incidence and concerns the incidence of a property tax change in a particular city. The new view provides a general equilibrium approach and concerns the differential incidence of property taxes in general.

Under the new view, the initial assumption is that the property tax can be, in the first instance, viewed as being imposed at a uniform rate on all forms of property. ${ }^{10}$ Although the

10. Note that the new view does not differentiate between residential and nonresidential property. 
effective tax rate varies by jurisdiction and type of property, an "average" tax rate on all property determines the incidence of the property tax system as a whole. The tax in any one jurisdiction is thus an average plus a differential.

The property tax under the new view is similar to a general tax on land and capital. If the total supply of land and capital is fixed, and certain other assumptions are made, the tax will simply lower the rate of return to capital and land and no tax shifting will take place. The burden of the tax will be in proportion to the ownership of land and capital.

In reality, the property tax is not a uniform tax on all forms of capital. A good deal of the capital stock is exempt from this tax and wide variations also exist in the effective tax rate because of type of capital and taxing jurisdiction. Differences exist in the composition of the tax base, exemptions, assessment methodology, rates, and other characteristics of the tax. These variations give rise to "excise tax effects."

The differential portion of taxes on land in fixed supply will, for example, tend to be capitalized, while the differential taxes on reproducible capital will lead to movements of capital among industries and jurisdictions so as to tend to offset these differentials and ensure that investors obtain similar after-tax returns on all investments. Over time, jurisdictions with above average property tax rates will suffer a decrease in local capital stock. The migration of capital out of the high-tax jurisdictions will be followed by the migration of other mobile resources, such as skilled labor, to the low-tax jurisdictions. The result is that the tax in the high-tax areas will be borne by the least mobile factors: unskilled workers, consumers who face higher prices for goods and services, owners of businesses that cannot move to other locations, and land owners. The opposite situation will occur in the low-tax jurisdictions.

In summary, the old view assumes the net return to capital is fixed and thus can only be applied to the analysis of a property tax in an individual municipality. It concludes that the property tax is regressive, that is, low-income taxpayers bear relatively more of the tax. The new view explicitly looks at the effect of a property tax system in the whole economy and assumes that the supply of capital in the economy is fixed. It concludes that the tax is progressive, borne relatively more heavily by high-income taxpayers.

\section{Property Tax Relief Measures}

Notwithstanding the lack of agreement on whether the property tax is progressive or regressive, most jurisdictions have implemented property tax relief measures to reduce the perceived burden on low-income taxpayers. Some property tax relief measures are designed to reduce the burden of property taxes on residential taxpayers in specific circumstances; other measures are provided indirectly through the tax system, for example, differential tax rates provide relief to some property classes such as residential and farm categories, and taxable assessment is sometimes calculated at different percentages of assessed value for different types of properties.

Relief measures vary according to a number of factors: characteristics of the property (residential versus nonresidential), characteristics of the beneficiaries (for example, owners versus renters, income, age), and the extent to which these measures are permanent or transitory. Because most relief schemes apply to residential property, table 10.3 summarizes the characteristics of residential property tax relief programs. Relief programs include tax credits; deferrals; grants; exemptions; special relief schemes for poor taxpayers such as reductions, cancellations, and refunds; and assessment credits.

PROPERTY TAX CREDITS. The property tax credit is designed to alleviate the perceived regressivity of the property tax by relating the amount of the credit to personal income. The tax credit is based on the amount of property taxes paid (or a portion of the rent for renters) and the income of the taxpayer. The credit is subtracted from the personal income taxes payable and is usually refundable. This means that if the property tax liability exceeds the income taxes 
Table 10.3 Residential Property Tax Relief Measures

\begin{tabular}{|c|c|c|c|c|}
\hline \multirow[b]{2}{*}{ Program } & \multicolumn{3}{|c|}{ Characteristics of beneficiaries } & \multirow[b]{2}{*}{$\begin{array}{c}\text { Permanent or } \\
\text { transitory }\end{array}$} \\
\hline & $\begin{array}{l}\text { Owners or } \\
\text { renters }\end{array}$ & $\begin{array}{c}\text { Based } \\
\text { on income }\end{array}$ & Other characteristics & \\
\hline Property tax credit & $\begin{array}{l}\text { Owners and/or } \\
\text { renters }\end{array}$ & Yes & n.a. & Permanent \\
\hline Tax deferral & Owners & No & $\begin{array}{l}\text { Elderly and/or } \\
\text { disabled }\end{array}$ & $\begin{array}{l}\text { Until time of } \\
\text { property transfer }\end{array}$ \\
\hline Grants & $\begin{array}{l}\text { Owners and/or } \\
\text { renters }\end{array}$ & Sometimes & $\begin{array}{l}\text { Sometimes restricted to } \\
\text { the elderly or those on } \\
\text { social assistance }\end{array}$ & Usually permanent \\
\hline Exemptions & $\begin{array}{l}\text { Owners or } \\
\text { renters }\end{array}$ & Sometimes & $\begin{array}{l}\text { Sometimes restricted } \\
\text { to the elderly }\end{array}$ & Permanent \\
\hline $\begin{array}{l}\text { Reductions and/or } \\
\text { cancellations } \\
\text { and/or refunds }\end{array}$ & $\begin{array}{l}\text { Owners or } \\
\text { tenants }\end{array}$ & Yes & Poverty or illness & $\begin{array}{l}\text { Usually for one year; } \\
\text { need to apply }\end{array}$ \\
\hline Assessment credits & Owners & No & n.a. & Permanent \\
\hline
\end{tabular}

n.a. Not applicable.

Source: Author.

payable, the government pays a refund to the taxpayer. These credits are progressive in incidence, especially if they are refundable, because they provide greater benefits to low-income households than to high-income households.

Property tax credits can, however, result in liquidity problems for low-income taxpayers, because they are required to pay property taxes throughout the year but do not receive the credit until they file their income taxes the following year. Furthermore, taxpayers are unlikely to make the connection between the property taxes they pay and the tax credit, in part because of the delay in receiving the credit, but also because a senior level of government administers the credits.

TAX DEFERRALS. Under a deferral scheme, property owners are permitted to defer some or all of their property taxes. Either the local government or a senior level of government recovers the amount. The outstanding amount becomes a lien against the property and is payable when the property is transferred. It is a deferral of taxes and not a tax rebate. In some cases, an interest charge (often below the market rate of interest) applies to the taxes deferred. Property tax deferral programs are generally restricted to elderly and disabled property taxpayers. They can be especially useful in addressing the cash flow problems of seniors who are asset rich but income poor. ${ }^{11}$

Although good economic arguments exist for using tax deferral schemes, they are not particularly popular among taxpayers. The take-up rate is low "largely owing to the strong attachment of the old to their homes and to their desire to leave them unencumbered for their heirs" (Bird and Slack 1978, p. 98).

GRANTS. Some municipalities or senior levels of government provide grants to eligible homeowners or renters. The grant may be the same amount for all taxpayers; it may be

11. Tax deferrals should not be expanded to include the non-elderly, because the loans would be outstanding for a much longer time, and it would be necessary to determine eligibility for a referral to ensure a reasonable number of beneficiaries. 
restricted to only some recipients, for example, the elderly or those on social assistance; or it may vary inversely with income. The advantage of a grant scheme over a tax credit scheme is that tax jurisdictions can link it more directly to the property tax liability; the taxpayer can receive the grant in time to pay the property tax. A grant scheme can also be more directly targeted to those in need, especially in smaller communities where hardship cases are easily identified.

EXEMPTIONS. An exemption removes specific properties from the tax base. Exemptions are similar to grants that completely offset the tax liability. If an exemption is only available to a class of taxpayers, such as elderly taxpayers, it will not necessarily be based on ability to pay.

Reductions, CANCELlations, AND Refunds. Some municipalities may refund, cancel, or reduce taxes in special cases of poverty or illness. The benefit of these programs usually only applies for one year, and taxpayers have to re-apply in subsequent years. These programs, like grants, work best in smaller communities where hardship cases are easily identified.

ASSESSMENT CREDITS. Assessment credits mean the removal of a fixed amount from the market value assessment of each residential property. The municipal council determines the fixed amount. Because the amount is the same for all properties, the scheme turns the property tax into a progressive tax. The assessment results in a smaller tax base overall. This means that to raise an equivalent amount of tax, higher tax rates are required. For those with relatively low property values, the effect of the assessment exemption would outweigh the effect of an increased tax rate. Thus they would benefit from lower property taxes. For those with relatively high property values, the tax rate increase would outweigh the effect of the assessment exemption, and they would pay higher taxes.

The assessment credit is based only on property values and not on property owners' ability to pay the tax. The credit would be based on ability to pay only to the extent that property values and incomes are highly correlated. For example, the elderly living in high-valued homes but with low incomes would gain little benefit.

Combined Property TAx Relief Options. Some municipalities provide more than one type of property tax relief. For example, property tax credits may be combined with tax deferrals for the elderly. Reductions, cancellations, or refunds may be needed for specific hardship cases even where tax jurisdictions use other relief schemes.

\section{Land-Based Revenue Systems}

In addition to the property tax, other forms of land-based revenues used by local governments include the following:

- Special assessments: property taxes for specific capital facilities in specific neighborhoods

- Land value increment taxes: taxes on increases in land value as a result of a proposed capital investments

- Land transfer taxes: taxes on the value of properties at the time of sale

- Development charges: taxes on developers to pay for the infrastructure required to develop land parcels.

With the exception of land transfer taxes, local governments generally use these land-based revenues to finance infrastructure, whereas they use property taxes mostly for operating expenditures (though sometimes they allocate portions to capital expenditures). 


\section{Special Assessments}

Special assessments, which are also known as local improvement charges, are compulsory charges imposed on residential, commercial, and industrial properties to pay for additions or improvements to existing capital facilities that border on those properties. They are most often used for capital expenditures to pave or repave streets, install or replace water mains or sewers, construct sidewalks, install street lighting, and so on. Although the magnitude of the charge is based on a particular capital expenditure in a particular year, the costs may be spread over a number of years.

The most common base for special assessments is the front footage of those properties that abut the capital works in question, but the charges can also be levied on the basis of lot size, assessed value of property, or zone. Special assessments are not as efficient as user fees, because the charge is not directly related to the use of the service, but they do approximate benefit taxes more closely than the property tax. Many public works increase the value of nearby land, providing a financial benefit to the owners. With a special assessment, the municipality constructs the works and then recoups the cost through a special assessment on the properties that directly benefit from the government expenditure.

In theory, the apportionment of capital costs to benefiting property owners should reflect the value of the additional benefits that each property receives, where the value is measured by the increase in property value. For example, a water main on a residential street would presumably make that street relatively more desirable. For a given supply of residential properties on that street, the resulting increase in demand would increase prices. Thus, all other things being equal, the benefit of the water main would be reflected in property values. In reality, however, isolating the effect of one capital expenditure from other influences on property values is difficult. For this reason, measures such as front footage and lot size are often used rather than assessed value.

Although Boadway and Kitchen (1999) note that special assessments do not generally contribute a large amount of money to municipal revenues in countries like Canada where they are used, they are an important way of financing local improvement projects. This is because the costs of the projects financed in this way are allocated on the basis of the benefits received from the infrastructure.

Local governments in Poland have the option of levying an "adjacency" fee to recover part of the costs of infrastructure investment, for example, street lights or sidewalks. When a public investment increases the value of adjacent property, the local government can levy a special assessment within three years after making the improvements. The cost for an individual property cannot exceed 50 percent of the increase in value attributable to the improvements. Property owners can pay in annual installments for a period not exceeding 10 years (Malme and Brzeski 2000).

\section{Land Value Increment Taxes}

Governments levy land value increment taxes to capture the increment in land value attributable to public efforts rather than to the landowner's own actions. These taxes are also known as land value capture taxes, betterment levies, and valorization taxes. Although land value increment taxes have had a long history in a number of Latin American countries, they are still not widely used around the world.

This form of taxation has generally been proposed in situations where a municipality is contemplating a major infrastructure investment such as a new subway. Other examples where a land value increment tax could be used include schools, parks, conservation areas, and any other public investment that increases the value of adjacent land. The unearned increments can be captured indirectly through conversion into taxes or fees or directly through on-site improvements that benefit the community at large (Smolka and Furtado 2001). 
A large investment of this nature requires a capital outlay of billions of dollars immediately, but the benefits will not be enjoyed for several years. The tax is designed so that the costs incurred during the current period are shared among future beneficiaries. This involves identifying the beneficiaries and the benefits they will receive and estimating the present value of those future benefits.

In terms of future benefits, the local government will enjoy increased property tax revenues; the benefits to the private sector can be described in terms of potential profits. Increased demand for development along the subway line, for example, will permit property owners to increase rents. Furthermore, zoning changes often accompany investment in infrastructure: increased densities permitted along the subway line, for example, will result in increased land values.

The decision of the public sector to construct major infrastructure results in a windfall gain to owners of property nearby. For example, a subway increases demand for housing and offices on properties located near it. Given normal demand and supply conditions, the increased demand results in higher prices being charged for these properties. Through no efforts on the part of the property owners, the value of their property increases. Rather, the efforts of the local government cause these values to increase. A land value capture tax is a way for the public sector to tax some or all of the windfall gain that it has created. However, isolating the change in property value arising from the public investment in infrastructure from other market forces that affect land prices does pose some difficulties. To some extent, the increased densities and increased land values will be reflected in property tax revenues if market value assessment is the base of the tax.

A review of valorization taxes in Colombia suggests that a number of elements are required for the implementation of this tax to be successful (Bird 1992). One particularly important element is the linking of taxes to benefits: "The valorization tax over the long run must have approached a benefit basis in fact as well as belief" (Bird 1992, p. 165). In the case of the subway example, the tax is specifically levied to pay for a subway line. Although earmarking of taxes along these lines is often criticized, earmarking the revenues of a land value increment tax can work if the tax rate is changed regularly to reflect revenue needs. ${ }^{12} \mathrm{~A}$ land value increment tax creates an incentive to examine the prospective benefits from projects more closely than might otherwise be done.

Those who criticize the fairness of the tax argue that land value increment taxes reduce the scope of income redistribution through taxation. This problem is lessened, however, to the extent that the income from these taxes finances specific projects, and as such does not constitute the main source of revenues to local governments.

In terms of tax administration, land value increment taxes have some advantages. Enforcement is somewhat easier than with a general property tax, because the tax is collected in large amounts from a relatively small number of taxpayers. Poor administration, however, can also lead to criticisms of the tax if, for example, projects financed by tax revenues are not on schedule or if the tax is calculated to be greater than the increase in property values.

Land value increment taxes are similar to site value taxes in that they both tax location rents, or the returns from a particular location regardless of the improvements to the site. In the case of land value increment taxes, only the portion of the increased value that is a direct result of the public investment is taxed. Site value taxes, by contrast, also tax increases in site values that may arise for other reasons, such as unique locational advantages. This means that the potential revenue from a site value tax is greater than from a land value increment tax.

The land value increment tax, like site value taxes but unlike property taxes, does not penalize the development of unimproved land. It will tend to encourage more intensive uses of land

12. Earmarking is sometimes criticized for limiting budgeting flexibility, which results in insufficient revenues for some activities and too much for others. 
by making it less profitable for landowners to withhold land for speculative purposes. The landowner will either realize the opportunity cost of holding the land vacant by putting it to more profitable use or will sell it to someone who will. The land value increment tax is likely to be more effective in increasing the intensity of land use than site value taxes, however, because it is a large tax assessed over a short period of time.

Land increment taxes can also be compared with a capital gains tax on property. Many countries tax capital gains from the sale of property, though capital gains on a principal residence are exempt in Australia and Canada, and a portion of the gains on a primary residence are exempt in the United States. Tax jurisdictions levy the tax on the increase in value between the acquisition price and the sale price of the property. The tax rate may depend on the length of the holding period. One of the main differences between capital gains taxes and land value increment taxes is that the latter tries to isolate only the increase in value arising from a public investment, whereas a capital gains tax is levied on all the gains regardless of their source. A capital gains tax on the land portion only would tax the increment in land value and not improvements to the property, but would not isolate the increase in land value arising from a public investment. Furthermore, payment of a capital gains tax generally takes place when the increment is realized by sale. Neither site value taxes nor capital gains taxes are designed to provide the public investments that will lead to the increment in land value.

A type of land value increment tax commonly used for urban revitalization in U.S. cities is tax increment financing (TIF). TIF legislation exists in 40 U.S. states, and the United Kingdom uses a similar program in local jurisdictions. TIFs have been applied to downtown areas that need revitalization, brownfield remediation, ${ }^{13}$ and to pay for deteriorating infrastructure (for a review of TIFs see Anderson 1990; Wassmer 1994). Under a TIF, the city government defines a district for renewal and freezes the annual property tax revenue accruing to all taxing authorities within the district, including the municipality, the county, school boards, and so on, at prerevitalization levels. These are known as the base level property taxes. For a period of time, generally between 15 and 35 years, all or some portion of the incremental tax generated beyond the base level accrues to the redevelopment agency to be used for the redevelopment. After the TIF period expires, tax revenues from the expanded assessment base again flow through the taxing authorities. Based on these TIFs, the local government (or the private sector) can borrow funds to pay for the infrastructure. TIF revenues are used to pay back the borrowed funds.

The idea behind a TIF is that investment in infrastructure or redevelopment will result in increased tax revenues for the TIF district. For example, property owners may benefit from a more appropriate or a more affordable site. Under this scheme, the tax authorities do not tax property owners at a different rate than other city landowners. Rather, property owners continue to pay the taxes on the assessment base, but the local government dedicates the incremental taxes to redevelopment or to infrastructure investment. If the TIF achieves the results predicted, no direct transfer of funds from the government takes place, nor does any transfer of tax dollars from one business subsidize another business.

Critics of TIFs point to several problems, however. TIFs may not be able to generate the predicted tax revenues, and the resulting lack of funds could threaten efforts to revitalize the designated area. Some have argued that TIFs may merely accelerate development that would have

13. Brownfields are urban sites that are underutilized, often vacant, and sometimes contaminated. Because of their proximity to downtown areas where infrastructure is generally in place, brownfields hold a great deal of potential for redevelopment. The realization of this potential is hindered, however, by the cleanup costs of contaminated land and the costs of upgrading or replacing existing but older infrastructure. In many cases, traditional sources of private financing are hesitant to invest in brownfield sites because of the risks associated with their redevelopment. Although there is the potential for future rewards, these lands often remain unused because of a lack of up-front redevelopment financing. 
occurred anyway. Other taxing authorities, such as school boards, resent that their property taxes are frozen when they are experiencing growth in demand as a result of the revitalization. Finally, TIFs have been criticized for targeting funds to a designated area at the expense of areas on the periphery of the TIF district or at the expense of overall municipal growth.

\section{Land Transfer Taxes}

Tax authorities levy land transfer taxes at the time of sale of a property and usually calculate them as a percentage of the value of the property transferred. The tax, which must be paid before the transfer is registered, is like a sales tax payable by the purchaser and is calculated as a percentage of the purchase price. A number of variations on land transfer taxes exist. For example, the tax rate sometimes increases with the value of the property; in some cases, taxes are higher on nonresidents.

Many countries impose transfer taxes. In Australia, Japan, Sweden, and the United Kingdom they are known as stamp duties. The following summarizes the use of land transfer taxes in four transition economies (Malme and Youngman 2000):

- In Armenia the real property transfer tax is a percentage of the declared value or official price, whichever is greater.

- In Estonia real property transfers are subject to a transfer fee, which is calculated as a rate times the value. The rate is a fixed amount for properties over a certain amount, and a sliding scale exists for properties of lower value.

- In Poland three transfer taxes or fees are levied on the property value: stamp duty, notarial fee, and title registration fee. Both the stamp duty and the notarial fee are levied at a percentage of the reported sales price. The Land Title Registry collects a fee, which is a percentage of the reported price, to record the new ownership title.

- In Slovakia the value of the base for the transfer tax is specified by a price decree of the Ministry of Finance. When property is transferred, administrators can choose the higher of the reported sales price or the assessed price. The assessment is done by appraisers.

Central and local governments can levy land transfer taxes. When levied at the local level tax rates have to be fairly low to avoid distortions (people moving in response to the tax). When rates are set low, however, the administrative costs at the local level end up being high relative to the amount of revenues collected. ${ }^{14}$

The revenues generated from a land transfer tax depend on activity in the real estate market. As land values rise and activity in the market grows, the yield of the tax will increase. A lull in the real estate market, however, will result in a lower yield from a land transfer tax. Land transfer taxes discourage full reporting of transaction amounts and thus reduce the reliability of this source of data for property tax administration (Bahl 1998).

The purchaser pays the land transfer tax to the government. In terms of incidence, individuals have little ability to pass on the tax, although consideration of the tax may lower the price a buyer is willing to pay for property. Because the tax is usually small, however, the effect on price is not likely to be significant. In the case of businesses, the tax is a capital cost that is likely to be recovered over time through higher prices for goods and services.

Although the tax is probably borne more by high-income people, the value of homes relative to income tends to decrease as incomes increase. This means that the land transfer tax is regressive relative to income for those who pay the tax. In cases where the tax rate is higher on

14. To the extent that the collection of land transfer taxes provides an opportunity to collect other unpaid taxes on the property being transferred, the administrative burden as a percentage of the total tax revenues may be lower. 
portions over a certain value, the tax would be less regressive. In terms of benefits received from the tax, governments generally bestow few benefits on property purchases that are not already picked up by user fees charged by the land titles or land registry office.

An example of a particular type of land transfer tax was the land speculation tax in Ontario, Canada. This was a provincial tax imposed in 1974 to tax gains realized on the disposition of real property, including buildings and fixtures. The purpose of the land speculation tax was to restrain the rate of increase of land and housing prices by curtailing speculation and to recover a major share of windfall gains from land speculation for the public. The tax rate of 20 percent applied to all realized capital gains with some exceptions. These exceptions included principal residences; developed industrial or commercial properties; properties sold to the government; properties that were substantially improved by building a new structure or renovating an existing structure; residential investment properties owned by transferors for at least 10 years that contained structures worth at least 40 percent of the total value; farm properties owned by transferors for at least 10 years; and properties that which were included in a registered plan of subdivision and had been wholly or partially serviced by the transferor.

Smith's (1976) study of the effect of the land speculation tax showed that while the tax caused a temporary reduction in the price of houses, it left the upward trend in house prices unaffected. Furthermore, the study found that a land speculation tax tends to increase concentration in the construction industry and in the ownership of residential investment properties, and thereby tends to reduce competition in the industry. It also encourages the deterioration of residential investment properties and reduces the availability of funds for investment in real property.

Finally, the tax requires a considerable bureaucracy to administer it and may not generate sufficient revenues to cover the administrative costs. In the extreme, if the tax did eliminate speculation, no tax revenues would accrue at all. In the Ontario example, the tax eliminated most of the taxable transactions, with the result that revenues were small and probably less than the administrative costs and other foregone tax revenues, such as land transfer, income, and capital gains taxes. The provincial government eventually eliminated the tax.

\section{Development Charges}

Local governments levy development charges (also known as exactions and lot levies) on developers in North American jurisdictions to cover the growth-related capital costs associated with new development, or in some cases redevelopment. These charges provide revenues from the private sector to municipalities to finance infrastructure needs arising from growth (for a review of the application of development charges by municipalities across Canada see Slack 1994). Municipalities generally levy development charges for officially mandated programs and have to use the funds collected to pay for the infrastructure made necessary by the development. ${ }^{15}$ Before municipalities levied development charges, they paid for infrastructure out of property tax revenues, user fees, intergovernmental transfers, reserves, and borrowing. Development charges require the private sector to pay for the capital costs imposed on municipalities resulting from development. The main rationale for development charges is simply that growth should pay for itself and not be a burden on existing taxpayers. The involvement of the private sector enables the provision of needed infrastructure when government funding is constrained.

15. Municipalities in Canada have, historically, required developers to provide or pay for on-site services, such as streets, street lighting, sidewalks, and other public facilities within a subdivision. More recently, municipalities have extended the responsibility to developers to pay for the off-site costs associated with new development. Although most municipalities specify the on-site costs that developers must cover, not all municipalities make developers pay for the off-site costs. Development charges only apply to the off-site costs. 
Development charges are usually structured according to a set of rules so that they cannot be negotiated. For example, local governments in Ontario are required to calculate the need for the services to be financed by development charges where the need for services depends on the forecasted growth over the next 10 years and the existence of excess capacity. Local governments have to specify future capital expenditures by category of expenditure and determine what portion of these expenditures is growth related. The calculation of the development charge cannot be based on a level of service that exceeds the average level of service provided in the municipality over the last 10 years. Municipalities are also required to estimate the effect of their capital expenditures on future operating expenditures to determine if these costs can be paid for out of local revenues such as property taxes and user fees. ${ }^{16}$

In terms of the geographic application of the development charge, a municipality can (a) charge all developments in the municipality for all services, (b) charge part of the municipality for all services, (c) charge different amounts in different municipal service areas to reflect different costs, or (d) levy a uniform charge across the municipality plus charges for specific services in specific areas.

Other formal or informal exactions on the developer exist that are part of the subdivision approval process, but are not strictly development charges. These include, for example, land dedications that require the developer to set aside land for roads, other public works, and school sites, or for environmental reasons; parkland dedications that require a portion of the land used for development to be set aside for parkland or the developer to make a cash payment in lieu of parkland; density bonusing whereby developers are granted higher densities than are permitted by planning regulations in return for meeting conditions such as providing day care, preserving an historic building, and so on; connection fees to permit developers to buy into existing water and sewer facilities; and oversizing provisions (sometimes called frontend financing) that require developers to provide more infrastructure than is required for their development. In some cases the municipality agrees to recover part of the costs on behalf of the developer from future benefiting owners.

Development Charges And Land Use. Development charges can be a useful tool in encouraging efficient land use and infrastructure use. To be efficient, however, jurisdictions must structure charges to reflect the true costs of providing public services. Area-specific charges allow municipalities to vary the charge by area of the city according to the different infrastructure costs imposed on the city by each area. The costs of services may vary by area, because the distance of each development from major facilities may be different, infrastructure may already exist in some areas, and service standards differ (Tomalty and Skaburskis 1997). Whatever the reason for the differential costs, efficient land use requires that developments that impose higher infrastructure costs on the city pay higher development charges than developments that impose lower costs.

If the development charge reflects the full private and social costs and benefits of the development, then developers will make efficient choices about where to locate their development. The charge is similar to a price for services rendered. In the absence of a development charge, the developer considers only the costs and benefits of alternative locations and does not consider the effect of the development on the municipality's costs of providing services.

Because the cost of services varies by the type and location of development, an efficient development charge would have to vary by these characteristics of the development. For example, developments located close to existing services should pay less than those farther away.

16. The estimated capital costs have to be reduced by an amount that reflects a municipality's excess capacity and by an amount that reflects the benefit to existing development. Furthermore, legislation requires that the capital costs be reduced by 10 percent for infrastructure other than water supply, wastewater, storm water drainage, services related to highways and electrical power, and police and fire protection services. 
Alternatively, a uniform charge levied across the city, regardless of variations in the actual cost of providing services, would provide an incentive to develop farther away from existing services. A development charge that is the same amount per unit regardless of where the unit is located will not reflect the true costs of the development to the municipality and will not lead to efficient development decisions. When urban form and density are not fully factored into the development charge, a market distortion occurs, and inefficient allocation of resources is often the result. A uniform charge subsidizes inefficient uses of land, and developments that incur lower costs end up subsidizing developments that impose higher costs.

INCIDENCE OF DEVELOPMENT CHARGES. A number of studies have investigated the issue of who bears the burden of development charges (for a review see Slack 1994). The developer pays the charge generally at the time of subdivision approval or issuance of the building permit or at the time of subdivision construction. As with the property tax, the economic incidence of the charge is not necessarily the same as the statutory incidence. The charge may ultimately be borne by new homebuyers, the predevelopment landowner, the developer or builder, or some combination of these players.

The incidence of development charges depends on the uniformity of the charge within housing markets, the demand and supply conditions in the market for new housing, and the developer's awareness of the charge and its magnitude before undertaking the development.

A uniform charge is one that is comparable across a particular housing market. With a uniform charge, the degree to which developers will pass it onto new homebuyers or back onto landowners depends on the demand and supply conditions in the housing market. In the long run most experts believe that demand for housing is price inelastic and that the supply of housing is elastic. On the demand side, this means that new homebuyers are relatively insensitive to price: if prices increase, the demand for housing will fall only slightly. On the supply side, an elastic supply means that development is responsive to price changes. The combination of inelastic demand and elastic supply means that a uniform charge is likely to be shifted forward onto new homebuyers.

If market conditions do not permit the developer to pass the charge forward onto the new homebuyer, then the developer will not develop the land. The price of land will fall, and the burden of the charge will be borne by the owner of the land at the time the charge was imposed. Thus the timing of the charge also influences who bears the burden. Even if the developer bears part of the burden in the short run, the developer is unlikely to bear the burden in the long run. Increased demand for housing in the future will cause prices to rise to the point where proceeding with the development is profitable. In the long term the burden will be shifted forward onto the new homebuyer.

Where the charge is nonuniform within the same housing market, for the developer to pass the charge forward onto the new homebuyer will be more difficult because competitors in nearby locations with lower development charges will not raise their house prices by as much. Where the charge cannot be passed forward, the developer will develop less land, and the price of land will come down. The landowner will bear the differential at the time the charge is anticipated. In the long term, when increased demand for housing results in an increase in the price of housing, the developer will be able to pass the charge forward onto the new homebuyer.

In summary, the development charge is likely to be passed forward onto the new homebuyer, if not in the short term, then certainly in the long term. With respect to rental housing, property owners are likely to pass the charge onto tenants. The analysis of who bears the burden of development charges on commercial and industrial property is similar: the charge is likely to be passed forward onto the consumers and producers of services provided by these properties in the same way that the residential charge is passed onto new homebuyers.

EfFect of Development Charges on Existing versus New Residents. One of the main advantages of development charges is that growth pays for itself and does not create a burden 
for existing residents. The previous discussion of who bears the burden of the development charge notes that the price of new housing would increase. The price of existing housing will also increase as a result of the levying of development charges because new housing and existing housing are reasonable substitutes. This means that owners of existing housing will enjoy a windfall gain as a result of the higher prices of their houses.

In comparing new and existing residents, two further points can be made. First, to the extent that property taxes and user fees paid by new residents are used to help defray the debt costs associated with existing infrastructure or to finance present or future capital expenditures, for example, where replacement costs of existing infrastructure are charged to existing residents through property taxes or user fees, new residents are paying not only for their own facilities but also for those of previous and future generations. Second, to the extent that infrastructure being enjoyed by existing residents was financed in large part by previous generations of taxpayers, a move from tax revenues to development charges on new residents means that existing residents enjoy a windfall gain. Their services were paid for, in part, by previous generations, and they are not required to pay for future generations.

Development Charges And Accountability. Where developers pass the development charge onto the new homebuyer, problems of accountability may arise. New homebuyers pay the charge before moving into the neighborhood, that is, before they are voters. In the case of property taxation, voters can register their opposition to high taxes at election time. In the case of development charges, those who pay them are not voters at the time the government levies the charges and cannot register their opposition.

DEVELOPMENT CHARGES AND BORROWING COSTS. In the absence of development charges, cities generally borrow funds to pay for infrastructure and pass the costs of the infrastructure (plus the borrowing costs) onto taxpayers through the property tax. With development charges, the developer pays the charge up-front using borrowed funds or equity and then passes these costs onto residents. ${ }^{17}$ In theory, in the absence of interest rate differentials, a new homebuyer should be indifferent between a development charge financed over the mortgage period and annual property tax payments. In reality, however, homebuyers face borrowing constraints. An addition to the purchase price of the house, resulting, for example, from a development charge, may mean that a new homebuyer facing a borrowing constraint can no longer purchase the house.

One of the differences between levying development charges and levying property taxes to pay for capital costs relates to who borrows funds. In the case of the development charge, developers and new homebuyers borrow funds; in the case of the property tax, the city borrows funds. If cities can borrow more cheaply than new homebuyers and more cheaply than developers, then development charges may be less efficient than municipal borrowing to finance infrastructure.

\section{References}

Anderson, John. 1990. “Tax Increment Financing: Municipal Adoption and Growth." National Tax Journal 43(2): 155-64.

Bahl, Roy. 1998. "Land Taxes Versus Property Taxes in Developing and Transition Countries." In Dick Netzer, ed., Land Value Taxation: Can It and Will It Work Today? Cambridge, Massachusetts: Lincoln Institute of Land Policy.

Bahl, Roy, and Johannes Linn. 1992. Urban Finance in Developing Countries. Cambridge, U.K.: Oxford University Press.

17. Municipalities can generally include borrowing costs in the development charge. 
Bell, Michael. 1999. “An Optimal Property Tax: Concepts and Practices.” World Bank, Intergovernmental Fiscal Relations and Local Financial Management Department, Washington, D.C.

Bird, Richard, M. 1992. Tax Policy and Economic Development. Baltimore, Maryland: The Johns Hopkins University Press.

Bird, Richard, M., and Enid Slack. 1978. Residential Property Tax Relief Measures in Ontario. Toronto: University of Toronto Press.

1993. Urban Public Finance in Canada, 2nd ed. Toronto: John Wiley.

Boadway, Robin, W., and Harry M. Kitchen. 1999. "Canadian Tax Paper No. 103." In Canadian Tax Policy, 3rd ed. Toronto: Canadian Tax Foundation.

Bryson, Phillip, and Gary Cornia. 2000. "Taxes on Real Property in the Czech Republic." In Jane H. Malme and Joan M. Youngman, eds., Case Studies. Washington, D.C.: World Bank.

Dillinger, William. 1992. Urban Property Tax Reform Guidelines and Recommendations. Washington, D.C.: World Bank, Urban Management Program.

Fischel, William A. 2000. "Homevoters, Municipal Corporate Governance, and the Benefit View of the Property Tax." National Tax Journal LIV(1): 157-73.

George, Henry. 1879, reprinted 1979. Progress and Poverty. New York: Robert Schalkenbach Foundation.

King, David, N. 1988. "Accountability and Equity in British Local Finance-The Poll Tax." Discussion Papers in Economics, Finance, and Investment, University of Stirling, Stirling, Scotland.

Kitchen, Harry. 1992. Property Taxation in Canada. Toronto: Canadian Tax Foundation.

Kitchen, Harry, and Enid Slack. 1993. Business Property Taxation. Kingston, Ontario: Queen's University.

Kitchen, Harry, and François Vaillancourt. 1990. “The Federal Grants-in-Lieu of Property Taxes Program: An Assessment." Canadian Tax Journal 38(4): 928-36.

Malme, Jane H., and W. Jan Brzeski. 2000. "Property Tax Developments in Poland." In Jane H. Malme and Joan M. Youngman, eds., Case Studies. Washington, D.C.: World Bank.

Malme, Jane H., and Joan M. Youngman, eds. 2000. “The Development of Property Taxation in Economies in Transition." In Case Studies. Washington, D.C.: World Bank.

McCluskey, William, ed. 1999. Property Tax: An International Comparative Review. Aldershot, U.K.: Ashgate Publishing.

Netzer, Dick. 1966. Economics of the Property Tax. Washington, D.C.: The Brookings Institution. 1998. "The Relevance and Feasibility of Land Value Taxation in the Rich Countries." In Dick Netzer, ed., Land Value Taxation: Can It and Will It Work Today? Cambridge, Massachusetts: Lincoln Institute of Land Policy.

Sjoquist, David L., and Mary B. Walker. 1999. “Economies of Scale in Property Tax Assessment." National Tax Journal 52(2): 207-20.

Slack, Enid. 1994. "Development Charges in Canadian Municipalities: An Analysis." Report commissioned by the Intergovernmental Committee on Urban and Regional Research, Toronto.

Slack, Enid, John LaFaver, and Thor Shpak. 1998. "Property Tax in Ukraine: Third Attempt." Budget and Fiscal Review (Fiscal Analysis Office, Verkhovna Rada) (2): 32-45. 
Smith, Larry. 1976. "The Ontario Land Speculation Tax: An Analysis of an Unearned Increment Land Tax." Land Economics 52(1): 1-12.

Smolka, Martin, and Fernanda Furtado. 2001. "Lessons from the Latin American Experience with Value Capture. Land Lines (newsletter of the Lincoln Institute of Land Policy, Cambridge, Mass.) 13(4): 5-7.

Strauss, Robert P., and Sean R. Sullivan. 1998. "The Political Economy of the Property Tax: Assessor Authority and Assessment Uniformity." State Tax Notes 15(December 21): 1603-10.

Tanzi, Vito. 2001. "Pitfalls on the Road to Fiscal Decentralization." Working Paper no. 19. Carnegie Endowment for International Peace, Washington, D.C.

Tomalty, Ray, and Andrejs Skaburskis. 1997. "Negotiating Development Charges in Ontario: Average Cost Versus Marginal Cost Pricing of Services." Urban Studies 34(12): 1987-2002.

Vaillancourt, François. 1998. "Local Government Finance in Tunisia: A Note." World Bank, Washington, D.C.

Vaillancourt, François, and R. Renneberg. 2000. "Revenue Sources of Cities." Urban and City Management Program, World Bank Institute, Washington, D.C.

Wassmer, Robert. 1994. “Can Local Incentives Alter a Metro City's Economic Development?" Urban Studies 31(18): 1251-78.

Youngman, Joan, and Jane Malme. 1994. An International Survey of Taxes on Land and Buildings. Netherlands: Kluwer Law and Taxation Publishers.

Zodrow, George R. 2000. "The Property Tax as a Capital Tax: A Room with Three Views." National Tax Journal LIV(1): 139-56. 



\title{
11
}

\section{Local Business Taxes}

\author{
Richard M. Bird
}

Cynics have sometimes said that economists cannot agree about anything, but many economists do agree on one important issue: while collecting many taxes through businesses is clearly convenient, there is little justification for taxing business as such. In the end, all taxes have an economic impact on people. Policy has little to gain and potentially much to lose by confusing the issue and pretending to tax companies and not people. Hiding who really pays the bills is not a good way to ensure accountable public sector decisions.

In addition, most forms of business taxation tend to impose economic costs by distorting decisions on such matters as the decision to incorporate, the debt-equity ratio, and the dividend policy along with where and how much to invest. Business taxes may also impose significant costs and barriers to the expansion of new and small firms. These arguments may sometimes be overstated, for example, when the untaxed allocation of resources is clearly distorted by monopoly or externalities. On the whole, however, they are sufficiently well founded to persuade many economists that, based on efficiency grounds, taxes on corporations in particular have few advantages, and much the same can be said for business taxes in general. Moreover, the economic case against such taxes seems even stronger at the local level than at the national level.

The virtual unanimity of professional economic advice on this issue is more than matched, however, by the unanimity with which governments at all levels appear to ignore it and impose such taxes. They do so for many reasons, some specious, some perhaps justifiable in certain circumstances, and some more compelling. Indeed, contrary to the conventional economic wisdom, there are often good reasons why in many instances local governments should indeed impose some form of taxation on businesses operating within their jurisdictions (for an argument supporting national corporation income taxes for quite different reasons see Bird 2002).

In addition to the case for and against business taxes, this chapter also discusses the difficult practical question of just how local governments should tax business. It then describes the surprisingly broad panorama of local business taxes found around the world by looking at practices in a number of countries. Next it turns to the evaluation of local business taxes, and then describes the two most promising forms of local business taxation. The chapter finishes with a brief conclusion.

\section{The Costs of Local Business Taxation}

Most economic costs that arise from taxing businesses grow in proportion with the mobility of capital. Capital is generally more mobile within than between countries. ${ }^{1}$ The argument that

I am grateful to François Vaillancourt for helpful comments on an earlier draft.

1. Helliwell and McKitrick (1999), for example, show that interprovincial capital mobility is much higher than international mobility in Canada, with the correlation between savings and investment for individual provinces being statistically indistinguishable from zero. As Dahlby (2000) shows, however, one must be cautious in interpreting correlations between saving and investment as reflecting capital mobility. In a simple endogenous growth model for a small, open economy, for example, a higher savings rate results in more investment in human capital, and because human capital is complementary to physical capital, it also results in an increase in the investment rate. 
taxes on business are economically distorting would therefore seem to be even stronger with respect to local business taxes. The basic tax competition model (Wilson 1999) implies that local competition for a tax base may lead to an inefficiently low tax rate on capital, and hence a correspondingly low level of public goods provision. The idea behind this result is simple. If the total amount of capital in a country is fixed, but capital is mobile between regions and the country has only two regions, then an outflow of capital from one region is, of course, an inflow to the other. An increase in the tax on capital in one region thus creates a positive externality in the other region, because the outflow of capital benefits the residents of the other region. Because each regional government is assumed to be concerned only with the welfare of its own residents, it will not take this external effect into account when setting its tax rates. Both regions will therefore set their tax rates-and therefore their levels of public goods provision-inefficiently low. In this model, local tax competition produces a "race to the bottom" and business taxes are more likely to be set too low than too high in efficiency terms.

From some perspectives, however, competition that keeps local taxes on businesses down is a good thing rather than a bad thing. One example is the so-called commitment problem. As governments with limited political lives cannot commit credibly not to increase taxes in the future on investments once made, fewer investments will be made (Kehoe 1989). Competition that tends to keep local tax rates down may therefore lead to increased private investment, and hence, presumably, to a higher growth rate.

Similarly, the public choice model suggests that in the absence of tax competition governments may tend to be inefficiently large (Edwards and Keen 1996). To some extent local governments can often "export" taxes by shifting the tax burden to nonresidents, for example, by taxing nonresident owners. In such cases not only will local business taxes tend to be inefficiently high, but by severing the connection between those who are taxed and those who benefit from the services financed by taxes, local business taxation may also reduce local accountability.

In the real world, of course, the degree and nature of competition for capital between governments are generally even more complicated than the most complex formal analysis suggests. No regional or local government is an island in economic terms. Each is affected by what happens outside its borders and, especially in the case of the larger localities, the actions of each in turn will exert some influence on the constraints facing others. Tax competition matters.

Thus on balance, local and regional taxes on business capital seem likely to be economically costly. The international and intranational mobility of the tax base, the ease with which businesses can shift income across boundaries, and the difficulty that small governments may have in enforcing taxes in such circumstances all point in the same direction. However, determining exactly how costly such taxes are is not easy. It depends on many things that are difficult to measure, such as the effect of taxes on economic growth and investment and the size of the associated distortions in the allocation of capital. Yet despite the measurement difficulty, consensus in the literature appears to be growing that taxes on business capital tend both to depress investment and to affect location decisions (see, for example, Chirinko, Fazzari, and Meyer 1999; Cummins, Hassett, and Hubbard 1998; Devereux and Griffith 1998). Even though the precise importance of such effects in any country is hard to determine, Whalley (1997) concludes that most studies estimated the efficiency cost of national taxes on capital to be in the neighborhood of 0.75 to 1 percent of gross domestic product (GDP). Such numbers may seem small, but they persist from year to year, and hence imply a substantial cumulative effect on growth and well-being. At the subnational level, as local economies are generally more open than national economies, such costs would presumably be even greater.

Thus theory, empirical evidence, and common sense all suggest that in most circumstances keeping local and regional taxes on business, especially taxes impinging on capital investment, as low as possible makes economic sense. Such taxes depress investment and distort economic decisions and reduce economic output, and hence the potential standard of living Moreover, by 
breaking the connection between those who pay taxes and those who benefit from the expenditures financed, they reduce local accountability and thereby weaken the critical hard budget constraint needed to ensure that decentralized public sector decisions are efficient (Bird 2001a).

\section{The Case for Local Business Taxes}

Despite the argument set out in the previous section, virtually every country does have some form of local business taxation. As least three arguments support local taxes on business: an efficiency argument, an equity argument, and a political argument.

In economic terms, the most convincing case for taxing business derives from one of the oldest principles of taxation, the benefit principle. To the extent that particular public activities result in particular firms receiving identifiable, cost-reducing benefits, those firms can and should be charged for the costs incurred in providing such benefits. Thus whenever feasible, direct user charges should be applied to businesses just as to any other direct beneficiary (Bird and Tsiopoulos 1997). For example, if business waste is more toxic and therefore more costly to remove and dispose of than household waste, an additional charge on those businesses imposing the additional cost is clearly warranted. Similarly, if large trucks impose heavier costs on roads and highways in terms of wear and tear, they should be charged accordingly.

In addition to services the public sector provides directly to identifiable private firms, for which it can and should levy user charges, a significant fraction of general public expenditure, particularly at the local government level, directly benefits businesses. In the case of Canada, for instance, Kitchen and Slack (1993) estimate that, on average, close to 40 percent of the noneducation municipal expenditures in eight Ontario cities benefited commercial and industrial activities (though the share was less than 20 percent if education were taken into account). Similarly, Oakland and Testa (1995) estimate the business share of U.S. state and local expenditures, including those on education, to be 13 percent. Even though both these studies assume that business receives no benefits from educational expenditures, both nonetheless conclude that the taxes levied on business actually constitute a higher share of the taxes levied by the respective governments than the benefits received by business. A solid efficiency case can therefore be made for levying some form of generalized benefit tax on business to cover such unattributable benefits to productive activities. ${ }^{2}$

Indeed, such benefit taxation has both an efficiency and an equity rationale. It is efficient because it ensures that, assuming local taxes are freely chosen by local people, someone is willing to pay an amount at least equal to the marginal cost of providing a particular service. At the same time, it is equitable in the sense that it is fair for everyone, whether rich or poor, to pay the same price for services received, whether from the public sector (refuse removal, for example) or from a private seller (such as bread or clothing).

From an efficiency perspective, levying taxes on firms and individuals that benefit from public services is economically necessary. Doing so will, for example, minimize the horizontal spillovers that would otherwise arise from such expenditures (Mintz and Tulkens 1986). As noted earlier, if local governments impose nonbenefit taxes that are paid by nonresidents rather than residents, local governments are likely to spend more than they should in terms of efficient resource allocation. The size of government will then be excessive, because through tax exportation nonresidents (who do not vote in the jurisdiction) pay for services enjoyed by residents. An additional horizontal spillover arises from competition for the tax base. In this case,

2. Feehan (1998), who argues that much government spending produces services that enhance firms' productive capacities, provides an interesting theoretical rationale for such a tax under certain conditions. As Bird (2002) notes, this benefit argument for imposing "tax-prices" in the form of a generalized business benefit tax should not be confused with some of the less tenable versions of the benefit rationale for taxing corporations that can be found in the literature. 
however, a jurisdiction may choose tax levels that are too low for fear of losing the tax base to other jurisdictions. Whether the result of local fiscal competition is too much or too little local spending in aggregate, however, in either case the efficient allocation of resources is distorted. To avoid this outcome taxes should, where possible, be allocated in accordance with a reasonable measure of benefits received. In many countries local and regional taxes levied on business may already be higher than can be justified on such efficiency arguments. This situation reflects the obvious political feasibility—perhaps even the political necessity (Sorensen 1995)—of taxing business. Often taxing business heavily is as politically attractive as it is economically undesirable, both because of the common belief that the rich pay such taxes and the real possibility that nonresidents may do so.

Moreover, there also seems to be a widespread belief that jurisdictions in which economic activities take place are in some sense entitled to part of the proceeds, regardless of whether the services provided by their governments contribute anything to production or whether any of the output is consumed within the jurisdiction. The common conflicts between central and regional governments over natural resource revenues, for example, arise at least in part from such deeply held, if seldom articulated, beliefs. ${ }^{3}$ This entitlement principle can be extended to encompass business taxes more generally. Of course, the extent to which one accepts this argument may rest largely on personal preference and the prevailing local interpretation of history. Nevertheless, when combined with the benefit argument, some version of the entitlement concept appears to constitute the strongest logical case in support of local taxes on business.

Many politicians, and indeed the public in most countries, sometimes seem to think that business taxes, especially those on large corporations, are not among the worst, but rather the best, of all taxes. One naive version of this argument is that because corporations are separate legal persons and some of them have a lot of money, they must have substantial ability to pay taxes and should therefore do so. Popular as such arguments are, they are clearly fallacious. Only people, not things, can pay taxes in the sense of having their private, real incomes decreased. Indeed, a major problem with most business taxes-though also one of their political attractions-is that no one can be certain who is actually paying them. The burden of corporate taxes may fall on workers, landowners, equity owners, consumers, or some combination thereof, and assessing exactly how the burden is likely to be distributed is surprisingly difficult (Whalley 1997).

Taxation is as much a political as an economic phenomenon, however. Governments go against popular perceptions of who should pay, how much, and in what way at their peril. If despite strong economic arguments to the contrary popular feelings are that businesses in general, and large corporations in particular, should pay taxes much larger than can possibly be justified on benefit grounds, then any government that wishes to stay in power has to bow to these wishes, at least to some extent. ${ }^{4}$ If the political cost of raising taxes from corporations is low, even if the economic cost is high, imposing such taxes may be perfectly rational. From a government perspective, both costs are real, and the optimal tax policy will equate total (economic and political) costs at the margin with total benefits (Gillespie 1991; Hettich and Winer 1999).

3. McLure (2000) articulates the entitlement principle in the international context. It is equally observable at the subnational level in most countries, especially with respect to resource taxes (McLure and Mieszkowski 1983). This last aspect is also discussed in the chapter by McKenzie in this volume. This argument should, of course, be distinguished from the case for adequate compensatory payments to local residents for, say, environmental damage caused by mining or similar activities.

4. As the Ontario Fair Tax Commission (1993, p. 399) put it, "For many of those who appeared at our hearings, declining revenue shares from corporate income and capital taxation stood as a symbol of increasing unfairness in our overall system of taxation." This symbolic aspect of taxation is developed in Bird (1991). 
Corporate income taxes and other taxes on business may therefore be economically irrational, but nonetheless make perfect sense from the perspective of political economy. When taxes induce significant economic distortions, as most forms of business taxation do, the associated costs in terms of output forgone, even though usually hidden from public and political eyes, should in principle be explicitly weighed against possible political benefits resulting from greater public acceptability. Nonetheless, the political realities of governing, certainly in democratic countries, seem to be such that governments will impose business taxes whatever economists may say (Pola 1991).

Under the circumstances, it is perhaps as well that some arguments support such taxes to a limited extent. For example, in some instances local business taxes may provide the only significant source of elasticity in local revenues, and may therefore be a critical source of finance for expanding local infrastructure and service needs. Moreover, despite the danger that business taxes may reduce accountability by severing the connection between payers and beneficiaries, in some cases local business taxes may play a critical role in improving accountability in the sense that they are sometimes the only revenues over which local governments have any significant discretionary authority and for which they may therefore be held accountable.

Just how well local taxes on business serve any of these purposes in practice will depend largely on how they are structured and administered. The more important question is therefore not whether countries impose local and regional taxes on business, but how they should impose them.

\section{Local Business Taxation Around the World}

Many forms of local and regional business taxation exist. Among the most common are corporate or enterprise income taxes, taxes on internal trade (such as octroi), gross receipts taxes, fixed or proportional taxes that vary by type of business and location (such as patente), local sales taxes (which often fall to a considerable extent on intermediate business activities rather than on final consumers), and nonresidential real property taxes. A variety of licenses and fees unrelated to any services provided by the public sector may also be imposed. Some countries impose several of these forms of business tax at the same level of government, some impose different types of taxes at different levels, and some impose different taxes on different sizes and types of business.

Unfortunately, information on the precise characteristics of such taxes, the variations from jurisdiction to jurisdiction within countries, the administration of such taxes, and the taxes' economic effects is sporadic and incomplete. This section simply summarizes some aspects of some taxes in some countries. The aim is not to provide a full picture of the situation in any country, but rather to illustrate something of the variety and complexity of local business taxes. ${ }^{5}$

\section{Canada}

Canada's provinces impose corporate income taxes, capital taxes, and payroll taxes on businesses. ${ }^{6}$ In addition, about half of the 10 provinces impose retail sales taxes that derive onethird or more of their revenues from taxing business capital investment and intermediate activities (Kuo, McGirr, and Poddar 1988). Four provinces impose conventional consumer value added taxes (VATs) - invoice-credit, destination basis levies-that do not tax either

5. The text discusses formal taxes. As Prud'homme (1992) notes in a case study of Zaire, many informal local taxes are also imposed on business in many developing countries, ranging from simple theft and extortion by local officials to systems of requisitions and contributions that are virtually formalized.

6. Capital taxes are usually especially heavy on financial enterprises (McQuillan and Cochrane 1996). On provincial payroll taxes see Dahlby (1993). 
investment or intermediate activities (Bird and Gendron 1998). In total, these taxes constitute a substantial burden on capital investment and on production in general. Bird and McKenzie (2001) estimate that in some provinces such taxes are twice as high as in others on manufacturing investment and are generally much higher on investment in the labor-intensive service sector than in manufacturing.

In addition to these provincial business taxes, Canadian municipalities impose the largest property taxes in the world (as a share of GDP), and about half of the yield from this tax comes from taxes on commercial and industrial property. In some instances, such property is explicitly subject to higher rates. In many cases, it is assessed at higher ratios of market value. Thirsk (1982) argues that the property tax's heavy dependence on the business tax base is one reason why the property tax, so often seen as the main accountability link between local spending and taxing decisions, is actually one of the main ways in which this link is severed.

\section{United States}

Subnational business taxation in the United States is similar to that in Canada. Most states impose corporate income taxes, most also impose retail sales taxes that fall to a considerable extent on business (Ring 1999), and most local governments rely heavily on nonresidential property taxes. State business taxation probably has more distorting effects than in Canada for two reasons. First, unlike Canada, which has a uniform formula for apportioning the tax base between provinces, the definition of the taxable corporate base differs substantially in different states. ${ }^{7}$ Second, no U.S. states have followed the path some Canadian provinces have taken and eliminated the business element of sales taxes by moving to a consumption type of VAT. Two states, however, have experimented with an income type of VAT.

Michigan first introduced a modified income type of VAT, the business activities tax, in 1953 (Ebel 1972). Even though Michigan abolished the business activities tax in 1967, the single business tax, introduced in 1976, was similar (Brazer 1977). The single business tax was basically a modified VAT computed through the addition method and measured on the income side as the sum of payments to labor and capital, but with a number of important deductions and limits that moved it closer to a consumption base (Advisory Commission on Intergovernmental Relations 1978).

Originally intended to replace the state corporate income tax and some other taxes on business, proponents considered the main virtues of the single business tax to be increased revenue stability and the extension of taxation to noncorporate forms of business. Of course opponents saw both of these virtues as vices, and businesses, especially small businesses, bitterly resented paying the single business tax when there would be no corporate income tax liability. In response to these pressures, and no doubt to the usual tendency of tax bases to erode over time and become more complex, (the single business tax came to be excessively complex and unpopular (Kenyon 1996). Thus in 1999, when Michigan once again drew back from its pioneering attempt to introduce a state VAT and decided to phase out the 2.3 percent tax over the next 22 years, beginning with reductions to 2.2 percent in 1999 and 2.1 percent in 2000, this was not a complete surprise. In 2001, however, under budgetary pressure, the state decided to maintain the rate of the single business tax at 1.9 percent, but to phase it out by the end of 2009 (Hines 2002).

The second attempt at a state VAT in the United States is much more recent. In $1993 \mathrm{New}$ Hampshire introduced the business enterprise tax, which differed from Michigan's single business tax in a number of important respects. First, the base of the business enterprise tax is essentially net income (Kenyon 1996). Second, the tax is levied at a much lower rate, 0.25 percent,

7. A huge literature is available on the workings, and defects of state corporate income taxes in the united States. A classic assessment is McLure (1981). For a more positive perspective see McIntyre (2002). 
compared with Michigan's current rate of 2.3 percent. Third, unlike Michigan, the business enterprise tax did not replace the corporate income tax in New Hampshire, but was instead seen as a complement to it. Despite these differences, the two taxes are also alike in some important respects. Both are levied on value added by the addition method, and both were intended to provide a more stable, efficient, and simple source of state revenues. Kenyon (1996) argues that the business enterprise tax has indeed increased stability, that it is less distorting than an increased corporate income tax would have been, and that it is relatively simple.

The main technical problem encountered with income-type, origin-based, state VATs concerns their application to multistate or multinational businesses. Michigan, for example, used the same apportionment rule for the corporate income tax, an equally weighted three-factor allocation formula (payroll, profits, and sales in the state), ignoring the illogic of using destination-based sales in this tax base. Recent moves in many states to double-weight such sales in the formula would accentuate this problem. By contrast, even though New Hampshire, unlike Michigan, actually has a corporate income tax, it does not use the same apportionment rule for the business enterprise tax, but instead applies different factors to each element of the tax base, thereby substantially complicating what is otherwise a simple tax. Such problems would be greatly simplified if, as in Canada, a simple, uniform, apportionment formula were applied throughout the country.

\section{Germany}

The grandfather of all value added local business taxes is probably the German trade tax or gewerbesteuer (this account is based largely on Bennett and Krebs 1988). As originally conceived, this tax was levied on the income of all factors of production, although not in a uniform fashion, but as is so often the way with fiscal institutions, over the years the scope of the tax base has been substantially eroded. For example, the payroll component of the base was abolished in 1980, and since 1984, 50 percent of interest on long-term debts has been deducted from the base. This not only creates an incentive to use more debt financing (Gropp 2002), but also reduces the relatively logical initial coherence of the tax. Moreover, in practice the tax has essentially been removed from all but larger enterprises.

Even though local authorities still have considerable discretion with respect to tax rates, base changes decreed from higher levels of government have substantially reduced local authorities' revenue autonomy. Thus most local governments' apparent support of a 1982 federal proposal to introduce an explicit local VAT at an estimated rate of about 3 percent on top of the federal VAT is not surprising. The tax was to be imposed on a net income origin basis and collected by the addition method, that is, on the sum of payroll, interest, rents, and net profits. In the end, however, this proposal failed largely-as in the Michigan case-because of business opposition to paying taxes when firms had no profits. Currently the Commission for Reform of Municipal Finances is once again considering possible revisions of the gewerbesteuer. Reportedly one reason for doing so is because the trade tax is considered to be overly dependent on economic cycles.

Larger cities generally impose higher rates. Recent analysis suggests that this may reflect the greater market power and urban externalities found in larger population centers, and hence their lesser concern with attracting mobile capital. At the same time, the rates imposed in one area are clearly affected by those imposed in neighboring jurisdictions (Buettner 1999, 2001).

\section{Italy}

Italy has a particularly interesting approach to the problem of how best to tax local business. In 1998 a regional income tax levied essentially on business income at a rate of about 16 percent, a tax on dividend distributions by corporations, a small net worth tax, and payroll contributions 
levied to finance a national health scheme were all replaced by a new business tax, the imposta regionala sulle activita produttive or regional tax on productive activity (IRAP) (Dell'Anese 1997; Maisto 1997). This was part of a broader reform of business taxation (see Bordignon, Gianni, and Panteghini 2001).The IRAP is essentially a net income type of VAT on an origin basis. Most firms, including all types of business and self-employed activities, are subject to the IRAP at a rate of 4.25 percent, although regional governments can levy an additional percentage point if they so choose.

The IRAP appears to be the closest approximation to a good local business tax that now exists. The tax base is calculated annually by a direct subtraction method as the difference between gross receipts (sales revenues) and the cost of intermediate goods and services (purchases from other firms plus depreciation), with specific rules for different types of financial institutions. Neither wages and salaries nor interest payments are deductible from the tax base. Outlays for capital goods are deducted in accordance with normal income tax depreciation schedules. Revenues are allocated among regions in proportion to labor costs incurred in each region. This tax now finances about a quarter of all regional spending in Italy.

A recent assessment of the IRAP stressed its neutrality with respect to both choice of organizational form and between equity and debt financing, regardless of the source of finance, but noted that it probably, on balance, favored capital over labor, because tax depreciation exceeded economic depreciation (Bordignon, Gianni, and Panteghini 2001). Its proponents saw the major virtue of this regional tax as being that it permitted a significant reduction of taxes on profits, and hence brought Italian profits taxes closer to those in other European Union (EU) countries. In addition, the U.S. Internal Revenue Service has agreed that a portion of the IRAP would be creditable for U.S. income tax purposes (Smith and Gann 1998), which on its face would appear to be a factor encouraging other countries to adopt this form of tax. The national government's recent decision to eliminate this tax, beginning with the exclusion of 20 percent of labor costs from the base in 2003, thus seems to be unfortunate. Because, as Keen (2003) notes, the government's reasons for doing this are not clear, and because how this essential source of regional finance will be replaced is also unclear, this move does not appear to augur well for the future of rational business taxation in Italy.

\section{Other European Union Countries}

The United Kingdom does not impose real estate tax (council tax) on enterprises, but Denmark and Ireland impose real estate taxes only on enterprises. As Messere (1993) reports that taxes on business constituted as much as 71 percent of total property taxes in Austria, 65 percent in Iceland, 60 percent in Germany, 50 percent in Finland, and 32 percent in France, the problem of possible tax exporting noted earlier with respect to Canada is hardly unique to that country.

Several EU countries in addition to Germany and Italy impose special local taxes on business in addition to the property tax. France, for example, has a local tax that is essentially on payroll and fixed assets; Belgium has one that is based on the number of people employed and "motive power" (or the power output of machinery); Portugal taxes on profits; and Spain on the number of people employed as well as on such other factors as area, sector of activity, and power usage.

\section{Hungary}

In 1998 Hungarian local governments collected 86 percent of their own source revenues from a local business tax introduced in 1990 with a maximum rate of only 0.3 percent, but on a base consisting of gross sales. In addition, a small communal tax at a fixed amount ( $\mathrm{Ft}$ $2,000)$ per employee is levied on the basis of the average number of employees of businesses 
with permanent establishments in the municipality. ${ }^{8}$ The business tax, which Szalai and Tassonyi (2002) refer to as "the curiosity of the Hungarian local taxation system," is levied at a locally-determined rate of up to a maximum of 2 percent on a base that seems to be essentially value added (sales revenue, excluding VAT, less the cost of goods sold, materials costs, and the cost of subcontractors). If a taxpayer has permanent commercial activities in more than one jurisdiction, the base is divided. Smaller taxpayers (those with a turnover of less than Ft 100 million) may choose to divide it either by the proportion of net assets or personnel payments, and larger taxpayers have to use the weighted average of these two factors.

This tax is much more important in larger than in smaller localities. On a per capita basis, for example, revenues are 27 times greater in Budapest than in villages and eight to nine times greater than in towns (OECD 2000). Most localities do not appear to carry out any serious audits of tax returns. A recent assessment by Szalai and Tassonyi (2002) notes that this tax is expensive to administer, because the base is calculated on a different basis to the corporate income tax, and that it is also economically inefficient and has likely engendered tax competition (for example, localities can grant exemptions), tax exporting, and tax avoidance and has reduced accountability. Nonetheless, the business tax has unquestionably been the mainstay of local taxation in Hungary since its inception.

\section{Ukraine}

Like other transition countries, Ukraine has for some time been wrestling with the problem of how to tax small business. Recently it introduced a simplified system consisting of fixed rates imposed on different activities carried out by sole proprietorships plus a 10 percent sales tax on gross sales by enterprises or alternatively, enterprises can opt for a 6 percent sales tax plus VAT at 20 percent. Although a share of the enterprise taxes imposed under this system goes to local governments, this part of the new system is clearly a national tax. ${ }^{9}$ However, local councils not only receive all the revenues from the tax on individuals engaged in business, but can also vary the rate of the low simplified tax on individuals engaged in a variety of business activities within fairly narrow limits (between approximately US\$50 to US\$500 a year). This levy is imposed in addition to a related system of local business taxation (the so-called patent) that imposes similar patent fees ranging from US\$50 to US\$250 annually on individuals engaged in trading. Such levies may not amount to much in terms of revenue, but they are nonetheless significant in terms of local accountability, because local governments have more discretion in applying them than they do with respect to other sources of revenue.

The current system has been under review for some time and seems likely to be changed soon. A proposal introduced in late 2002, for example, introduced a single corporate tax at 5 percent on small and medium enterprises, although it would also require them to pay both VAT and social security contributions. As yet, however, how the system will be changed, if at all, is far from clear, and views about its virtues and problems vary widely. On one side, the Department for Economic Development of Entrepreneurship (2002) has argued that the simplified system has been a major success in terms of promoting small and medium businesses, because it has greatly reduced the complexity of the tax system with which such businesses must grapple. Moreover, the department's report suggests that for most firms the result of adopting what is

8. Like many countries, Hungary also makes it easy for local governments to impose special taxes on nonresidents, specifically tourists, in the form of a tax of Ft 300 per person per night (for a review of tourism taxes see Bird 1992). Many countries also have special local taxes on entertainment of various sorts. As with tourist taxes, such taxes appear to be politically highly acceptable

9. A similar national levy is imposed, at low rates varying by types of land, on agriculture, with a share going to local budgets. For a description of the Ukrainian system see World Bank (2002). 
essentially a fixed tax system has been to greatly increase the number of people in the formal tax system, and hence has increased tax revenues. By contrast, the State Tax Administration considers the simplified system to be ineffective. Its reported solution is simply to exempt small businesses from tax completely (Lungu 2002). At the same time, the World Bank (2002) has expressed considerable reservations about the whole system, suggesting that over time it may erode the entire tax system because of the incentives it gives firms to masquerade as small and the obvious difficulty facing the tax administration in uncovering the truth. Although the current discussion focuses largely on national tax issues, how these issues are finally resolved has serious implications for the future of local business taxation. ${ }^{10}$

\section{Japan}

In Japan, both regional (prefectural) and municipal governments levy taxes not only on property, but also on both personal and enterprise incomes. Corporations, for example, are subject to a municipal tax assessed on the basis of the national corporation tax paid the previous year, with the tax base being allocated among jurisdictions in proportion to the number of employees. This tax is both assessed and collected locally. The same is true of the business fixed assets tax, which is imposed not only on land and buildings, but also on business assets that are depreciable for income tax purposes. Although the assessment of this tax is local, a uniform system of assessment is applied throughout the country. Local governments must impose at least a standard tax rate of 1.4 percent of taxable value, but if they wish can increase the rate up to 2.1 percent. About 10 percent of municipalities impose higher rates (Kitazato 2002). In addition to this municipal tax, prefectures can levy a separate tax on certain assets held by larger businesses.

Beginning in April 2004, the local tax imposed on corporations with capital of more than $¥ 100$ million ( 31,000 out of 2.5 million corporations) will be altered to include both a value added component and a capital component. The value added tax base will be the sum of wages, net interest paid, net rents paid, and taxable income (profits) and the capital tax base will consist of paid-in capital (amounts invested) plus capital surplus. The larger corporations subject to this new tax will continue to be subject to local business tax based on their taxable income (profits), but at a reduced rate (maximum of 7.2 percent, compared with the normal maximum of 9.6 percent for the local enterprise tax). In addition, however, these larger corporations will now be taxed at a rate of 0.48 percent on value added and an additional 0.2 percent on capital. The purpose of this new system is essentially to reduce the sensitivity of local tax revenues to economic fluctuations, thereby insulating local finances to some extent from the effects of Japan's continuing recession.

\section{South Asia}

In India the most striking form of local business taxation is octroi, in effect a local customs duty on goods entering a locality, that is enforced by physical inspection at the "border." For example, in 2002 the state of Uttar Pradesh reportedly had 105 border check posts. The rates of octroi vary widely from place to place, and also by product. It is generally levied as a percentage of value. Much of the revenue-more than 40 percent in Gujarat according to Rao (1984)—comes from taxing intermediate and capital goods.

10. Other countries emerging from the former Soviet Union seem to have encountered similar difficulties in working out how best to tax small business. At one point, for example, legislation intended to simplify small business taxation in both the Kyrgyz Republic and Russia required such businesses to calculate tax liabilities using both the simplified system and the standard system. 
Octroi is supposed to be collected only from goods that are destined for use in the taxing locality. Those responsible for goods that are passing through are supposed to get a transit pass exempting them, although in some cases they are charged octroi in any case and have to seek reimbursement on proof of exit. (In Nepal, where octroi is also levied, Zimmerman 1998 notes that such reimbursement is rarely forthcoming.) Others have noted that in many instances octroi amounts to a tax on exports. Octroi obstructs the free movement of trade within the country and is often assessed and collected in an arbitrary, costly, and corrupt fashion. To illustrate the scale of the problem, at one time the state of Maharasthra had as many as 10,000 local octroi check posts. The costs of collection in the state of Karnataka were estimated to be high, varying between 6 and 18 percent of collections. As Purohit (1998, p. 39) notes with respect to the corruption within the system: "A facilitation fee is considered as the way of life when there is an octroi post."

Octroi is thus complex and nontransparent, has induced cascading, has encouraged vertical integration, and has greatly increased transport costs. According to Das-Gupta (2002), border procedures take between an hour and several days at the state level, implying economic costs of more than 1 percent of GDP and perhaps much more. For all these reasons, even though octroi is both the most important and most buoyant source of local own revenue, especially in urban areas, Rao (1984) has characterized octroi as "obnoxious, vexatious, wasteful and distorting." Indeed, almost everyone who has looked at how this tax works appears to agree that Napoleon did the right thing when he abolished similar levies in France 200 years ago. Some Indian states have abolished octroi and others are considering abolishing it. Nevertheless, in 1999 this form of tax still existed in at least six states, though sometimes in the form of an "entry tax" (essentially a sort of customs duty imposed by the state rather than the local government) as in West Bengal. Karnataka abolished octroi in 1979-197 of the state's 226 municipalities had been levying the tax-but again replaced it with a state entry tax on a similar base. At the time octroi was abolished, it accounted for 40 percent of the revenue of Bangalore (the capital of Karnataka) and up to 60 percent of the revenue of other urban areas in the state. The so-called octroi compensation grant introduced to make up for this loss did not demonstrate the same buoyancy (or responsiveness to local wishes) as the old tax, and by the late 1990s the need for local revenues, particularly in urban areas, led the state to consider reintroducing the octroi (Rao 1998). Indeed, Das-Gupta's (2002) study of the border check posts used to enforce octroi and entry tax suggests that in the absence of other appropriate subnational taxes and competent tax administration, even such costly and distorting tax enforcement techniques as check posts may be better than the available alternatives.

Octroi is also, or has been, important elsewhere in South Asia. For example, Zimmerman (1998) reports that 87 percent of local revenue in Nepal came from octroi. German Technical Cooperation (1999) notes that octroi in Nepal is supposed to be replaced by a local development fee to be levied by customs as a 1.5 percent tax on imports and distributed to municipalities by the central government. In Bangladesh octroi was abolished and replaced by a central grant that turned out to be a much less productive, reliable, and elastic source of revenue. In Pakistan urban local governments collected octroi until 1999, at which time it was replaced by a transfer based on 2.5 percent of general sales tax revenue.

\section{Brazil}

Local business taxes have a long history in Brazil, dating back to the early 19th century (Silveira 1989). The current tax, the imposto sobre servicios or tax on services (ISS), established in 1966, is levied on the gross receipts of independent professionals and firms in the service sector, although some important services, such as communications, finance, and transport, are excluded. Originally, some 79 specific services were subject to the tax, but this number has been extended over time. The municipality in which the service is provided levies the tax. Initially, national law limited both the base and the rates of the ISS, but in recent years local governments 
have had full rate autonomy within the maximum rate fixed by federal law. The application and enforcement of this tax varies widely around the country, with the more developed cities generally collecting relatively more. In Brazil as a whole, the ISS yielded 0.57 percent of GDP in 2001 , or almost 2 percent of total taxes collected, compared with 0.45 percent for the property tax, the other main source of local tax revenue (Wiesner 2002). Silveira (1989) suggests that even though the incidence of the tax is probably regressive and its effects on economic efficiency are questionable, to some extent these defects are not as bad as they seem, because the tax extends into the informal sector in a way that state and federal taxes do not. The existence of a large sector of the economy that is effectively not subject to direct taxation substantially influences assessments of the effects of different fiscal instruments on equity. For example, the real progressivity of a nominally progressive personal income tax that mainly affects wage earners, and which many high-income recipients seem to escape, may be low. Thus in countries like Brazil, an indirect tax on the service sector such as the ISS may in the end be as or more progressive as this sort of income tax.

\section{Other Latin American Countries}

Many other countries in Latin America have special local taxes on business. These taxes take two main forms: taxes on gross receipts or some form of patente (fixed tax). Argentina, for example, has a provincial tax on gross receipts at rates ranging from 1 to 12 percent. Nicaragua has a 1 percent tax on gross receipts. In Colombia the rate of the gross receipts tax (industria y comercio) ranges from 0.2 to 1 percent. In practice, these taxes are usually levied on an annual basis, that is, at a fixed amount calculated as the tax rate multiplied by the estimated tax base for the previous year, often as estimated by the taxpayer. Much of the revenue from such taxes often comes from a few sectors such as financial enterprises. The second common form of local business tax in Latin America is some form of tax on wealth, often called a patente. Chile, for example, imposes this tax at rates of 2.5 or 5 percent depending on the enterprise's estimated net wealth. Ecuador imposes a similar tax at a rate of 1 percent.

\section{South Africa}

An interesting local tax imposed in South Africa is the regional services council levy (Bahl and Solomon 2000). Like many local taxes around the world this tax, imposed mainly in urban areas, is levied at rates and on a base established by the central government. In Capetown, for example, it accounts for about one-third of revenues. The regional services council levy has two components: two-thirds of the revenue comes from a flat tax imposed on gross sales and the balance comes from a similar tax on payrolls. ${ }^{11}$ Bahl and Solomon's (2000) study criticizes almost every aspect of this tax, but somewhat paradoxically concludes that the combination of its low rates and its weak administration probably made it more or less acceptable. The tax's future is currently the subject of considerable discussion in South Africa.

\section{Kenya}

Kenya has recently undertaken a major reform of its local business tax system. The major local taxes levied specifically on business take the form of license fees. Such fees or charges, found in various forms in many countries, are in principle intended to serve both regulatory and revenue purposes-although these two objectives often conflict. Sometimes they are levied as flat

11. As mentioned earlier, Canadian provinces, like Australian and Mexican states, can also levy taxes on payrolls. While some portion of such taxes undoubtedly falls on business, at least in the short run, as a rule economists think such taxes are borne largely by workers in the long run. In the Canadian case, for example, Dahlby (1993) estimates that workers bear two-thirds of the tax. 
lump-sum charges; sometimes as charges that vary by the type, size, and location of the business; and sometimes as a proportion of sales, turnover, or income. As Kelly and Devas (2001) note, the latter approach is likely the best, but it is also the most complex to administer and the most likely to lead to problems of competition, not only between localities, but between levels of government, because higher-level governments generally already impose taxes on sales and income. For this reason, the 1999 Kenyan reform followed the second path, establishing a matrix of fixed charges that vary with business type and size.

Policymakers considered the previous form of license fees out-of-date, burdensome to business, and conducive to corruption. To reduce these problems the reform introduced the single business permit system. This system was intended to achieve several purposes: (a) to reduce compliance costs by streamlining business licensing procedures and eliminating multiple licensing of the same business, (b) to establish a more rational rate structure, and (c) to allow local authorities to exercise some discretion over rates by choosing from a range of permitted rate schedules. Under the previous system, fees had varied from place to place on a completely discretionary basis, and they had also varied from business to business with no apparent rationale. The result was that in one town the fee for a butcher might be twice that for a baker while the opposite was true in the next town. To reduce such unnecessary distortions the new schedules classify businesses into easily distinguishable broad categories, for example, traders operating in the open are taxed differently than those in temporary structures, and the latter in turn are distinguished from those with premises in permanent buildings. Traders are then further classified by number of employees and size of premises. Local rates are set by choosing a local base-level value, for example, K Sh 100, and then applying the established relative rate factors, which range from 2 for, say, small informal traders, to 100 for such enterprises as large, five-star hotels or manufacturers employing more than 50 people. Localities can choose from among 16 base levels. The system is apparently working well.

\section{Francophone Africa}

As in most African countries formerly ruled by France, the major form of local business tax in Côte d'Ivoire is the patente, a differentiated set of fixed taxes that vary by type, size, and location of a business. This tax, based on a pre-independence French tax, produces substantial revenue for local governments, for instance, about one-third of total revenues in Abijdan, but it is not particularly elastic, in part because the tax schedules are not indexed, and hence the effective rate falls with inflation (World Bank 1989). The tax is based in part on fixed amounts differentiated by type of activity, number of employees, and so on and in part takes the form of a property tax based on the rental value of premises. A similar tax exists in Morocco, where six tax rates are applied to several hundred categories of businesses classified by rental value, type of business, and nature and quantity of inputs used (Vaillancourt 1998). For example, a dentist's office is taxed at different rates depending on the number of chairs. In contrast, in Tunisia the business tax is levied at a rate of one-fifth of 1 percent on gross business income (up to a maximum). A problem with this tax is that businesses do not provide a breakdown of their activities by locality, so that cities with head offices obtain most revenues. To deal with this problem, in 1997 revenues were allocated on the basis of the square meters of premises used. In both countries, as is common in francophone Africa, all tax rates are set nationally. In principle, the patente is simple to administer because it is based on visible indicators such as size of premises, type of business, and number of employees. ${ }^{12}$ In practice, however, it is

12. Note that this resembles the structure of some forms of imputed and presumptive national taxes. Other such taxes amount to gross receipts taxes. For a recent review of such taxes see Wallace (2002). The similarity between presumptive taxation and many of the issues arising with respect to local business taxes, for example, the extent to which such taxes really tax the indicators (number of employees, size of premises), deserves more attention. 
cumbersome because of its complex structure, the need to update the taxpayer register each year, and the fragmentation of administration between several different agencies. Even though it is a local tax in the sense that all the revenues go to the local government, the patente is actually administered by the central government. The patente is supplemented in most countries that have it by other, less important, forms of local business taxation, such as a tax on small crafts people and traders and professional and business license fees. The latter are also often differentiated by activity, for example, they are higher for businesses selling alcohol.

\section{Appraisal of Local Business Taxes}

As the previous section illustrates, local business taxation is characterized by great variety. Some countries rely mainly on taxes on profits and property, some on various forms of sales taxation, some on a range of specific charges and fees. How can one appraise this diverse variety of levies? As table 11.1 suggests, a number of criteria can be used for this purpose. Even though the entries in the table are essentially subjective, it is hard to avoid concluding that most local taxes on business do not score well in terms of many criteria. Few such taxes are equitable; almost none are neutral; all accentuate rather than reduce disparities between localities, giving most to those who have most; most lend themselves to tax exporting, thereby violating the correspondence principle that those who pay should be those who benefit; and most are costly to administer, especially if the costs of compliance and the facility with which the tax can serve as the basis for corrupt transactions are taken into account.

Nevertheless, local business taxes thrive around the world precisely because many of them score highly on some of the other criteria. Such taxes are, for example, highly politically acceptable, in part because no one knows who really pays them, but many people think someone else does. Local business taxes also provide an important, and relatively elastic, source of revenue, particularly for larger cities. Finally, in many countries local business taxes, defective as they often are in design and execution, provide one of the few ways in which local governments have any degree of fiscal autonomy. ${ }^{13}$

The question is therefore to what extent countries can realize the virtues of local business taxation-essentially revenues and autonomy-while minimizing such vices as economic distortions, high administrative costs, and lack of adherence to the correspondence principle. While the low rates of most such taxes dampen these problems, the next section describes two possible approaches to local business taxation aimed at minimizing the problems, one primarily for the local level and one primarily for the regional level of subnational government.

No matter how well designed, however, no form of local business taxation can overcome two fundamental problems. First, any tax on business will obviously give more revenues to those jurisdictions that have a greater tax base. It will therefore accentuate fiscal disparities among regions and localities, and partly to offset this effect, many countries have introduced some equalization component in intergovernmental transfers (see Bird and Smart 2002). Second, even though one of the virtues of local business taxation is that it is politically acceptable, this virtue is almost inescapably accompanied by two potential vices: some weakening of the correspondence principle and a consequent increase in the lack of clarity about the equity of local taxation.

The first of these weaknesses is much more important, although in principle it is simple to overcome by introducing clear political responsibility for the taxes imposed at the local level, for example, by allowing local governments some degree of discretion with respect to tax rates. Even when central governments collect taxes on bases those governments determine, political

13. Note that table 11.1 does not consider user charges, which are almost always the most desirable way for local governments to raise revenue (see Bird 2001b). 
Table 11.1 Evaluation of Local Business Taxes

\begin{tabular}{|c|c|c|c|c|c|c|}
\hline Criterion & $\begin{array}{c}\text { Property tax higher } \\
\text { than on residential } \\
\text { property }\end{array}$ & Income tax & Gross sales tax & VAT & Taxes on trade & Patente/licenses \\
\hline Revenue adequacy & Potentially yes & Unlikely & Yes & $\begin{array}{l}\text { Yes, at the regional } \\
\text { level }\end{array}$ & Yes & $\begin{array}{l}\text { Perhaps at the local } \\
\text { level }\end{array}$ \\
\hline Revenue buoyancy & No & Yes & Yes & Yes & Yes & Perhaps if indexed \\
\hline $\begin{array}{l}\text { Correspondence of } \\
\text { payers and } \\
\text { beneficiaries }\end{array}$ & Not high & Not high & Not high & $\begin{array}{l}\text { Potentially } \\
\text { satisfactory }\end{array}$ & Not high & $\begin{array}{l}\text { Potentially } \\
\text { satisfactory }\end{array}$ \\
\hline Compliance costs & Not high & Medium & Low & Higher than sales tax & Very high & $\begin{array}{l}\text { Probably moderate } \\
\text { if well designed }\end{array}$ \\
\hline $\begin{array}{l}\text { Latitude for } \\
\text { corruption }\end{array}$ & Moderate & $\begin{array}{l}\text { Probably high in } \\
\text { most countries }\end{array}$ & Moderate & Moderate & Very high & High \\
\hline Distortionary impact & Moderate & Moderate & High & Low & High & Low \\
\hline
\end{tabular}

Source: Author. 
accountability can be achieved so long as the subnational government that receives and spends the revenues is clearly responsible to its citizens for setting the tax rates. In some instances, local rate discretion may need to be limited, however, especially with respect to business taxes. To reduce tax exporting and maintain the correspondence principle, imposing a maximum rate may be desirable. At the same time, however, when differences in the tax base from locality to locality are large, as is usually the case with business taxes, imposing a minimum rate might be advisable to restrict the ease with which areas with larger tax bases may be able to attract the tax base from other areas by imposing lower tax rates.

As for the second weakness, even though most local business taxes are somewhat regressive, the equity of local taxation is much less important than some people think. From many perspectives, local governments can be considered as entities that provide services to residents, so that the appropriate equity perspective is the benefit principle rather than the ability to pay principle, as argued in detail elsewhere (Bird 1993). Even from the latter perspective, the equity issue may be addressed by means of two different approaches. The first approach considers the details of the relative treatment, in law and in practice, of the tax burdens imposed on taxpayers in the same and different economic circumstances. The second approach focuses on the overall effects of taxation on people's income and well-being. Economists tend to take the second approach, while much popular discussion of taxation takes the first approach.

The policy implications of these two different ways of approaching the equity of taxation can differ. Focusing on the implications for equity of details of particular taxes tends to result in proposals to alter the rates and structures of particular taxes. Such proposals, even though they might improve horizontal and vertical equity within the limited group actually subject to the full legal burden of the tax in question, may at the same time actually exacerbate broader inequity. From the perspective of social and economic inequality, what matters in the end is the overall impact of the budgetary system on the distribution of wealth and income. The precise incidence of specific local government taxes seldom is important in this context, and excessively complicating the system in terms of economic, administrative, and compliance costs in an attempt to achieve miniscule, if any, gains in equity terms would be a mistake.

\section{Two Approaches to Local Business Taxation}

Many countries have at least two levels of subnational government, one at the regional level and one at the local level. Each of these levels may wish to impose taxes on business, but the best way to do so may differ. Local governments, particularly the smaller ones, have fewer avenues for such taxation open to them than larger regional governments. While countries' circumstances vary, describing two ideal approaches to subnational business taxation may be useful, one applicable to smaller, lower-level, local governments and one more suitable for larger regional (or metropolitan area) governments.

The smaller the government, the more closely it is likely to adhere to the benefit model mentioned earlier; therefore the ideal form of business taxation for local governments would appear to be a system that is as benefit related as possible. In addition to imposing properly designed user charges, such governments might therefore consider a system of business licenses like that recently introduced in Kenya (Kelly and Devas 2001). In some instances supplementing, or perhaps even replacing, such a system with a low-rate gross receipts levy, such as that in Tunisia (Vaillancourt 1998), might be desirable.

The advantage of the Kenyan system is that it is based on objective evidence, that is, information that should be readily visible to tax assessors. The disadvantage is that the need for direct contact between assessors and taxpayers opens the process to corruption. Another disadvantage is that such taxes often tend to become irrationally differentiated between different activities and businesses of different sizes, again opening the door to complexity and corruption. The advantage of the Tunisian system is that it is less distortionary, because it is not a tax 
on specific inputs, but it is essentially self-assessed, and hence open to evasion. Low-rate taxes on gross receipts may also give rise to problems of interjurisdictional apportionment and may, like the business license approach, sometimes evolve into highly differentiated, and in all likelihood distorting, systems. Either approach may be acceptable at relatively low rates, and determining which path, if either, is best for any specific country requires careful study and assessment.

In contrast, at the regional level, and perhaps also for larger metropolitan local governments, in theory the best form of business taxation is a broadly based levy neutral to factor mix, such as a tax on value added. As Sullivan (1965) points out, the original concept of the VAT was as a business benefit tax. The most appropriate form of VAT for this purpose is a value added income tax or a VAT based on income rather than the usual consumption VAT, as set out in, for example, Ebrill and others (2001). ${ }^{14}$

Businesses add value by combining labor and capital with other purchased inputs. The value added by labor is the cost of labor (wages and salaries), while the value added by capital is the cost of capital (both debt and equity). The base of the local business tax that Bird and Mintz (2000) call the business value tax (BVT) consists of revenues, less purchases of current inputs except labor, less depreciation allowances. From an administrative perspective, such a tax base could be calculated in two ways. The first is simply to add back the appropriate amounts of interest and wages to the base of a business income tax as usually calculated. The second is to impose a payroll tax and an appropriate tax on capital, and the easiest way to do this in most countries is to tax the same base as a VAT. ${ }^{15}$

Compared with a conventional VAT, a BVT has two important distinguishing features. First, it is a tax on income, not consumption, that is, it is imposed on profits as well as wages or, to put it another way, on investment as well as consumption. ${ }^{16}$ Second, as a tax on production rather than on consumption, it is imposed on an origin rather than a destination basis, and thereby taxes exports but not imports.

As a replacement for many existing local and regional business taxes, which in effect tax capital to a substantial extent, an income-based BVT would improve the tax system in at least two ways. First, such a tax would be more neutral than income and capital taxes, which discriminate against capital investment. Second, a BVT would be less susceptible to base erosion. The tax rate would be lower and the base larger and unaffected by the degree of debt financing. Economic distortion costs would therefore be lower. Taxes of the BVT type are sometimes criticized (as in the case of the German and Michigan taxes discussed earlier), because they do not sufficiently resemble income taxes in that they have to be paid whether a company makes profits or not, but this is precisely one reason why they are much more efficient taxes. Moreover, to the extent that the rationale for taxing business rests on benefit or entitlement grounds, a BVT is more equitable than an income tax.

Even though the efficiency gains from switching to a BVT at the local or regional level may be substantial in principle, many countries would face difficulties in implementing such a

14. Many analysts in the United States have reached a similar conclusion. For two recent examples see Ebel (2000) and Papke (2000).

15. Although the two approaches are effectively identical for a fully taxpaying firm, they may differ for nontaxpaying firms depending on the nature of loss offsetting. Under the second approach all firms will pay taxes regardless of their profitability. Under the first approach firms could be in a loss position and therefore not pay the BVT in a particular year.

16. Note that if capital is expensed rather than depreciated, the business value tax becomes a consumption-based rather than income-based tax. Financial income would not be included in the tax base and interest on borrowed funds would not be deductible. A special regime would therefore be necessary with respect to financial institutions and insurance companies, because most of their value added would not be included in the tax base. Presumably countries would need to levy a combination of capital and payroll taxes on this sector, as Israel does for its VAT, for example. 
proposal, for instance, in relation to resolving the numerous detailed definitional issues. For low-rate local business taxes the need for such adjustments is reduced, and any rules introduced for these purposes could be highly simplified.

An important coordination issue needs to be resolved, however. Ideally, the tax base should be identical everywhere to facilitate compliance with and administration of the BVT. Even if it is, the allocation formula for business value added must also be determined. Businesses that operate in only one region (province, state) or one locality (municipality, district) would be taxed solely by that jurisdiction. In principle, value added earned in more than one jurisdiction would need to be allocated according to formula weights based on such factors as payroll, sales (on an origin basis), capital, or some combination thereof (see Gordon 1986 for a discussion of this apportionment problem with state origin-based VATs). As Smith (1998) documents in the case of provincial business taxes in Canada, negotiations about who gets what tax base are never easy, but they can be successful. Indeed, as Bird and McKenzie (2001) argue in relation to the Canadian case, while a number of difficult points have to decided in designing a BVT, none of them seem to be unsolvable in either principle or practice. Moreover, as the status quo seems to be increasingly unsatisfactory in many countries, adequate solutions may perhaps be found more readily with the BVT than by tinkering further with the existing imperfect taxes.

In any case, subnational governments around the world do, and probably always will, tax business. Doing so through a BVT is less distorting than through most other possible local business taxes and it deserves consideration for this reason.

\section{Conclusion}

Local business taxes, like the weather, are always with us and always a matter for discussion, and often dissatisfaction. Unlike the weather, however, we can do more than deplore unfortunate outcomes. Both the design and the implementation of local business taxation can be substantially improved in most countries. This chapter has suggested two broad approaches toward improving local business taxation: developing a more strictly benefit system of business licenses and fees on the one hand, and developing a more neutral, uniform variety of VAT, the BVT, on the other hand. As table 11.1 suggests, neither approach is without flaws, but together or separately they appear more likely to yield satisfactory results than the many other forms of local and regional business taxation now found around the world.

\section{References}

The word processed describes informally reproduced works that may not be commonly available through libraries.

Advisory Commission on Intergovernmental Relations. 1978. The Michigan Single Business Tax. Washington, D.C.

Bahl, Roy, and David Solomon. 2000. "The Regional Services Council Levy: Evaluation and Reform Options." Georgia State University, Atlanta.

Bennett, Robert, and Gunter Krebs, eds. 1988. Local Business Taxes in Britain and Germany. Baden-Baden, Germany: Nomos Verlagsgesellschaft.

Bird, Richard M. 1991. “Tax Structure and the Growth of Government.” In Lorraine Eden, ed., Retrospectives on Public Finance. Durham, North Carolina: Duke University Press.

1992. “Taxing Tourism in Developing Countries." World Development 20(August): $1145-58$.

1993. "Threading the Fiscal Labyrinth: Some Issues in Fiscal Decentralization." National

Tax Journal 46(June): 207-27. 
. 2001a. Intergovernmental Fiscal Relations in Latin America: Policy Designs and Policy Outcomes. Washington, D.C.: Inter-American Development Bank, Sustainable Development Department.

. 2001b. "User Charges in Local Government Finance." In Richard Stren and Maria Emilia Freire, eds., The Challenge of Urban Government. Washington, D.C.: World Bank Institute.

. 2002. "Why Tax Corporations?" Bulletin for International Fiscal Documentation 56(5): 194-203.

Bird, Richard M., and Pierre-Pascal Gendron. 1998. "Dual VATs and Cross-Border Trade: Two Problems, One Solution?" International Tax and Public Finance 5(3): 429-42.

Bird, Richard M., and Kenneth J. McKenzie. 2001. Taxing Business: A Provincial Affair? Commentary no. 154. Toronto: C. D. Howe Institute.

Bird, Richard M., and Jack M. Mintz. 2000. "Tax Assignment in Canada: A Modest Proposal." In Harvey Lazar, ed., Canada: The State and the Federation 1999/2000. Toward a Mission Statement for Canadian Fiscal Federalism. Kingston, Ontario: Institute of Intergovernmental Relations.

Bird, Richard M., and Michael Smart. 2002. "Intergovernmental Fiscal Transfers: International Lessons for Developing Countries." World Development 30(6): 899-912.

Bird, Richard M., and Thomas Tsiopoulos. 1997. “User Charges for Public Services: Potentials and Problems." Canadian Tax Journal., 45(1): 25-86.

Bordignon, Massimo, Silvia Gianni, and Paolo Panteghini. 2001. “Reforming Business Taxation: Lessons from Italy?" International Tax and Public Finance 8(2): 191-210.

Brazer, Harvey E. 1977. "Michigan's Single Business Tax: Theory and Background." In Stanley J. Bowers, ed., Proceedings of the 69th Annual Conference on Taxation. Louisville, Ky.: National Tax Association and Tax Institute of America.

Buettner, Thiess. 1999. "Determinants of Tax Rates in Local Capital Income Taxation: A Theoretical Model and Evidence from Germany." Working Paper no. 194. Center for Economic Studies and Ifo Institute for Economic Research, Munich.

2001. "Local Business Taxation and Competition for Capital: The Choice of the Tax Rate" Working Paper no. 440, Center for Economic Studies and Ifo Institute for Economic Research, Munich.

Chirinko, Robert, Steven Fazzari, and Andrew Meyer. 1999. "How Responsive Is Business Capital Formation to Its User Cost? An Exploration with Micro Data." Journal of Public Economics 74: 53-80.

Cummins, Jason, Kevin Hassett, and Glenn Hubbard. 1998. “Tax Reforms and Investment: A Cross-Country Comparison." Journal of Public Economics 62: 237-73.

Dahlby, Bev. 1993. “Payroll Taxes.” In Alan Maslove, ed., Taxing Business. Toronto: University of Toronto Press.

2000. Tax Reform and Economic Growth in Alberta. Calgary, Alberta: Canada West Foundation.

Das-Gupta, Arindam. 2002. "Internal Fiscal Barriers in India: Check Posts." Indiraa Gandhi Institute of Development Research, Mumbai, India. Processed.

Dell'Anese, Luca. 1997. “Italy Introduces New Regional Tax." Tax Notes International, November 17, pp. 1589-90. 
Department for Economic Development of Entrepreneurship. 2002. Simplified Taxation Regimes: Application Practices and Development Trends. Kyiv, Ukraine.

Devereux, Michael, and Rachel Griffith. 1998. "Taxes and Location of Production: Evidence from a Panel of U.S. Multinationals." Journal of Public Economics 68: 335-67.

Ebel, Robert D. 1972. The Michigan Business Activities Tax. East Lansing, Michigan: Michigan State University, School of Business Administration, Division of Research.

. 2000. "Robert Ebel on Tax Reform, Federalism, and Sound Tax Policy." State Tax Notes, May 29, pp. 1877-79.

Ebrill, Liam, Michael Keen, Jean-Paul Bodin, and Victoria Summers 2001. The Modern VAT. Washington, D.C.: International Monetary Fund.

Edwards, J. S. S., and Michael Keen. 1996. “Tax Competition and Leviathan." European Economic Review 40: 113-40.

Feehan, James P. 1998. "Public Investment: Optimal Provision of Hicksian Public Inputs." Canadian Journal of Economics 31: 693-707.

German Technical Cooperation. 1999. Urban Development through Local Efforts. Kathmandu, Nepal.

Gillespie, W. Irwin. 1991. Tax, Borrow, and Spend. Ottawa: Carleton University Press.

Gordon, Roger H. 1986. "A Critical Look at Formula Apportionment." In Final Report of the Minnesota Tax Study Commission. St. Paul, Minnesota: Butterworths.

Gropp, Reint E. 2002. “Local Taxes and Capital Structure Choice.” International Tax and Public Finance 9(1): 51-71.

Helliwell, John, and Ross McKitrick. 1999. “Comparing Capital Mobility Across Provincial and National Borders." Canadian Journal of Economics 32(5): 1164-73.

Hettich, Walter, and Stanley Winer. 1999. Democratic Choice and Taxation Cambridge, U.K.: Cambridge University Press.

Hines, James R., Jr. 2002. “Michigan's Flirtation with the Single Business Tax.” University of Michigan, Ann Arbor, Mich. Processed.

Keen, Michael. 2003. “Tax Reform in Italy.” Tax Notes International, February 17, pp. 665-82.

Kehoe, Patrick. 1989. "Policy Cooperation among Benevolent Governments May Be Undesirable." Review of Economic Studies 56: 289-96.

Kelly, Roy, and Nick Devas. 2001. “Regulation or Revenues? An Analysis of Local Business Licensing, with a Case Study of the Single Business Permit in Kenya." Public Administration and Development., 21: 381-91.

Kenyon, Daphne. 1996. "A New State VAT? Lessons from New Hampshire." State Tax Notes, December 2, pp. 1605-15.

Kitazato, Toshiaki. 2002. "Japanese Fixed Property Tax." Paper prepared for the World Bank, Washington, D.C. Processed.

Kitchen, Harry, and Enid Slack. 1993. "Business Property Taxation." Government and Competitiveness Paper no. 93-24, Queen's University, School of Policy Studies, Kingston, Ontario.

Kuo, C. Y., T. McGirr, and S. Poddar. 1988. "Measuring the Non-Neutralities of Sales and Excise Tax in Canada." Canadian Tax Journal., 36(3): 655-70. 
Lungu, Iurie. 2002. "Official Proposes Exempting Small Businesses from Tax." Tax Notes International October 21, pp: 246.

Maisto, Guglielmo. 1997. "Italy Introduces Regional Tax on Productive Activities." Tax Notes International, March 31, pp. 1029-31.

McIntyre, Michael J. 2002. "Thoughts on the Future of the State Corporate Income Tax." State Tax Notes, September 23, pp. 931-47.

McLure, Charles E., Jr. 1981. “The Elusive Incidence of the Corporate Income Tax: The State Case." Public Finance Quarterly 9(October): 395-413.

2000. "Source-Based Taxation and Alternatives to the Concept of Permanent Establishment." In 2000 World Tax Conference Report. Toronto: Canadian Tax Foundation.

McLure, Charles E., Jr., and Peter Mieszkowski, eds. 1983. Fiscal Federalism and the Taxation of Natural Resources. Lexington, Massachusetts: Lexington Books.

McQuillan, Peter E., and E. Cal Cochrane. 1996. "Capital Tax Issues.” Working Paper no. 96-8. Department of Finance, Technical Committee on Business Taxation, Ottawa.

Messere, Ken. 1993. Tax Policy in OECD Countries. Amsterdam: IBFD Publications.

Mintz, Jack M., and Henry Tulkens. 1986. “Commodity Tax Competition between Member States of a Federation: Equilibrium and Efficiency." Journal of Public Economics 29: 133-72.

Oakland, William H., and William A. Testa. 1995. "Community Development-Fiscal Interactions: Theory and Evidence from the Chicago Area." Working Paper Series. Federal Reserve Bank of Chicago, Research Department, Chicago.

OECD (Organisation for Economic Co-operation and Development). 2000. Economic SurveysHungary. Paris.

Ontario Fair Tax Commission. 1993. Fair Taxation in a Changing World. Toronto: University of Toronto Press.

Papke, James A. 2000. “Rethinking Local Business Taxation: Substituting a State Value Added Tax for the Local Ad Valorem Tax on Business Personal Property." State Tax Notes, February 28, pp. 669-82.

Pola, Giancarlo, ed. 1991. Local Business Taxation: An International Comparison Milan, Italy: Vita e Pensiero.

Prud'homme, Remy. 1992. "Informal Local Taxation in Developing Countries." Environment and Planning C: Government and Policy 10(1): 1-17.

Purohit, Mahesh C. 1998. "Recalling Octroi and Its Implications: A Case of Karnataka." In M. N. Rao, ed., Octroi: Pros and Cons. Bangalore, India: AIUD Trust.

Rao, M. Govinda. 1984. Entry Tax as an Alternative to Octroi. New Delhi: National Institute of Public Finance and Policy.

Rao, M. Nageswara, ed. 1998. Octroi: Pros and Cons. Bangalore, India: Asia Institute of Urban Development.

Ring, Raymond J. 1999. "Consumers' Share and Producers' Share of the General Sales Tax." National Tax Journal 52(1): 81-92.

Silveira, Ricardo. 1989. “The Local Tax on Services in Brazil” Working Paper no. 7. World Bank, Policy Planning and Research Staff, Urban Development Division, Washington, D.C.

Smith, Ernest H. 1998. Federal-Provincial Tax Sharing and Centralized Tax Collection in Canada. Toronto: Canadian Tax Foundation. 
Smith, Paul A., and Jennifer Gann. 1998. “U.S. IRS to Allow Partial Credit for New Italian Local Tax." Tax Notes International, April 13, pp. 1114-15.

Sorensen, Peter Birch. 1995. "Changing Views of the Corporate Income Tax." National Tax Journal., 48(2): 279-94.

Sullivan, Clara K. 1965. The Tax on Value Added. New York: Columbia University Press.

Szalai, Akos, and Almos T. Tassonyi. 2002. "Value-Based Property Taxation: Options for Hungary." Toronto. Processed.

Thirsk, Wayne R. 1982. "Political Sensitivity Versus Economic Sensibility: A Tale of Two Property Taxes." In Wayne R. Thirsk and John Whalley, eds., Tax Policy Options in the 1980s. Toronto: Canadian Tax Foundation.

Vaillancourt, François. 1998. "'Morocco and Tunisia: Financing Local Governments: The Impact on Infrastructure Finance." In Richard M . Bird and François Vaillancourt, eds., Fiscal Decentralization in Developing Countries. Cambridge, U.K.: Cambridge University Press.

Wallace, Sally. 2002. "Imputed and Presumptive Taxes: International Experiences and Lessons for Russia." Working Paper no. 02-03. Georgia State University, Andrew Young School of Public Policy, International Studies Program, Atlanta.

Whalley, John. 1997. "Efficiency Considerations in Business Tax Reform." Working Paper no. 97-08. Department of Finance, Technical Committee on Business Taxation, Ottawa.

Wiesner, Eduardo. 2002. "Bank Lending for Subnational Development: The Policy and Institutional Challenges." Inter-American Development Bank, Office of Evaluation and Oversight, Washington, D.C. Processed.

Wilson, John. 1999. “Theories of Tax Competition.” National Tax Journal 52(2): 269-304.

World Bank. 1989. “The Administration of the Patente in the Côte d'Ivoire." Washington, D.C. . 2002. “Ukraine: Tax Policy and Administration." Washington, D.C. Processed.

Zimmerman, Horst. 1998. Strengthening Local Government Finance: Principles of Fiscal Decentralization and Nepal Case Study. Escheim, Germany: German Technical Cooperation. 


\title{
12
}

\section{Fiscal Federalism and the Taxation of Nonrenewable Resources}

\author{
Kenneth J. McKenzie
}

This chapter discusses selected issues that arise in connection with the taxation of nonrenewable resources from a fiscal federalism perspective. There are at least two reasons for singling out exhaustible resources for special attention in this regard. Both of them relate to the essence of nonrenewable resources in that they are inherently limited in total supply and they tend to be distributed unevenly across geographical regions.

The fact that exhaustible resources are fixed in total supply suggests that they have the potential to generate economic rent. Economists are familiar with the concept of economic rent, but noneconomists often view it with some suspicion. However, this notion is vital to understanding the taxation of nonrenewable resources.

Economic rent is simply the return to a resource that is fixed in total supply. It is measured as the difference between the gross revenues received from selling the resource and the economic cost of extracting it. The economic cost of extracting a resource is equal to the opportunity cost of the inputs employed in the extraction. The opportunity cost of an input is the return that is forgone by using the input to produce the resource rather than employing the input in some other activity. For some inputs the opportunity cost is relatively easy to measure. For example, the opportunity cost of labor employed in the production of a natural resource consists simply of the wages paid to the workers. In a reasonably well-functioning labor market, these wages reflect the need to pay the workers a reasonable salary to keep them away from alternative occupations and uses of their time, and perhaps an amount needed to compensate them for difficult working conditions associated with the extraction of natural resources.

The opportunity cost of other inputs is more difficult to measure. For example, one of the more important opportunity costs in the capital-intensive resource sector is the return required on the capital employed in the extraction of the resource. That capital could be employed in some other activity or location, and could generate income accordingly. To attract it to the natural resource sector in a particular location, the capital must generate a return that is at least as high as the return that the capital could earn if employed in some other activity, or location, with a similar risk profile. That forgone return, plus any decline in the value of the capital due to physical depreciation and/or changes in its price, is the opportunity cost of capital employed in the resource sector.

Economic rent consists of the revenues generated from the resource in excess of the opportunity cost of the labor, capital, and other inputs employed in its extraction. Economists are interested in the economic rent generated by a nonrenewable resource for two reasons.

The first reason is motivated by pure tax policy considerations. There are both efficiency and equity reasons for imposing taxes on the economic rent generated by the extraction of nonrenewable resources. From an efficiency perspective, the existence of rent enables tax revenue to be raised in an efficient, or nondistortionary, manner. Because economic rent represents compensation in excess of the costs required to bring the resource into production, the government may claim a portion of those rents without inhibiting or distorting the production of the resource. Taxes on pure economic rents are said to be economically neutral or 
nondistortionary. Neutral taxes are generally desirable because, in the absence of other distortions in the marketplace, taxes that distort economic decisions impose real costs on the economy by providing an incentive for firms and individuals to alter their choices and efforts in an inefficient manner. Tax policy analysts often assume that the government faces the dilemma of choosing between "heavy taxes," which raise significant revenue but are extremely distortive, and "light taxes," which are nondistortive but generate little revenue. The presence of economic rent offers a way out of this dilemma, at least partly, because significant revenue can be raised in a neutral manner.

Taxing economic rent is also compelling from an equity perspective. Because the economic rent of a nonrenewable resource is equal to its value after all necessary costs have been recovered, there are strong grounds for the government to claim at least a portion of that rent on behalf of the community. Because governments typically rely, at least to some extent, on private companies to help exploit the resource, taxes are an obvious way to extract this value (price controls and regulations are others). There are no reasons-economic, moral, ethical, or otherwise-why economic rent should accrue exclusively to the shareholders (as the owners of capital) or to the workers of the companies that extract the resources. Remember that rent accrues only after the owners of the companies and their workers have been compensated for their efforts in accordance with market prices that reflect the relative scarcity of the inputs used to produce the resource.

Much research on the taxation of natural resources has focused on the extent to which different types of taxes approximate nondistortionary taxes on economic rent. To the extent that they do not, the emphasis has been on what types of distortions the various types of taxes may introduce.

The second reason that economists are interested in resource rent concerns how that rent is allocated among different governments. Given that, as discussed previously, there are good tax policy reasons for the government to claim a portion of the rent generated by nonrenewable resources on behalf of the community, the question of which government and which community-local, state, or national—naturally arises. Exploring this question involves the study of fiscal federalism.

Two related concepts are relevant in this regard. The first concerns the degree of fiscal decentralization, or the extent to which various levels of government have the power to levy taxes on the rents generated by nonrenewable resources. A key question relates to the implications of assigning the ability to levy taxes on a resource to the subnational government (state or provincial) rather than the national (federal) government, and vice versa. The fact that nonrenewable resources tend to be concentrated in specific geographical regions within a country gives rise to the second issue: revenue sharing. Aside from the question of which level of government is responsible for initially imposing taxes on the nonrenewable resource is the question of how those resource rents should be shared, not only between levels of government, but between governments at the same level.

This suggests the need to consider the role of revenues from resource taxation within the context of intergovernmental transfers through an equalization system or other such mechanism. Although this chapter does not directly address the role of resource revenues in this connection, the idea of sharing economic rents arising from natural resources across jurisdictions permeates much of the discussion that follows.

The intent of this chapter is not to provide a survey of various approaches to the taxation of natural resources in various countries. This type of survey has been done many times by practitioners with specific expertise in the area (see, for example, Kemp 1994; Otto 2000). Nor is the intent to provide a survey of the literature in fiscal federalism applied to emerging capitalist economies. This topic too has received significant attention elsewhere (see, for example, Boadway, Roberts and Shah 1994; Shah 1994). Rather, this chapter focuses on a few key issues related to natural resource taxation within a federation and illustrates how some simple economic 
concepts can shed light on those issues. The level of analysis is intended to provide individuals with only a little formal training in economics a sense of the fundamental insights economic analysis can add to an understanding of natural resource taxation in a fiscal federalism context. The remainder of this chapter is structured as follows: The next section emphasizes tax policy issues, temporarily setting aside issues related to fiscal federalism and the distribution of resource tax revenue. This condensed discussion sets up the analysis in the second section. The third section reviews some of the international experience regarding the allocation of tax powers associated with natural resources.

\section{Resource Taxation}

The bulk of research on the economics of resource taxation focuses on the extent to which various types of taxes approximate taxes on economic rent. This preoccupation with the distortionary effects of resource taxes does not necessarily imply a belief that tax neutrality is always a desirable policy objective, but a recognition that neutrality is the boundary between policies that encourage some type of activities and policies that discourage them. Governments may well have reasons to intervene in private markets for exhaustible resources on efficiency grounds if the economy exhibits other distortions that the government is seeking to correct.

For example, resource extraction may proceed too rapidly because of common property problems or too slowly if markets are not competitive. Extraction paths for the resource may not be optimal from a social perspective, and firms may undertake too much or too little processing of the raw natural resource if the government's social discount rate and firms' private discount rate differ. There may also be environmental externalities (such as pollution), or informational spillovers associated with natural resources exploration and development activities. For all these reasons, and others, the government may seek to undertake corrective actions using the tax system. Nonetheless, if economists are to make meaningful policy prescriptions, an understanding of the characteristics of the neutral boundary is important.

Nonrenewable resources tend to be subject to a myriad of special taxes, much more so than other sectors. The taxes typically levied on the resource industry may be classified as follows:

- Severance taxes, levied on a per unit basis either on the amount of the raw resource extracted or on the amount of processed or refined material produced

- Gross royalties, determined as a percentage of gross sales

- Net royalties, similar to gross royalties but allowing for the deduction of selected costs

- Income taxes, similar to net royalties, but allowing for the deduction of more costs based on a broader notion of profits earned by the firm

- Resource rent taxes, levied on the present value of the resource

- Property taxes and various franchise and license fees.

These taxes can distort, to varying degrees, all sorts of decisions regarding the exploitation and development of nonrenewable resources, including

- The time profile of extraction

- The exploration and development decision

- The choice of factor mix and production structure, including the relative use of labor, capital, and energy in the mix of nonresource inputs

- The degree of processing of the resource once it is extracted

- The choice of the optimal cutoff grade and intertemporal grade selection profile.

This chapter focuses on how selected taxes distort perhaps the most fundamental decision regarding the natural resource: the extraction decision.

The time profile of extraction is fundamental, because this is what determines the intergenerational allocation of the returns to the resource stock. For pedagogical purposes, and to focus 
the discussion squarely on the timing decision, consider the following simple state of affairs. A single firm has the right to exploit a fixed, known deposit of a resource of homogenous quality that requires no processing beyond extraction and that can be extracted at a constant per unit cost. In this overly simplistic case, the firm will exhaust the entire reserve and the only decision involves the rate at which it should extract the reserves. Despite its obvious limitations and abstractions, this simple model generates some illuminating insights.

Assume, for example, that the resource in question is oil. The assumption is that the firm will choose an extraction path for the oil that will maximize the present discounted value of the profits generated from the oil reservoir. To do this, the firm will choose a time profile for extracting the resource that follows a simple rule: it will allocate the extraction of the oil over time so that the present value of the profits generated by the extraction of one more barrel of oil, discounted back to the current period, is the same over all periods. To see that this decision rule constitutes the optimal, value-maximizing, extraction policy for the firm, consider a situation where this is not the case: assume that the present value of extracting an additional barrel of oil next year is greater than the present value of extracting that barrel this year. In this case, the firm could increase the present value of its profits by delaying production and shifting the extraction of the barrel of oil from this year to next year. Only when the firm has chosen a time profile in which the present value of the profits on the extraction of an additional barrel of oil is the same in all time periods can it no longer increase the present value of the profits from the oil reservoir by undertaking this sort of intertemporal reallocation. This simple rule is key to understanding how various types of taxes may distort the extraction profile by either speeding up or slowing down the rate of extraction.

Consider the imposition of some sort of tax on the production of oil from the reservoir. The pre- and post-tax extraction paths will be the same (and therefore the tax will be nondistortionary or neutral) only if the present value of the tax levied on the production of an incremental barrel of oil is the same in all periods. This requires the rate of increase in the tax levied on an additional barrel of oil to be equal to the rate at which the firm discounts profits back to the current time period. If the tax on an additional barrel of oil increases at a rate that is higher than the firm's discount rate, the tax will increase in present value terms over time, and producers will have an incentive to accelerate extraction to lower the present value of their tax payments. They will move extraction from the future to the present to lower the present value of their tax payments. The opposite is true if the tax on an incremental unit increases at a rate that is less than the firm's discount rate; in that case extraction is delayed.

What is the firm's discount rate? In simple terms, it is the rate of return that the firm could earn by investing the proceeds from the extracted resource elsewhere. In simple models with no risk or uncertainty and no other market failures, the discount rate is simply equal to the interest rate. However, in more complicated and realistic models, the interest rate must be adjusted to reflect risk, and perhaps other market imperfections.

Based on this reasoning, the following subsections assess the impact of various types of taxes on the extraction decision.

Severance taxes are levied at a constant dollar amount per unit of output, for example, US $\$ X$ per barrel. The amount of tax collected per barrel is the same in every period, and the tax acts just like a constant dollar reduction in the price of the oil. This means that the rate of increase in the tax on an incremental barrel of oil is zero. Using the reasoning outlined earlier, the present value of the tax declines over time, and the firm can lower the present value of the severance taxes it pays by reallocating extraction from the present to the future. Thus per unit severance taxes tilt the extraction profile from the present to the future by providing an incentive for firms to delay extraction.

Gross royalties are determined as a constant percentage of gross revenue. The discounted after tax price of a barrel of oil is reduced by the same proportion in each period, which means that the rate of increase in the tax on an incremental barrel of oil is equal to the rate of increase 
in the price of oil. Thus if the growth rate in the oil price is greater than the firm's discount rate, the present value of the royalties is increasing over time, and the firm will accelerate extraction. If the price is increasing at a rate that is less than the interest rate, the present value of the tax on a per barrel basis is declining over time, and the firm will have an incentive to delay extraction to avoid paying the tax. Thus gross royalties cause firms to accelerate, delay, or leave extraction unchanged according to whether the growth rate in the price of the resource is greater than, less than, or equal to the interest rate. Of course, in reality, sometimes the price of oil increases at a rate that is greater than the interest rate, and at other times the price increases at a rate that is less than the interest rate. Moreover, the growth rate in the price is not known with certainty, but rather is risky or uncertain. Thus the key comparison is between the expected rate of growth in the price of oil and the risk-adjusted discount rate facing the firm. Regarding the impact on the extraction path, gross royalties have the same effect as production sharing contracts, whereby the government claims some portion of the resource extracted by the private enterprise.

Property taxes are levied on the assessed value of the resource property. Ideally, property taxes should be levied on the present value of the remaining reserves net of the extraction costs, which correctly reflects the opportunity cost of the inputs used in the extraction decision. This is equal to the market value of the resource at any point in time. In these cases the property tax is equivalent to a resource rent tax and will not distort the extraction path. However, in practice, the present value of reserves may be difficult for the government to measure. Therefore, an alternative form of assessment is often used that is frequently based on the cumulative amount of the resource extracted. The cumulative amount is easier to measure than the present value of reserves. When the assessment is performed using cumulative measures, the property tax is negatively related to the amount of the resource extracted. In other words, the more of the resource that is extracted, the lower the tax base. The tendency is therefore for property taxes to act as a subsidy to rapid extraction, providing an incentive to increase extraction now and decrease it in the future.

Net royalties or profit taxes differ from gross royalties because they allow certain costs to be deducted from gross revenues in the determination of the tax liability. Net royalties and profit taxes differ from each other with regard to the nature and scope of the costs allowed as deductions. Net royalties typically allow the deduction of current extraction costs only; they do not allow a deduction for the capital costs associated with extraction. Because extraction costs are assumed to be constant over time in our example, a net royalty acts like a gross royalty and increases, decreases, or leaves unchanged the rate of extraction as the growth rate in the price of oil is greater than, less than, or the same as the rate at which the firm discounts the profits from the reservoir.

A profits tax also allows some form of deduction for the capital costs associated with resource extraction. The nature of this deduction determines the impact on the extraction decision. For example, if the deduction reflects the true opportunity cost of capital employed in resource extraction, then the net profits tax is a tax on economic rent with no impact on the extraction profile. As mentioned earlier, the true opportunity cost of capital reflects both its depreciation over time and the rate of return it could earn if employed in an alternative activity or location. A profits tax that properly accounts for the opportunity cost of all the inputs is neutral with respect to the extraction decision, because in the long run average profits must increase at the rate of return required by shareholders. As this is also the rate used to discount future profits, taxes on profits will increase at the firm's discount rate in the long run. In this case the present value of the taxes paid on an extra barrel of oil extracted is constant over time and the firm has no incentive to alter its extraction path for tax reasons.

Tax policy analysts sometimes argue that a depletion allowance is required under a profits tax to account for the decrease in the value of the reservoir as oil is extracted. Governments often grant two kinds of depletion allowances as a deduction against income under a profits 
tax. Percentage depletion allowances are equal to some constant percentage of gross revenue. Cost depletion allowances are a constant per unit deduction based on the amount of the resource extracted. As long as the size of the initial reservoir is fixed and known, there is no need to grant a depletion allowance to ensure neutrality. In this case percentage depletion allowances act just like a negative gross royalty, while cost depletion allowances act like a negative severance tax, with precisely the opposite effects on the extraction path. When the size of the initial reserve is not fixed, but depends on the firm's exploration and development efforts, an income tax does require a depletion allowance to be neutral. The depletion allowance is needed because there are now two decisions that the firm must make: how big the initial reserve should be (in other words, how much exploration effort to undertake) and how fast to extract it. What is required for neutrality along both these dimensions is a depletion allowance that grows at a rate equal to the difference between the rate of growth in the market price of oil and the rate at which the firm discounts its profits.

Resource rent taxes are levied on the present value of the resource, net of all extraction costs. Because these taxes are intended to be levied explicitly on economic rent, if designed properly they have no impact on the extraction decision. However, measuring the net present value of the resource is not always straightforward. As such, two approaches to implementing a resource rent tax are employed in practice. One is to levy a cash flow tax, which is equivalent to a tax on economic rent in present value terms. A cash flow tax allows all the costs associated with extraction, both current and capital, to be deducted immediately. In the case of capital costs, the entire purchase price of capital is deducted when incurred, and there is no need to provide subsequent deductions for depreciation of the forgone rate of return on the capital. To be neutral, a pure cash flow tax must be fully refundable. This means that in the early stages of the project, when the firm has little revenue and its capital expenditures may be quite large, it receives a tax refund from the government equal to the size of the negative cash flow times the tax rate.

Another way to levy a resource rent tax-which skirts the necessity of the government having to issue refunds in the early stages of the project-is to allow the firm to fully recover all the costs associated with its initial investment in the resource, including the forgone rate of return, before levying a net royalty tax. In this situation, the firm pays no taxes and receives no refund for several years at the beginning of a resource project, and pays a net royalty tax only after the rate of return on the project reaches a level equal to the firm's discount rate. One way to implement this approach is to carry the negative cash flows from the early stages of a nonrenewable resource development forward for deduction against future positive cash flows. These negative cash flows are carried forward at the firm's discount rate.

Note that for practical purposes, the foregoing discussion was limited in relation to the types of taxes and distortions it could include. However, the analysis does elucidate the need for each government to carefully consider the tax design and the implications for the decisions of the firms involved in the extraction decision when designing a tax system intended to obtain a share of the rent generated by a nonrenewable resource.

\section{Resource Taxation and Fiscal Federalism}

This section explores how revenues from the taxation of the economic rents from natural resources may be distributed across governments and jurisdictions. The conventional economic wisdom in this regard is that the taxation of natural resources should be centralized with the national-as opposed to state-government. This section sets out an economic model or argument for centralization, which will make the case on both efficiency and equity grounds. This fundamental result is then qualified along both economic and political dimensions, which imply that exclusive central control may not be completely desirable and that there may be at least some role for state governments in the area of resource taxation. 


\section{The Simple Case for Centralization}

As stated before, a defining characteristic of natural resources is that endowments tend to be unevenly distributed across geographical regions. This situation creates problems when the geographical boundaries that demarcate the distribution of those resources coincide, or lie within, the political boundaries that define the subnational governments or states.

Consider a simple case of a federation with just two states, A and B. State A is endowed with a natural resource, for example, oil, which generates economic rents, while state B is not. The state government in both states is responsible for delivering a set of local public goods and services that only benefits the residents of the state in question. In other words, there are no spillovers between states in the provision of these local public goods. Assume also that the population in the entire country is fixed, coincides with the working population, is perfectly mobile between the two states, and is able to migrate between them costlessly. Assume also that migration decisions are based solely on economic considerations, such as the wages individuals can earn in each state. Finally, assume that the residents of each state are fully informed about the level of local public goods and services and the taxes required to finance them, not only in their own state, but in the other state as well.

Similar to the example used in the previous section illustrating the economic implications of different types of resource taxes on the extraction decision, this example is vastly oversimplified. Nonetheless, it is useful in illustrating important points that carry over into more complex, and more realistic, environments.

To begin, consider a situation where state A, the state endowed with oil, does not impose any taxes on the rents generated by the natural resource. Instead imagine that both states finance the provision of their local public goods exclusively with benefit taxes. Benefit taxes are taxes equal to the economic benefit provided to residents by the public goods and services. In practice, these taxes may be approximated by user fees or similar charges. Although the use of benefit taxes is obviously restricted in practice to public goods that are excludable, in the sense that only those who pay for the goods receive the benefits-although many public goods are in fact nonexcludable - the idea of benefit taxes serves a useful pedagogical purpose. When public goods are financed exclusively by benefit taxes, taxpayers receive no excess benefit, or surplus, from the public goods provided by the government over and above the amount they have to pay for them. In the jargon of economics, the net fiscal benefit associated with the provision and financing of public services with benefit taxes is zero. The net fiscal benefit refers to the value of the pubic goods and services to the citizens in excess of the taxes they pay to receive them.

The fact that the net fiscal benefit in each of the states is zero under this hypothetical scenario suggests that the residents of either state will have no reason to migrate to the other state to access the public goods the other state offers. No matter where citizens choose to live, they pay an amount equal to the value of the public goods and services to them, earning no surplus. This means that the allocation of residents across the two states will be independent of fiscal considerations, and will be determined purely by economic considerations, particularly by the wages individuals can earn by living in each state. ${ }^{1}$ The equilibrium in this initial scenario is illustrated in figure 12.1 .

The horizontal axis in figure 12.1 measures the population size of the entire country. Any point along this axis represents an allocation of the population between the two states. Moving along the horizontal axis to the right from the left-hand origin, labeled $\mathrm{O}_{\mathrm{A}}$, signifies a reallocation of the population away from state $\mathrm{B}$ and toward state $\mathrm{A}$, while moving to the left from the right-hand origin, labeled $\mathrm{O}_{\mathrm{B}}$, is a reallocation in the opposite direction. For example, consider

1. For the allocation of workers across the two states to be independent of fiscal considerations, the only requirement is a zero net fiscal benefit in each state. 
Figure 12.1 Equilibrium Migration

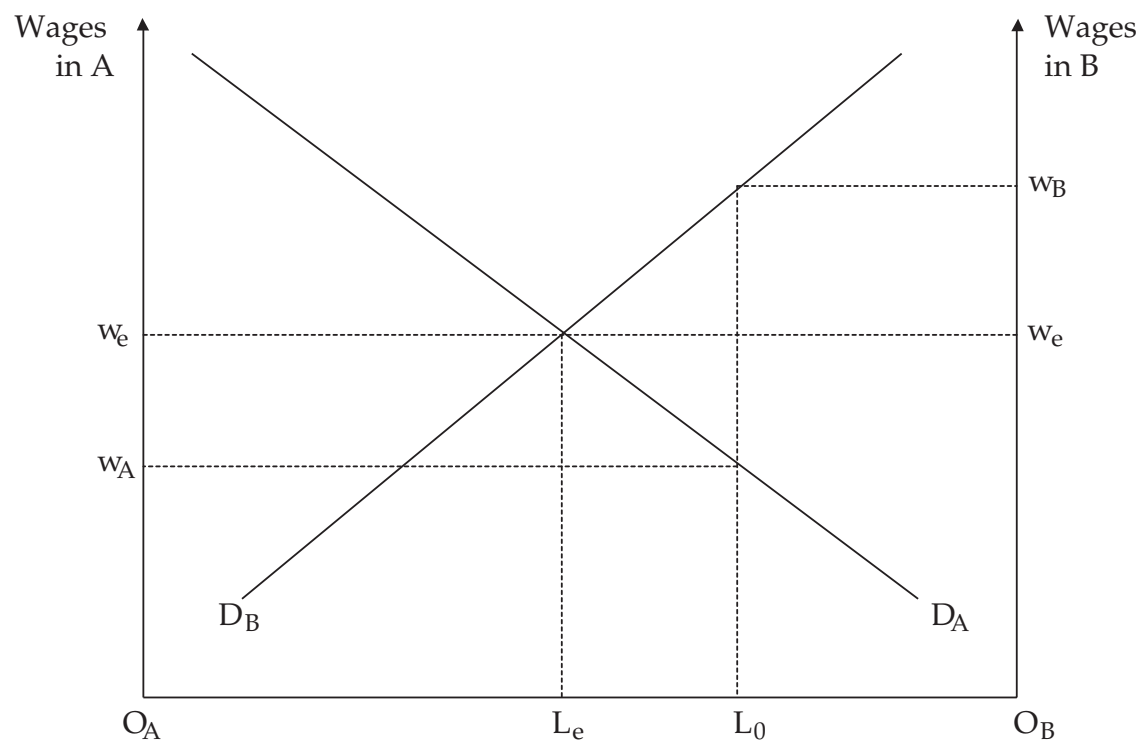

Source: Author.

some initial population allocation, such as point $\mathrm{L}_{0}$. The distance $\mathrm{O}_{\mathrm{A}} \mathrm{L}_{0}$ then represents the population of state $A$, while the distance $\mathrm{O}_{B} \mathrm{~L}_{0}$ is the population of state $\mathrm{B}$. The vertical axis is a measure of dollar value, such as wages.

The curves in the diagram represent the demand for labor in each state. The curve sloping down to the right, labeled $\mathrm{D}_{A}$, is the demand for labor in state $\mathrm{A}$, and is oriented with the origin $\mathrm{O}_{A}$, while the curve sloping down to the left, labeled $D_{B}$, oriented to the origin $O_{B}$, is the demand for labor in state B.

These demand for labor curves are determined by the value of the marginal product of labor in each state. The value of the marginal product of labor is equal to the amount of income generated by hiring one more worker in each state. Firms motivated by earning higher profits will hire labor up to the point that the value of the marginal product of labor is equal to the wage that the firm must pay an additional worker. To understand this imagine a situation in which the value of the marginal product of labor is greater than the wage rate. Here, hiring an additional worker generates more income for the firm than it costs to hire that extra worker, resulting in additional profits earned by the firm. A firm seeking to maximize its profits will keep hiring additional workers so long as the value of the marginal product of that worker exceeds the wage rate. Only when the additional income generated by hiring one more worker is exactly equal to the cost of hiring that worker will the firm stop hiring, because hiring additional workers past that point will lower the firm's profits. The curves slope downward, because as more labor is hired, each additional worker is presumed to be less productive than the previous one (this is called the law of diminishing marginal returns), thereby adding less to the firm's profits.

An equilibrium allocation of the population between the two states occurs when the wages paid in each state are equalized. This equalization is determined by the intersection of the demand for labor curves, and is indicated by point $\mathrm{L}_{\mathrm{e}}$ and the wage rate $\mathrm{w}_{\mathrm{e}}$ in figure 12.1. To see that the equilibrium allocation of workers between the two states in this simple model is defined by the equality between the wage rates, consider an initial allocation of population at point $\mathrm{L}_{0}$. In this case, workers can earn a wage rate of $\mathrm{w}_{\mathrm{B}}$ in state $\mathrm{B}$ and $\mathrm{w}_{\mathrm{A}}$ in state $\mathrm{A}$, but as $\mathrm{w}_{\mathrm{B}}$ is greater than $w_{A}$, workers in state $A$ have an incentive to migrate to state $B$. This migration drives down the wages in state $\mathrm{B}$ and increases wages in state $\mathrm{A}$, and this continues until the 
wage rates in the two states are equalized, after which there is no longer an incentive for workers to migrate from one state to another. At this point, an equilibrium has been achieved.

As mentioned earlier, because the net fiscal benefit associated with the provision of local public goods in each state in this initial situation is presumed to be zero, workers migrate from one state to the other only in response to wage differentials, and not in response to higher public services or lower taxes. When this is the case, the equality of wages also means that the value of the marginal product of labor is equal in the two states. This situation means that it is not possible to increase the total amount of income generated in the entire country by allocating labor from one state to another. In this situation, the allocation of labor between the two states is said to be economically efficient, in the sense that any other allocation will result in lower national income. To further visualize this situation, remember that labor will be hired up to the point that the value of the marginal product is equal to the wage rate, and consider again the alternative allocation associated with $\mathrm{L}_{0}$. At $\mathrm{L}_{0} \mathrm{w}_{\mathrm{B}}=\mathrm{VMPL}_{\mathrm{B}}>\mathrm{VMPL}_{\mathrm{A}}=\mathrm{w}_{\mathrm{A}}$, where $\mathrm{VMPL}_{i}$ stands for the value of the marginal product of labor in state $i$, and $i=\mathrm{A}, \mathrm{B}$. Thus, at $\mathrm{L}_{0}$, the reduction in income from losing one worker in state $\mathrm{A}$ is less than the increase in income from gaining one worker in state $\mathrm{B}$, and total income generated in the country can be increased by taking one worker from state A and moving this worker to state B. This type of increase in national income resulting from moving workers from one state to the other can take place for all allocations of labor between the two states except that given by $\mathrm{L}_{\mathrm{e}}$, where $\mathrm{w}_{\mathrm{A}}=\mathrm{VMPL}_{\mathrm{A}}=$ $\mathrm{VMPL}_{\mathrm{B}}=\mathrm{w}_{\mathrm{B}}$. Thus in the absence of differences in net fiscal benefits between the two states, migration ensures an efficient, income-maximizing allocation of workers between states.

Remember, however, that state A is fortunate enough to be endowed with oil reserves that generate economic rent. Say the total rent generated by those reserves is equal to an amount $R_{A}$. As discussed earlier, these rents are earned over and above the opportunity cost of extracting the resource, and thus represent the excess value of the resource over and above the wages paid to the workers and the return to the owners of capital involved in the extraction. State A can impose taxes on these rents without discouraging or distorting the production of the resource (including the time profile, as discussed earlier). State A can use the resulting tax revenue to either enhance the public goods and services it currently offers or to lower the taxes currently paid by its residents (or some combination of the two). In either case, the presence of this rent and the revenue it gives rise to generate a positive net fiscal benefit to the residents of state A. In other words, the value of the publicly provided goods and services that residents of state A now receive exceeds the amount they have to pay for them. The value of that benefit, on a per capita basis, is $R_{A} / L_{A}$, where $L_{A}$ is the population of state $A$. The positive net fiscal benefit in state $A$ created by these rents means that individuals in state $B$ now have an incentive to move to state A to access that benefit. The reason for this is that because the net fiscal benefit in state $B$ is still zero (because of its use of benefit taxes), the economic benefit that workers receive from living in state $\mathrm{B}$ is determined solely by the wage rate in state $\mathrm{B}, \mathrm{w}_{\mathrm{B}}$. By contrast, the economic benefit that workers receive from living in state $A$ is determined by the sum of the wage rate and the (now positive) net fiscal benefit in state $A$, or $w_{A}+R_{A} / L_{A}$. Workers will move between states until the economic benefit of living in each state is equalized. In the presence of a positive net fiscal benefit in state $\mathrm{A}$, the equilibrium allocation of the population between the two states will thus be determined by the condition $\mathrm{w}_{A}+\mathrm{R}_{\mathrm{A}} / \mathrm{L}_{\mathrm{A}}=\mathrm{w}_{\mathrm{B}}$, which is illustrated in figure 12.2.

The original equilibrium from figure 12.1, with a population allocation of $\mathrm{L}_{\mathrm{e}}$ and wages in each state equalized at $\mathrm{w}_{\mathrm{e}}$, is reproduced in figure 12.2. The effect of the positive net fiscal benefit financed by taxing the economic rents generated by the oil reserves in state $\mathrm{A}$ is illustrated by shifting the labor demand curve in state $A$ from $D_{A}$ up to the right to $D_{A}+R_{A} / L_{A}$. This is the labor demand curve augmented by the net fiscal benefit associated with the resource rents. The equilibrium allocation of workers between the two states is determined by the intersection of this augmented labor demand curve in state $\mathrm{A}$ with the labor demand curve in state B, generating a population allocation given by point $\mathrm{L}_{\mathrm{f}}$. The presence of a positive net fiscal benefit in 
Figure 12.2 Net Fiscal Benefits and Fiscally Induced Migration

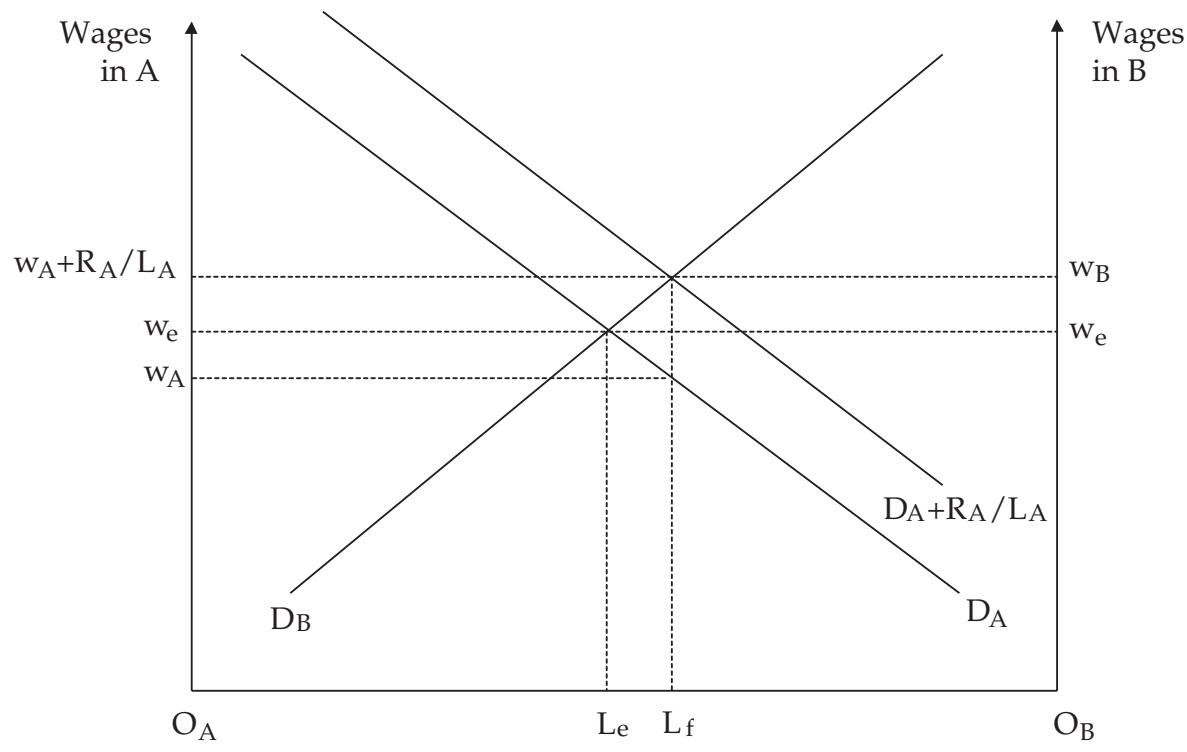

Source: Author.

state $\mathrm{A}$, relative to state $\mathrm{B}$, means that workers migrate from state $\mathrm{B}$ to state $\mathrm{A}$ in pursuit of the positive net fiscal benefit. The increased supply of labor in state A drives down the wage rate in state $A$ from $w_{e}$ to $w_{A}$, while the decreased supply of labor in state $B$ drives up the wage rate in state $B$ from $w_{e}$ to $w_{B}$, until there is no longer an incentive for workers to migrate between the two states, in other words, when $\mathrm{w}_{\mathrm{A}}+\mathrm{R}_{\mathrm{A}} / \mathrm{L}_{\mathrm{A}}=\mathrm{w}_{\mathrm{B}}$.

The migration of workers from one state to another in response to differences in net fiscal benefits is called fiscally induced migration. In this case, the fiscally induced migration is caused by differences in the allocation of a nonrenewable resource-oil-and the resulting ability of one of the states to use the resulting rents to finance enhanced public services and/or lower taxes.

All this seems to be a quite reasonable, albeit overly simplistic, representation of migration decisions in the real world. However, a key insight in relation to the example used here is that fiscally induced migration caused by the presence of resource rents in state A accessed by the local government results in an inefficient allocation of workers between the two states from a national perspective. To see this, note that in the fiscally induced equilibrium given by point $\mathrm{L}_{\mathrm{f}}$, $\mathrm{w}_{\mathrm{A}}=\mathrm{VMPL}_{\mathrm{A}}<\mathrm{VMPL}_{\mathrm{B}}=\mathrm{w}_{\mathrm{B}}$, and the value of the marginal product of labor in state $\mathrm{A}$ is therefore less than the marginal product of labor in state $B$. This means that national income could be increased by moving workers away from the equilibrium allocation from state A to state $\mathrm{B}$. Fiscally induced migration thus leads to a reduction in national income and an inefficient allocation of workers between states.

Herein lies the crux of the simple efficiency argument against allowing state governments access to the economic rent generated by natural resources. Quite simply, the ability on the part of some states to access the rent from a natural resource, while other states are not able to access that rent, can generate differences in net fiscal benefits across states that can lead to inefficient fiscally induced migration. There are several ways to deal with this kind of situation. One obvious approach is to centralize the collection of resource rent with a national government. The national government can then use the resource rent to finance public goods and services that benefit all citizens of the country, regardless of which state they reside in. An alternative approach is for the national government to collect the rent from natural resources, 
but then share the rent on an equal per capita basis with all the state governments via a system of intergovernmental transfers. Yet another approach would be to include resource rent in an equalization system that seeks to equalize fiscal capacity and net fiscal benefits across state governments (see chapter 2 in this volume). Regardless of the approach, the possibility of fiscally induced migration associated with local government access to resource rent provides a compelling efficiency argument in favor of a strong central government presence in the area of resource taxation.

A theoretical case in favor of centralization of the taxation of natural resources may also be made on equity grounds. An important concept underlying the analysis of equity considerations related to public policy is the idea of ability to pay. The ability to pay approach to the analysis of equity says quite simply that the amount that individuals pay (in taxes or otherwise) for public goods and services should somehow be related to their ability to pay for those goods and services. Ability to pay may be measured in several ways, but for the purposes of this chapter think of it simply as income. The principle of horizontal equity then says that individuals with the same ability to pay should pay the same amount for the public goods and services that they receive. For this reason, horizontal equity is often referred to simply as the equal treatment of equals.

The presence of unequally distributed resource endowments, and the associated rent, across states suggests that the principle of horizontal equity will be violated on a national level if local governments are able to access the rent generated by the natural resources, even if there is no possibility for migration between states. To visualize this possibility, consider the discrepancy between the net fiscal benefits associated with public goods in states A and B, as described previously. An individual living in state A who has the same ability to pay (in other words, the same income) as an individual living in state B will pay less for the same level of public good provision (or the same for a higher level of public good provision). This violates the principle of horizontal equity. If the collection and/or distribution of resource rent is centralized with the national government, differences in net fiscal benefits between states caused by discrepancies in the endowment of natural resources is eliminated, and horizontal equity may be maintained.

\section{Qualification I: The Economic Environment}

The previous example was based on a very simple and stylized set of assumptions about the economic environment. For example, the efficiency argument for the centralization of taxing power over natural resources relied on an assumption of perfect labor mobility across states. In practice, this assumption does not hold, and to the extent that labor is not perfectly mobile across states, the efficiency argument for central control is obviously reduced. However, the model still identifies the pressures that may exist in the presence of local government control over resource rent taxes. Moreover, some evidence in other countries indicates that individuals do indeed base their migration decisions on differences in net fiscal benefits across states, at least in part (Winer and Day 1994). These pressures are the basis for the conventional economic wisdom suggesting that the central government can play a prominent role in the taxation of natural resources.

Several elements can be added to the economic environment that could soften the argument that the central government should have exclusive jurisdiction over the taxation of natural resources. This section focuses on two such elements in a nontechnical manner.

The first consideration involves the provision of services and infrastructure by state and local governments in support of the exploitation of natural resources. Taxes and other charges levied on natural resources might be considered compensation for the costs associated with the provision of this infrastructure.

A related idea involves the presence of negative externalities associated with the production and development of the natural resource. For example, the development of natural resources is often associated with negative environmental impacts. These negative environ- 
mental impacts tend to be concentrated locally, within state boundaries. The presence of these negative environmental impacts suggests that state governments may have a role in monitoring and regulating activities related to the production of the natural resource, for instance, by imposing environmental standards and regulations. Similar to other infrastructure provided by state and local governments, the costs associated with this regulatory activity need to be financed in some way, and a natural candidate would be the rents generated from the exploitation of the natural resource.

State compensation for costs associated with infrastructure and regulatory activity related to natural resources can take many forms. One is to allow state governments to impose taxes or other levies on the companies involved in exploiting the resource. Another possibility is to retain the central government's dominance in the taxation of the resource, but to allocate some of the rents generated by the resource to the state government.

A related issue concerns the costs imposed by the negative environmental externality itself. The presence of these environmental externalities may suggest an argument for lowering the rate of extraction of the resource below that determined by the private market. The introduction of this chapter alludes to this possibility in connection with the importance of establishing a neutral boundary. As discussed in the previous section on the economic effects of resource taxes, taxes can affect many decisions related to the production of the natural resource, including the time profile of extraction. If the government with jurisdiction over the taxation of the natural resource does not fully internalize, or take account of, the negative externalities associated with the extraction of the resource, then it may not properly implement a tax system designed to generate an appropriate time profile, that is, one that reflects the negative environmental externalities associated with the extraction of the natural resource. To the extent that the central government does not properly internalize negative local environmental externalities associated with resource extraction, the result will not be socially optimal. This suggests that the state government has a role in imposing taxes designed to reflect the negative externality, perhaps by slowing down the rate of extraction of the resource. An obvious candidate for this type of tax is a state-level severance tax that tilts the time profile of resource extraction from the present to the future.

The second consideration that modifies the argument for exclusive central government control over resource taxation concerns the very existence of the positive net fiscal benefits arising from the taxation of resource rents. The simple model presented previously presumed that the value of the net fiscal benefit was simply equal to the per capita rents generated by the natural resource. This may not be the case in practice if the supply curve for the local goods and services provided by the state government is upward sloping. If this is the case, as the state endowed with the natural resource (state $\mathrm{A}$ in the previous example) expands its provision of local public goods and services, the per unit cost of providing those goods and services increases. This means that the per unit cost of providing government goods and services in state A will be greater than the cost in state B. In the extreme case, this cost differential may be enough to dissipate the net fiscal benefit in state A altogether, in which case both the equity and efficiency arguments in favor of centralization cease to hold. Although the extreme case is unlikely in practice, it does suggest that the net fiscal benefit arising from the natural resource endowment in state A may be lower than suggested by simply measuring the per capita economic rent generated by the resource. If the net fiscal benefit is lower, the efficiency cost of allowing state government control over the taxation of the natural resource may be lower than might be expected as well.

\section{Qualification II: The Political Environment}

The model discussed previously, or variations of it, is often used to justify the dominant, if not exclusive, role of the central government in natural resource taxation on economic grounds. 
Despite this conventional economic wisdom, precisely the opposite seems to be the case in many, if not most, federal countries. For example, while Canada's national government has a virtually unrestricted ability to levy taxes on all activities, including natural resources, the ownership of natural resources is constitutionally enshrined with the provincial (state) governments, which impose royalties and other types of special taxes on their natural resources. This situation is not at all uncommon in many federalist countries.

The phrase "political considerations" is often invoked to explain public policies that seem to go against conventional economic wisdom, and in the case of the taxation of natural resources the phrase seems to be particularly apt. Yet as an explanation, political considerations are clearly unsatisfactory. The political and constitutional history of each federation is unique, and a single theory cannot adequately encompass all cases. However, employing some concepts from cooperative game theory in economics can shed some light on the way that political considerations might influence the allocation of the rents from natural resource taxation across governments in a generic sense. ${ }^{2}$ To do this consider the following economic benefits that a member state or jurisdiction may derive from being part of a federation:

- Some economies of scale may be realized in the provision of public goods on a national basis. An example of this might be the provision of national defense, whereby the per capita cost of providing the service declines as the size of the federation increases.

- Something akin to insurance benefits can come from belonging to the federation. These benefits arise from risk pooling in a federation where business cycles are not perfectly correlated across regions. This introduces some stability in to the provision of public goods and services and/or taxes that might not exist in a unitary state. Indeed, this may be particularly relevant in the area of natural resource taxation, because revenue from such taxes tends to be quite volatile.

- States within a federation typically share, at least to some extent, a common set of laws, regulations, language, and culture. This situation facilitates trade and lowers the transaction costs associated with this trade.

- Collection of some taxes, including resource taxes, by a national government may prevent the type of inefficient, fiscally-induced migration between jurisdictions discussed earlier (presuming labor mobility between independent states).

Of course, economic costs are also associated with being part of a federation. These costs involve the loss of autonomy a region incurs because some of the tax and spending policies imposed on its citizens originate with the central government. If the policy preferences of a region or state do not coincide with the preferences of the nation as a whole, the resulting outcome can impose real economic costs on the state's citizens.

Whether or not a particular state is a net beneficiary from belonging to a federation, in economic terms, depends on whether or not the benefits of federation are greater than the costs. Before getting into the economic analysis of political considerations, let us assume that being part of the federation is indeed beneficial to all the states that belong to it. The revealed preference argument for this assertion is simple: if this were not the case, a state would not choose to be a member of the federation. Again, this situation is overly simplistic because federations are formed - or not - on the basis of other aspects such as the cultural and political history of the regions in question, and not just on the basis of economic considerations. Moreover, regions typically cannot decide to simply join or leave a federation arbitrarily. While these considerations are obviously important, what matters for the purposes of this discussion is the simple

2. The technical literature contains vast amounts of information on bargaining in economics. This chapter does not attempt to discuss this literature. 
idea that being part of a federation can somehow generate a surplus over and above the level of well-being that each region could achieve if it remained independent. This surplus can then be shared among all regions in the federation, resulting in all states and regions faring better as a member of the federation than being independent.

Although much of the economic analysis of fiscal federalism is based on fiscal competition among noncooperative members of a predetermined federation, at its most fundamental level the essence of federalism is, in fact, cooperation. By agreeing to be part of a federation in the first place, states must cooperate with each other. Although this requirement may seem obvious, this simple observation is not reflected in much of the analysis of fiscal federalism, especially in the analysis of the allocation of resource rents. With this idea in mind, states can be viewed as negotiating with each other over the allocation of the net surplus associated with being part of the federation.

Although cooperation is the essence of federalism, this does not mean that individual states do not attempt to do as well as they can for the residents of their particular region. Each state can be viewed as engaging in the bargaining process to obtain as high a share of the surplus arising from the federation as it can. Consider the previous two-state example to illustrate this idea, which is graphically depicted in figure 12.3. In figure 12.3 the horizontal axis measures the well-being of a representative citizen of state A, while the vertical axis measures the well-being of a representative citizen of state B. This well-being reflects, among other things, the fiscal (tax and expenditure) choices made by the states' governments, and reflects the policy preferences of citizens in each state. The point labeled 1 is referred to as the best alternative to a negotiated agreement (BATNA) point. It indicates the level of well-being that citizens of each state may achieve in the absence of an agreement about the surplus from confederation, for example, if the states are independent. Thus if state A was not a member of the federation, its citizens would achieve a level of well-being of $\mathrm{U}_{0}^{\mathrm{A}}$, while citizens of state $\mathrm{B}$ would achieve a level of well-being of $\mathrm{U}_{0}^{\mathrm{B}}$. The curve labeled $\mathrm{F}^{\prime}$ is called the efficient frontier. It represents the levels of well-being achievable by the citizens of each state under a federation. As the BATNA point lies inside the efficient frontier, this indicates that the federation does indeed have the potential to

Figure 12.3 Benefits of a Federation

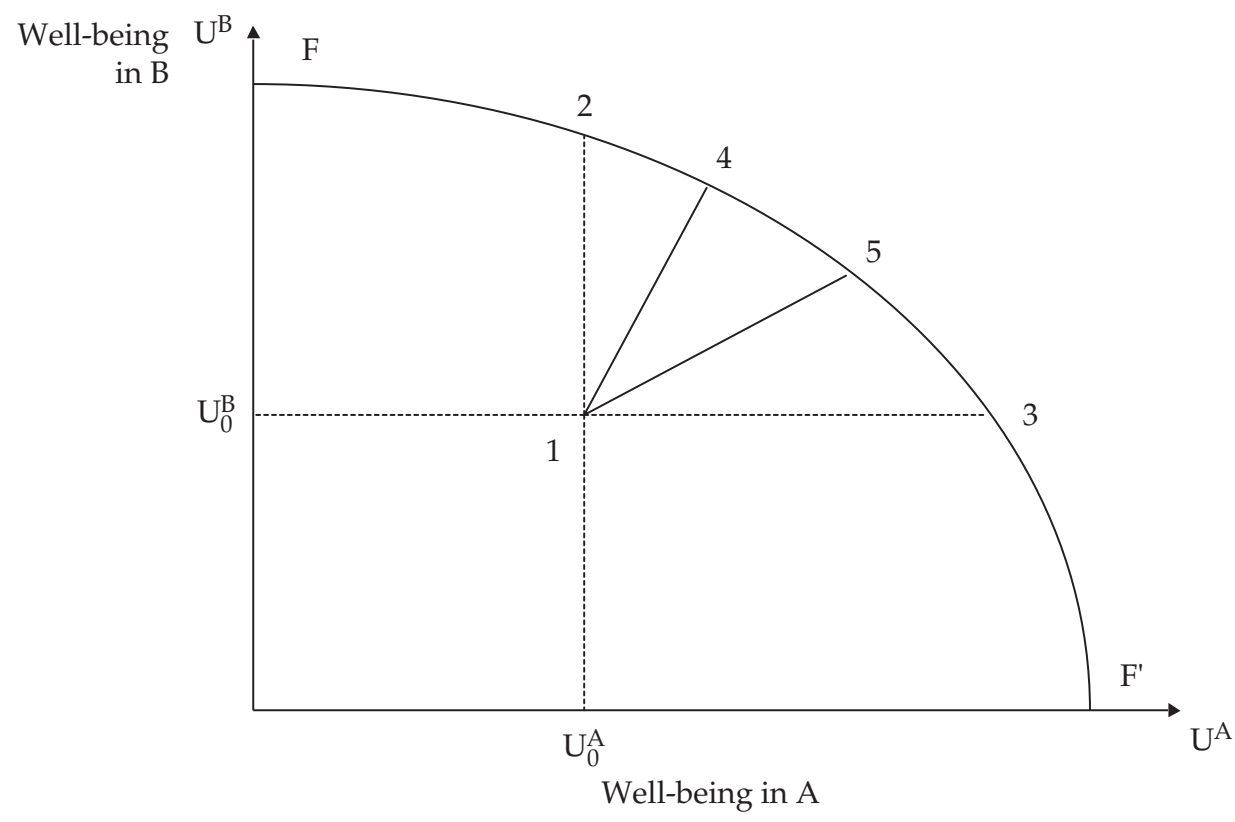

Source: Author. 
generate a surplus for the citizens of each state, allowing them to achieve a level of well-being that they would not be able to attain as unitary states.

The process of negotiation within the federation involves capturing the surplus and moving from the BATNA point to the efficient frontier. The question is where do the states end up on the frontier? What share of the surplus from forming a federation goes to each state? The nature of bargaining is that it is mutually beneficial; in other words, both participants must be better off under the negotiated outcome than under the BATNA. In terms of figure 12.3, this means that whatever the outcome of the bargaining process, the end result will lie on the efficient frontier somewhere between points 2 and 3, where the citizens of both states are better off than their BATNA points. ${ }^{3}$

The process of negotiation between member states of a federation and the role that the central government plays in this process, can be complicated. The institutional framework within which this occurs varies significantly from federation to federation and can have an important impact on the outcome. The simple approach represented in figure 12.3 does not begin to take account of the richness of the bargaining process in the real world. However, two ideas generic to all bargaining processes can be roughly accommodated within the framework: the concepts of bargaining power and outside options.

Obviously the relative bargaining power that each party brings to a negotiation helps determine the surplus allocation.. Relative bargaining power can reflect several things, including the institutional context of the negotiations (in other words, how many "votes" each party has), agenda setting power, negotiating skill, and experience. The relative degree of bargaining power between states $A$ and $B$ can be represented in figure 12.3 by the slope of the ray from the BATNA point to the efficient frontier. The flatter this ray, the more bargaining power state $\mathrm{A}$ has relative to state B. For example, if the relative bargaining power of the two states is represented by the ray from points 1 to 4 , the negotiations will end up at point 4 on the efficient frontier. If for some reason the bargaining power of state $A$ increases relative to state $B$, represented by a rotation of the ray to that depicted from points 1 to 5 , then the outcome of the negotiations will be at point 5 , where state $A$ is relatively better off than before because of an increase in its bargaining power, while state $B$ is relatively worse off than it was before (although still better off relative to its BATNA).

The outside options available to the parties involved in the negotiations can also have an important impact on the outcome of the negotiations. Outside options in this context refer to the level of well-being the citizens of each state can achieve outside the federation in the absence of an agreement. This level of well-being is represented by the location of the BATNA point. Intuitively, the state with the relatively better outside option (BATNA) might be expected to do better in the negotiations because it does not need or desire an agreement as much as the other state. Like bargaining power, the relative size of each state's BATNA can determine where the state ends up on the efficient frontier.

To illustrate this consider figure 12.4, which re-creates the initial state scenario shown in figure 12.3, with a BATNA represented by point 1 and relative bargaining given by the slope of the ray from points 1 to 4 . The outcome, or equilibrium, of the bargaining process in this case is point 4. Now imagine that there is an increase in the BATNA of state A, holding state B's BATNA constant. This means that the well-being of the citizens of state $\mathrm{A}$ as an independent state increases from $\mathrm{U}_{0}^{\mathrm{A}}$ to $\mathrm{U}_{1}^{\mathrm{A}}$, and the BATNA point shifts from point 1 to point 5 . Holding relative bargaining power (the slope of the ray from the BATNA point to the efficient frontier) constant, the new equilibrium outcome of the bargaining process is point 6 , whereby a greater share of the surplus from joining the federation is allocated to state A.

3. Figure 12.3 assumes that none of the surplus is left unrealized following the bargaining process and that the bargaining process involves no costs. 
Figure 12.4 Change in BATNA

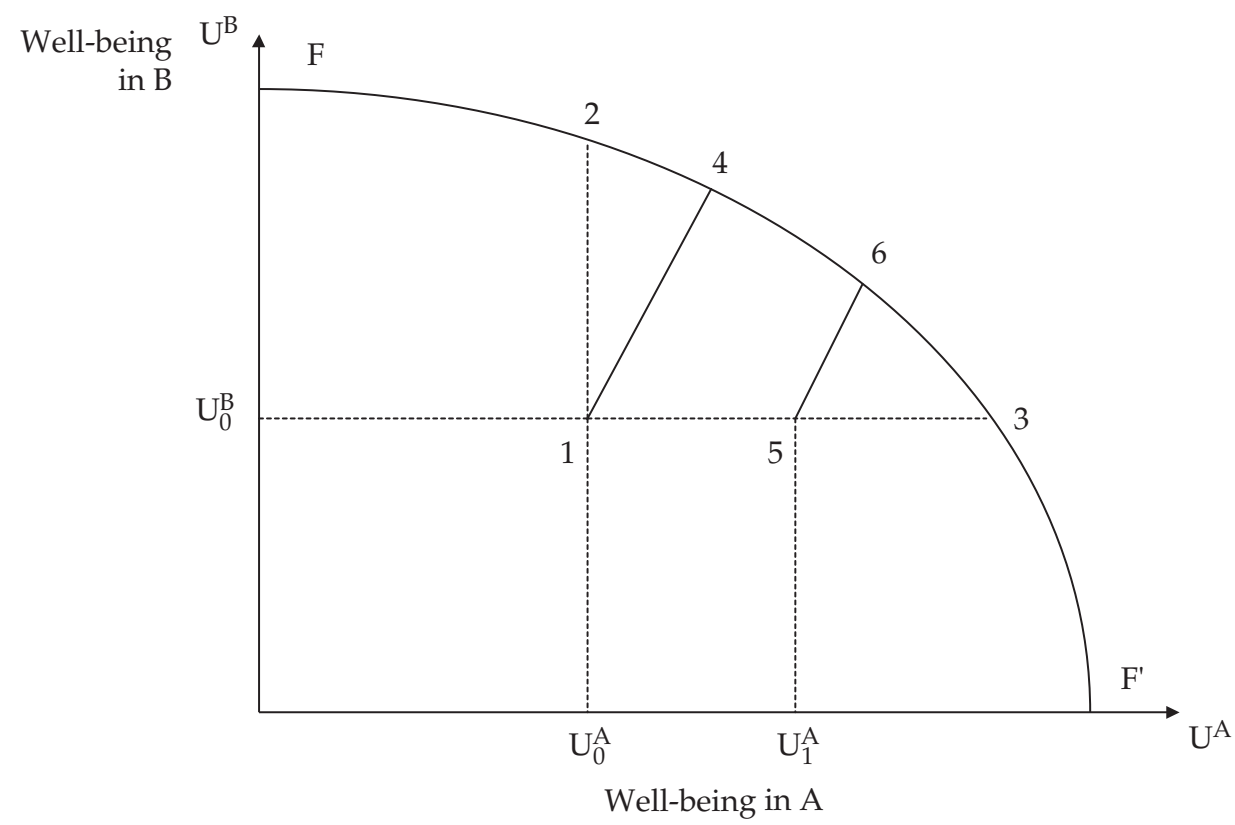

Source: Author.

Thus the relative strength of the two states outside the federation helps determine the allocation of the surplus within the federation. The more attractive a state's outside options-in other words, its economic prospects outside the federation-the greater the share of the surplus from participating in confederation.

This insight can be applied to an analysis of the allocation of resource rents across states. Imagine, as before, that the resource rents arise from a natural resource, oil, located in state A. Now imagine a process whereby state $A$ and state $B$ bargain about the allocation of those rents, as well as about other aspects of fiscal policy within the federation. State B can be viewed as the other state within a two-country federation or as a national government representing the other states in the federation that are not endowed with the natural resource. Either way, even with its endowment of natural resources, state A can still benefit from being part of the federation for the reasons discussed earlier. However, its endowment of natural resources, and the associated economic rents, can be thought of as increasing state A's BATNA relative to the other states in the federation. As illustrated in figure 12.4, the bargaining process will allocate a greater share of the benefits of confederation to state A than would otherwise be the case. One obvious way to achieve this is to allow state A to maintain a greater share of the resource rents arising from its endowment of the natural resource. Political considerations, at least in the rather abstract and imprecise way modeled here, can therefore act to constrain the economic considerations, which suggests that resource rents should be collected by the central government and shared among all states of the federation by the provision of a national public good, by intergovernmental transfers, or by an equalization system. In simple terms, the analysis suggests that resource-rich states may need to be permitted to maintain a significant share of the rent generated by natural resources within their boundary in order to remain part of the federation. Doing so would allow all states within the federation to share in the surplus resulting from confederation.

Even though the foregoing analysis was framed in terms of a stark outside option associated with withdrawing from (or not joining) the federation, similar reasoning applies to outside options and BATNA points that are less stark. For example, even if withdrawing from the 
federation is not a viable and credible option for a resource-rich state, there are still various degrees of cooperation among states within the context of federalism that may be available to each state. Cooperation can include a variety of activities, from participating in the harmonization of tax and spending programs across states to facilitating the collection of taxes (including resource taxes) by the central government. Canada again offers an informative example in this regard. Several areas of governance are constitutionally under the responsibility of Canadian provinces, but have been abdicated in large part to the national government. These include the provision of the government pension plan, the collection of personal income taxes, provincial policing, and some aspects of health care policy. Although the important national presence in these and other areas obviously contributes to the harmony and synchronization of the resulting programs, the provinces can, if they so choose, withdraw from the federal programs and set up their own alternatives. Indeed, the province of Quebec has chosen to do just that on many fronts. The point is that Canadian provinces can choose to be more or less cooperative with each other and with the national government within the context of the existing federation.

Regardless of the precise form of the outside option available to the states involved in the negotiating process, either directly or indirectly via a national government, if the endowment of the natural resource increases the relative attractiveness of the outside option available to resource-rich states, then political considerations suggest the need for these states to retain some sort of interest in the rent generated by their endowment of natural resources. This is consistent with the observation that many federalist countries in the real world do in fact allocate a good deal of the share of natural resource rents to originating state governments by assigning them taxing power.

\section{International Experience}

This chapter does not provide an in-depth overview of the international experience with regard to various approaches to either resource taxation or to the allocation of taxing powers across levels of governments. Nonetheless, briefly discussing some aspects of the international experience is useful. Table 12.1 lists several types of taxes that are levied on natural resources in selected countries and indicates whether or not the tax is under national, state, or local government authority.

The table indicates that national governments are heavily involved in the taxation of natural resources in all the countries, and in virtually every tax field. The exceptions to national involvement are in the area of sales and excise taxes on equipment and services purchased by natural resource companies and property taxes. The former is due primarily to the lack of sales and excise taxes imposed at the national level in general, while the latter reflects a tendency to leave property taxes to state and local governments. Along with property taxes, the most common involvement by state or local governments in the taxation of natural resources is via the imposition of a mineral royalty or severance tax and land fees.

The involvement of state and local governments in property and land taxes may be justified by referring to some of the economic qualifications offered in the previous section, which argued that to the extent that state governments provide infrastructure that is beneficial to the natural resource sector, the state government should be compensated for it. Property and landbased taxes are natural candidates for this compensation.

Although the tendency of several state-level governments in table 12.1 to have authority over royalties and severance taxes may also be justified on these grounds-in other words, as compensation for environmental damage-such charges are in most cases more likely explained by political and constitutional considerations. As discussed earlier, resource-rich states may need to retain some share of the tax revenue collected from natural resources in order to maintain cooperation within the federation. Royalties and severance taxes levied by state governments are one way to do this. 
Table 12.1 Taxation Authority for Selected Taxes and Fees, Selected Countries

\begin{tabular}{|c|c|c|c|c|c|c|}
\hline Country & $\begin{array}{l}\text { Corporate } \\
\text { income tax }\end{array}$ & $\begin{array}{l}\text { Mineral } \\
\text { royalty or } \\
\text { severance } \\
\text { tax }\end{array}$ & $\begin{array}{l}\text { Excise/sales } \\
\text { tax on } \\
\text { equipment } \\
\text { and services }\end{array}$ & $\begin{array}{c}\text { VAT on } \\
\text { imported } \\
\text { equipment }\end{array}$ & $\begin{array}{l}\text { Property } \\
\text { tax }\end{array}$ & $\begin{array}{c}\text { Fee based } \\
\text { on land area }\end{array}$ \\
\hline Argentina & $\mathrm{N}$ & $\mathrm{S}$ & S & $\mathrm{N}$ & & $\mathrm{S}$ \\
\hline Australia & $\mathrm{N}$ & S & $\mathrm{N}$ & $\mathrm{N}$ & $\mathrm{S}$ & \\
\hline Bolivia & $\mathrm{N}$ & S & & $\mathrm{N}$ & & $\mathrm{N}, \mathrm{S}$ \\
\hline Canada & $\mathrm{N}, \mathrm{S}$ & S & & $\mathrm{N}$ & $\mathrm{S}$ & S \\
\hline Chile & $\mathrm{N}$ & & $\mathrm{N}$ & $\mathrm{N}$ & & $\mathrm{N}$ \\
\hline China & $\mathrm{N}, \mathrm{S}$ & $\mathrm{N}$ & & & & $\mathrm{N}$ \\
\hline Ghana & $\mathrm{N}$ & $\mathrm{N}$ & $\mathrm{N}$ & $\mathrm{N}$ & & $\mathrm{N}$ \\
\hline Denmark & $\mathrm{N}$ & & & & & \\
\hline Indonesia & $\mathrm{N}$ & $\mathrm{N}$ & & $\mathrm{N}$ & & \\
\hline Côte d'Ivoire & $\mathrm{N}$ & $\mathrm{N}$ & & $\mathrm{N}$ & $\mathrm{N}$ & $\mathrm{N}$ \\
\hline Kazakhstan & $\mathrm{N}$ & $\mathrm{N}$ & & $\mathrm{N}$ & L & L \\
\hline Mexico & $\mathrm{N}$ & & & $\mathrm{N}$ & $\mathrm{N}, \mathrm{S}, \mathrm{L}$ & $\mathrm{N}, \mathrm{S}, \mathrm{L}$ \\
\hline \multicolumn{7}{|l|}{ Papua New } \\
\hline Guinea & $\mathrm{N}$ & $\mathrm{N}$ & $\mathrm{N}, \mathrm{S}$ & $\mathrm{N}$ & $\mathrm{N}$ & $\mathrm{N}$ \\
\hline Peru & $\mathrm{N}$ & & & $\mathrm{N}$ & & $\mathrm{N}$ \\
\hline Philippines & $\mathrm{N}$ & $\mathrm{N}$ & & $\mathrm{N}$ & $\mathrm{L}$ & $\mathrm{L}$ \\
\hline Poland & $\mathrm{N}$ & & & & $\mathrm{L}$ & \\
\hline South Africa & $\mathrm{N}$ & & $\mathrm{N}$ & $\mathrm{N}$ & & \\
\hline Sweden & $\mathrm{N}$ & & & $\mathrm{N}$ & $\mathrm{N}$ & $\mathrm{N}$ \\
\hline Tanzania & $\mathrm{N}$ & & & & $\mathrm{L}$ & $\mathrm{N}$ \\
\hline United States & $\mathrm{N}, \mathrm{S}$ & $\mathrm{S}$ & S, L & & $\mathrm{L}$ & \\
\hline Uzbekistan & $\mathrm{N}$ & & & $\mathrm{N}$ & $\mathrm{L}$ & $\mathrm{L}$ \\
\hline Zimbabwe & $\mathrm{N}$ & & & & & $\mathrm{N}$ \\
\hline
\end{tabular}

L Local government.

N National government.

S State government.

Source: Otto (2001).

The popularity of royalty taxes on natural resources at the state level, as opposed to more profit-sensitive taxes such as corporate income taxes or resource rent taxes, is due to the volatility of the resource sector and the related fact that resource companies often do not earn positive profits. Revenue stability concerns thus dictate the need to levy taxes on a less volatile base, and gross revenue or production certainly qualifies. However, as discussed earlier, these taxes can impose significant distortions, for example, on the time profile of extraction. A better candidate for generating natural resource revenue for the state would be net royalties or some form of resource rent tax, both of which are less distortionary.

The most reasonable way for a resource-rich state to receive some of the rent generated by these taxes is to allocate a share of the revenue of a tax levied by the national government to the state. The national government's share would then be allocated across all states in the federation via some combination of nationally provided public goods and services or intergovernmental grants (perhaps as part of an equalization program). Although the negotiations of the appropriate share of these rents that will remain at the local level may be difficult, this shared, negotiated approach to the allocation of rents, rather than independently allowing both levels of government to tax the activities of resource companies, results in a less contentious and more sensible resource tax regime in the long run.

Again referring to Canada, even though provinces have constitutional ownership of natural resources, and therefore levy royalties and other taxes on that basis, the federal government 
has, at various times, levied special taxes on the resource sector. This shared jurisdiction approach, as opposed to sharing the proceeds from a resource levy, has not only resulted in a good deal of acrimony, but in heavy taxation of the natural resources sector, in particular, the oil and gas sectors (see, for example, Boadway and McKenzie 1989; Boadway, McKenzie, and Mintz 1990).

\section{References}

The word processed describes informally reproduced works that may not be commonly available through libraries.

Boadway, Robin, and Kenneth McKenzie 1989. “The Economic Impact of Tax Reform on the Resource Sector." In J. Mintz and J. Whalley, eds., The Economic Impacts of Tax Reform. Canadian Tax Paper no. 84. Toronto: Canadian Tax Foundation.

Boadway, Robin, Kenneth McKenzie, and Jack Mintz. 1990. Federal and Provincial Taxation of the Canadian Mining Industry: Impact and Implication for Reform. Kingston, Ontario: Queen's Centre for Resource Studies.

Boadway, Robin, Sandra Roberts, and Anwar Shah. 1994. The Reform of Fiscal Systems in Developing Countries: A Federalism Perspective. Washington, D.C.: World Bank.

Kemp, Alexander G. 1994. "International Petroleum Taxation in the 1990s." Energy Journal (Special Issue: The Changing World Petroleum Market): 291-309.

Otto, James L. 2000. "Mining Taxation in Developing Countries." United Nations Conference on Trade and Development, Geneva. Processed.

2001. “Fiscal Decentralization and Mining Taxation." World Bank, Mining Department, Washington, D.C. Processed.

Shah, Anwar. 1994. The Reform of Intergovernmental Fiscal Relations in Emerging and Developing Market Economies. Washington D.C.: World Bank.

Winer, Stanley and Kathleen Day. 1999. "Internal Migration and Public Policy: An Introduction to the Issues and Review of Empirical Research on Canada" in Alan Maslove, ed., Issues in the Taxation of Individuals. Toronto: University of Toronto Press. 




\section{World Bank Institute}

The World Bank Institute (WBI) develops capacity in World Bank client countries through courses and seminars, policy advice, diagnostic tools, and other products and services to help countries achieve their development goals. Through traditional face-to-face and distance learning methods, WBI and its partners around the world work with policymakers, technical experts, business and community leaders, and civil society stakeholders to foster the kinds of analytical and networking skills that support effective socioeconomic programs and policymaking. The Institute collaborates with World Bank operations staff on high priority themes including human development, poverty reduction and economic management, environmentally and socially sustainable development, and finance and private sector development.

1818 H Street, N.W.

Washington, D.C. 20433, U.S.A.

Telephone: 2024731000

Facsimile: 2024776391 